\title{
SKELETAL MORPHOLOGY AND EVIDENCE FOR SWIMMING IN A FOSSIL STEM PINNIPED, PUIJILA DARWINI, FROM THE CANADIAN HIGH ARCTIC
}

Joanna Mary Northover

B.Sc. Earth Sciences, Carleton University

A thesis submitted to the Faculty of Graduate Studies in partial fulfilment of the requirements for the degree of

Master of Science

Department of Earth Sciences

Carleton University

Ottawa-Carleton Geoscience Centre

Ottawa, Ontario

December 6, 2010

Copyright (C) 2010, Joanna Northover 


\section{ABSTRACT}

Puijila darwini is a new genus of fossil carnivore discovered in sediments of the Haughton Formation within the Haughton impact crater on Devon Island, NU $\left(75^{\circ} \mathrm{N}\right) . A$ previous phylogenetic analysis identified Puijila and the Oligocene fossil Potamotherium vallentoni as stem pinnipeds (seals, sea lions, walrus). Unlike extant pinnipeds, Puijila did not have flippers, but shows evidence of webbed manus and pes. Puijila has limb proportions and a long tail which are more reminiscent of terrestrial carnivores. Puijila is an important morphological intermediate between modern pinnipeds and their terrestrial ancestors and can provide insight into the early land-to-sea transition of the group. A comparative description of the forelimb indicated Puijila was more postcranially specialized for swimming than modern otters (lutrines), but less specialized than its fossil relative Potamotherium. The forelimb specializations of Puijila provide evidence that the limb may have been used differently during swimming than those of otters. Tetrapod lineages that become secondarily aquatic often display specializations in their internal bone structure that accompany this transition. These specializations can be understood in ancestral pinnipeds, such as Puijila, by examining the relationship between bone microstructure and swimming behaviour in their extant relatives, Arctoidea (bears, weasels, pinnipeds etc.). Bone microstructure parameters and swimming behaviour and body mass were compared using phylogenetically independent contrasts. Swimming behaviour and body mass were positively correlated. Bone microstructure showed evidence of correlated evolution only with body mass, indicating 
that body mass is the best predictor of swimming behaviour in arctoids. Linear discriminant function analysis supported the observations made from the forelimb description that Puijila was semi-aquatic. 


\section{ACKNOWLEDGMENTS}

I would like to thank the following people and organizations for their support of my research. This project would not have been possible without the support from the Canadian Museum of Nature (CMN), Carleton University Department of Earth Sciences (CU), N. Rybczynski (CMN) and C. Schröder-Adams (CU). Access to NUFV-405 was granted by the Government of Nunavut. Field work $(2009,2010)$ was made possible by a paleontology permit from the Government of Nunavut, Department of Culture, Language, Elders and Youth (CLEY) and with the permission of Qikiqtani Inuit Association, especially Grise Fiord (Nunavut). Financial support provided by Archaeology and Palaeontology Student Grant-in-Aid program (CLEY) and the Northern Scientific Training Program; logistic and other support provided by the Polar Continental Shelf Project and the 2009 and 2010 field crews: N. Rybczynski (Leader, CMN), J. Gosse (Dalhousie University), M. Gilbert (CMN), M. Dawson (Carnegie Museum of Natural History, $\mathrm{CMNH}$ ), T. Cullen(CU) and M. Lipman. Surface scanning was completed the Arius 3D Imaging Center, at the $\mathrm{CMN}$, by P. Bloski (Arius 3D). The 3D graphics rendering and animation were by A. Tirabasso (CMN). L. Gordon (Smithsonian National Museum of Natural History, USNM) and J. Jacobs (USNM) helped with access to the USNM collection material and digital X-Ray equipment. B. Frohlich (USNM) allowed access to equipment and provided technical support and expertise for computed tomography scanning at the USNM. R. Héroux (Head of Radiology) and S. Boyle (Radiology Technician) provided the permission and expertise to CT scan NUFV-405 at the Montfort 
Hospital in Ottawa, ON. B. Engesser (Naturhistorisches Museum Basel, NMB), donated specimens of Potamotherium to the CMN and L. Costeur (NMB) provided access to the NMB collections of Potamotherium material. M. Gilbert (CMN) and A. Tabrum (CMNH) prepared NUFV-405. S. Hinic-Frlog (CU), D. Fraser (CU), L. Cooper (University of Illinois), G. Rowe and S. Madar (Hiram College) provided insight into statistical methods, data collection and gave general academic support. M. Girondot (Université Paris Sud) and M. Laurin (Muséum National d'Histoire Naturelle) provided troubleshooting and help with the Bone Profiler 4.4.11 software. S. Mattioli performed the otter forelimb dissection and provided figures. Scholarships and research funding was provided by Dr. George (Juri) Alexander Jeletzky Endowment for Paleontology; NSERC discovery grant of C. Schröder-Adams and N. Rybczynski (CMN); CMN internal grant to N. Rybczynski; CU Graduate Student Fellowships. My family and friends always provided their love and support. Finally, I would like to express my gratefulness to N. Rybczynski for her guidance, encouragement and patience throughout this academic adventure. 


\section{TABLE OF CONTENTS}

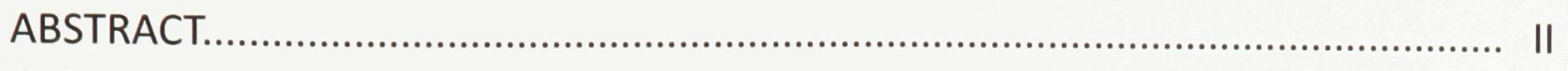

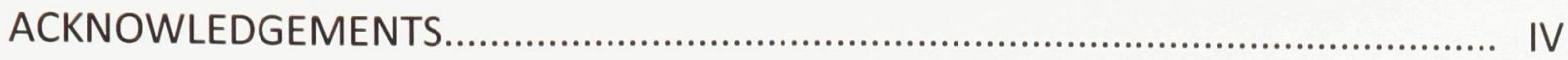

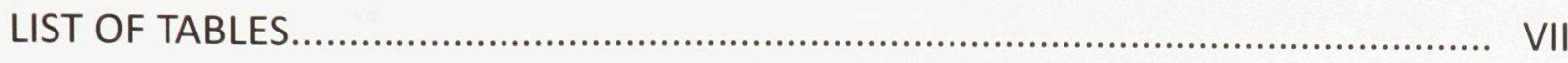

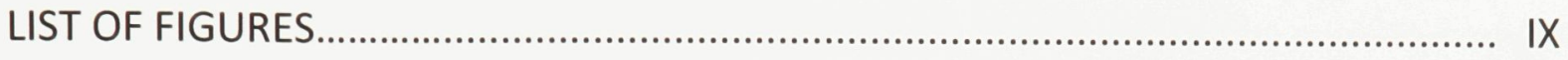

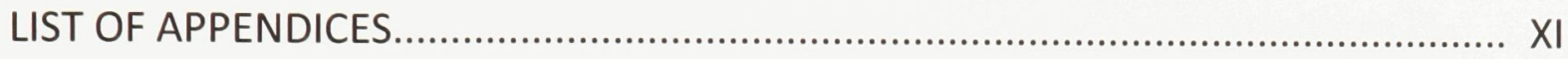

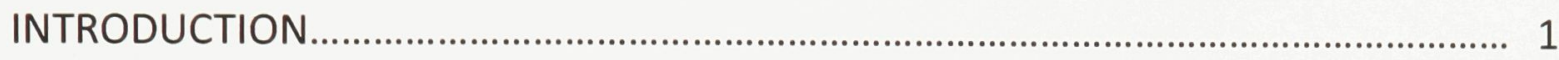

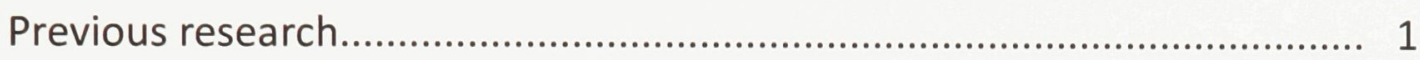

Geological setting and paleoenvironmental inferences.............................. 8

CHAPTER 1 - THE PECTORAL GIRDLE AND FORELIMB OF PUIJILA DARWINI

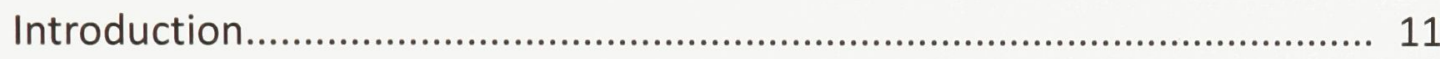

Materials and methods................................................................... 14

Morphological description................................................................... 17

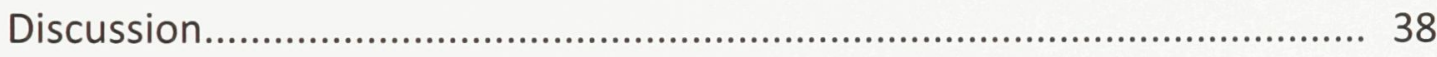

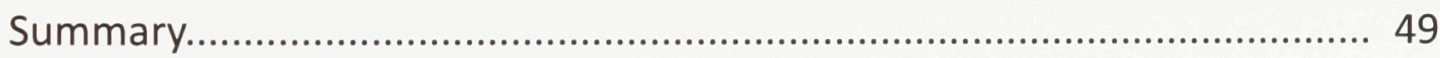

CHAPTER 2 - EVIDENCE FOR CORRELATED EVOLUTION BETWEEN LONG BONE COMPACTNESS, SWIMMING BEHAVIOUR AND BODY MASS IN ARCTOIDEA (MAMMALIA: CARNIVORA)

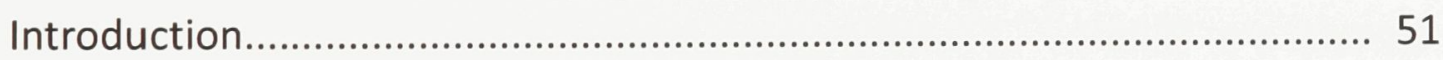

Materials and methods..................................................................... 54

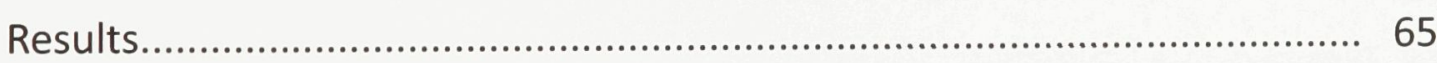

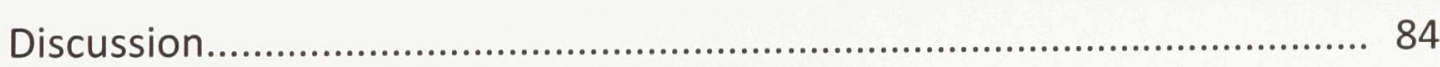

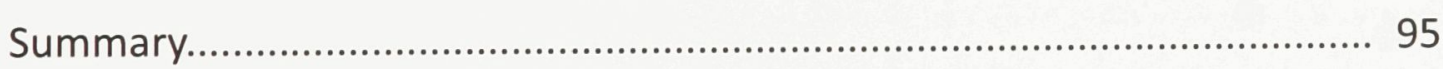

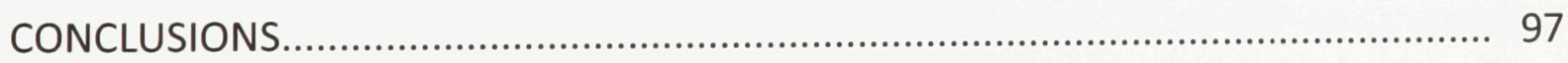

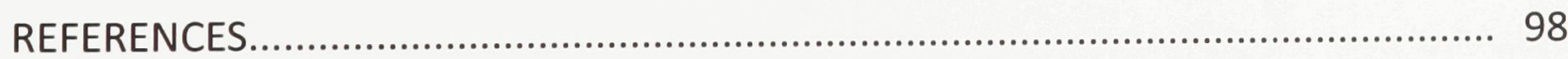

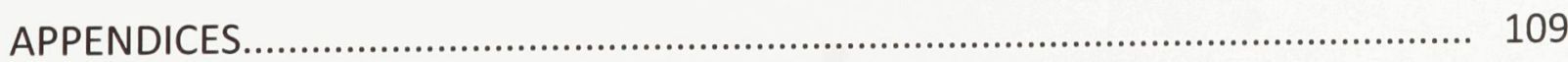




\section{LIST OF TABLES}

TABLE 1. Specimens of Potamotherium vallentoni examined for comparative descriptions

TABLE 2. Measurements of the forelimb skeleton of Puijila darwini..... 37

TABLE 3. Mean values of $P$ for all animals in different swimming behaviour and phylogenetic groupings, compared with those of Puijila darwini..... 65

TABLE 4. Results of the plot of absolute values of independent contrasts of P vs. standard deviations for branch length algorithms applied to the full tree 69

TABLE 5. Results of the plot of absolute values of independent contrasts of S and Min vs. standard deviations for branch length algorithms applied to the reduced tree. 70

TABLE 6. Results of the plot of absolute values of independent contrasts of C vs. standard deviations for branch length algorithms applied to the reduced tree. .71

TABLE 7. Pearson product-moment correlation coefficients phylogenetically independent contrasts (PIC) of SC vs $\log \left(m_{b}\right)$ for four different branch length algorithms .72

TABLE 8. Pearson product-moment correlation coefficients PIC of P vs SC and $\log \left(m_{b}\right)$

using natural log transformed Nee method branch lengths.

TABLE 9. Pearson product-moment correlation coefficients PIC of S vs SC and $\log \left(m_{b}\right)$ for three different branch length algorithms .74

TABLE 10. Pearson product-moment correlation coefficients PIC of Min vs SC and $\log \left(m_{b}\right)$ for three different branch length algorithms 75 
TABLE 11. Pearson product-moment correlation coefficients PIC of $C$ vs SC and $\log \left(m_{b}\right)$

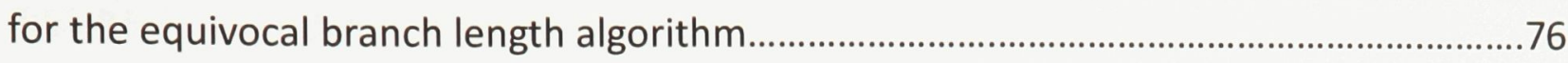
TABLE 12. Pearson product-moment correlation coefficients PIC of P vs SC and $\log \left(m_{b}\right)$

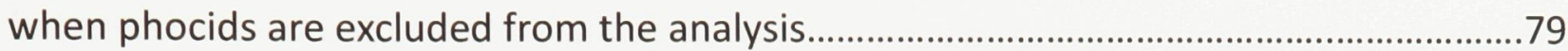
TABLE 13. All values of K-statistic calculated using the APE package for the $\mathrm{R}$ project for statistical computing. .80 TABLE 14. Results of predicted swimming behaviour for Puijila darwini, using linear discriminant function analysis. .83 


\section{LIST OF FIGURES}

FIGURE 1. An updated reconstruction of the skeleton of Puijila darwini (NUFV-405) indicating preserved elements and locality map of Haughton Crater, Devon Island, Nunavut

FIGURE 2. Simplified phylogenies of the extant families of pinnipeds

FIGURE 3. Scapulae of Puijila darwini and a reconstruction of the scapula of

Potamotherium vallentoni. 18

FIGURE 4. Right humerus of Puijila darwini and 3D renderings of the same element constructed from surface scanning data. 20

FIGURE 5. Left radius of Puijila darwini and 3D renderings of the same element constructed from surface scanning data.....

FIGURE 6. Right ulna of Puijila darwini and 3D renderings of the same element constructed from surface scanning data. .25

FIGURE 7. Carpals of Puijila darwini and a diagram showing the arrangement of their facet articulations, as compared to those of Potamotherium.

FIGURE 8. 3D renderings of the right manus of Puijila darwini, reconstructed from surface scanning data.

FIGURE 9. Phylogeny of the 43 species of extant arctoid used in the bone microstructure analysis. .55

FIGURE 10. Measurements taken on the six major long bones for the bone microstructure analysis .56 
FIGURE 11. Visual representation of the parameters extracted from compactness profiles that are generated for bone sections by Bone Profiler. .58

FIGURE 12. Phyologenies, of the 43 arctoids, showing proportional branch lengths assigned by four different branch length algorithms

62

FIGURE 13. Example plots of $P_{h}$ and $\log (m b)$ for each swimming behaviour group illustrating the positive trends within groups.

FIGURE 14. The residuals of the independent contrasts of $C_{f i}$ Vs $\log \left(m_{b}\right)$ and $P_{\text {avg }}$ vs $\log \left(m_{b}\right)$ plotted against those of $S C v s . \log \left(m_{b}\right)$ with the trend line of the ordinary least square regression through the origin. 


\section{LIST OF APPENDIXES}

APPENDIX 1. Summary of important reconstructed musculature, their visible points of origin and insertion and their proposed function, in the forelimb of Puijila darwini....109 APPENDIX 2. A complete list of all Potamotherium material available at the Canadian Museum of Nature

APPENDIX 3. List of species, with specimen numbers, CT scanned and X-Ray imaged at the Smithsonian National Museum of Natural History.

APPENDIX 4. Log transformed body mass data and P, C, S and Min for each long bone collected from CT scan images (using Bone Profiler v.4.11.11 for windows) and from x-ray images.

APPENDIX 5. Rubric used for calculating swimming behaviour (SC).

APPENDIX 6. Variable names and definitions

APPENDIX 7. Instructions on how to calculate K-statistic in the R project for statistical computing, using nexus file created from Mesquite

APPENDIX 8. Canonical plots and discriminant scores from all discriminant function analyses. 


\section{INTRODUCTION}

Puijila darwini is a genus of fossil carnivore discovered in 2007 in the Canadian High Arctic. The genus is represented only by the holotype specimen that originates from Early Miocene lacustrine sediments in the Haughton impact crater on Devon Island, Nunavut (Fig. 1). Rybcyzinski et al. (2009) described the specimen and performed a phylogenetic analysis in which Puijila grouped with a known fossil stem pinniped. The analysis and description focused on cranial characters, but also made general observations about its postcrania. Unlike modern pinnipeds, Puijila lacks flippers, retains a long tail and longer limbs of a terrestrial form. It also has skeletal specializations, such as a large manus and pes, flattened phalanges and shortened ilium, which may be indicative of swimming. It appears to be the least postcranially specialized for swimming of the stem pinnipeds included in the phylogenetic analysis. The early evolution of pinnipeds is not well represented in the fossil record and therefore, Puijila represents a crucial example of a transitional form between modern pinnipeds and their terrestrial ancestors. Describing the musculoskeletal and microstructural specializations of the postcrania of Puijila in more detail can help to better understand how this animal swam and provide insight into the evolution of pinnipeds from a land to sea habitat.

\section{Previous Research}

Since conquering the land during the late Carboniferous, tetrapods have become secondarily aquatic multiple times (Carroll, 1988; Uhen, 2007; Canoville and Laurin, 2010). Within reptiles, birds and mammals, there are many examples of fossil and 
A
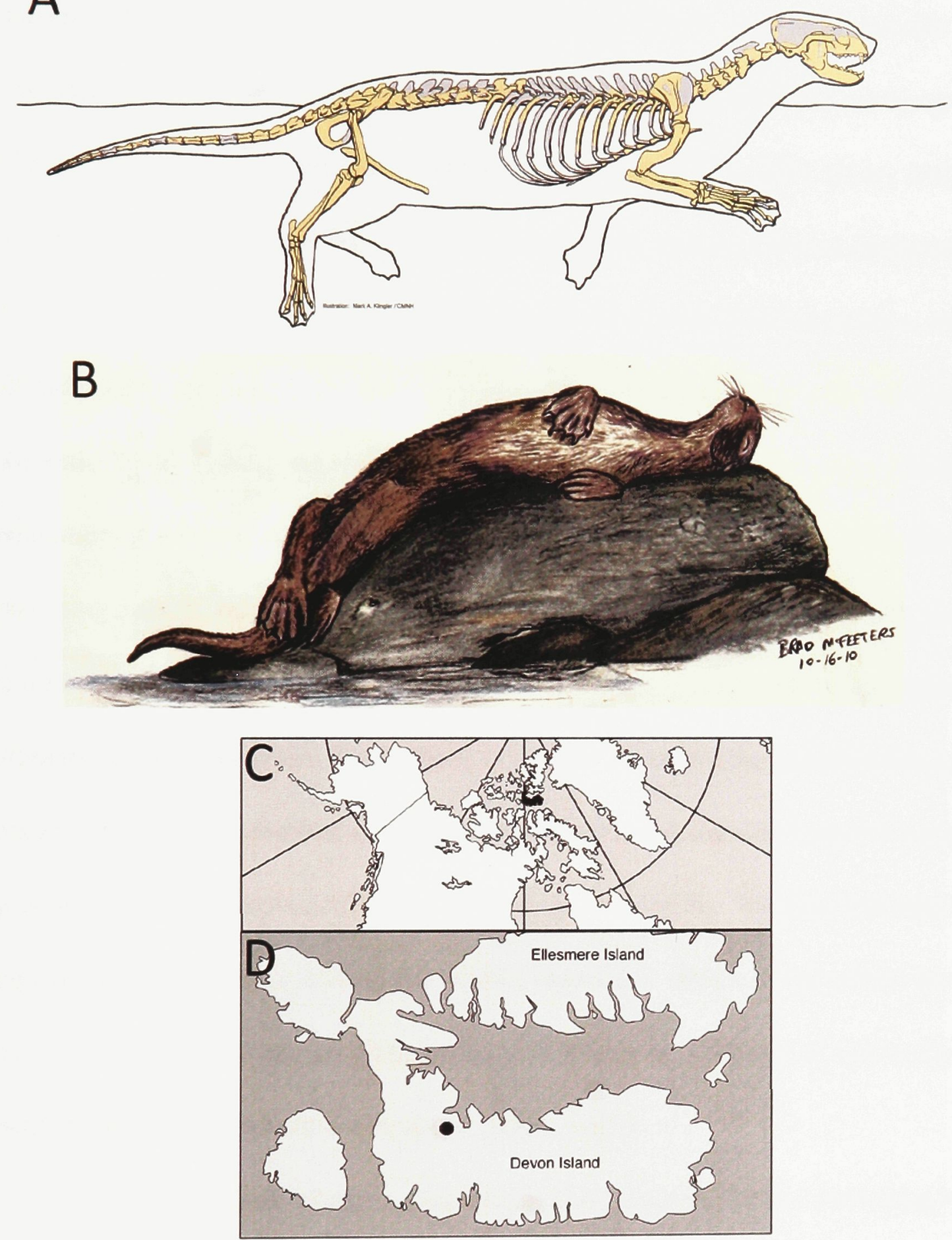

FIGURE 1. A, Reconstruction of the holotype skeleton of Puijila darwini, NUFV-405, preserved bones are pictured in yellow (modified from Mark A. Clinger in Rybczinski et al., 2009); B, reconstruction of Puijila darwini, resting on a rock near the lake shore (image by Brad McFeeters); C, Map of the Canadian High Arctic, Devon Island shaded in black (modified from Rybczynski et al., 2009); D. Map of Devon Island, circle indicates the location of the Haughton Impact Crater where Puijila darwini was discovered, (from Rybczynski et al., 2009). 
modern taxa, descended from terrestrial lineages, which now occupy freshwater or marine habitats (Howell, 1930; Carroll, 1988; Uhen, 2007). Within Mammalia specifically, there are multiple lineages which are considered aquatic, some of which occupy a strictly marine habitat (Howell, 1930; Nowak, 1991, 2003; Uhen, 2007). The modern marine mammals are typically considered to include Cetacea (dolphins, porpoises, whales), Sirenia (sea cows, dugongs), Pinnipedia (seals, sea lions, walrus), Enhydra lutris (sea otter), Lontra felina (marine otter) and Ursus maritimus (polar bear) (Nowak, 2003). Certain recognizable morphological changes usually accompany the transition of a lineage from a terrestrial to an aquatic existence. The characteristics including a short, robust humerus and femur, elongated digits of the manus and pes and the development of webbing on the feet, help to reduce drag and increase thrust and stability while in the water (Fish, 1996; Uhen, 2007). In marine mammal lineages, modifications to the feeding apparatus to support a diet derived from the water, tend to precede these morphological specializations to aquatic life. This may indicate feeding ecology was a key factor driving the marine mammals' return to the water. In order to overcome the challenges posed by an aquatic existence, a variety of mechanisms and evolutionary pathways were employed (Uhen, 2007).

For some groups of marine mammals, the transition from a terrestrial to an aquatic lifestyle is well represented in the fossil record. The origins of cetaceans can be traced using morphological and molecular evidence to within artiodactyls and the fossil remains of Indohyus have provided evidence for the raoellids as their sister group 
(Thewissen and Williams, 2002; Thewissen et al., 2007; Uhen, 2007). The fossil record documents their evolutionary transition from terrestrial quadrupedal pakicetids, to semi-aquatic ambulocetids, to completely aquatic fossil and modern cetaceans (Thewissen and Williams, 2002). Geological and isotope evidence has provided further evidence on the ecology of the intermediate forms, suggesting the ancestral cetaceans first occupied freshwater habitats and then transitioned to estuarine and coastal waters, before becoming fully marine (Thewissen and Williams, 2002; Clementz et al., 2006; Thewissen et al., 2007). Other marine mammals have equally well represented links to their terrestrial ancestors. Pezosiren portelli, a middle Eocene, semi-aquatic, quadrupedal sirenian has provided insight into the early evolution of this lineage. Isotopic evidence suggests the earliest sirenian ancestors evolved directly into a marine habitat and sea grass diet without occupying a freshwater environment (Domning, 2001; Clementz et al., 2006).

Among marine mammals, the early evolution of Pinnipedia remains the most elusive. Historically, there has been debate whether the group is monophyletic or diphyletic (McLaren, 1960; Tedford, 1976; Berta and Wyss, 1994; Sato et al., 2006; Higdon et al., 2007). Molecular and morphological studies that support a monophyletic origin for pinnipeds have disagreed on whether Musteloidea (weasels, badgers, skunks, raccoons, otters etc.) or Ursidae (bears) is the sister group to the clade and the earliest fossil record of the lineage remained sparse (Berta and Wyss, 1994; Lento et al., 1995; Flynn et al., 2005; Arnason et al., 2006; Sato et al., 2006; Higdon et al., 2007). Multiple 
molecular phylogenetic studies have supported that pinnipeds diverged from a single common ancestor based on the use of at least 5 different nuclear DNA, 3 different mitochondrial DNA loci and amino acid sequences, and the majority of those studies identified musteloids as their sister group (Wyss and Flynn, 1993; Berta and Wyss, 1994; Flynn et al., 2005; Fulton and Strobeck, 2006; Sato et al., 2006; Finarelli, 2008). However, our understanding of the appearance and ecology of their earliest ancestors remains lacking, an understanding which would provide insight into their early evolution and their land to sea transition.

Previously, Enaliarctos was widely accepted as the most basal fossil pinniped and considered the sister taxon to all other pinnipeds. Yet, Enaliarctos is a fully marine, flippered animal (Berta et al., 1989; Berta and Ray, 1990) and so provides little information about the pinniped's evolution from a terrestrial form. Puijila darwini bridges this morphological gap in the pinniped fossil record and may provide insight into the transitional period of the group's evolution (Rybczynski et al., 2009).

In the phylogenetic analysis of Rybczynski et al. (2009), Puijila was grouped in a clade with Amphicticeps shackelfordi, Potamotherium vallentoni and the stem pinniped Enaliarctos mealsi (Tedford, 1976; Berta et al., 1989; Rybczynski et al., 2009). Of these taxa, Puijila appears to be the best candidate as a representative of the pinnipeds' earliest shift towards an aquatic life. The Asian arctoid Amphicticeps was identified as the most basal within the clade, but it is only known from cranial elements and so does not provide clues to its level of postcranial aquatic specialization. The European 
Oligocene mammal Potamotherium is not unanimously considered to be a pinniped. It was originally described by Savage (1957) as a highly specialized lutrine, though even in his original description Savage frequently stated many of its postcranial specializations as being reminiscent of the seal, Phoca. Subsequently, Potamotherium has been classified as a stem musteloid, an arctoid of unknown affiliation, an oligobunine and a pinniped (Wolsan, 1993; Wyss and Flynn, 1993; Wang et al., 2005; Finarelli, 2008; Rybczynski et al., 2009). Both Potamotherium and Puijila have limb proportions that are closer to terrestrial musteloids than pinnipeds, lack flippers and retain a long tail, but Puijila appears to have less reduction and specialization of the proximal elements of its forelimb (Savage, 1957; Rybczynski et al., 2009). Therefore, regardless of its affiliations, Potamotherium has more specialized postcrania than Puijila, suggesting Puijila is a closer link to the terrestrial ancestors of pinnipeds (Savage, 1957; Rybczynski et al., 2009).

Puijila has already provided interesting insight into pinniped evolution. Its discovery in the High Arctic provides support for the hypothesis of an arctic origin for pinnipeds. Its discovery in lacustrine sediments, coupled with the discovery of other proposed stem pinnipeds, such as Potamotherium and the Asian taxon Semantor, in freshwater sediments, provides evidence for a freshwater stage in pinniped evolution (Orlov, 1933; Tedford, 1976; Rybczynski et al., 2009).

In addition to the external musculoskeletal specializations required for life in the water, it has been suggested that changes to internal bone microstructure would also accompany a lineage's transition into an aquatic habitat (Wall, 1983; Stein, 1989; Fish 
and Stein, 1991; Girondot and Laurin, 2003; Laurin et al., 2004; Cubo et al., 2005;

Germain and Laurin, 2005; Laurin et al., 2006; Gray et al., 2007; Kriloff et al., 2008; Houssaye, 2009; Canoville and Laurin, 2010). These modifications to bone microstructure are related to bone density (Wall, 1983). Increased bone density is associated with overall body density; this would be beneficial to animals which forage under the water, as it would offset the natural buoyancy of the animal's body and facilitate diving (Wall, 1983; Stein, 1989; Domning and Debuffrenil, 1991; Fish and Stein, 1991). Increase in bone density (= compactness) can be achieved through "thickening" cortical bone and reducing the size of the medullary cavity within the limb bone, or by thickening the trabecular struts in the spongy bone (Wall, 1983; Houssaye, 2009). Increased bone compactness has been observed in aquatic and semi-aquatic mammals such as beavers, sea otters, ancestral whales and sirenians (Wall, 1983; Stein, 1989; Domning and Debuffrenil, 1991; Fish and Stein, 1991; Houssaye, 2009). I investigated the relationships of bone microstructure, swimming behaviour and body mass within Arctoidea (bears, pinnipeds, weasels, skunks, badgers etc.) that are the extant relatives of Puijila. I assessed whether bone microstructure is a good predictor of swimming behaviour in arctoids in order to attempt to predict the swimming behaviour of Puijila from its long bone compactness. This aspect of the thesis is presented in the second chapter. 
Geological Setting and Paleoenvironmental Inferences of the Puijila darwini locality

Puijila darwini was discovered in lacustrine sediments of the Haughton Formation within the Haughton Crater on Devon Island, in the Territory of Nunavut (Rybczynski et al., 2009). The Haughton Crater $\left(75^{\circ} 22^{\prime} \mathrm{N}, 89^{\circ} 40^{\prime} \mathrm{W}\right)$ is a nearly circular impact structure situated in Lower Ordovician to Upper Silurian dolomite and limestone target rocks (Frisch and Thorsteinsson, 1978; Hickey et al., 1988). The raised crater rim is nearly $16 \mathrm{~km}$ in diameter, whereas the entire impact structure reaches $\sim 23 \mathrm{~km}$ in diameter (Hickey et al., 1988; Osinski et al., 2005). Previously classified as a diapiric structure, the "Haughton dome" was identified as an impact crater in 1972 based on the abundance of shatter cones within the crater (Frisch and Thorsteinsson, 1978; Hickey et al., 1988; Osinski et al., 2005).

The Haughton impact crater was initially dated at $22.4 \pm 1.4 \mathrm{Ma}$ based on fission track dating (Omar et al., 1987). Subsequent studies in 1988 and 2005, both using ${ }^{40} \mathrm{Ar}-$ ${ }^{39} \mathrm{Ar}$ radiometric dating, obtained conflicting results of the ages $23.4 \pm 1 \mathrm{Ma}$ and $39 \pm 2 \mathrm{Ma}$ respectively (Jessberger, 1988; Sherlock et al., 2005). The lacustrine sediments within the crater have been estimated to possibly range in age from late Oligocene to middle Miocene, based on ostracod, plant and vertebrate fossil material, with a more specific estimate of an age of early Miocene ( 20mya) (Whitlock and Dawson, 1990).

The unconsolidated, intra-crater sediments of the fossiliferous Haughton Formation are intermittently exposed over an area of $8.62 \mathrm{~km}^{2}$ and have a maximum thickness of 48 m (Hickey et al., 1988; Whitlock and Dawson, 1990; Osinski and Lee, 
2005). The formation is separated into six geographically separate areas; the largest and most fossiliferous portion is crossed by West Rhinoceros Creek and Rabbit Run Creek (Osinski and Lee, 2005). The Haughton Formation's lacustrine sediments are erosional material from the Silurian aged dolomites and limestones of the Allen Bay Formation (Hickey et al., 1988; Osinski and Lee, 2005). The Haughton Formation itself is composed of unconsolidated dolomitic silt-rich muds, with a minor component of dolomitic sand ranging in colour from pale grey to yellow-brown.

The Puijila site is located within the active layer above the permafrost.

Sediments at the site were observed during excavation to be highly cryoturbated. Throughout the site the cryoturbation was manifested as pockets of grey silt and clay interspersed within yellow-brown sands, destroying the lateral continuity of the original bedding planes. The grey coloured silt and clay sediments produced the majority of the Puijila fossil material.

The climate in that area of the Arctic, at the time of the deposition of the Haughton Formation, was different than what is currently experienced in the crater (Hickey et al., 1988; Whitlock and Dawson, 1990; Osinski and Lee, 2005).

Palynomorph analysis of sediments from the crater by Hickey et al. (1988) produced a picture of a cool-temperate climatic regime. Whitlock and Dawson's (1990) comparisons of fossil pollen from the crater to modern assemblages inferred the climate to be humid, with severe winters and a maritime coastal effect. Both studies found palynological evidence for the presence of a mixed conifer and hardwood forest, with a mean average 
temperature estimated at $8^{\circ} \mathrm{C}$ to $12^{\circ} \mathrm{C}$ and a growing season of 120 to 200 days (Hickey et al., 1988; Whitlock and Dawson, 1990). During the early Miocene the crater would have experienced the same photo-periodicity that it does in modern times (Whitlock and Dawson, 1990).

The fossil vertebrate assemblage is consistent with a cool temperate habitat. In particular, fossil remains of smelt and trout suggest a cool water environment. The fossil remains of rabbit, shrew, rhinoceros, deer and swan also indicate the environmental conditions in the crater was less severe than it is today (Hickey et al., 1988; Whitlock and Dawson, 1990). The fossil fauna discovered in the crater lake sediments display a high level of endemism (Hickey et al., 1988). Puijila is currently the only carnivore to have been discovered in the Haughton Formation (Hickey et al., 1988; Whitlock and Dawson, 1990; Rybczynski et al., 2009). 


\title{
CHAPTER 1 - THE PECTORAL GIRDLE AND FORELIMB OF PUIJILA DARWINI
}

\author{
INTRODUCTION
}

Pinnipedia is an aquatically specialized group of marine mammals that includes Phocidae (seals), Otariidae (sea lions) and Odobenidae (walrus). The group is now widely considered to be monophyletic and Musteloidea is considered the most likely sister taxon (Flynn et al., 2005; Fulton and Strobeck, 2006; Sato et al., 2006; Finarelli, 2008). Before these relatively recent molecular phylogenetic studies, it had been hypothesized, based on morphological and paleontological evidence, that pinnipeds were biphyletic. Otariids were hypothesized to be closely related to ursids (bears) and phocids were thought to have a sister-group relationship with mustelids (weasles) (Tedford, 1976) (Fig. 2).

A

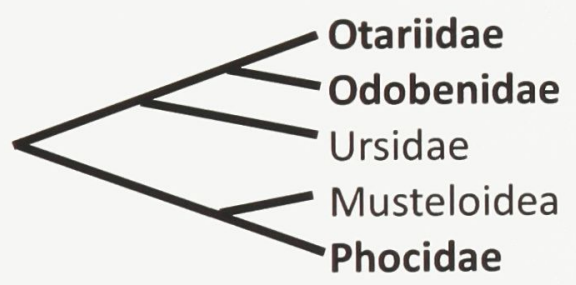

B

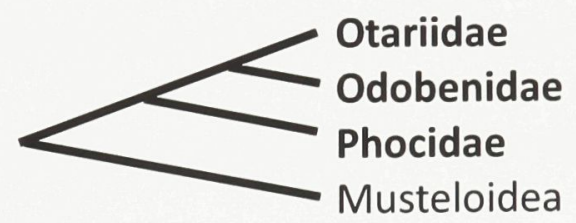

FIGURE 2. Simplified phylogenies depicting the various hypothesized relationships of the of the modern pinnipeds families; $\mathbf{A}$, the biphyletic hypothesis; $\mathbf{B}$, the more recent monophyletic hypothesis. The names of the modern pinnipeds families are in bold.

Modern pinnipeds also have distinctly different swimming modes. Obobenids and phocids are primarily hindlimb dominated swimmers, and otariids are forelimb dominated swimmers (Howell, 1929; Tarasoff et al., 1972; Demere et al., 2003; Bebej, 2008). Although the idea that pinnipeds derived from separate terrestrial ancestors has 
been widely replaced with the idea of a single origin based on both molecular and morphological evidence, there is little fossil evidence from the earliest stages of pinniped evolution. This creates gaps in our understanding of the ecology and morphology of the transitional ancestors of pinnipeds and how they could lead to the variety of swimming modes displayed by modern pinnipeds.

Despite their different swimming styles, pinnipeds share similarities in their forelimb osteology. The humeri of pinnipeds have enlarged greater and lesser tuberosities, a deep and rounded biciptal groove, large raised deltoid crests, large lateral epicondylar wings and a deep trochlea. The radii appear "club-like" because they expand anteriorly in the distal half and have a large rounded radial head. The ulna has an expanded and hook-like olecranon process and a shallow trochlear notch (Howell, 1929; English, 1977). The greatest difference between the osteology of phocids and otariids is seen in the scapulae. However, despite the differences in the general morphology of the element, they share a posterodorsal expansion for an enlarged teres musculature (Howell, 1929; English, 1976; Tedford, 1976). In order to better understand the early evolution of the pinniped lineage, and how two such different swimming modes could evolve, an improved understanding of the swimming behaviour of the earliest pinnipeds becomes essential.

Puijila darwini, described by Rybczynski et al. (2009), represents a morphological intermediate between extant pinnipeds and their terrestrial ancestors. The preliminary description of the holotype specimen of Puijila focused on cranial characters and a 
phylogenetic analysis grouped it in a clade with Potamotherium and the stem pinniped Enaliarctos. Of these genera, the postcranial remains of Puijila appear the least aquatically specialized.

Although the initial description did not focus on the postcrania, Rybczynski et al. (2009) did make preliminary observations about Puijila's musculoskeletal specializations for swimming and possible modes of locomotion. Superficially, Puijila appears otter-like and resembles Lontra canadensis. It differs by having a manus and pes which are proportionally larger, a shoulder region which is more specialized and overall, a more robust skeleton than Lontra. Its large feet and unspecialized tail led Rybczynski et al. to tentatively conclude that it swam by quadrupedal paddling. This is a form of locomotion which could have given rise to both the fore and hindlimb dominated swimming modes displayed by modern pinnipeds (Fish, 1996).

The holotype specimen of Puijila (NUFV-405) was 65\% complete when it was first described, and more fragments have since been collected from the same individual. This provides a unique opportunity to study the musculoskeletal swimming specialization of a stem pinniped in more depth. Here I present the first comparative description of the forelimb of Puijila darwini, and attempt to assess its possible modes of swimming, with the aim of providing some insights into the earliest stages of pinniped evolution. 


\section{MATERIAL AND METHODS}

The holotype material examined for Puijila darwini (NUFV-405) is housed at the Canadian Museum of Nature (CMN) in Ottawa, Ontario and represents $~ 80 \%$ of a single, male individual. The specimen is curated as part of the Nunavut Fossil Vertebrate Collection. The skeletal elements of the forelimb and pectoral girdle were examined for the purpose of this study and included the left and right partial scapulae, complete right and partial left humerus, complete left and right radii and ulnae, the right triquetrum and hamate, both scapholunars and pisiforms, right metacarpals I, II, IV, V and left metacarpals II-V and multiple examples of proximal, intermediate and ungual phalanges. The primary comparative materials used in the description were specimens of the semiaquatic musteloid Lontra canadensis (river otter - CMNMA-Z170, USNM-256976), various specimens of the fossil Potamotherium vallentoni (Table 1) and terrestrial musteloids specimens Mephitis mephitis (striped skunk - CMNMA-4828, CMNMA-75568) and Martes americana (american marten - CMNMA-11785). Other specimens examined for the description included of the semi-aquatic musteloids Enhydra lutris (sea otter CMNMA-6283) and Pteronura braziliensis (giant otter - USNM-304663); the terrestrial musteloids Gulo gulo (wolverine - CMNMA-4389), Procyon lotor (raccoon - CMNMA41037) and Martes pennanti (fisher - CMNMA-3894); the extant pinnipeds Halichoerus grypus (grey seal - CMNMA-52829) and Eumetopias jubatus (northern sea lion CMNMA-2609) and the fossil pinniped Enaliarctos mealsi (USNM-250345). 
TABLE 1. Specimens of Potamotherium vallentoni examined for the comparative description.

Scapula NMB-Ma.704, NMB-Ph.1368, NMB-Ph.3661, NMB-Sg.361, NMB-Sg.369, NMB-Sg.3188 NMB-Sg.4367, NMB-Sg.4369, NMB-Sg.4375, NMB-Sg.5579, NMB-Sg.6970, NMB-Sg.6991, NMB-Sg.7622, NMB-Sg.7623, NMB-Sg.7624, NMB-Sg.7626, NMB-Sg.17975, NMB-Sg.18133, NMB-Sg.18552, NMB-Sg.19899, NMB-Sg.21224, NMB-Sg.21225, NMB-Sg.21226, NMB-Sg.21227, NMB-Sg.21228, NMB-Sg.21231, NMB-Sg.21232

Humerus NMB-Sg.7627, NMB-Ph.3665, CMNFV-54090

Radius NMB-Ma.2827, NMB-Ma.2838, NMB-Ma.2839 NMB-Sg.10830, NMB-Sg.3195m, CMNFV-54093, CMNFV-54093

Ulna NMB-Ma.2830, NMB-Sg.7629, NMB-Sg.7634, NMB-Sg.7639, NMB-Sg.11346, NMB-Sg.22328, CMNFV-54091, CMNFV-54092

Carpals Scapholunar - NMB-Sg.097, NMB-Sg.17653; Pisiforme - NMB-Sg.6351; Triquetrum - NMB-Sg.11368, NMB-Sg.ii368; Hamate - NMB-Sg.373i

Metacarpal I NMB-Ma.2894, NMB-Ma.2896, NMB-Sg.i298, NMB-Sg.i62.8i, NMB-Sg.1734, NMB-Sg.14073

" II NMB-Ma.976, NMB-Sg.i396i, NMB-Sg.3524, NMB-Sg.13565

" III NMB-Sg.4438, NMB-Sg.7002, NMB-Sg.13569, NMB-Sg.2i307, NMB-Sg.2i3i3

" IV NMB-Sg.1738, NMB-Sg.7036, NMB-Sg.16024, NMB-Sg.18576, NMB-Sg.2i3i2, NMB-Sg.23060

" V NMB-Sg.ii309, NMB-Sg.ii3i2, NMB-Sg.8036, NMB-Sg.10891, NMB-Sg.19724, NMB-Sg.2009i

Phalanges Proximal-NMB-Sg.3923, NMB-Sg.i3975, NMB-Sg.i4208, CMNFV-54100, CMNFV-54101, CMNFV-54102, CMNFV-54103; Intermediate - NMBSg.i4090, NMB-Sg.i42i3, NMB-Sg.17650, CMNFV-54104

Unguals NMB-Sg.ii404, NMB-Sg.9581 
Literature comparisons also referred to include: Evans (1993) (terrestrial Carnivora); Savage (1957) (Potamotherium valletoni); Howell (1929), English (1976, 1977), Berta and Ray (1990), Berta and Wyss (1994), Berta (1994) (modern and fossil Pinnipedia); Howard (1973), Fischer (1942) (Lutrinae); Hall (1926, 1927); Leach (1977b, a) (terrestrial Musteloidea).

Institutional abbreviations-CMN, Canadian Museum of Nature, Ottawa, Canada; USNM, National Museum of Natural History, Washington, District of Columbia; NMB, Naturhistorisches Museum Basel, Basel, Switzerland. 


\section{MORPHOLOGICAL DESCRIPTION OF THE FORELIMB}

\section{Scapula}

There are two partial scapulae that together represent the majority of the scapula with the exception of its anterior portion. Both glenoids, both caudal borders, the majority of the left dorsal border and the left and right scapular spines are preserved as articulated fragments (Fig. 3). Only a little of the supraspinatus fossa is preserved. The scapula of Puijila does not resemble terrestrial musteloids and shows only a slight resemblance to Lontra. It has the greatest similarity to that of Potamotherium, though it is less specialized.

The scapula of Puijila shares with Lontra a narrow infraspinatus fossa which is reduced relative to the supraspinatus fossa, a raised scapular spine and a caudal border with an enlarged infraglenoid tubercle. Compared to the humerus, the scapula of Puijila is proportionally larger than that of Lontra and Potamotherium. From the glenoid cavity to dorsal margin, it extends nearly $84 \%$ the length of the humerus, compared with $75 \%$ in Potamotherium and 78\% in Lontra, according to the measurements of Savage (1957). The scapula of Puijila also differs from Lontra by possessing a more robust scapular spine and caudal border, a robust and raised dorsal border, a deeper and narrower infraspinatus fossa and a proportionally larger triceps muscle scar, characteristics which are shared by Potamotherium. The greatest similarity between Puijila and Potamotherium is an area of posterodorsal expansion of the scapula, presumably for the teres major muscle, separated from the infraspinatus fossa by a small ridge - called a 


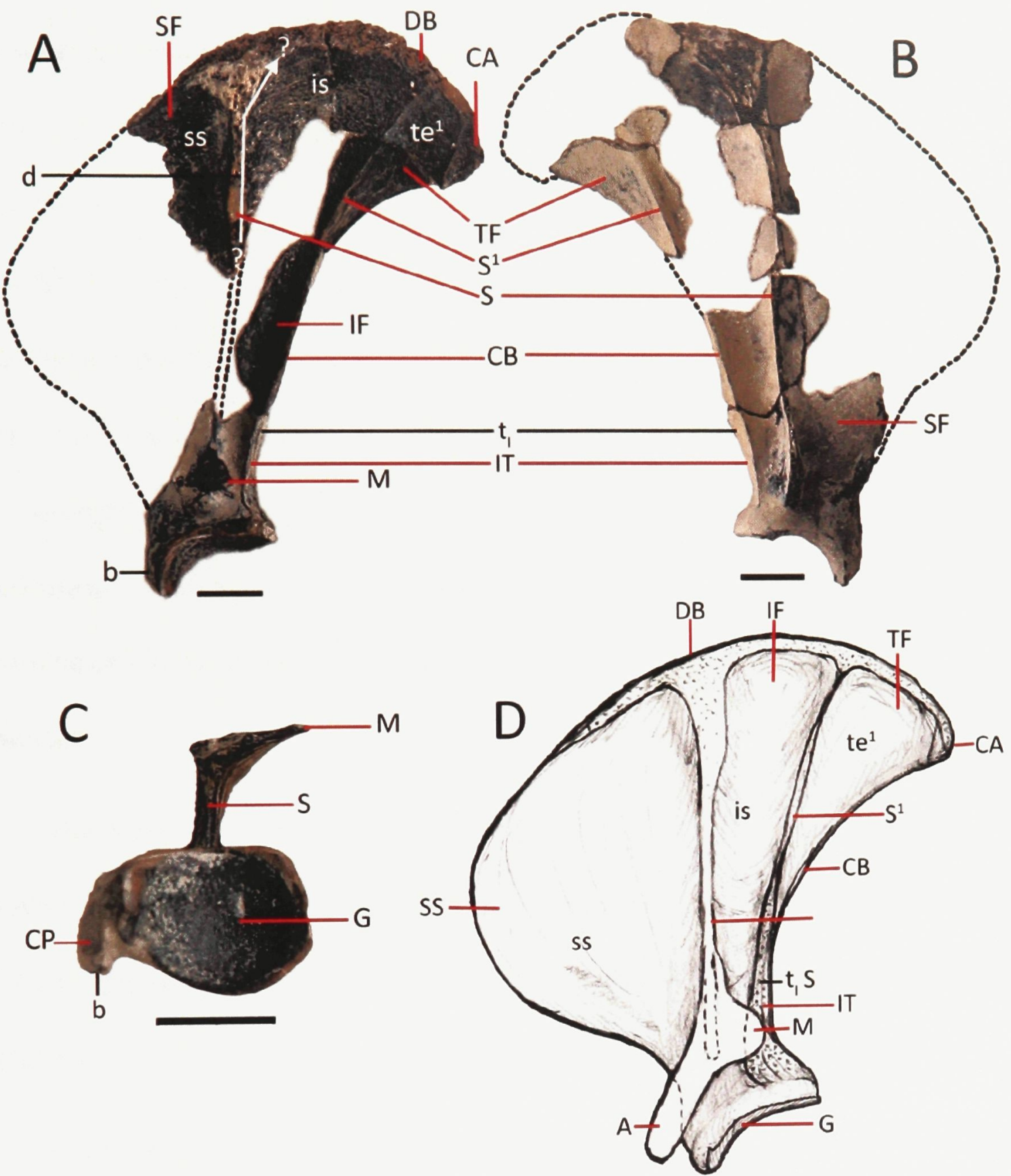

FIGURE 3. Scapulae of Puijila darwini, NUFV-405. A, left scapula, lateral view; B, right scapula, lateral view; C, glenoid, left scapula, anteroventral view; D, reconstruction of the scapula of Potamotherium vellentoni (updated from Savage, 1957 using specimens from the Naturhistorisches Museum Basel listed in Table 1.) This reconstruction of the scapula is used for the comparative description of Puijila. Abbreviations: $C A$, caudal angle; $C B$, caudal border; $C P$, coracoid process; $D B$, dorsal border; G, glenoid; IF, infraspinatus fossa; IT, infraglenoid tubercle; $M$, metacromion; $S$, scapular spine; $S^{1}$, secondary spine; $S F$, supraspinatus fossa; $T F$, teres fossa; $b$, origin of biceps muscle; $d$, origin of deltoid muscle; is, origin of infraspinatus muscle; ss, origin of supraspinatus muscle; $t_{1}$ origin of triceps musculature (long head); te ${ }^{1}$, origin of teres major muscle. Scale bars equal $1 \mathrm{~cm}$. 
"secondary spine" by Savage (1957). Compared to Lontra, Puijila and Potamotherium also possess a smaller scapular notch, slightly rounder glenoid, a larger supraglenoid tubercle, larger medially extended coracoid process and a more robust and proportionally shorter scapular spine. The acromion and metacromion of Puijila is only partially preserved, but appears similar to Potamotherium, having indications of a large metacromion and lacking the distinct indentation between the two processes, as seen in Lontra. Puijila differs from Potamotherium in having a proportionally smaller area of postero-dorsal expansion and a less distinct secondary spine, a shallower scapular notch, proportionally smaller triceps scar, a proportionally less robust scapular spine, less narrowing of the infraspinatus fossa and a proportionally larger scapula overall.

\section{Humerus}

The humerus of Puijila is represented by a complete right and partial left humerus (Fig. 4). The partial left humerus preserves the shaft with incomplete proximal and distal epiphyses. The humerus of Puijila resembles lutrines rather than terrestrial musteloids, and also shows some characteristics in common with Potamotherium.

The humerus of Puijila differs from terrestrial musteloids, such as Mephitis and Martes, by having a robust, anteriorly curving shaft, a prominent and enlarged deltopectoral crest, enlarged greater and lesser tuberosities, medial epicondyle and lateral epicondylar wing. These characteristics, in addition to being reduced in length relative to the ulna, give it a superficial resemblance to that of Lontra. However, there is 

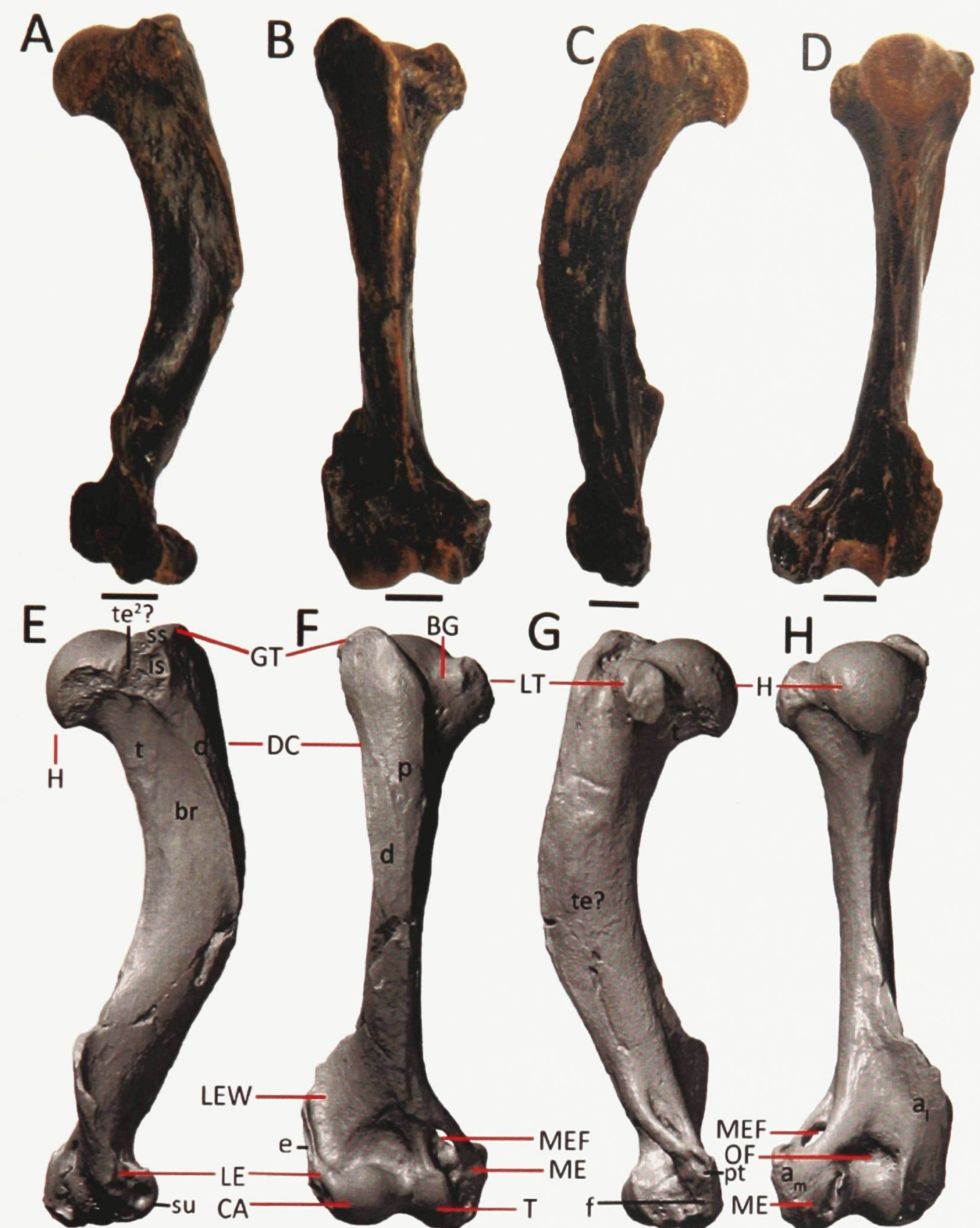

FIGURE 4. Right humerus of Puijila darwini, NUFV-405. A, lateral view; B, anterior view; $C$, medial view; $D$, posterior view; $E-H$, images from $3 D$ surface scan data. Abbreviations: BG, bicipital groove; CA, capitulum; DC, deltopectoral crest; GT, greater tuberosity; $\mathrm{H}$, humeral head; LE, lateral epicondyle; LEW, lateral epicondylar wing; LT, lesser tuberosity; ME, medial epicondyle; MEF, medial epicondylar foramen; OF, olecranon fossa; $T$, trochlea; $a_{1}$, insertion of lateral anconeous muscle; $a_{m}$, insertion of lateral anconeous muscles; br, origin of brachialis muscle; $d$, insertion of deltoid muscle; $e$, origin of extensor muscles; $f$, origin of flexor muscles; is, insertion of infraspinatus muscle; $p$, insertion of pectoralis muscle; $p t$, origin of pronator teres muscle; su, origin of supinator muscle; ss, insertion of supraspinatus muscle; $t$, origin of triceps musculature; $\mathrm{te}^{1}$, insertion of teres major muscle; $\mathrm{te}^{2}$, insertion of teres minor muscle. Scale bars equal $1 \mathrm{~cm}$. 
a greater expansion of the greater and lesser tuberosities, creating a deeper bicipital groove, when compared to that of Lontra. Puijila possesses a more robust and distinct lateral epicondylar ridge, than that of Lontra, which is located on the margin of the lateral epicondylar wing. The medial epicondyle is slightly more enlarged and expands further ventrally in Puijila and the trochlea of its humerus is deeper and steeper sided. The most striking difference between the humerus of Lontra and Puijila is the greater expansion of the deltopectoral crest in the latter. The crest extends two thirds the length of the shaft in Puijila and only half the length of the shaft in Lontra. The deep bicipital groove, robust medial epicondyle and lateral epicondylar ridge, deep and steeply sided trochlea and long deltopectoral crest of Puijila, all resemble those of Potamotherium. Potamotherium and Puijila show a similar degree of enlargement in the tuberosities of the humerus and both possess a larger medial epicondylar foramen than those of Lontra or Martes. However, Puijila differs from Potamotherium by possessing a proportionally smaller lateral epicondylar wing, having lesser ventral expansion of the medial epicondyle and a slightly shallower trochlea. The deltopectoral crest of Puijila is enlarged, but is unlike the anteriorly expanded and raised high ridge of bone seen on the humeri of pinnipeds and Potamotherium; which is referred to as the "deltoid crest" in modern pinnipeds (Howard, 1929; English, 1977).

\section{Radius}

Both radii are fully represented in the holotype specimen of Puijila darwini, though the left is severely weathered (Fig. 5). The radius of Puijila appears similar to 

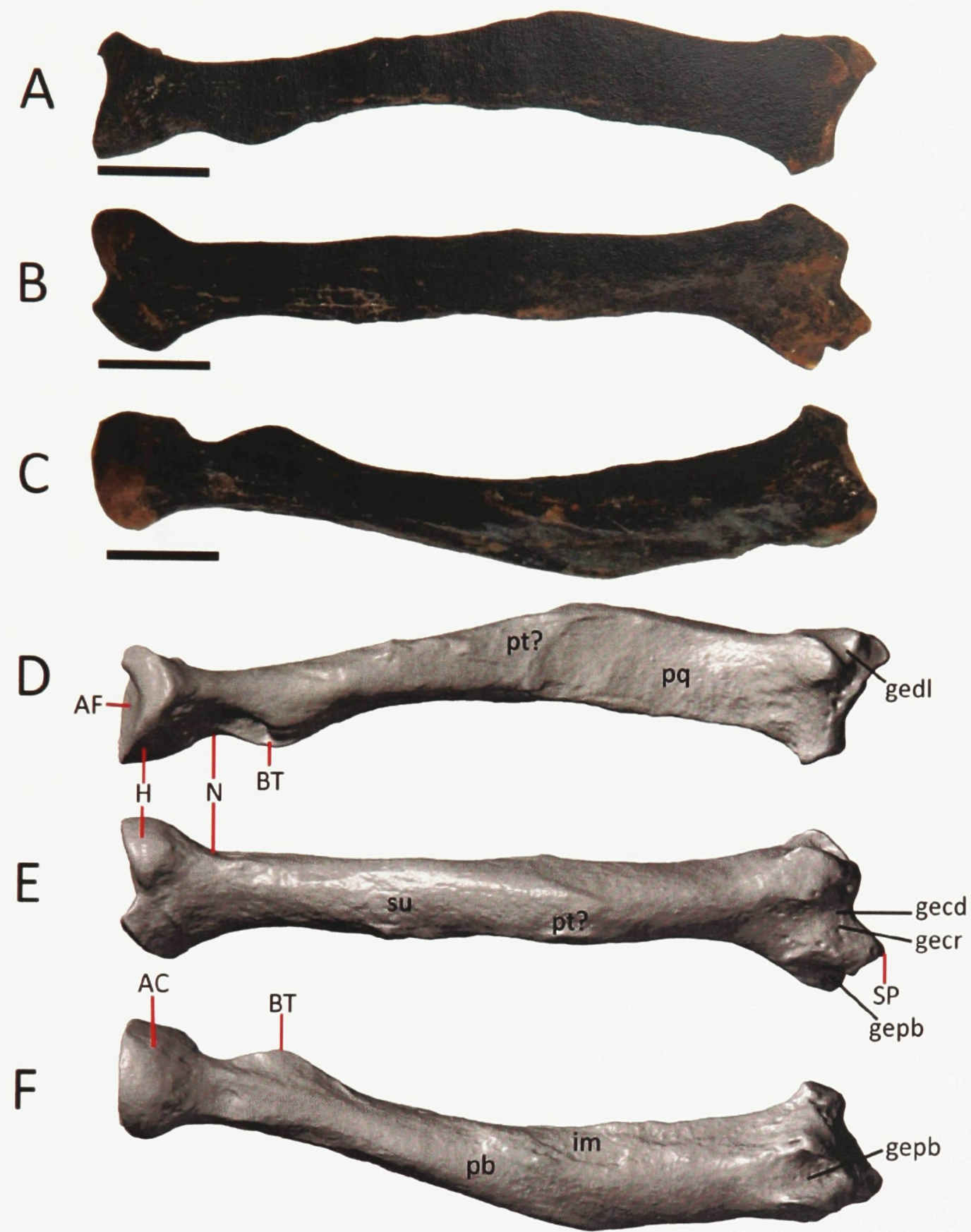

FIGURE 5. Left radius of Puijila darwini, NUFV-405. A, medial view; B, anterior view; $C$, lateral view; D-F, images rendered from $3 D$ surface scan data of the same radius. Abbreviations: AC, articular circumference; AF, articular fovea; BT, biceps tubercle; $\mathrm{H}$, radial head; $\mathrm{N}$, radial neck; SP, styloid process of the radius; gecd, groove for the tendon of the extensor carpi digitorum muscle; gecr, groove for the tendon of the extensor carpi radialis muscle; gedl, groove for the tendon of the extensor digitorum lateralis muscle; gepb, groove for the tendon of the extensor pollis brevis muscle; im, attachment of interosseous membrane; $p b$, origin of extensor pollis brevis muscle; pq - insertion of pronator quadrate muscle; pt, insertion of pronator teres muscle; su, insertion of supinator muscle. Scale bars equal $1 \mathrm{~cm}$. 
both Lutrinae and Potamotherium, by being more robust and more convex anteriorly than the radii of terrestrial musteloids such as Martes and being flattened mediolaterally and expanded antero-posteriorly the distal half. Puijila also shares with Lontra and Potamotherium an enlarged radial head, large biceps tubercle, a deep bicipital pit and a mediolaterally flare on the distal end of the radius. In Puijila, the mediolateral expansion of the distal radial epiphysis occurs to a similar degree as in Lontra. The bicipital pit, located on the proximal side of the biceps tubercle of the radius is larger than in Lontra, but not as deep as that of Potamotherium. The radial shafts of Puijila and Potamotherium lack the ridge of bone, for the attachment of the interosseous membrane, as seen in Lontra, and instead display an oval tubercle for its attachment in a similar position on the bone. The styloid process is expanded and more pointed in Puijila than in Lontra, and the ulnar articulation is smaller and oriented more ventrally. Compared to Lontra, Puijila displays deeper grooves for the tendons of the extensor carpi radialis, extensor communis digitorum and extensor metacarpi muscles; causing the styloid process to appear elevated. Puijila and Potamotherium have a unique triangular tubercle on the medial side of the distal end of the radius, which is absent in Lontra. The anterior side of that tubercle forms part of the extensor metacarpi groove. Puijila further differs from Lontra, Potamotherium and the terrestrial condition by having a more circular articular fovea, a thick articular circumference that extends around two thirds of the radial head, and being generally more robust. These characteristics combined make the overall shape of the head somewhat similar to modern pinnipeds. 
Ulna

The holotype specimen of Puijila includes left and right ulnae, both of which are well preserved (Fig. 6). The ulna of Puijila is similar to that of the larger specimens of Potamotherium. It is more gracile than that of Lontra and smaller specimens of Potamotherium, and slightly resembles that of Mephitis. Unlike terrestrial musteloids, Puijila possesses an olecranon which is proportionally larger and more robust than that of terrestrial musteloids and Lontra, yet less expanded than that of Potamotherium. On the olecranon, there are large areas of attachment for the triceps musculature on the proximal surface and along the posterior portion its lateral side. The ulna of Puijila can be distinguished from Potamotherium by a large lateral tuberosity on the olecranon that covers the ventral half of the lateral face of the olecranon and tapers to a point distally. Like Potamotherium, the olecranon of Puijila is narrowest at its center and has a pronounced expansion toward its proximal end and anconeal process. This gives it an hour-glass outline in anterior view. It appears to project medially, as compared to that of Lontra, and this is driven by the medial and ventral expansion of the posterior margin of the olecranon. The trochlear notch of Puijila and Potamotherium is more open than in Lontra, whose notch is more convex and whose anconeal and coronoid processes draw closer together with ontogenic age (Fischer, 1942). However, the trochlear notch of Puijila is less open than that of Potamotherium or flippered pinnipeds. The radial notch of Puijila is similar in shape to that of Potamotherium, being larger, more circular 

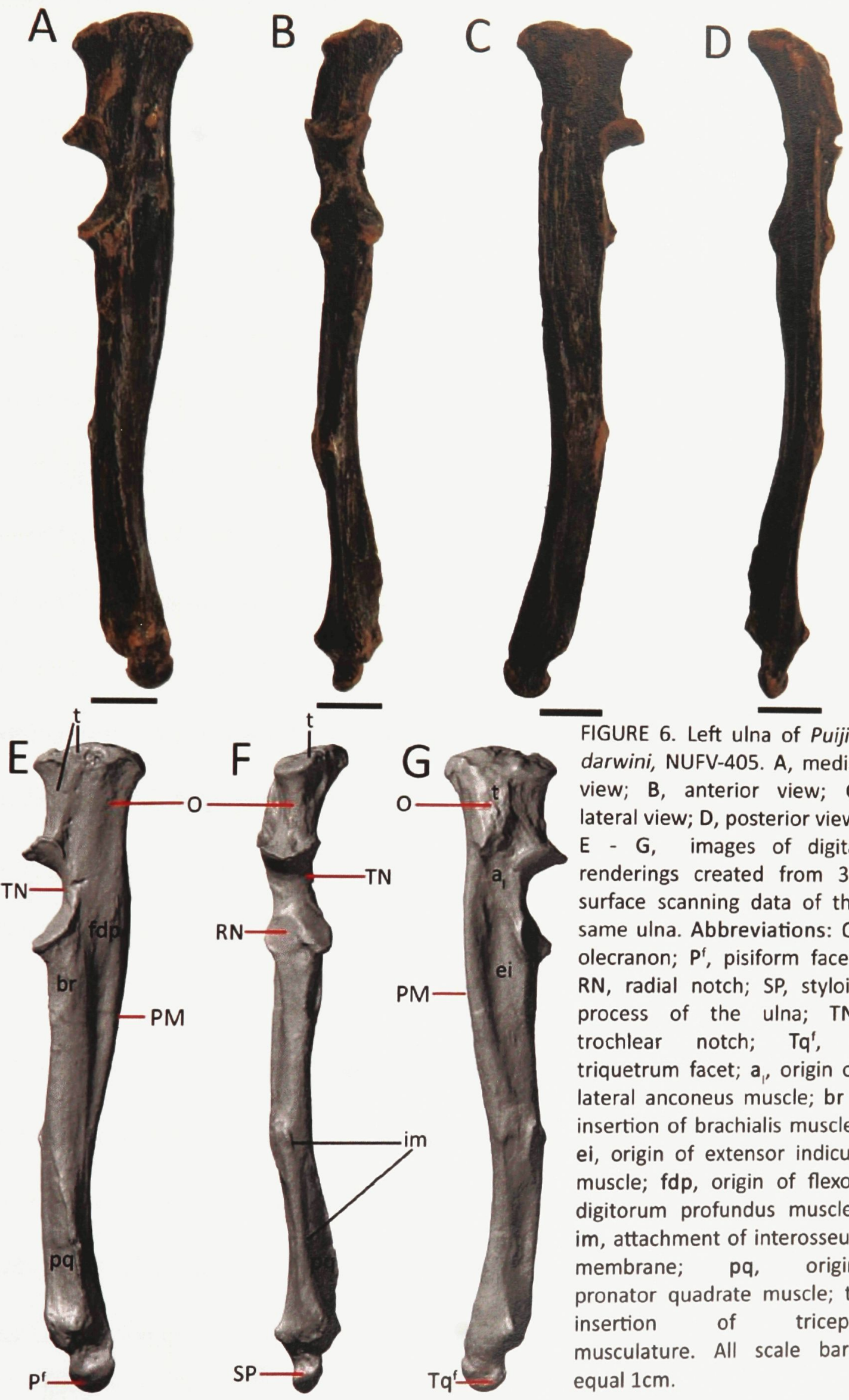

FIGURE 6. Left ulna of Puijila darwini, NUFV-405. A, medial view; B, anterior view; C, lateral view; D, posterior view; E - G, images of digital renderings created from $3 D$ surface scanning data of the same ulna. Abbreviations: 0 , olecranon; $\mathrm{P}^{\mathrm{f}}$, pisiform facet; $R N$, radial notch; SP, styloid process of the ulna; TN, trochlear notch; $\mathrm{Tq}^{\dagger}$, triquetrum facet; $a_{1}$, origin of lateral anconeus muscle; br insertion of brachialis muscle; ei, origin of extensor indicus muscle; fdp, origin of flexor digitorum profundus muscle; im, attachment of interosseus membrane; pq, origin pronator quadrate muscle; $t$, insertion of triceps musculature. All scale bars equal $1 \mathrm{~cm}$. 
and inclined further from the antero-posterior axis of the ulna, than that of Lontra. There is a deep groove for the brachialis muscle just distal to the trochlear notch. The shaft of the ulna narrows distally and is roughly triangular in cross section. The posterior margin of the shaft, distal to the trochlear notch, has a gentle curvature that makes it dorsally convex. This is strikingly different from the robust, straight and stout ulna of Lontra. There is a prominent tubercle on the lateral portion of the midpoint of the shaft for the attachment of the interosseous membrane, which is proportionally larger and more robust in Puijila than the condition seen in Potamotherium and Lontra. In both Potamotherium and Puijila, this interosseous tubercle is expanded laterally and gives the ulnar shaft a bent appearance. The distal portion of the ulnar shaft is expanded mediolaterally as compared with that of Lontra and Potamotherium and the styloid process is proportionately smaller in Puijila than in Lontra, though similarly shaped in lateral view. The pisiform facet on the styloid is half-moon shaped in Puijila, resembling that of Potamotherium, but u-shaped in Lontra. The surface itself is angled more anteriorly than that of Lontra, in both Puijila and Potamotherium.

\section{Carpals}

The carpal bones preserved in Puijila are the left and right scapholunars and pisiforms and the right triquetrum and hamatum (Fig. 7). The general arrangement of the carpals is the same as the terrestrial musteloid condition, though the shape of each bone differs slightly. The shapes of the carpals of Puijila are most similar to Potamotherium and together they resemble Lontra (Fig. 7). As Savage (1957) observed, 

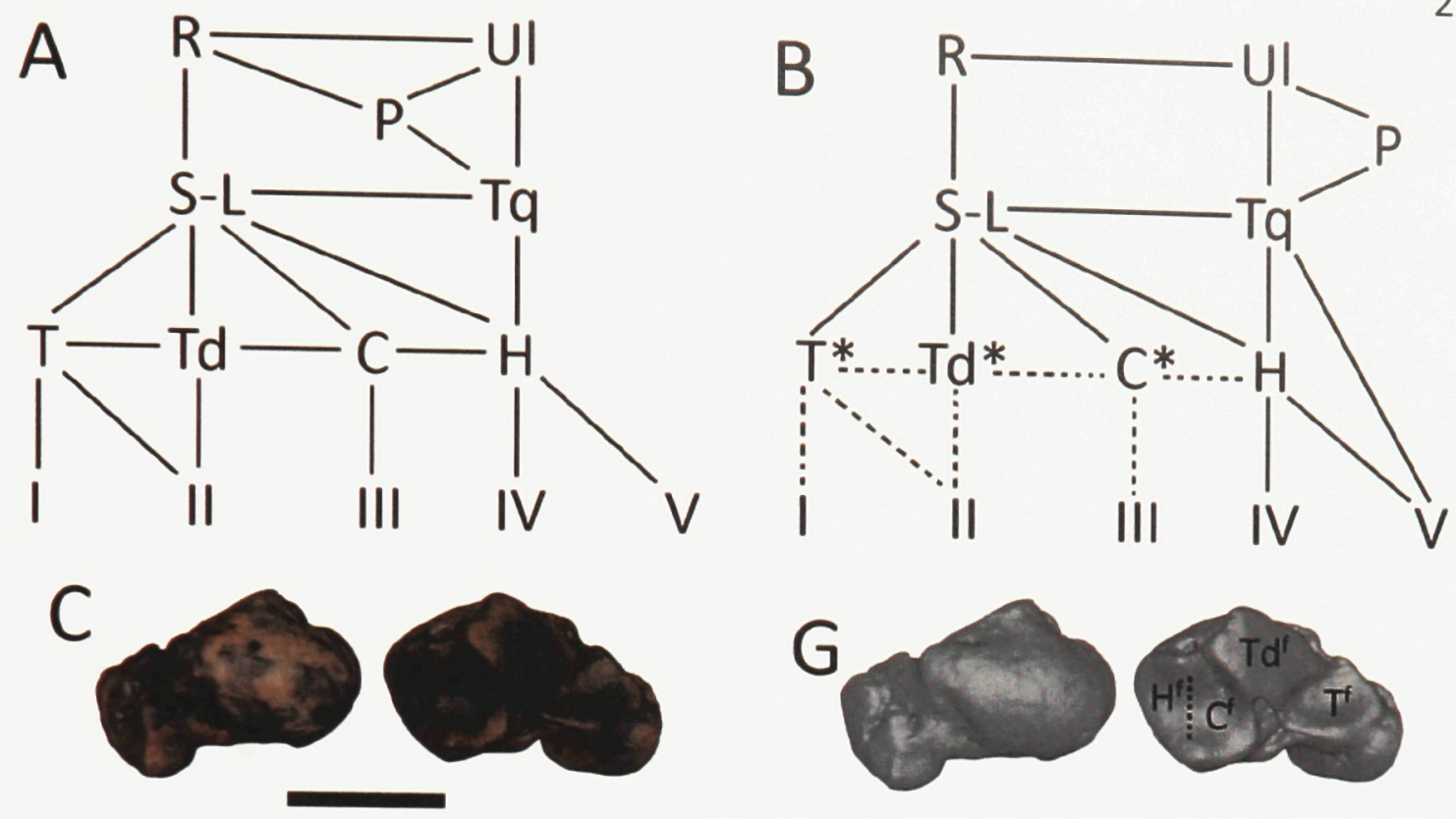

D
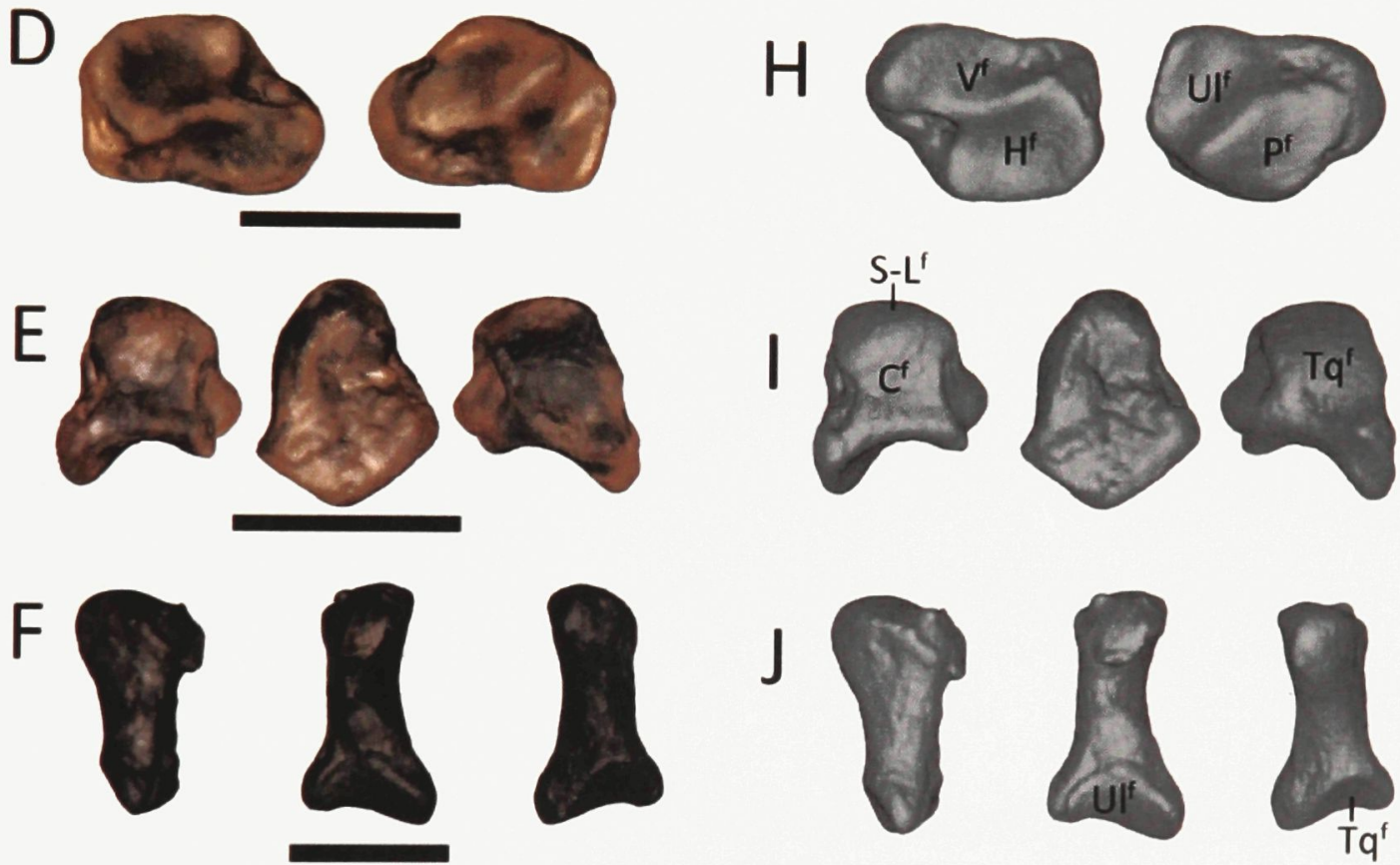

FIGURE 7. A, Diagram showing the proposed arrangment and articulations of the left carpals of Potamotherium vallentoni, (modified from Savage, 1957); B, proposed arrangment and articulations of the left carpals of Puijila darwini (*indicates bones not preserved in NUFV-405; dotted lines represent assumed articulations between the missing elements); C, right scapholunar, in dorsal and ventral views; $D$, right triquetrum, in medial and dorsolateral view; $E$, right hamatum, in medial, dorsal and lateral view; F, right pisiform, lateral, dorsal and ventral views; G-J, images of the same elements rendered from $3 D$ surface scanning data. Abbreviations: $C$, capitatum; $H$, hamatum; $P$, pisiform; $R$, radius; S-L, scapholunar; $T$, trapezium; $T d$, trapezoid; Tq, triquetrum; UI, ulna; I-V, metacarpals I to $V ; X^{\ddagger}$, facet, of element " $X$ ". All scale bars equal $1 \mathrm{~cm}$. 
Potamotherium has carpals which were similar to those of Lontra and that show none of the specializations of those of pinnipeds.

Pisiform - The pisiform of Puijila displays similarities with Potamotherium and Lontra, but also resembles the condition of the terrestrial musteloids Martes and Mephitis. The shape of the ulnar and triquetrum facets in Puijila resembles those of Potamotherium, being larger and more rounded than those of Lontra and Martes. These facets meet, forming a triangular cross-section in lateral view. Puijila differs from Potamotherium in that the junction of the two facets curves inward, not outward, in dorsal view, an appearance also shared by Lontra and Martes. Puijila also differs from Potamotherium in that it lacks the anteroposterior expansion of its posterior end, which gives the pisiform of Potamotherium an hourglass outline in both dorsoventral and mediolateral aspect. The ventral portion of the pisiform of Puijila is less reduced than that of Lontra, resembling Martes, Mephitis and Potmotherium. Puijila differs from Martes and Mephitis by having a more robust pisiform that displays a greater dorsoventral expansion at its ventral end.

Scapholunar-The scapholunar of Puijila appears more similar to Potamotherium than to Lontra and terrestrial musteloids, such as Martes. A difference between the scapholunars of Puijila and Martes is the shape of the trapezium and trapezoid facets. Those of Puijila are more distinct from one another and the trapezium facet of Puijila is deeper than that of Martes. Puijila also has a proportionally wider scapholunar medilaterally and enlargement and increased robusticity of the sesamoid process, as 
compared with Martes. The sesamoid process of Puijila is also proportionally more enlarged than Lontra, and has a similar level of expansion to that of Potamotherium. Compared to Lontra, Puijila has a less rectangular radial facet and a smaller angle, and greater distinction, between the trapezium and trapezoid facets. The scapholunar of Puijila appears most similar to Potamotherium and both appear more heart shaped in dorsal view, unlike the rectangular outline of those of Martes and Lontra. Puijila differs from Potamotherium by having more ovoid and anteroposteriorly compressed capitatum and hamatum facets, a proportionally smaller trapezium facet, which is more ovoid than circular, and a radial facet which is slightly more elongate mediolaterally.

Triquetrum - The triquetrum of Puijila is has a shape which is reminiscent of terrestrial musteloids such as Martes, but is lengthened anteroposteriorly like Lontra and Potamotherium, giving it an almost rectangular outline in lateral and medial view. Its dorsolateral surface appears most similar to that of Lontra, but its medial surface is more similar to that of Potamotherium. The positioning and orientation of the ulnar and pisiform facets, on the dorsolateral side of the triquetrum of Puijila generally resembles those of Lontra and Martes, but the ulnar facet of Puijila and Lontra is deeper than that of Martes. The ulnar facet of Puijila is proportionally smaller than the pisiform facet, whereas in Lontra they are roughly equal size. The medial side of the triquetrum of Puijila also differs from Lontra, whose large hamatum facet is similar in shape to terrestrial musteloids. Puijila has a proportionally smaller hamatum facet and a more distinct, larger metacarpal $V$ facet than Lontra or terrestrial musteloids. The shape and 
relative proportion of these facets in Puijila are closer to those of Potamotherium.

Puijila differs from Potamotherium by having a proportionately smaller metacarpal V facet and larger hamatum facet and proportionately smaller pisiform facet and larger ulnar facet.

Hamatum - The shape of the hamatum of Puijila is similar to that of Potamotherium and Lontra, but differs from terrestrial musteloids, such as Martes. Unlike Martes, the dorsal surface of the hamatum of Puijila is expanded anteriorly to form a triangular wedge, which points between metacarpals IV and V. The hamatum of Puijila is similar to that of Lontra, but the metacarpal IV and V facets are more distinct from one another, and the articulation surface they create is more concave, in Puijila. The hamatum of Puijila and Potamotherium have similar shaped triquetrum and capitatum facets, which are more rectangular than those of Lontra.

\section{Manus}

The right metacarpals I, II, IV and V and the left metacarpals II, III, IV and V of Puijila were recovered. All the metacarpals present are in good condition with little weathering and no breakage. The metacarpals do not immediately resemble those of terrestrial musteloids, being more robust than Martes, more elongate than Mephitis and possessing more robust epiphyses than either (Fig. 8). They are proportionately longer than those of Lontra and are more similar in size and shape to the modern lutrine, Pteronura. The metacarpals of Puijila broadly resemble those of Potamotherium, but differ by being proportionately shorter, more robust proximally and slightly more gracile 

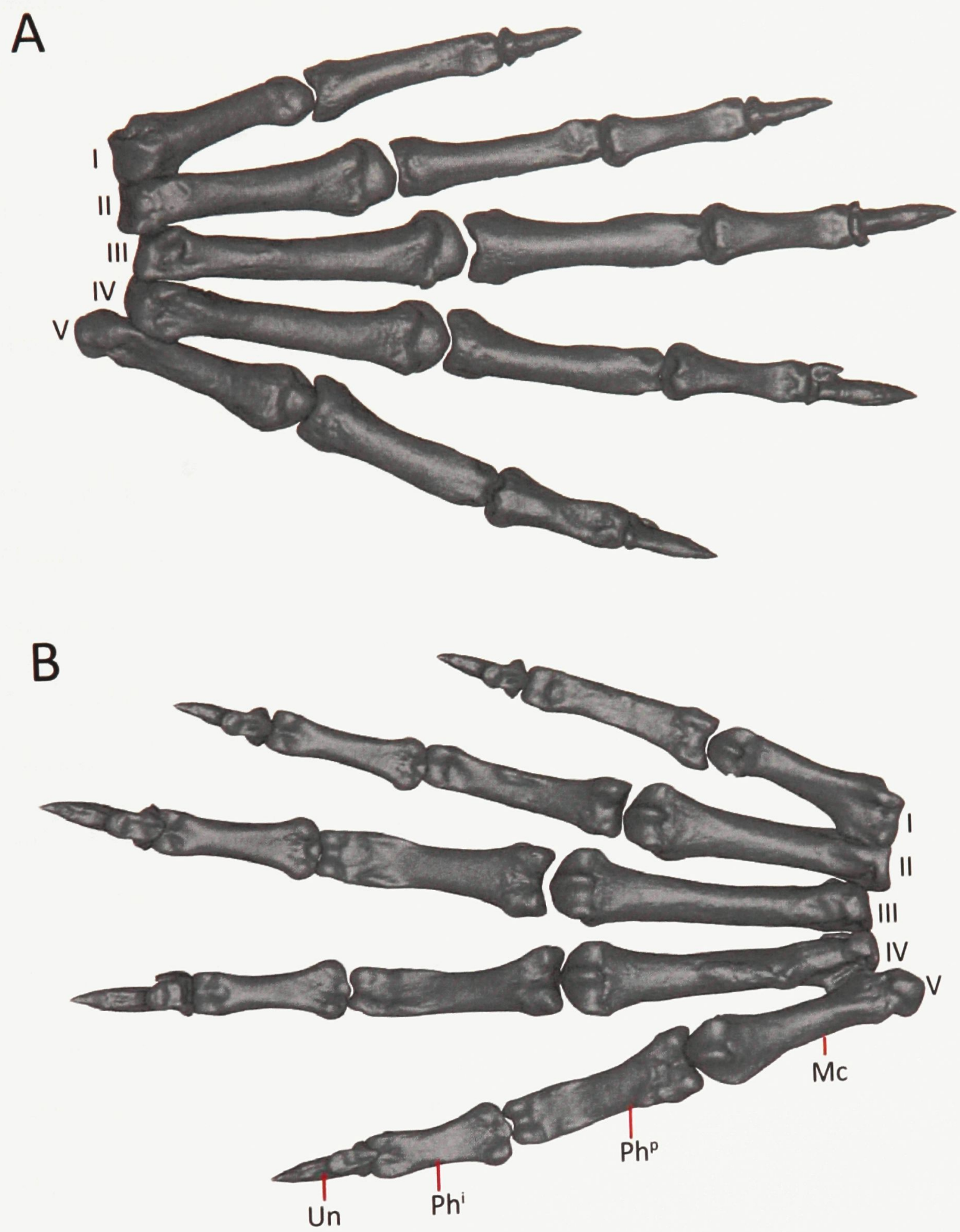

FIGURE 8. Reconstruction of the left manus of Puijila darwini, NUFV-405 rendered from $3 \mathrm{D}$ imaging data. $A$, dorsal view; $B$, ventral view. Abbreviations: $\mathrm{I}-\mathrm{V}$, manual digits I to $\mathrm{V}$; Mc, metacarpal; $\mathrm{Ph}^{\mathrm{i}}$, intermediate phalanx; $\mathrm{Ph}^{\mathrm{P}}$, proximal phalanx; Un, ungual phalanx. All scale bars equal to $1 \mathrm{~cm}$. 
distally. The shape of the manus of Puijila differs from Potamotherium, as metacarpals I and V are shorter in comparison to II, III, and IV, resembling the proportions of those of Lontra. However, the entire manus of Puijila is proportionally much larger than that of Lontra and metacarpal II is noticeably longer than metacarpal V, a condition shared by Potamotherium. The order of the length of the metacarpals in Puijila is $3 \geq 4>2>5>1$, as compared to $4 \geq 3>2 \geq 5>1$ in Lontra and $4 \geq 3>2>5>1$ in Potamotherium.

The phalanges of Puijila are well represented, with at least one of proximal phalanges I-V, intermediate phalanges III-V and ungual phalanges III-V, being represented by either a right or left element. They appear almost identical to those of Potamotherium, also being similar to Lontra and differing from terrestrial musteloids, by being flattened dorsoventrally and elongated relative to their associated metacarpal. The greatest degree of dorsoventral flattening occurs in the proximal phalanges of Puijila and is not uniform between the proximal and intermediate phalanges like in Lontra.

Metacarpal I-Metacarpal I differs from Potamotherium by having a shaft which is more flared proximally. The metacarpal is unlike Potamotherium as it is concave in lateral view. It resembles Pteronura, in that respect, though the curvature in Puijila is slightly more pronounced. The proximal end of the bone expands further ventrally in Puijila than in Potamotherium. The metacarpal I of Puijila has a deeper elongate ushaped trapezium facet than that of Lontra, which has a shallower and more triangular facet. 
Metacarpal II-In Puijila, metacarpal II differs by being less robust than that of Potamotherium. The shaft of the bone is more slender and lacks a tuberosity which appears prominently on the proximal half of the medial surface of that of Potamotherium. The metacarpal appears similar to Potamotherium in all other respects. It is also similar to that of Lontra, except for being proportionately longer.

Metacarpal III-The metacarpal III, of Puijila, appears similar to Potamotherium and Lontra, but has a more slender shaft and a gentle tapering of its proximal end. Its lateral articulation surface extends only slightly over the adjacent metacarpal IV capitatum facet, causing the proximal end to appear to slant laterally in dorsal view, in addition to the narrowing. This is distinct from the square proximal epiphysis seen in Potamotherium and Lontra. Also, the articulation between metacarpal III and metacarpals II and IV appears better fitted than in Potamotherium and Lontra. The element is slightly more convex than that of Potamotherium and proportionally longer than in Lontra.

Metacarpal IV_Puijila differs from Potamotherium by having less mediolateral expansion at its proximal end and a tuberosity located ventrally on the lateral surface of the shaft, just distal of the lateral articulation for metacarpal V. The bone is expanded dorsally in the proximal half of the bone, as compared with Potamotherium. The bone has a similar curvature to that of Potamotherium. The proximal articulation surface narrows more, ventrally, in Puijila. The articular facets at the proximal end of the element, for metacarpals III and V, taper towards each other creating a V-shaped outline 
in dorsal view in Puijila. This is unlike the metacarpal IV of Lontra, where the proximal end of the bone is shaped like a parallelogram in dorsal aspect. Metacarpal IV of Puijila is also proportionately longer than that of Lontra.

Metacarpal V-The metacarpal V, of Puijila, is distinct from that of Potamotherium as it curves medially and appears slightly more convex in lateral view. It is somewhat similar in appearance to that of Lontra, but is less dorsoventrally flattened and narrower mediolaterally in its proximal half. In most respects it appears almost identical to that of Potamotherium, including the shape and relative size of its proximal articulation surfaces.

Proximal Phalanges-The proximal phalanges of Puijila are elongated to approximately $70 \%$ the length of the metacarpals. They differ from those of terrestrial musteloids, such as Martes and Mephitis, by being dorsoventrally flattened. They differ from those of Lontra by having a slightly greater degree of flattening and elongation of the elements. Puijila, Potamotherium and Lontra possess a widening toward the distal portion of the shaft of the proximal phalanges, associated with two ventral tubercles located on the medial and lateral sides of the ventral shaft surface, just proximal to the distal articulation of the element. These are larger in Puijila than in Lontra, and associated with a greater degree of mediolateral expansion in that area of the element. The phalangeal shafts of both Puijila and Potamotherium appear slightly more slender, elongate and gracile than those of Lontra. The epiphyses of the phalanges of Puijila show the same trend of enlargement and robusticity as seen in the metacarpals. 
Intermediate phalanges-The intermediate phalanges of Puijila resemble those of Potamotherium, but differ slightly by possessing a lesser degree of elongation, anteroposterior flattening and mediolateral expansion. They differ from those of Lontra by being less flattened and more gracile. Also, the proximal articularsurfaces of the intermediate phalanges of Puijila and Potamotherium are different from those of Lontra. In Puijila and Potamotherium, they are shallower and crossed by a dorsoventrally aligned ridge, which separates the medial and lateral side of the articular surface into two oval pits. In dorsal view, there is a small lip of bone jutting out into the center of the articular surface, which is the dorsal termination of the ridge. The entire shape of the articular surface gives the proximal end of the intermediate phalanges, of both Puijila and Potamotherium, a shallow w-shaped outline in dorsal view, as opposed to the simple ushaped outline of that of Lontra. The articular surface in terrestrial musteloids, such as Mephitis and Martes, appears similar in shape to that of Puijila and Potamotherium, but are slightly deeper. The rest of the element is not similar to Puijila and Potamotherium, as it is not flattened in the terrestrial forms. Therefore, the intermediate phalanges of Puijila are less flattened than those of Lontra, being similar to those of Potamotherium, and possess a proximal articulation surface that is similar to terrestrial musteloids.

Ungual phalanges-The ungual phalanges are difficult to assign to a specific digit. Those included in this study have been tentatively assigned to digits III to V, based on their size and the shape of their articularsurfaces. The other unguals found in association with the Puijila skeleton have been tentatively associated with the pes. The 
ungual phalanges of Puijila appear similar to those of Lontra and Potamotherium, being slightly reduced in size and rounded at their tips, relative to some terrestrial musteloids such as Mephitis. They appear less reduced than those of Potamotherium and similar to those of Lontra. They are greatly reduced in size and length when compared to a digging specialized musteloid, such as Taxidea taxus. 
TABLE 2. Measurements (in $\mathrm{mm}$ ) of the forelimb skeleton of Puijila darwini.

\begin{tabular}{|c|c|c|c|}
\hline \multicolumn{2}{|c|}{ Measurement } & Right & Left \\
\hline \multicolumn{2}{|c|}{ Scapula, length(glenoid cavity to dorsal border) } & $77.82 *$ & $81.05^{*}$ \\
\hline \multicolumn{2}{|c|}{ Scapular spine, max. height } & NA & $13.86^{*}$ \\
\hline \multicolumn{2}{|c|}{ Teres expansion, max length } & NA & $33.04 *$ \\
\hline \multicolumn{2}{|c|}{ Teres expansion, max width } & $13.87^{*}$ & $15.53^{*}$ \\
\hline \multicolumn{2}{|c|}{ Humerus, max. length } & 97.22 & $95.12^{*}$ \\
\hline \multicolumn{2}{|c|}{ Deltopectoral crest, length } & 56.89 & NA \\
\hline \multicolumn{2}{|c|}{ Distal condylar, width, ml } & 29.82 & NA \\
\hline \multicolumn{2}{|c|}{ Diaphysis, diameter, $\mathrm{ml}$} & 8.37 & 8.18 \\
\hline \multicolumn{2}{|c|}{ Diaphysis, diameter, ap } & 15.06 & 15.28 \\
\hline \multicolumn{2}{|c|}{ Radius, max. length } & 73.77 & 73.39 \\
\hline \multicolumn{2}{|c|}{ Diaphysis, diameter, $\mathrm{ml}$} & 7.23 & 7.01 \\
\hline \multicolumn{2}{|c|}{ Diaphysis, diameter, ap } & 7.82 & 7.43 \\
\hline \multicolumn{2}{|c|}{ Ulna, max. length } & 97.48 & 96.8 \\
\hline \multicolumn{2}{|c|}{ Functional length (styloid to coronoid process) } & 66.62 & 66.81 \\
\hline \multicolumn{2}{|c|}{ Olecranon, max. length } & 15.87 & 17.43 \\
\hline \multicolumn{2}{|c|}{ Diaphysis, diameter, ml (of func. length) } & 6.03 & 5.88 \\
\hline \multicolumn{2}{|c|}{ Diaphysis, diameter, ap (of func. length) } & 7.54 & 7.93 \\
\hline \multicolumn{2}{|c|}{ Metacarpal I, max. length } & 23.22 & NA \\
\hline & II, max. length & 30.58 & 30.81 \\
\hline$"$ & III, max. length & NA & 36.46 \\
\hline$"$ & IV, max. length & 35.93 & 35.76 \\
\hline & $\mathrm{V}$, max. length & 28.09 & 28.02 \\
\hline Proxim & halanx I, max. length & 21.95 & NA \\
\hline & II, max. length & 23.92 & 23.5 \\
\hline$"$ & III, max. length & 26.75 & 26.99 \\
\hline$"$ & IV, max. length & 24.94 & 24.86 \\
\hline & $\mathrm{V}$, max. length & 22.78 & 22.84 \\
\hline Interm & ate Phalanx III, max. length & 18.06 & 18.4 \\
\hline & IV, max. length & 17.34 & 17.4 \\
\hline & V, max. length & 16.24 & 16.18 \\
\hline Ungual & alanx III**, length & $12.51^{*}$ & $11.73^{*}$ \\
\hline " & $\mathrm{IV}^{* *}$, length & $11.89 *$ & $11.49^{*}$ \\
\hline$"$ & $\mathrm{~V}^{* *}$, length & $10.85 *$ & NA \\
\hline
\end{tabular}

*- measurements are affected by the element being fragmented.

** - digit association uncertain.

Abbreviations: $\mathrm{ml}$, mediolateral; ap, anteroposterior. 


\section{DISCUSSION}

The exceptional preservation of the forelimb of Puijila darwini allows for identification of specializations that may be shared with other members of the pinniped lineage and specializations that have functional implications and may be useful for behavioural reconstruction. Skeletal specializations of the forelimb of Puijila which are shared with Potamotherium and pinnipeds include the presence of a "teres fossa" on the scapula, a deep humeral trochlea, an enlarged greater and lesser tuberosity of the humerus, a proportionately large manus, a shallow trochlear notch of the ulna and a robust, rounded radial head. Other traits which could suggest a pinniped affinity are the robust deltopectoral crest of the humerus and an expanded olecranon. These skeletal features are more developed than in modern lutrines, but do not yet approach the condition seen in flippered pinnipeds and Potamotherium.

The specializations of the scapula in Puijila and Potamotherium indicate that many of their shoulder muscles were relatively larger than those of modern musteloids, including the semi-aquatic Lontra (Savage, 1957), but less robust than those of flippered pinnipeds. The specializations of the scapula which indicate enlargement or strengthening of muscle groups in Puijila include: a large infraglenoid tubercle, for the origin of the long head of the triceps, and an enlarged coracoid process, presumably for the origin of the biceps and coracobrachialis (Savage, 1957; Howard, 1973; Evans, 1993).

The coracobrachialis muscle, which sometimes originates from the coracoid process, is absent in Lontra and modern pinnipeds (Howell, 1929; Fischer, 1942). It is 
also absent in some terrestrial musteloids, such as 39 seeming to only exist in Martes (Hall, 1926, 1927; Leach, 1977b). In Martes, the coracobrachialis and biceps muscles both originate from the coracoid process, but in Lontra, modern pinnipeds and the other terrestrial musteloids the coracoid process is the site of the origin of the biceps muscle only (Hall, 1926, 1927; Howell, 1929; Fischer, 1942; Savage, 1957; Leach, 1977b). If Puijila did not possess a coracobrachialis, then only the enlarged biceps muscle would originate on the coracoid process of the scapula. Typically, the biceps muscle originates as a tendon which passes through the bicipital groove, between the greater and lesser tuberosities of the humerus. The main portion of the muscle is located along the anterior surface of the humerus, before again becoming a tendon which inserts onto the biceps tubercle of the radius. The main action of this muscle is as a forearm flexor (Fischer, 1942; Howard, 1973; Evans, 1993). In modern pinnipeds the coracoid process, from which the biceps muscle originates, is greatly reduced, but in the early fossil pinnipeds Enaliarctos and Pteronarctos it is larger and hook-like (Howell, 1929; Berta and Ray, 1990; Berta, 1994; Berta and Wyss, 1994). Puijila possess a coracoid process which is not reduced, being slightly enlarged in comparison to both Potamotherium and Lontra; possibly indicating a larger biceps muscle or an enlarged biceps and coracobrachialis muscle (Savage, 1957).

The infraglenoid tubercle, of both Puijila and Potamotherium is larger than those of terrestrial musteloids and Lontra, but its shape and position are similar. This would provide an enlarged area for the origin of the long head of the triceps; which, combined 
with the other muscles of the triceps muscle complex, inserts onto the olecranon and acts to extend the elbow (Howard, 1973; Evans, 1993). The origin of the long head of the triceps in the sea lion Zalophus is also on the infraglenoid tubercle; similar to Puijila, Potamotherium and modern musteloids (Howell, 1929; Fischer, 1942; Howard, 1973; English, 1977; Evans, 1993). However, in the true seal Phoca, the position of the origin of the long head of the triceps is different; it originates from the posterodorsal edge of the infraspinatus fossa and along the dorsal margin of the scapula (Howell, 1929; English, 1977). The shape and size of the infraglenoid tubercle in Puijila, the likely origin for the long head of the triceps, suggests Puijila had a more robust musculature in the lower portion of the scapula, which was arranged similarly to modern musteloids. The lower portion of the scapula of Puijila shows great similarities to that of Potamotherium, indicating they likely possessed a similar arrangement of muscles; one that was less specialized, but similar in arrangement to what is found in some modern pinnipeds, such as Zalophus.

The most striking feature of the scapula of Puijila is the posterodorsal expansion, which can be interpreted confidently as providing attachment for an expanded teres major muscle. The teres major muscle originates from the lateral surface of the caudal angle in terrestrial and semi-aquatic musteloids and inserts on the medial side of the humerus, just below the lesser tuberosity (Fischer, 1942; Howard, 1973; English, 1977; Leach, 1977b, a; Evans, 1993). It provides adduction and flexion of the humerus (Evans, 1993). In pinnipeds the caudal angle is expanded forming a "teres fossa" that is 
separated from the infraspinatus fossa by a ridge known as the "caudal scapular ridge" (English, 1977), or "secondary spine" (Savage, 1957) (Fig. 3). In Lontra, which can be considered one of the most swimming specialized of modern musteloids, there is no separated area of expansion on the scapula (Fischer, 1942). The expansion for the teres musculature in Potamotherium was noted by Savage (1957) to be comparable to the pinniped condition and similar areas of expansion appear in Enaliarctos and Pteronarctos. Therefore, this expansion may be associated with the pinniped condition, of the enlargement of the teres major muscle.

The deltoid muscle in terrestrial musteloids and Lontra is separated into the acromiodeltoid and spinodeltoid muscles which together originate from the scapular spine, metacromion and acromion and insert onto the deltoid ridge along the lateral side of the deltopectoral crest of the humerus (Hall, 1926, 1927; Fischer, 1942; Howard, 1973; English, 1977). The primary action of these two muscles is to abduct the humerus as well as contribute to its extension and external rotation (Fischer, 1942; Howard, 1973). In pinnipeds the deltoid is a single muscle, which in phocids originates on the acromion and along the length of the scapular spine, and in otariids continues further, turning to follow along the edge of the dorsal border, almost to the caudal angle (Howell, 1929; English, 1977). English (1977) performed gross dissections on 14 individuals of four species of otariids, including Zalophus, comparing them with terrestrial and semi-aquatic musteloids. He found that the expansion of the caudal angle in otariids was occupied with the teres major and the caudal fibers of the deltoid 
muscle. English (1977) did not report a teres minor in Zalophus. However, Howell (1929), through observations of his dissections of two genera of modern pinnipeds, associated the area of expansion, or "teres fossa", with the origin of the teres minor in Zalophus and the teres major in Phoca. Howell (1929) noted that the teres minor was distinct and located outside the infraspinatus fossa between the infraspinatus and teres major muscles, in both Phoca and Zalophus. This is unlike musteloids where the teres minor is often indistinguishable from the infraspinatus and shares a close or common origin with the infraspinatus when present (Hall, 1926, 1927; Fischer, 1942; Howard, 1973). The shape and position attributed to the origin of the caudal fibers of the deltoid in Zalophus, as described by English (1977), is the same as what Howell (1929) identified as the origin of the teres minor. In terrestrial mammals, the deltoid overlays the teres minor (Evans, 1993). Therefore, it is likely that these were two different names given to the same muscle. English (1977) suggested that the migration of the origin of the deltoid muscle allowed it to associate with the acromiotrapezius muscle and, by working together, these muscles would increase their functional length, thereby allowing for abduction of the forelimb through a greater range of movement, at a rapid rate and with a greater state of tension. Therefore, the presence of a posterodorsal expansion and secondary spine in Puijila indicates an enlargement of the teres major muscle and possibly also the teres minor muscle and may be associated with the enlargement, consolidation and migration of the deltoid muscle. It provides evidence that the muscles of the pectoral girdle of Puijila and Potamotherium may have resembled the condition of 
the pinnipeds, rather than terrestrial or semi-aquatic musteloids.

The specializations of the humerus further support the indications of an enlarged biceps and deltoid musculature. The enlarged lesser and greater tuberosities of the humerus create a deep bicipital groove, which the biceps tendon pass through, and an enlarged deltopectoral crest, creating a larger area for the insertion of the deltoid and pectoralis muscles. The enlargement of the greater and lesser tuberosities of the humerus may also signify well developed supraspinatus and subscapularis muscles, and imply that the missing portion of the supraspinatus fossa was probably large in comparison to that of Lontra, possibly approaching the proportions seen in Potamotherium (Howell, 1929; Savage, 1957; English, 1977).

In Puijila, the relative size of the origin of the infraspinatus, as compared with the size of the suprascapularis, is smaller than in terrestrial musteloids. There is a deep groove for the infraspinatus insertion on the lateral facing side of the greater tuberosity of Puijila. Therefore, the infraspinatus appears to have still been a well developed muscle in Puijila. The area for the insertion of the teres minor is broken on both humeri, making it impossible to add to the partial evidence, provided by the scapula, that this muscle may have been separate from the infraspinatus in Puijila.

The expanded lateral epicondylar wing creates a large surface for attachment of the lateral anconeus muscle posteriorly and the brachialis muscle and extensor muscles of the wrist and hand anteriorly. Its proportionately larger size in Puijila and Potamotherium may indicate these muscles showed greater development in these two, 
than in Lontra. Extensors that originate along the lateral margin of the lateral epicondylar wing include: extensor carpi radialis longus, extensor carpi radialis brevis, extensor digitorum communis and extensor digitorum lateralis (Howard, 1973; English, 1977; Evans, 1993). Together, these muscles dorsiflex the wrist and extend the digits away from the palm, while also stabilizing them in that position(Howard, 1973).

Combining that motion with abduction of the digits would create a powerful opening and good stabilization of the manus; thus producing a large surface area that could be used for the creation of thrust in the water. The enlargements of the extensors in Potamotherium and Puijila, as compared to those of Lontra, were likely associated with the proportionately larger manus size. The medial epicondyle does not appear to have especially enlarged areas for the attachment of the corresponding flexors of the wrist and manus. However, there is well developed origin for the pronator teres muscle along its posterior margin.

Savage (1957) noted that the anterior curvature of the humeri of pinnipeds and Potamotherium made it similar to a bow, with tension being provided by the triceps musculature. According to Savage (1957), a curved humerus, such as that of Puijila, in conjunction with a strong triceps musculature, provides the strength to resist the strain caused by strong flexion and rotation of the forearm, without having to thickening the shaft.

The ulna and radius possess further indications of a powerful upper forelimb musculature, including an enlarged olecranon and area for the insertion of the triceps 
musculature, a deep groove for the insertion of the brachialis, a large biceps tubercle of the radius and a large area for the insertion of the deep digital flexors and extensor indicus on the ulna.

The elements also display evidence that the forearm and hand musculature in Puijila were specialized. Puijila displays a robust insertion for the pronator quadrate muscle on both the radius and ulna. The large area of origin for this muscle and the mediolateral expansion of the distal ulna, are both indications for its enlargement in Puijila. It appears to have been more expanded in Puijila than in Lontra. There is a large area for the insertion of the supinator on the anterior side of the radius. The depth of the grooves for the tendons of the extensor muscles provides further evidence that Puijila had more specialized carpal and manus extensor musculature than Lontra, perhaps to support its proportionately larger manus.

The interosseus membrane serves as an attachment for muscles, stabilization of the radius and ulna and to translate movement of the radius to the humerus (English, 1976, 1977; Leach, 1977b, a; Evans, 1993). The robusticity of this structure in Puijila is indicated by the interosseus tubercles of the radius and ulna, which are both expanded. Savage (1957) observed that aquatic animals often hold the hand midway between pronation and supination during aquatic locomotion. English $(1976,1977)$ also observed that otariids hold the hand in this way and that they possess lower forelimb musculature that is designed to stabilize the radioulnar joint. He attributed this stabilization to the need to keep the forelimb flattened during aquatic locomotion, in order to increase 
surface area during propulsion and to maintain a hydromechanical advantage while drawing the limb back through the water during the recovery stroke. Most of the rotary movement needed for the propulsive and recovery stroke of the forelimb during swimming is produced at the glenohumeral joint. Therefore, the main function of the pronator and supinator muscles is one of stabilization (English, 1976, 1977). This corresponds with the observations of Howell (1929) that pinnipeds had large pronator and supinator muscles, but due to the limited range of motion in their radioulnar joints, the muscles were used primarily for stabilization. This suggests the strong pronator, supinator and robust interosseus membrane in Puijila were important for stabilization of the manus during swimming.

In every element of the forelimb skeleton of Puijila there is evidence that its forelimb musculature was more specialized for swimming and likely more powerful than in Lontra. The actions of the enlarged teres major, deltoid, pectoralis, triceps and anconeus create flexion of the shoulder joint and extension of the elbow. These movements, combined with the extension and abduction of the digits to create an open webbed manus, would generate a powerful backwards stroke. The actions of the large supraspinatus, pectoralis, biceps and brachialis cause extension of the shoulder joint and flexion of the elbow. Combining these movements, and allowing the manus to close, would provide a strong recovery stroke. In addition, the actions of the teres major, deltoid, supraspinatus and pectoralis show the limb was capable of powerful abduction and adduction. These muscles, along with the subscapularis and infraspinatus assisted 
with rotation of the humerus, indicating that the forelimb may have been capable of powerful rotary movements during swimming strokes (English, 1977). The specializations of these muscle groups in Puijila suggest that its forelimb was capable of creating more power, over a greater range of motion, than the limb of Lontra.

Specifically, the enlargement of the muscles in the forelimb of Puijila suggests that the limb was capable of powerful backward and recovery strokes, powerful limb abduction and adduction.

Evidence from this powerful forelimb musculature may suggest behavioural specializations for swimming and/or digging. However, Puijila does not exhibit fossorial specializations, such as enlarged unguals. Instead the unguals are small, and the elongated digits and flattened phalanges imply the presence of webbing, suggesting that the robust forelimb musculature was primarily associated with a behavioural specialization for swimming (Rybczynski et al., 2009). This is supported by the fact that Puijila shows the greatest specialization in the proximal elements of the forelimb, a pattern that Savage (1957) observed in Potamotherium and stated was typical of an aquatically specialized animal.

The few similarities seen in the forelimb of Puijila and Lontra, particularly in the general shape of the humerus, suggest the forelimbs may have been used in similar ways during swimming. Lontra swims primarily using dorsoventral undulations to create propulsion with the hind feet and tail while submerged. The forelimbs are used primarily for steering underwater and for propulsion during surface swimming when the 
animal employs drag-based quadrupedal paddling (Fish, 1996). However, the forelimb of Puijila is more specialized than that of Lontra and therefore it likely employed its forelimb to a greater extent while swimming than Lontra.

Savage (1957) postulated that the adaptations of the forelimb of Potamotherium indicate the limb may have been favoured for powerful "dog-paddle" swimming for periods of slower locomotion. During periods where speed was more important, they may have only been used primarily for steering, by adduction and abduction while the animal swam by pelvic undulation. This is similar to the suggestion of Rybczynski et al. (2009) that Puijila swam, at least in part, using quadrupedal paddling. The powerful forelimb of Puijila was certainly heavily involved in its swimming behaviour and the similarities in the forelimbs of Potamotherium and Puijila may indicate that Puijila exhibited a similar swimming behaviour to Potamotherium.

Although molecular phylogenetics has indicated that Pinnipedia is monophyletic, it can only provide evidence that pinnipeds are more closely related to one another than to other terrestrial arctoids. Though pinnipeds shared a common ancestor, molecular studies cannot determine the nature of that common ancestor. Pinnipeds may have diverged from a single terrestrial ancestor and become aquatic separately, or they could have had a single return to the water and originated from a semi-aquatic ancestor. Fish (1996) suggested that as a lineage evolves from being quadrupedal terrestrial animals to occupy an aquatic habitat, they first employ drag-based propulsion by quadrupedal paddling, followed by the evolution of more efficient alternate pelvic or pectoral 
paddling. The two forms of aquatic locomotion in modern pinnipeds, forelimb and hind limb dominated swimming, are each specific to different extant pinniped lineages. If stem pinnipeds, like Puijila, did employ quadrupedal paddling as part of their aquatic locomotion, it is possible that these forms could have given rise to both of the swimming styles displayed by the modern pinnipeds.

Further understanding of the swimming mode of Puijila will require a detailed description of the remaining postcrania, in order to better understand the contributions that the vertebral column, pelvic girdle and hind limb had to its aquatic locomotion. The preliminary observations gained from the description of the pectoral girdle and forelimb will become more informative when they are integrated with observations from the rest of the postcrania.

\section{SUMMARY}

The comparative description of the forelimb musculoskeletal system of Puijila indicates it was more specialized for swimming than that of living lutrines, yet less specialized than that of Potamotherium. The comparative description provided here provides a basis for identifying traits of the forelimb which may be phylogenetically informative. The specializations of the forelimb of Puijila suggest that it was adapted to provide powerful forward and recovery strokes during swimming and its level of specialization suggests that it could have been used more frequently during aquatic propulsion than the forelimb of Lontra. This may indicate that quadrupedal or forelimb paddling was a more important, or a more frequently used form of locomotion in Puijila 
than it is in modern lutrines or that Puijila simply used its forelimb differently than modern lutrines. Comparative descriptions of the specializations of the hind limb, pelvic girdle and vertebral column will provide insight into the role that they played in the aquatic locomotion of Puijila. A better understanding of the whole skeleton in a comparative framework will continue to shed light on the possible origin and evolution of the various swimming modes exhibited by modern Pinnipedia. 


\section{CHAPTER 2 - EVIDENCE FOR CORRELATED EVOLUTION BETWEEN LONG BONE COMPACTNESS, SWIMMING BEHAVIOUR AND BODY MASS IN ARCTOIDEA \\ (MAMMALIA: CARNIVORA)}

\section{INTRODUCTION}

Many groups of mammals have become secondarily adapted to life in water and some have achieved high levels of aquatic specialization, including the cetaceans (whales), sirenians (sea cows, dugongs) and pinnipeds (seals, sea lions and walrus) (Reidenerg, 2007; Uhen, 2007; Houssaye, 2009). The modification of internal bone microstructure to increase bone density has been hypothesized to be a specialization for aquaticism developed in these lineages (Wall, 1983; Stein, 1989; Fish and Stein, 1991; Girondot and Laurin, 2003; Laurin et al., 2004; Cubo et al., 2005; Germain and Laurin, 2005; Laurin et al., 2006; Kriloff et al., 2008; Houssaye, 2009; Canoville and Laurin, 2010). An increase in bone density through the outward thickening of cortical bone is known as pachyostosis, an inward thickening of cortical bone is osteosclerosis and the combination of both is pachyosteosclerosis (Domning and Debuffrenil, 1991; Laurin et al., 2004; Gray et al., 2007; Houssaye, 2009). However, in addition to cortical bone thickening, a bone's "compactness" can also be increased by the increased deposition of trabecular bone.

Increased bone density as a specialization for aquatic life has been studied in both modern and fossil organisms. Previous studies of modern mammals directly measureD bone density by weighing bones and measuring the volume of water they 
displaced when fully saturated, and then used the relationship of density=mass/volume to calculate their density (Wall, 1983; Stein, 1989; Fish and Stein, 1991). Due to mineralization of bone during fossilization, these methods cannot be used to compare fossil and modern bone (Madar, 1998). An alternative approach would be to examine a bone's internal structure, which directly contributes to bone density. Wall (1983) identified that the increase in density in some of the species he examined was due to an increase in cortical bone thickness. In an attempt to compare modern and fossil bone, Madar (1998) examined cortical bone thickness by taking X-rays and using them to compare the diameter of the medullary cavity (ID) and the overall diameter (ED) at the diaphysis of the bone (Currey and Alexander, 1985; Madar, 1998). By averaging the ratio of ID/ED in anteroposterior and mediolateral directions, an average value, referred to as K, could be produced and compared between species (Currey and Alexander, 1985). However, this method did not measure increased deposition of trabecular bones which can also increase bone density, and it did not accurately represent variations in the thickness of cortical bone around the entire circumference of the section. More recently studies by Canoville and Laurin (2010), Kriloff et al. (2008), Germain and Laurin (2005), Laurin et al. $(2006,2004)$ have begun to examine multiple aspects of bone microstructure which might be related to aquatic specialization by using the software Bone Profiler (Girondot and Laurin, 2003). This software produces parameters that better represent a bone's compactness because they are generated by analyzing the entire section as a whole. 
If bone microstructure is associated with an animal's swimming ability or behaviour, then it could provide a powerful tool to reconstruct swimming behaviour in extinct mammals. Fossil representatives of the earliest stages of the land-to-sea transition of both sirenians and cetaceans are known (Domning, 1982; Thewissen and Fish, 1997; Domning, 2001; Thewissen and Williams, 2002), but until recently there was no early morphological intermediate between swimming pinnipeds and their terrestrial ancestors represented in the fossil record. The fossil taxon that was most commonly recognized as the most basal pinniped was Enaliarctos (Berta et al., 1989; Berta, 1991). However, Enaliarctos was similar to modern pinnipeds, as it had flippers, a streamlined body, reduced limbs and was fully marine (Berta et al., 1989; Berta and Wyss, 1990; Berta, 1991). Puijila darwini fills the morphological gap between flippered pinnipeds and their terrestrial ancestors (Rybczynski et al., 2009). Study of the musculoskeletal specializations of the forelimb, detailed in the previous chapter, showed that Puijila had a greater degree of aquatic specialization than modern lutrines and likely employed its forelimbs to a greater degree than modern semi-aquatic carnivores.

This study examines the trends in bone microstructure of extant pinnipeds and their terrestrial relatives to see if they can be used as a predictive tool for reconstruction of the swimming behaviour of fossil arctoids which are suspected to be specialized for swimming. Some aquatic species within Arctoidea have been said to have elevated bone compactness, such as Enhydra and some pinnipeds (Wall, 1983; Fish and Stein, 1991), but the patterns of bone compactness have not been studied for this entire group. 
Evidence of correlated evolution between swimming behaviour, body mass and bone microstructure in modern Arctoidea will be examined by using phylogenetically independent contrasts. The bone compactness data will also be used for predicting the swimming behaviour of the fossil stem pinniped Puijila using discriminant function analysis. If bone microstructure is an effective predictor of swimming behaviour, it could be a useful tool for reconstructing the changes of locomotor specializations during the early land-to-sea evolution of pinnipeds.

\section{MATERIALS AND METHODS}

\section{Sampling Methods}

A total of 43 species of arctoids were selected to represent the ecological and taxonomic diversity of the clade (Fig. 9). Each species was represented by a single male individual from the collections of the Smithsonian Institution National Museum of Natural History (USNM) (see Appendix 3). One humerus, radius, ulna, femur, tibia and fibula were analyzed from each individual. The specimens were computer tomography scanned using a Siemens Emotion Somatom flat bed scanner at the USNM. A single $1 \mathrm{~mm}$ slice was taken at the mid-diaphysis for most elements. For pinniped humeri, which are highly derived, the scan was taken at the distal end of the deltoid crest. To standardize sampling of the ulna, the scan was taken at the midpoint of the "functional" length of the element, which did not including the length of the olecranon (Fig. 10).

The CT scan images were analyzed using Bone Profiler 4.4.11 (for Windows) to calculate the variables P, S, Min and C. Bone Profiler models a bone's compactness by 


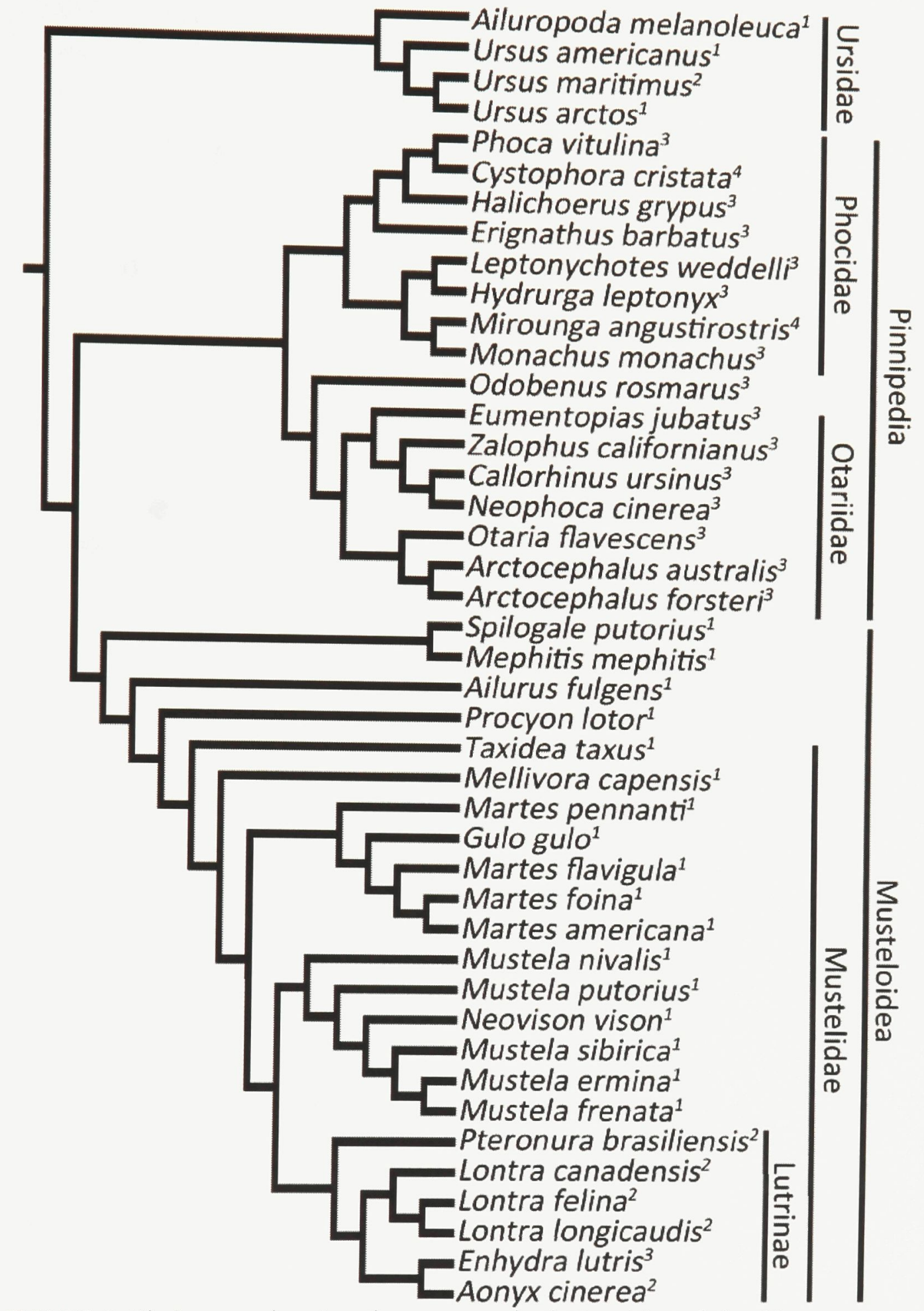

FIGURE 9. Phylogeny showing the proposed relationships of the 43 extant arctoid species used in this study. The tree was created in Mesquite and was modified from Flynn et al. (2005), Arnason et al. (2006), Fulton and Strobeck (2006), Finarelli (2008) and Koeplifi et al. (2008). Swimming behavior categories are indicated as numbers beside species names. Abbreviations: species $^{1}$, Terrestrial ( $\left.\mathrm{SC}=0-1.49\right)$; species $^{2}$, Semi-aquatic ( $\left.\mathrm{SC}=1.5-2.99\right)$; species $^{3}$, Aquatic $(\mathrm{SC}=3-3.99) ;$ species $^{4}$, Aquatic/Semi-pelagic ( $S C=4)$. 

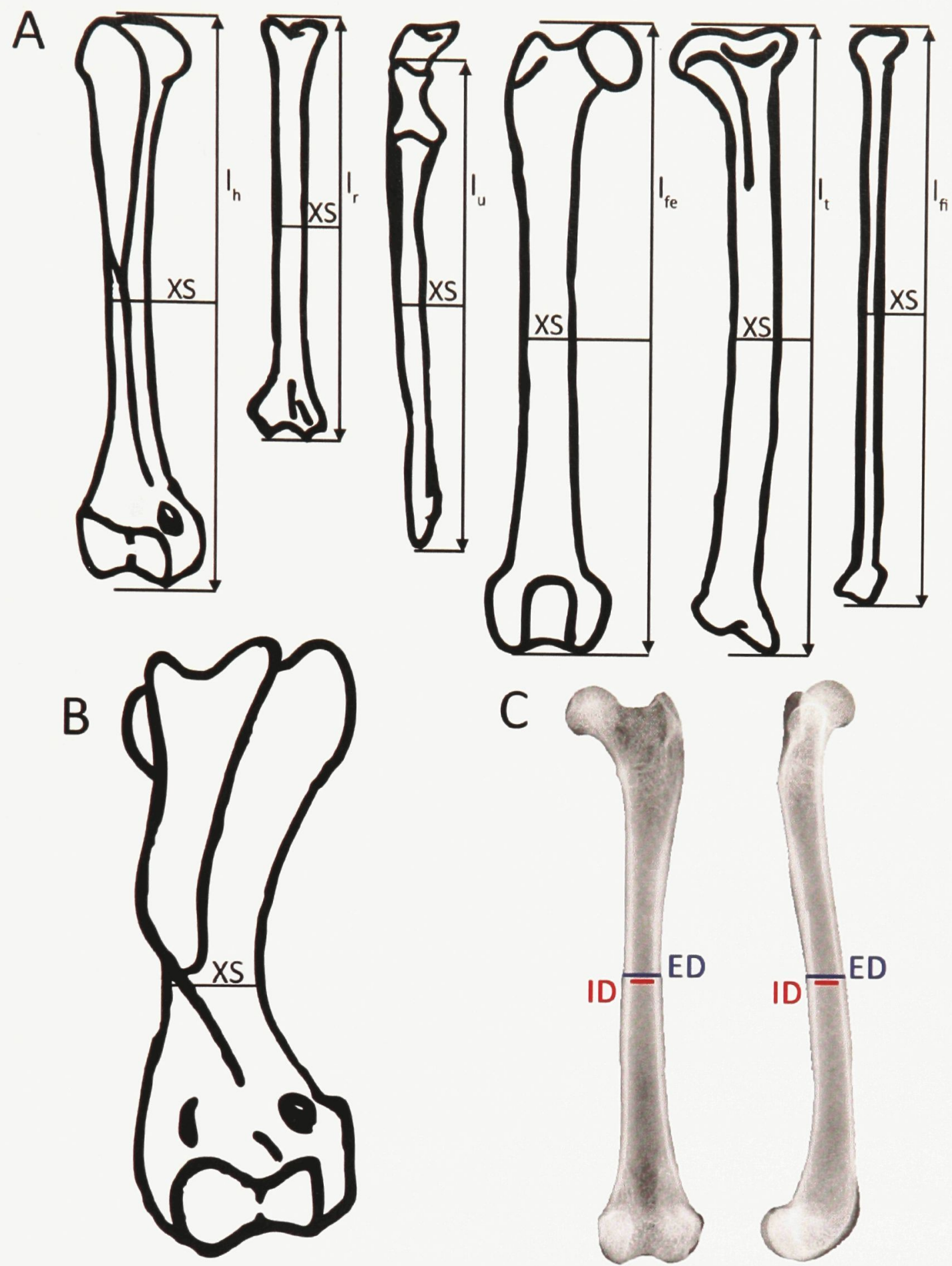

FIGURE 10. A, position on the shaft where the bone was CT scanned and a depiction of how length measurements of the bone were taken; B, modified positioning of the CT scan location on the shaft of pinniped humeri to avoid the deltoid crest and supinator wing; $C$, measurements of the internal diameter of the medullary cavity (ID) and the total diameter of the bone (ED) taken from digital $x$-ray images to calculate the cortical bone thickness ratio $K=(I D / E D)$. Abbreviations: $I_{x^{\prime}}$ length of element $x ; X S$, cross-section where bones were CT scanned. 
dividing its cross-sectional image into 60 radial sections and then analyzing the compactness in each section from the bone's center to its edge (Girondot and Laurin, 2003). These data are graphed and a compactness curve is fitted to the data to create a compactness profile. The compactness profile is then used to produce values for the variables $P, S$, Min, and $C$ that represent various aspects of the bone's microstructure (Fig. 11). The value P produced by Bone Profiler is roughly equivalent to the ratio $\mathrm{K}$ ( $K=I D / E D)$ produced from $X$-ray images in previous studies (Currey and Alexander, 1985; Madar, 1998; Girondot and Laurin, 2003). The variable S represents the width of the transition zone between the outer compact cortical bone and the medullary cavity. The value of Min reflects the amount and prominence of the trabeculae in the center of the section. Bone sections with thin, little or no trabeculae at their center will have a Min of zero, whereas sections with thicker, more abundant trabeculae will have higher values of Min, reflecting more bone volume towards the center of the section. Finally, C represents the overall compactness of the section and is calculated by simply dividing the number of pixels identified by the program as bone, by the total number of pixels in the section. Values of compactness at the outer edge of the section (i.e., variable referred to as "Max") were constrained to be $<1$ and Min was constrained to be $>0$, so that calculated values of Max and Min would not exceed their theoretical maximums.

Distortion at the edges of the bone on the CT scan image increases the apparent diameter of the slice and this difference becomes more pronounced for smaller taxa. Consequently, for taxa with body mass of less than $30 \mathrm{~kg}$, the long bones were digitally 
X-rayed in lateral and anterior orientations using a Thermo Kevex X-Ray, model \# PXS10-

$16 \mathrm{~W}$ and an Amorphus-Silicon Imaging System panel. The ID and ED were measured using Vernier calipers from each digital X-Ray image and the ratio $\mathrm{K}$ calculated for each bone. The values of $\mathrm{P}$ from $\mathrm{CT}$ scans were compared with those of $\mathrm{K}$ from the $\mathrm{X}$-Ray images to see if the CT scans adequately represented the true thickness of cortical bone for that species. The values were also compared to determine whether the variation in the distribution of cortical bone around the circumference of the section was properly

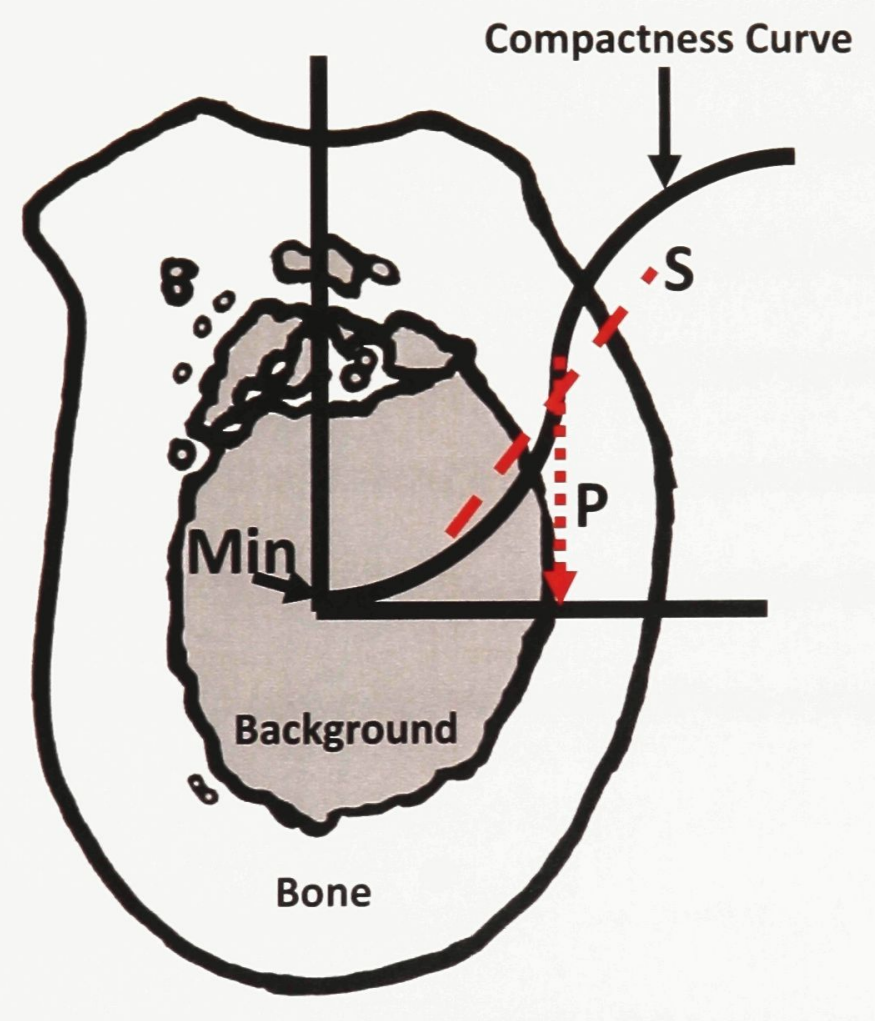

FIGURE 11. A representation of some of the bone microstructure parameters that are estimated from sections of bone analyzed by Bone Profiler 4.11.11. A sample compactness profile that is generated from the analysis of a bone section has been superimposed on an example bone image, to best illustrate the relationship between the parameters and the structure of an actual section. Modified from Girondot and Laurin (2003). 
represented. From these comparisons, species with an average male body mass of $8 \mathrm{~kg}$ or higher were evaluated from CT scans using Bone Profiler and species averaging smaller than $8 \mathrm{~kg}$ were only represented by the $\mathrm{K}$ values, calculated from their X-ray images (Appendix 4). Given that $K$ is roughly equal to $P$, values of $K$ ratios calculated from X-rays were referred to in the analyses as $P$.

Body mass $\left(m_{b}\right)$ estimates were averaged for males of each species, as reported from Walker's Mammals of the World (Nowak, 1991, 2003), Silva and Downing (1995) and Animal Diversity Web. The log of these averages $\left(\log \left(m_{b}\right)\right)$ were used in the analyses (see Appendix 4). A continuous variable representing an animal's "swimming behaviour category" (SC) was calculated from a rubric with four categories representing a species' external aquatic specializations, diving capabilities, habitat and diet (see Appendix 5). For the purpose of some analyses, the continuous values of SC were grouped into four bins representing distinct categories of swimming behaviours: terrestrial ( $\mathrm{SC}=0-1.49)$, semi-aquatic ( $S C=1.5-2.99)$, aquatic $(S C=3-3.99)$, aquatic/semi-pelagic $(S C=4)$. For some analyses the aquatic and semi-pelagic groupings were merged into a single aquatic group (SC=3-4).

\section{Comparisons without Phylogenetic Correction}

Mean values of $\mathrm{P}, \mathrm{S}, \mathrm{C}$ and Min were calculated for different swimming behaviour groups and compared. Data for the parameter $\mathrm{P}$ for all taxa and all bones, were imported into the data analysis package PAST 2.04 (Hammer et al., 2001). Bivariate plots of log transformed body mass $\left(\log \left(m_{b}\right)\right)$ and the bone microstructure variable $P$ were 
constructed and ordinary least squares linear regressions were performed, to better understand the relationships between these characters without phylogenetic correction (Hammer et al., 2001).

\section{Testing for Evidence of Correlated Evolution}

Trends in bone compactness within Arctoidea may be affected by ancestry. In order to control for phylogeny, the variables SC and $\log \left(m_{b}\right)$ were compared pair-wise to each other and to the values of P, S, C and Min for each long bone, using Phylogenetically Independent Contrasts (PIC), calculated using the program Mesquite's PDAP:PDTREE package (Garland et al., 1993; Midford et al., 2005; Maddison and Maddison, 2006). PIC analyses use the topology of a phylogenetic tree to contrast species' character data and uses branch lengths as a measure of the expected amount of variance between these data to generate a set of independent contrasts for the character (Felsenstein, 1985; Garland et al., 1992). A significant correlation coefficient ( $p$-value $<0.05$ ) between the independent contrasts of two characters means that there is evidence of correlated evolution between those variables, independent of the influences of phylogeny. The Arctoidea tree used for PIC analyses was constructed in Mesquite and represents a strict consensus of the molecular phylogenetic trees of Flynn et al. (2005), Arnason et al. (2006), Fulton and Strobeck (2006), Finarelli (2008) and Koepfli et al. (2008) of various groups within Carnivora (Fig. 9). A full tree containing all 43 taxa was used for PIC analyses involving the variable $\mathrm{P}$ and a reduced tree of only the 27 larger bodied taxa whose CT scans were analyzed successfully by Bone Profiler, was used for the PIC's 
involving the variables S, C and Min. Each PIC analysis was repeated four times, using four branch length algorithms provided within Mesquite. The four algorithms used were the Equivocal (all branch length equal one), the methods of Grafen (1989), those of Pagel (1992), and those of Nee as cited by Purvis (1995) (Fig. 12). To evaluate which branch length algorithms applied to the phylogenetic tree were a good fit to the tip data (SC, $\left.\log \left(m_{b}\right), P, S, C, M i n\right)$, the PDAP diagnostic chart of "Absolute contrasts vs. Standard deviation" was examined for each set of contrasts generated for each variable using each branch length method. The independent contrasts calculated from the tree topology were standardized by dividing them by the square root of their variance (or standard deviation) (Felsenstein, 1985; Garland et al., 1992). The standard deviation of a contrast is the square root of the sum of its branch lengths (Garland et al., 1992). If the independent contrasts generated for a certain branch length algorithm are adequately standardized, the slope of the least-squares linear regression between the standardized independent contrasts and their standard deviations should be significant (Garland et al., 1992; Garland et al., 1993; Midford et al., 2005). For those traits which were adequately standardized, and that correlated with both SC and $\log \left(\mathrm{m}_{\mathrm{b}}\right)$, the residuals of the linear regression of the trait $(P, S, C$ or $M i n)$ on $\log \left(m_{b}\right)$ were compared with the residuals of the regression of $\mathrm{SC}$ on $\log \left(\mathrm{m}_{\mathrm{b}}\right)$, using an ordinary least squares regression forced through the origin, in the program PAST. These regressions can then test for relationships between SC and bone microstructure while controlling for both phylogeny and body size (Garland et al., 1992; Garland and Janis, 1993). 


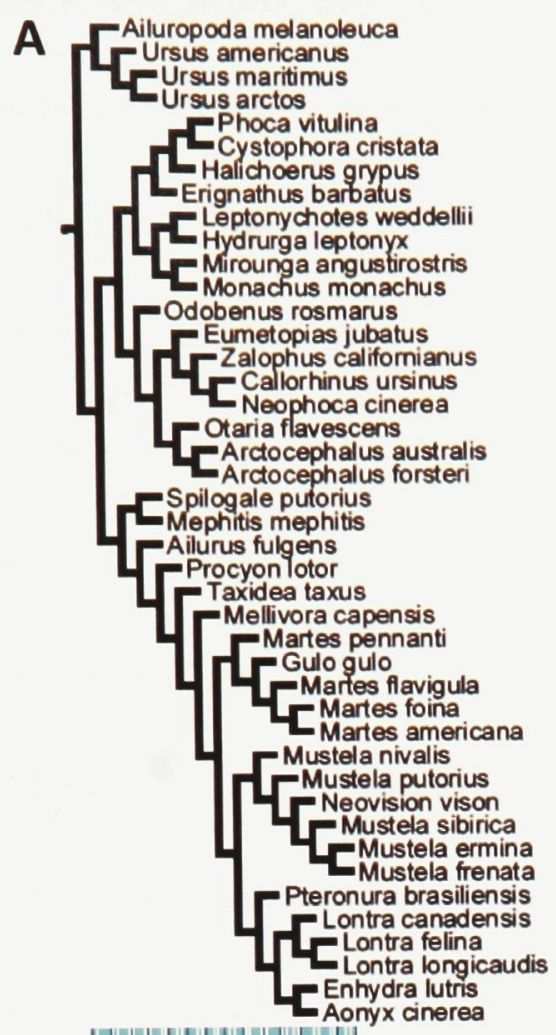

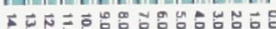

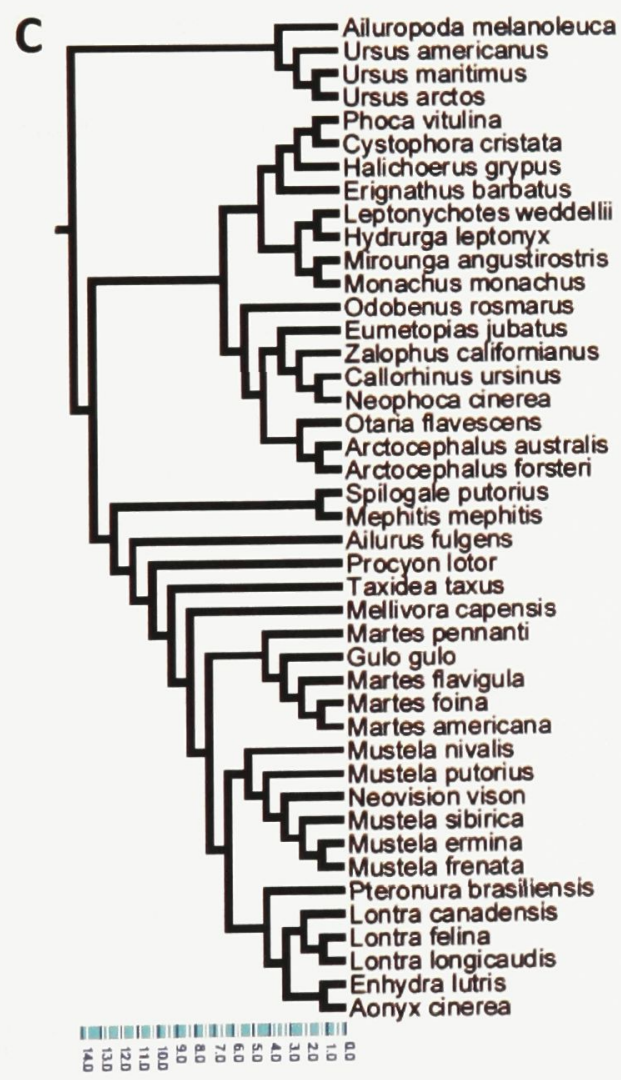

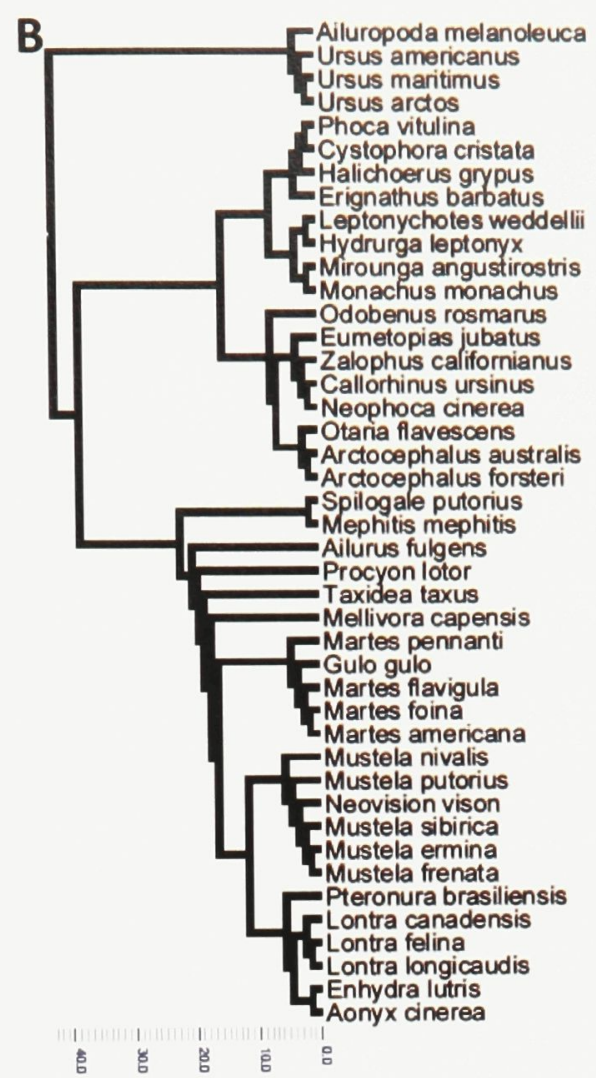

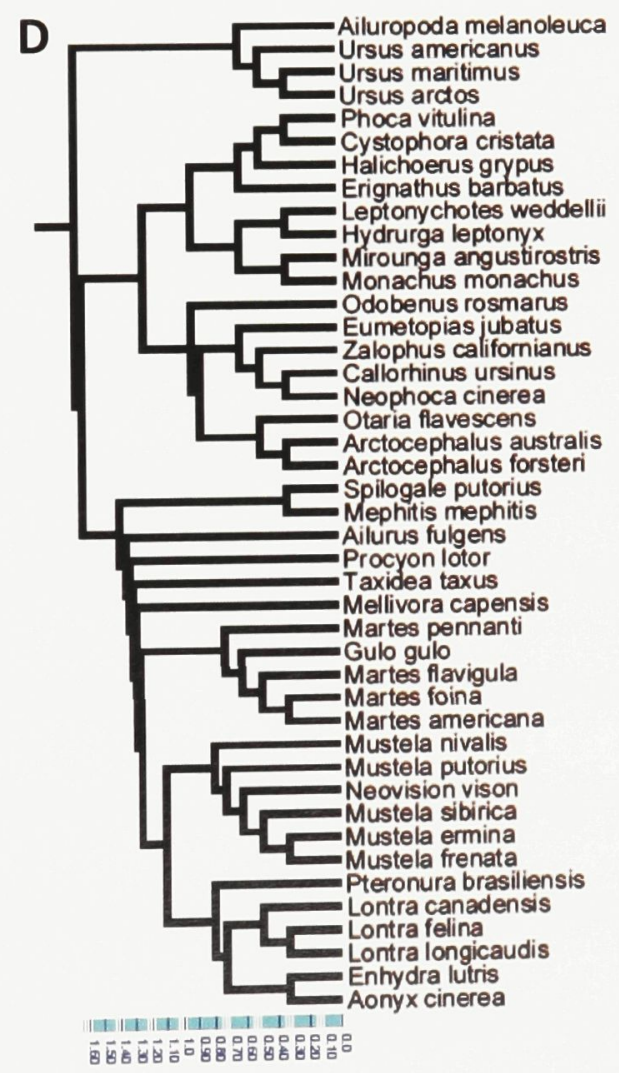

FIGURE 12. Phyologenies, of the 43 arctoids, showing proportional branch lengths assigned by the A, Equivocal; B, Grafen (1989); C, Pagel (1992); D, Nee algorithms. 
Testing for Phylogenetic Signal

K-statistics were calculated for $\log \left(m_{b}\right), S C, P, S, C$, and Min to evaluate the phylogenetic signal for each variable. The statistic was calculated using the same four branch length algorithms used in PIC analyses. K-statistic assumes Brownian motion and is another way to determine if the portion of the variance explained by a phylogenetic signal within the data is significant (Blomberg et al., 2003). A K-statistic $<1$ means a weak phylogenetic signal and indicates that variance in the data could be explained by correlated evolution with another character. A K-statistic $>1$ indicates a strong phylogenetic signal and that variation in the data is likely explained by taxon relatedness. Values of K-statistic were calculated using the APE package for the R project for statistical computing (Blomberg et al., 2003).

\section{Inferring the Swimming Behaviour of Puijila darwini}

Discriminant function analysis (DFA) was performed using the JMP 9 statistical package. In this study DFA can be used to gauge the effectiveness of the continuous variables at predicting swimming behaviour category of the arctoids (terrestrial, semiaquatic, etc.). The data for $\log \left(m_{b}\right), S C, P$ for all 43 taxa and $\log \left(m_{b}\right), S C, P, S$, Min and C for 27 taxa were analyzed separately using linear DFA. The DFA was completed using both the original and log transformed data. When measurements of a microstructure variable yield a value of zero they were adjusted to be $10^{-7}$ to prevent the data from becoming undefined when log transformed. For $\mathrm{P}$ a value of zero implies that the medullary canal is absent. For the variable $S$ a value of zero indicates that there was 
little difference between the compactness at the outside and the inside of the bone section. Changing the original value of zero to $10^{-7}$ is not expected to effect interpretation of results. The DFA was then used to infer swimming behaviour for the fossil taxon Puijila darwini. The body mass of Puijila was estimated from cranial measurements using the methods of Van Valkenburgh (1990) for predicting body mass in carnivores. Body mass was estimated using the regressions for mustelids and also for ursids. The log of these two body mass estimates were used as the values for $\log \left(m_{b}\right)$ for Puijila as well as a third estimate which was simply the average of the mustelid and ursid values. Then the three estimated $\log \left(m_{b}\right)$ and the Bone Profiler data produced from CT scans of the long bones of Puijila were added to the DFA and swimming behaviour was predicted for the fossil. Finally, variables were removed from the analyses one at a time to see their effect on the classification of Puijila. 


\section{RESULTS}

\section{Means and Bivariate Plots}

Mean values of $\mathrm{P}$ were calculated for three swimming categories: terrestrial (SC1), semi-aquatic (SC 2) and aquatic (SC3\&4). To evaluate the difference that large body size may have on the average, the mean of only terrestrial taxa over $20 \mathrm{~kg}$ was also calculated. The mean of aquatic taxa was calculated excluding the semi-pelagic $(S C=4)$ species to evaluate whether any changes in their bone microstructure associated with their long periods at sea could be affecting the average compactness for aquatic taxa. Finally, to assess whether the use of their limbs on land may have affected bone compactness, the mean compactness of otariids and walrus was calculated and compared in order to see if it differed from the mean compactness of only the phocids. The calculated means are presented in Table 3 and compared with values of $\mathrm{P}$ for Puijila darwini.

TABLE 3. Mean values of $P$ (relative size of the medullary cavity) compared with those of Puijila darwini

\begin{tabular}{|c|c|c|c|c|c|c|c|c|c|c|}
\hline & $\underline{\log \left(m_{b}\right)}$ & $\underline{P}_{h_{-}}$ & $\mathbf{P}_{\mathbf{r}}$ & $\mathbf{P}_{\underline{u}}$ & $\underline{P}_{\mathrm{fe}}$ & $\mathbf{P}_{\mathrm{t}}$ & $P_{\mathrm{fi}}$ & $\mathbf{P}_{\text {for }}$ & $\underline{P}_{\text {hind }}$ & P $_{\text {avg }}$ \\
\hline Terrestrial & 0.50 & 0.56 & 0.41 & 0.36 & 0.55 & 0.44 & 0.20 & 0.44 & $0 . \overline{40}$ & 0.42 \\
\hline $1>20 \mathrm{~kg}$ & .99 & 0.6 & 7 & 0.42 & 0.51 & 0.4 & 0.31 & 0.50 & 0.43 & 0.4 \\
\hline Sem & .25 & .53 & 0.4 & .38 & 0.55 & 2 & 8 & .45 & 0.42 & 0.44 \\
\hline Aqu & 46 & .47 & 0.55 & 0.46 & 0.59 & 0.47 & 0.43 & 0.49 & 0.50 & 0.50 \\
\hline & 40 & 2 & 2 & 0.41 & 0.54 & 0.44 & 0.39 & 0.45 & 0.45 & 0.45 \\
\hline & 51 & 0.36 & 0.5 & 0.39 & 0.42 & 0.44 & 0.34 & .42 & .40 & 0.41 \\
\hline & 53 & & & & & & & & 0.62 & 0.61 \\
\hline Puij & 83 & & & 09 & & 03 & 00 & 0.26 & .18 & 0.22 \\
\hline & 55 & 0.43 & & 0.09 & & 0.03 & 0.00 & 0.26 & 0.18 & 0.22 \\
\hline Puijila (avg.) & 1.19 & 0.43 & 0.27 & 0.09 & 0.51 & 0.03 & 0.00 & 0.26 & 0.18 & 0.22 \\
\hline
\end{tabular}
(must., ursid, avg.) = Three different body mass estimates for Puijila darwini calculated from the regressions of Van Valkenburgh (1990). See methods. 
Compared to the terrestrial group, average values of body mass are higher in semi-aquatic and aquatic groups. Mean values of $\mathrm{P}$ were higher (thinner cortical bone) in the humerus and femur and lower in the more distal long bones. Terrestrial taxa over $20 \mathrm{~kg}$ had larger values of $\mathrm{P}$, or less cortical bone thickness than the average for all terrestrial taxa, except in the case of the femur. The semi-aquatic group had average values of $\mathrm{P}$ that were similar to the terrestrial group. The phocids had the highest average values of $\mathrm{P}$. Otariids have mean values for the humerus and femur which are smaller than the terrestrial and semi-aquatic group, but higher values of the radius, ulna, tibia and fibula.

Some of the ordinary least square regressions of $\log \left(m_{b}\right)$ and $P_{h, u, r, f e, t, f i}$ show a significant positive correlation between $\mathrm{P}$ and body mass within the three swimming categories. Terrestrial arctoids showed a significant positive correlation between body mass and $P_{h}(r=0.52866, p$-value $=0.017), P_{u}(r=0.51302, p$-value $=0.02)$ and $P_{f i}(r=0.51804$, $p=$ value $=0.019)$ (Fig. 13). Semi-aquatic arctoids showed a significant positive correlation between body mass and $P_{h}(r=0.90774, p$-value=0.012). Finally the aquatic groups showed a significant positive correlation between body mass and $P_{r}(r=0.69458, p-$ value $=0.002), P_{u}(r=0.63233, p$-value $=0.007)$ and $P_{f i}(r=0.48712, p=v a l u e=0.048)$. The femur was the only bone to show a negative correlation within the terrestrial and semiaquatic groupings, but the relationships were not significant. As an example of these ingroup trends, Fig. 13 shows the least square regression for $P_{h}$ and body mass, of which the terrestrial and semi-aquatic groups have significant positive correlations. 


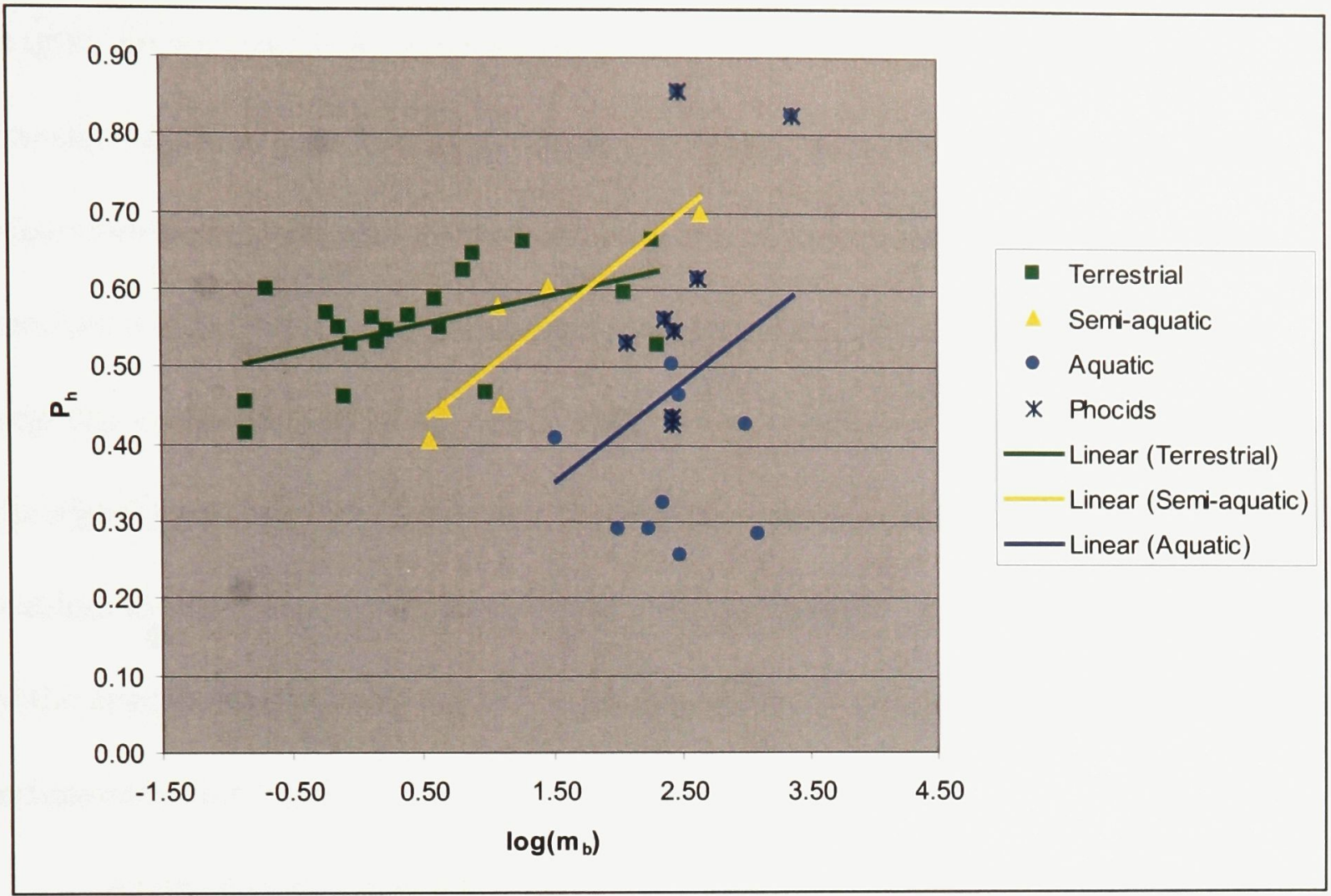

FIGURE 13. Example plots of $P_{h}$ and $\log (\mathrm{mb})$ for each swimming behaviour group illustrating the positive trends within groups. (Terrestrial: $\mathrm{SC}=0-1.49$; Semi-aquatic: SC=1.5-2.99; Aquatic: SC=3-4), phocids are identified by dark blue stars overlaid on their aquatic data points.

\section{Phylogenetically Independent Contrasts}

The four branch-length algorithms (Equivocal, Grafen (1989), Pagel (1992), Nee) were tested for which produced adequately standardized independent contrasts for each character (Tables 4,5$)$. The character $\log \left(m_{b}\right)$ was adequately standardized using any of all branch length algorithms on both the full $(n=43)$ and reduced $(n=27)$ trees. The trait SC was not adequately standardized using the Equivocal branch length algorithm on the full tree, but was for all other branch length algorithms applied to the full or reduced trees. The variable $\mathrm{P}$ showed significantly negative slopes for a minimum of six 
characters for all four branch length algorithms on the full tree, indicating that branch lengths were a poor fit for the tip data in most cases (Midford et al., 2005). Log transformation of branch length, shrinks long branches relative to short ones, and is recommended to help standardize contrasts when non-transformed branch lengths produce a plot of independent contrast vs standard deviations with a significantly negative slope (Garland et al., 1992). Natural log transformations of branch lengths for the algorithms of Grafen (1989) and Pagel(1992), without first multiplying by a constant, resulted in the collapsing of several nodes into polytomies. Natural log transformation of the branch lengths assigned by the Nee algorithm, produced adequately standardized independent contrasts for the variable $\mathrm{P}$ (Table 4).

Adequately standardized independent contrasts were produced for the trait S using the branch lengths produced from the Equivocal, Grafen (1989) and Nee methods (Table 5). The contrasts for the character Min were standardized when branch lengths were produced using the Grafen (1989), Pagel (1992), and Nee methods (Table 5). The results of correlations between the independent contrasts of $\log \left(m_{b}\right)$ and SC and those of bone microstructure $\mathrm{P}, \mathrm{S}$ and $\mathrm{Min}$, were only considered for the branch lengths for which they were adequately standardized. 


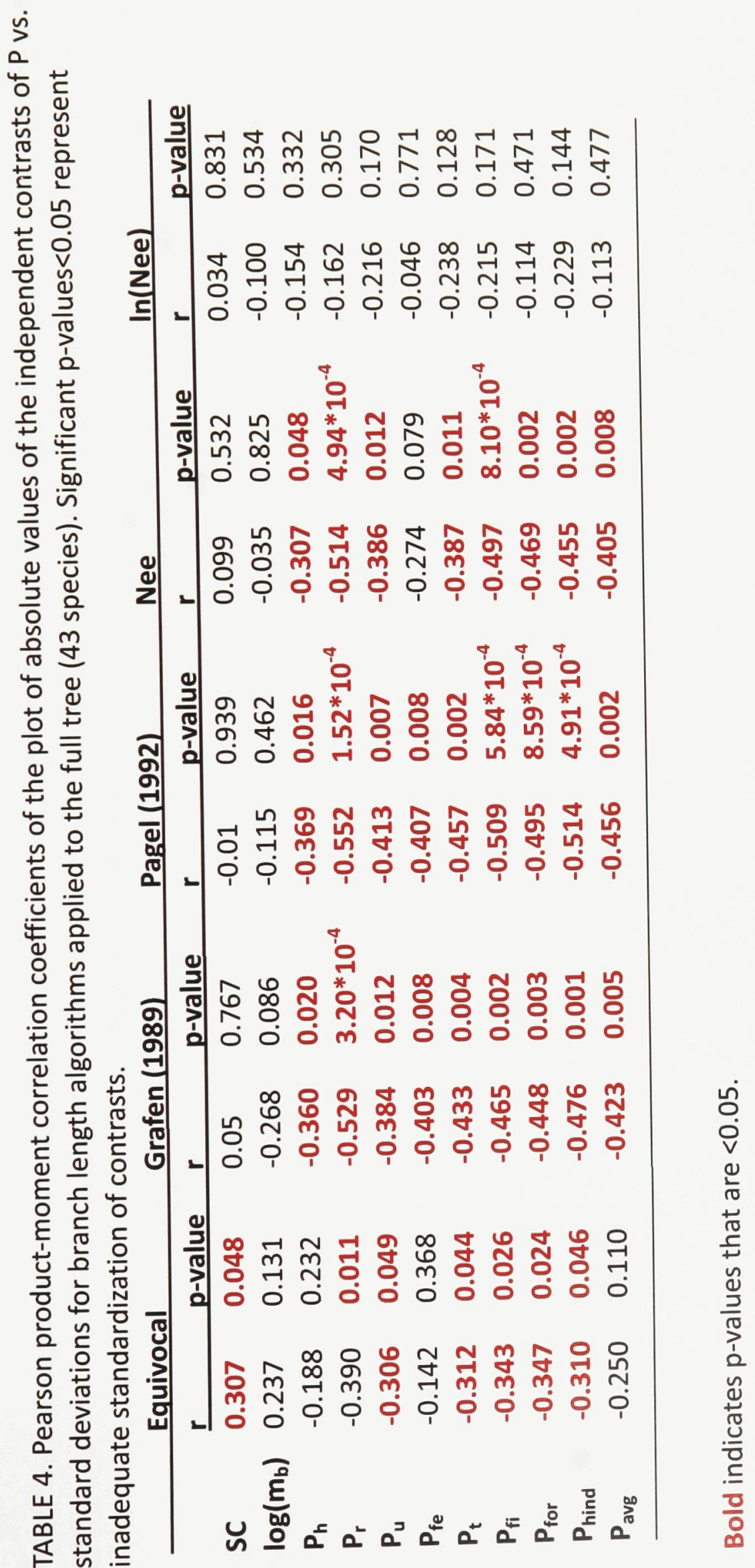




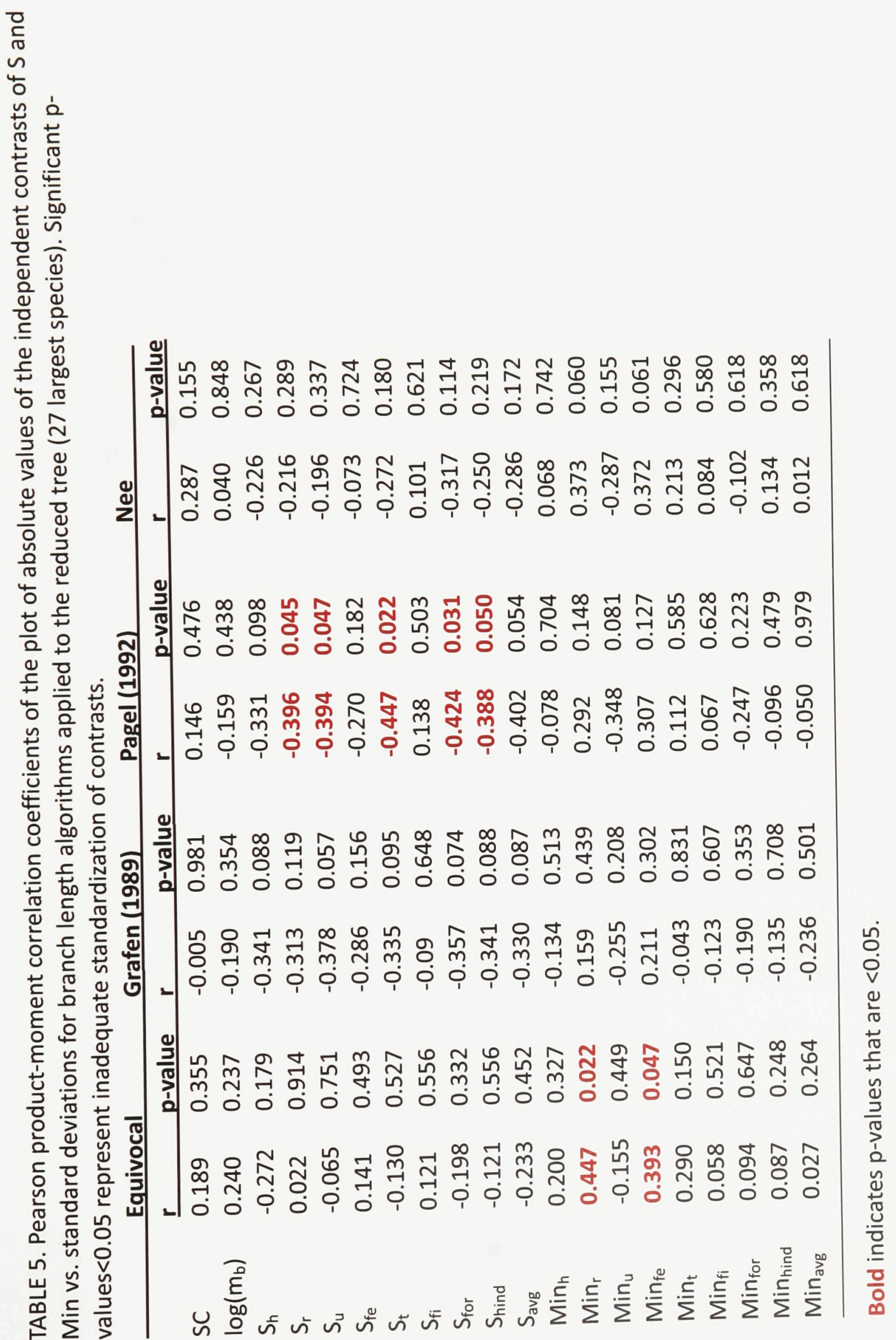




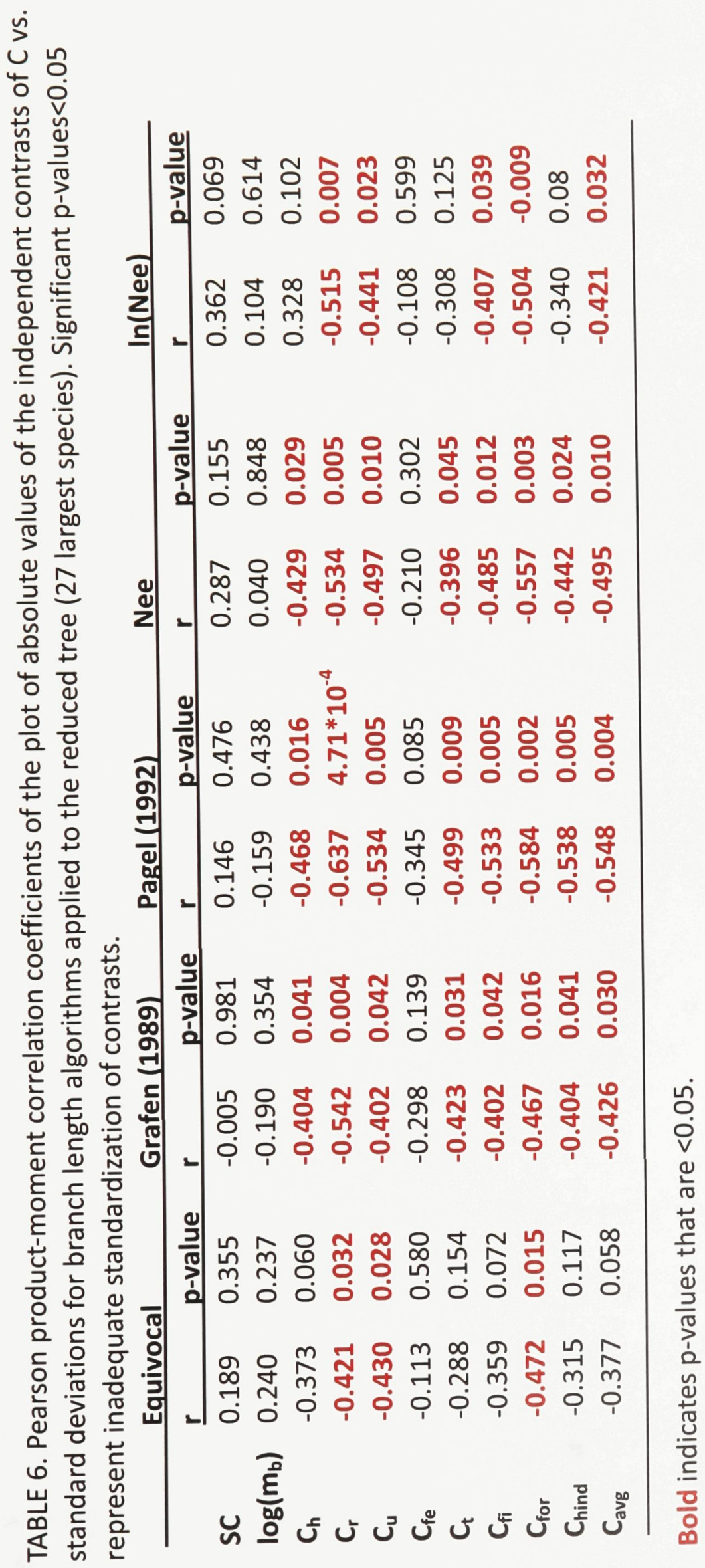


Finally, the contrasts for the character $\mathrm{C}$ were not adequately standardized for every bone by using a single Branch length algorithm (Table 6). The equivocal branch length method adequately standardized all but $C_{r}, C_{u}$ and $C_{f o r}$. The equivocal branch length method was used for correlations between the independent contrasts of SC and $\log \left(m_{b}\right)$ and the results of these correlations were only reported from those variables which were adequately standardized (i.e., $C_{h}, C_{f e}, C_{t}, C_{f i}, C_{h i n d}$, and $C_{a v g}$ ).

Tables 7 to 11 show the correlation coefficients, and their associated two-tailed p-values, describing the relationship between each bone microstructure variable and body mass or SC using standardized independent contrasts. Body mass and swimming behaviour showed evidence of correlated evolution for all branch length methods ( $n=43$, $\mathrm{n}=27$ ) (Table 7,8$)$.

TABLE 7. Pearson product-moment correlation coefficients $(r)$ and their associated twotailed $p$-values of the independent contrasts of $\log (\mathrm{mb})$ vs. independent contrasts of SC, calculated from four different branch length algorithms applied to the reduced tree $(n=27)$.

\begin{tabular}{lll} 
& $r$ & p-value \\
\hline Equivocal & 0.606 & $8.04 * 10^{-4}$ \\
Grafen (1989) & 0.558 & 0.002 \\
Pagel (1992) & 0.601 & $9.08 * 10^{-4}$ \\
Nee & 0.545 & 0.003 \\
\hline
\end{tabular}

Bold indicates a significant correlation with 2-tailed p-values $<0.05$

The variable $P_{f i}$ and $P_{\text {avg }}$ covaried with $S C$ and $P_{h}, P_{u}, P_{\text {for }}$ and $P_{\text {avg }}$ covaried with $\log \left(m_{b}\right)(n=43)($ Table 8$)$. The character S showed no relationship with SC. When branch lengths were set to be equivocal, $\mathrm{S}_{r}, \mathrm{~S}_{\mathrm{u}}, \mathrm{S}_{\mathrm{t}}, \mathrm{S}_{\mathrm{fi}}, \mathrm{S}_{\mathrm{for}}$ and $\mathrm{S}_{\mathrm{avg}}$ had evidence of a relationship with $\log \left(m_{b}\right)$. When the branch length algorithms of Grafen (1989) were used $S_{r}$ and $S_{t}$ 
had evidence of a relationship with $\log \left(m_{b}\right)$. Finally, when using the branch lengths produced by the Nee method, $S_{r}, S_{t}$ and $S_{f o r}$ had evidence of a relationship with $\log \left(m_{b}\right)$ $(n=27)$ (Table 9). There was no relationship between Min and SC and only Min fe $_{\text {covaried }}$ with $\log \left(m_{b}\right)$ for each of Grafen (1989), Pagel (1992) and Nee branch length algorithms $(n=27)$ (Table 10). Finally, C covaried significantly with SC and $\log \left(m_{b}\right)$. When branch lengths were set to be equivocal, $C_{\mathrm{fi}}$ had a relationship with $\mathrm{SC}(\mathrm{n}=27)$. The bone microstructure character $C_{\mathrm{fe}}, \mathrm{C}_{\mathrm{fi}}, \mathrm{C}_{\mathrm{hind}}$ and $\mathrm{C}_{\mathrm{avg}}$ had a negative correlation with $\log \left(\mathrm{m}_{\mathrm{b}}\right)$ using the equivocal branch length method $(n=27)$ (Table 11).

TABLE 8. Pearson product-moment correlation coefficients $(r)$ and their associated twotailed $p$-values produced as a result of Phylogenetically Independent Contrasts of $P$ with SC and $\log \left(m_{b}\right)$ using a natural log transformed Nee branch length algorithm $(n=43)$.

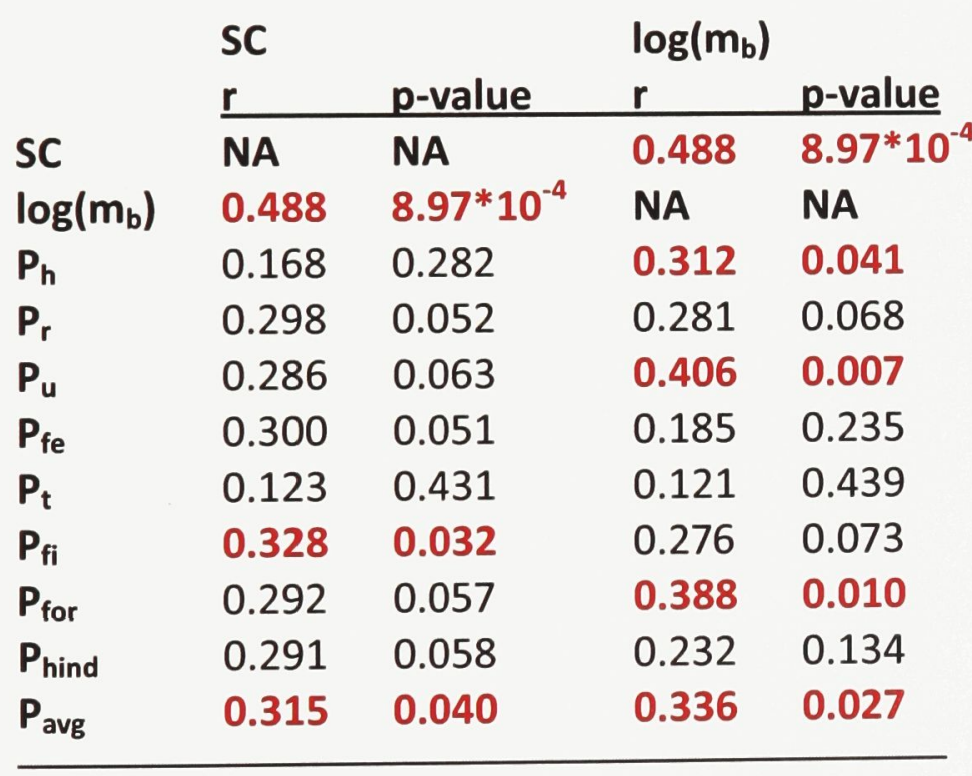

Bold indicates a significant correlation with 2-tailed $p$-values $<0.05$ 


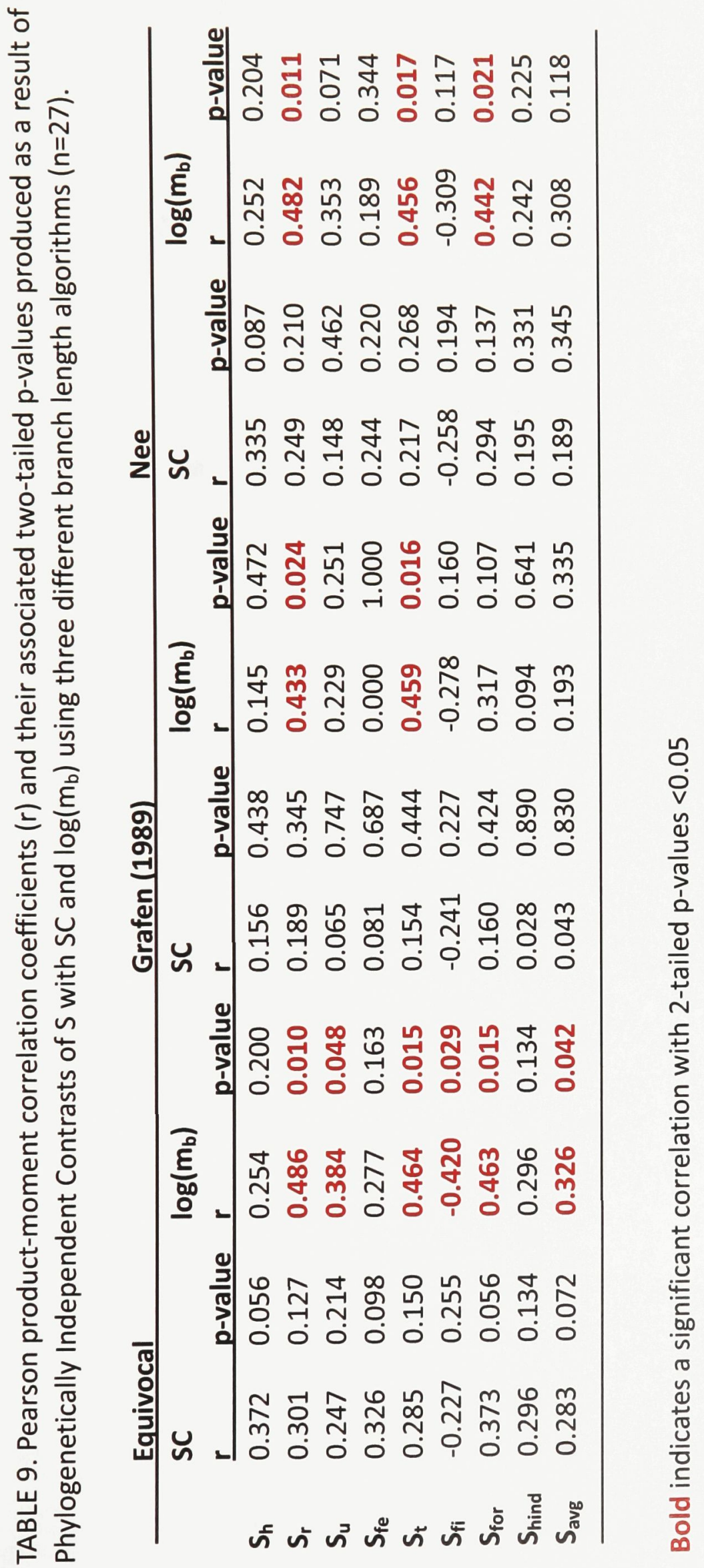




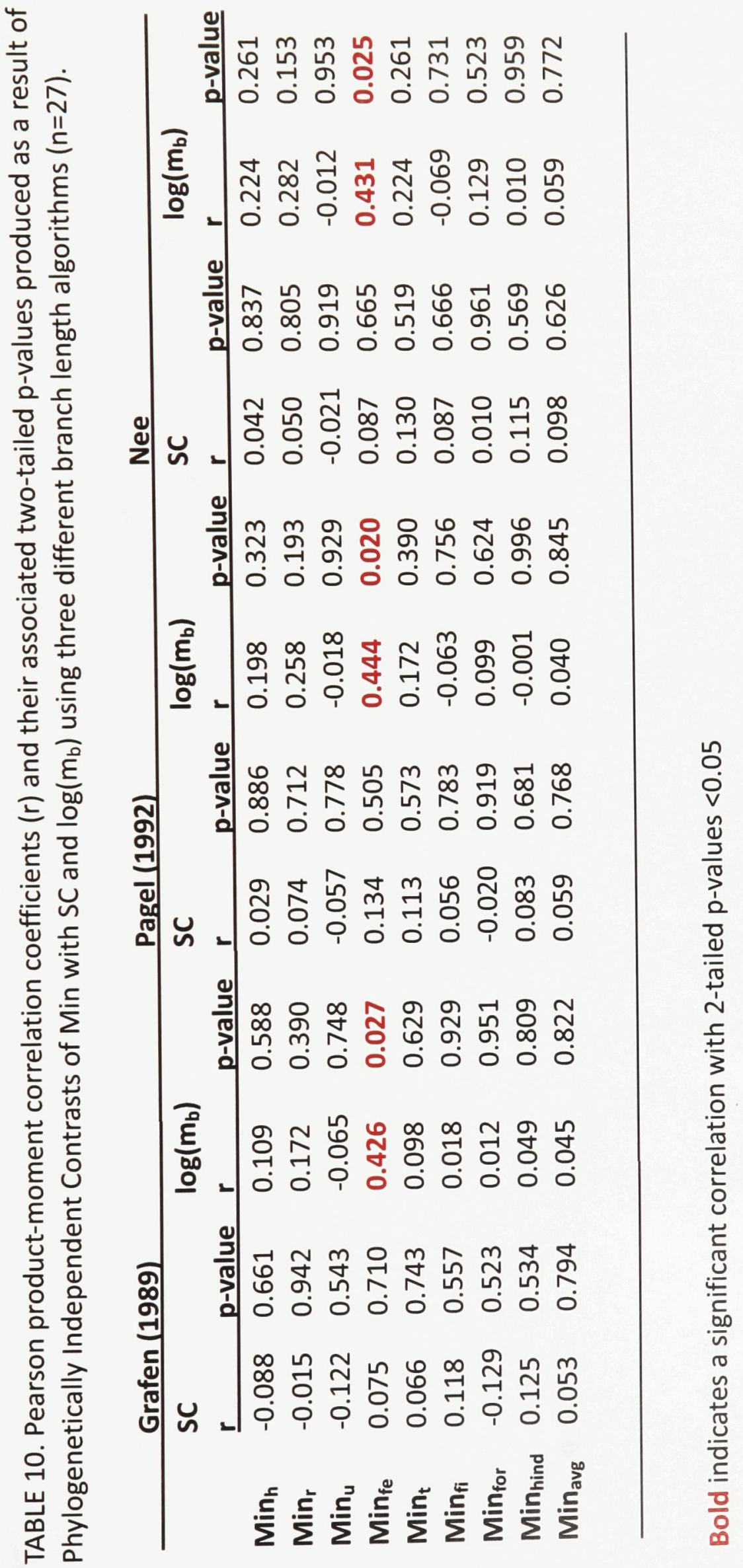


TABLE 11. Pearson product-moment correlation coefficients $(r)$ and their associated twotailed $p$-values produced as a result of Phylogenetically Independent Contrasts of $C$ with $S C$ and $\log \left(m_{b}\right)$ using equivocal branch lengths $(n=27)$. The independent contrasts of $C_{r}$, $\mathrm{C}_{\mathrm{u}}$ and $\mathrm{C}_{\text {for }}$ were not adequately standardized and so their results are omitted.

\begin{tabular}{|c|c|c|c|c|}
\hline & \multicolumn{2}{|l|}{ SC } & \multicolumn{2}{|l|}{$\log \left(m_{b}\right)$} \\
\hline & $r$ & P-value & $r$ & P-value \\
\hline$c_{h}$ & -0.133 & 0.510 & -0.315 & 0.110 \\
\hline$C_{r}$ & NA & NA & NA & NA \\
\hline $\mathrm{C}_{\mathrm{u}}$ & NA & NA & NA & NA \\
\hline $\mathrm{C}_{\mathrm{fe}}$ & -0.367 & 0.060 & -0.394 & 0.042 \\
\hline$C_{t}$ & -0.221 & 0.267 & -0.191 & 0.340 \\
\hline$C_{f i}$ & -0.443 & 0.021 & -0.488 & 0.010 \\
\hline$C_{\text {for }}$ & NA & NA & NA & NA \\
\hline$C_{\text {hind }}$ & -0.380 & 0.050 & -0.397 & 0.041 \\
\hline $\mathrm{C}_{\mathrm{avg}}$ & -0.351 & 0.072 & -0.472 & 0.013 \\
\hline
\end{tabular}

Bold indicates a significant correlation with 2-tailed $p$-values $<0.05$

For those characters that covaried with both SC and $\log \left(m_{b}\right)$ the residuals of the regression of their standardized independent contrasts on the positivized contrasts of $\log \left(m_{b}\right)$ were plotted against the residuals of the regression of the independent contrasts of SC on those of $\log \left(m_{b}\right)$. The bi-variate plots of those residuals, with the ordinary least squares regression line forced through the origin, are shown in Fig. 14. None of the bone microstructure variables retained a significant Pearson correlation coefficient $(r)$ with SC, when their residuals were plotted to control for phylogeny and body mass. 

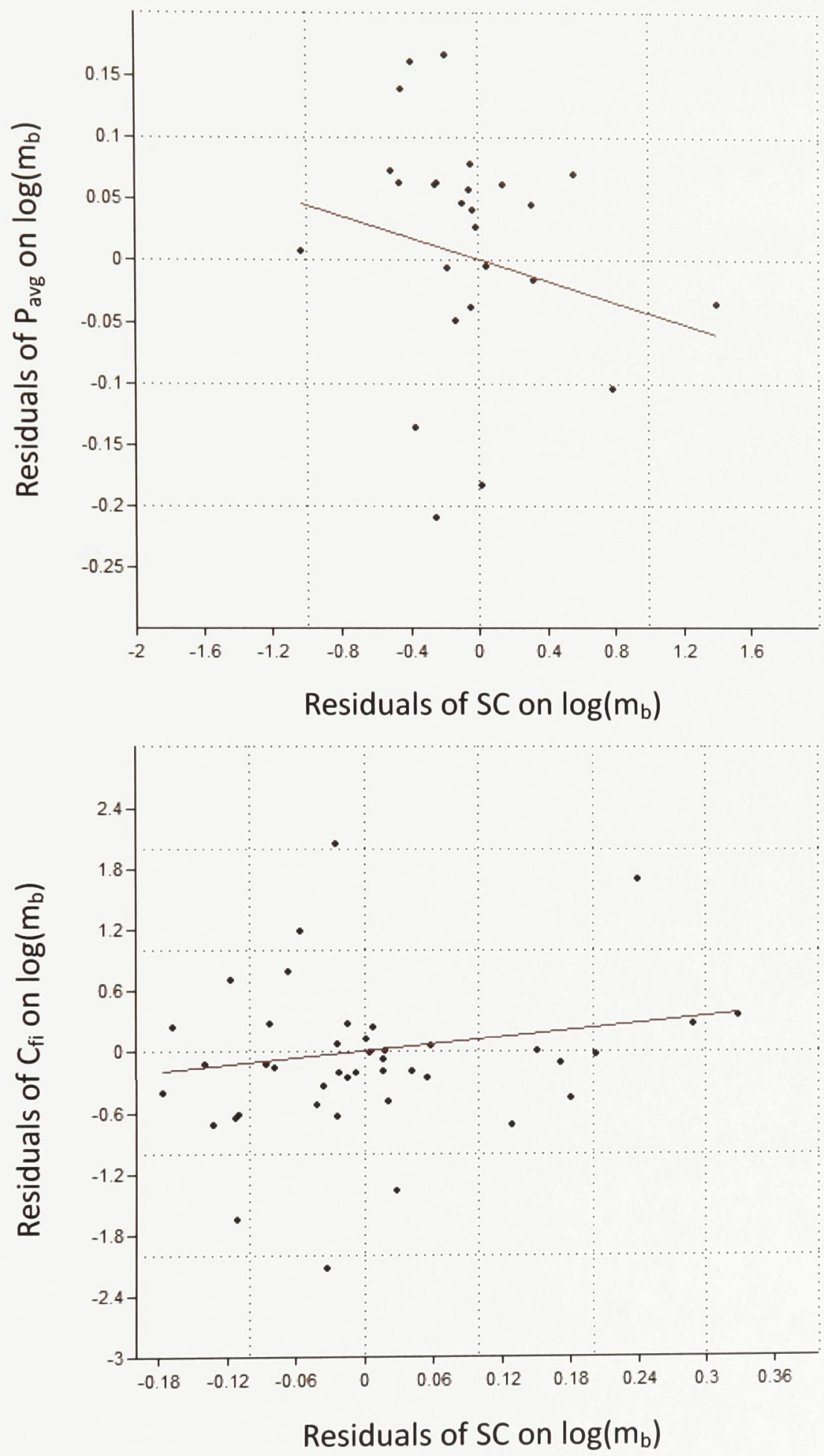

FIGURE 14. A) The residuals of the independent contrasts, standardized using Equivocal branch lengths, of $C_{f i}$ vs $\log \left(m_{b}\right)$ plotted against those of $S C$ vs. $\log \left(m_{b}\right)$ with the trend line of the ordinary least square regression through the origin. ( $n=27, r=-0.20115, p-$ value $=0.32445)$; $B$ ) The residuals of the independent contrasts, standardized using $\ln ($ Nee $)$ branch lengths, of $P_{\text {avg }}$ vs $\log \left(m_{b}\right)$ plotted against those of $S C$ vs $\log \left(m_{b}\right)(n=43$, $r=0.19435, p$-value $=0.21746$ ) 
It has been hypothesized that cortical bone thickness is related to the

requirements of terrestrial animals to support their mass on land (Currey and Alexander, 1985; Egi, 2001). Phocids do not use their limbs on land for structural support and they have large average body masses, so they were removed from the PIC analysis of the character $\mathrm{P}$ in order to evaluate whether the group might be influencing the positive relationship between $P$ and $\log \left(m_{b}\right)$. When the two species of phocids that had the highest possible $\mathrm{SC}$ scores $(\mathrm{SC}=4)$ were removed from the data set, all relationships between $S C$ and $P$ were lost and $\log \left(m_{b}\right)$ only showed a relationship with $P_{u}(n=41)$ (Table 12). The natural log transformed Nee method remained adequate for standardizing all characters on the 41 taxa (no SC 4) tree. When all eight species of phocids were removed from the analysis, all evidence of correlated evolution between $\mathrm{P}$ and $\mathrm{SC}$, and between $P$ and $\log \left(m_{b}\right)$ were lost $(n=35)$. The natural log transformed branch lengths produced by the Nee method still performed the best of all the branch length methods in diagnostic tests, but $\mathrm{P}_{\mathrm{t}}$ was no longer adequately standardized on the 35 taxa (no phocid) tree. Therefore, the coefficient of correlation and associated p-value were not examined for the results. The PIC analysis involving S, C and Min were not repeated with the exclusion of phocids as that would have resulted in an analysis with only 19 taxa and the small data set would have been less informative about overall trends in Arctoidea. In all analyses SC and $\log \left(\mathrm{m}_{\mathrm{b}}\right)$ showed evidence of correlated evolution. 
TABLE 12. Pearson product-moment correlation coefficients $(r)$ and their associated twotailed $p$-values produced as a result of Phylogenetically Independent Contrasts of $P$ with $\mathrm{SC}$ and $\log \left(\mathrm{m}_{\mathrm{b}}\right)$ using a natural log transformation Nee branch length algorithm. Results were calculated excluding species with an SC=4 ( $n=41)$.

\begin{tabular}{lllll} 
& SC & \multicolumn{3}{l}{$\log \left(\mathbf{m}_{\mathbf{b}}\right)$} \\
$\mathbf{S C}$ & $\mathbf{r}$ & p-value & $\mathbf{r}$ & p-value \\
\cline { 2 - 5 } $\log \left(\mathbf{m}_{\mathbf{b}}\right)$ & $\mathbf{N A}$ & $\mathbf{N A}$ & 0.444 & 0.004 \\
$\mathbf{P}_{\mathbf{h}}$ & -0.038 & 0.004 & $\mathbf{N A}$ & $\mathbf{N A}$ \\
$\mathbf{P}_{\mathbf{r}}$ & 0.218 & 0.815 & 0.177 & 0.269 \\
$\mathbf{P}_{\mathbf{u}}$ & 0.126 & 0.432 & 0.192 & 0.230 \\
$\mathbf{P}_{\text {fe }}$ & 0.157 & 0.325 & 0.337 & $\mathbf{0 . 0 3 2}$ \\
$\mathbf{P}_{\mathbf{t}}$ & $1.03 * 10^{-4}$ & 0.999 & 0.019 & 0.949 \\
$\mathbf{P}_{\text {fi }}$ & 0.219 & 0.169 & 0.161 & 0.313 \\
$\mathbf{P}_{\text {for }}$ & 0.144 & 0.369 & 0.295 & 0.061 \\
$\mathbf{P}_{\text {hind }}$ & 0.152 & 0.342 & 0.092 & 0.568 \\
$\mathbf{P}_{\text {avg }}$ & 0.170 & 0.287 & 0.220 & 0.168 \\
\hline
\end{tabular}

Bold indicates $p$-values that are significant $(<0.05)$.

\section{Phylogenetic Signal}

K-statistic results show there is very little phylogenetic signal in the bone microstructure character data ( $\mathrm{P}, \mathrm{S}, \mathrm{C}$ and Min) for all long bones, but that SC and $\log \left(m_{b}\right)$ contain a strong phylogenetic signal (Table 13). The compactness of the femur showed evidence of a strong phylogenetic signal in one instance when using the Nee branch length algorithm. 
TABLE 13. All values of K-statistic calculated using the APE package for the $\mathrm{R}$ project for statistical computing. K-statistic $<1$ indicates a weak phylogenetic signal and K-statistic $>1$ indicated a strong phylogenetic signal.

Equivocal Branch Lengths

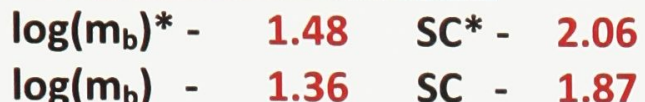

$\begin{array}{llll}\text { P* } & \text { S } & \text { C } & \text { Min }\end{array}$

$\begin{array}{llll}\text { Humerus } & 0.43 & 0.68 & 0.42\end{array}$

$\begin{array}{llll}\text { Radius } & 0.4 & 0.67 & 0.51\end{array}$

Ulna

$0.34 \quad 0.61$

0.33

$0.75 \quad 0.86$

0.83

Tibia

0.34

0.7

0.45

$\begin{array}{ll}0.52 & 0.4\end{array}$

0.48

0.69

0.37

0.69

0.57

0.71

$0.46 \quad 0.46$

0.57

0.64

0.41

0.66

0.5

0.33

0.55

0.38

All

0.44
Grafen Branch Lengths

$\begin{array}{llll}\log \left(m_{b}\right)^{*}- & 0.76 & S C^{*}- & 1.08 \\ \log \left(m_{b}\right)- & 0.58 & \text { SC }- & 0.9\end{array}$

Pagel Branch Lengths

\begin{tabular}{|c|c|c|}
\hline $\log \left(m_{b}\right)^{*}-$ & 1.54 & SC \\
\hline $\log \left(m_{b}\right)$ & 1.23 & SC \\
\hline
\end{tabular}

Nee Branch Lengths

\begin{tabular}{lll}
\hline $\log \left(m_{b}\right)^{*}-2.48$ & SC* & 2.89 \\
$\log \left(m_{b}\right)-1.58$ & SC - & 1.82
\end{tabular}

\begin{tabular}{llllllllll} 
& P* & S & C & Min & & P* & S & C & Min \\
Humerus & 0.27 & 0.63 & 0.35 & 0.59 & Humerus & 0.56 & 0.81 & 0.51 & 0.72 \\
Radius & 0.3 & 0.55 & 0.48 & 0.84 & Radius & 0.62 & 0.76 & 0.65 & 0.87 \\
Ulna & 0.21 & 0.57 & 0.28 & 0.38 & Ulna & 0.46 & 0.75 & 0.42 & 0.55 \\
Femur & 0.5 & 0.72 & 0.78 & 0.92 & Femur & 0.96 & 0.91 & 1.04 & 0.9 \\
Tibia & 0.19 & 0.59 & 0.4 & 0.59 & Tibia & 0.43 & 0.82 & 0.59 & 0.69 \\
Fibula & 0.37 & 0.46 & 0.42 & 0.42 & Fibula & 0.79 & 0.58 & 0.61 & 0.5 \\
Forelimb & 0.23 & 0.57 & 0.32 & 0.51 & Forelimb & 0.5 & 0.77 & 0.47 & 0.7 \\
Hindlimb & 0.31 & 0.59 & 0.51 & 0.47 & Hindlimb & 0.66 & 0.79 & 0.73 & 0.55 \\
All & 0.28 & 0.6 & 0.4 & 0.5 & All & 0.61 & 0.8 & 0.58 & 0.61 \\
& & & & & & & & & \\
\hline
\end{tabular}

* indicates results calculated with the full 43 taxa tree Bold indicates a strong phylogenetic signal. 


\section{Linear Discriminant Function Analysis}

Results of linear discriminant function analysis (DFA) of the original values for $P$ for all 43 taxa as well as $\log \left(m_{b}\right)$ incorrectly classified $11.63 \%$ of species within the four swimming behaviour category bins (terrestrial=1, semi-aquatic $=2$, aquatic $=3$, semipelagic=4). Log transforming the data for $\mathrm{P}$ improved the results to only $9.302 \%$, or four of 43 species misclassified. Ursids were often misclassified as semi-aquatic and when this group is removed from the analysis the percent of misclassified species drops to $2.564 \%$ with non-transformed data. However, when $\log \left(m_{b}\right)$ is excluded from the analysis the percent of misclassified species increases to $16.28 \%$ with original data and $34.88 \%$ with log transformed data. When swimming categories were further simplified into 3 bins (terrestrial=1, semi-aquatic $=2$ and aquatic $=3$ ), by including the semi-pelagic forms in the aquatic group, the number of misclassified species increased to $13.95 \%$ for non-transformed data and remained constant at $9.032 \%$ for log transformed data.

When the original data for S, C, and Min, for the 27 larger taxa, and $\log \left(m_{b}\right)$ are included together in a linear DFA only $3.704 \%$ of species are misclassified. When the data is log transformed this improved to $100 \%$ of species correctly classified. When the values of $\mathrm{P}$ are also included for these 27 species, it produces a singular in the covariance matrix as the number of variables is greater than the number of species to be classified. Therefore, P was omitted from the DFA's which used 27 species.

Body mass estimates for Puijila darwini were produced using regressions of log transformed cranial measurements and log transformed body mass from Van 
Valkenburgh (1990). Estimates were produced using three different cranial

measurements and the regressions from the families Ursidae and Mustelidae. This gave three estimates of $\log \left(m_{b}\right)$ for Puijila of 0.83 as a mustelid, 1.51 as an ursid and an average of these two values of 1.19. These translate to body mass estimates of approximately $7 \mathrm{~kg}, 32 \mathrm{~kg}$ and $16 \mathrm{~kg}$ respectively. When Puijila was compared to the modern taxa in analyses which included body mass, it was consistently predicted to belong to either the semi-aquatic or aquatic bins. In DFA, where the estimated body masses were not used, Puijila was more often predicted to belong to the semi-aquatic swimming behaviour grouping (Table 14).

When variables were removed one at a time from DFA which included the variables $\log \left(\mathrm{m}_{b}\right)$ and $\mathrm{P}$, Puijila retained his classification as a swimming arctoid (SC=2 or 3) as long as $\log \left(m_{b}\right)$ was present. When $\log \left(m_{b}\right)$ was not included in the DFA, the removal of $\mathrm{P}_{t}$ or $\log \left(\mathrm{P}_{\mathrm{t}}\right)$ caused Puijila to be reclassified as terrestrial instead of semiaquatic or aquatic. This remained true in analyses where SC 4 taxa were included with SC 3 in a single grouping. This indicates that log body mass is important for the classification of Puijila as swimming arctoid, but that the values of cortical bone thickness of the tibia also contribute to its designation. However, the tibia does not classify Puijila as terrestrial in the absence of $\log \left(m_{b}\right)$ in analyses where ursids are not included.

The removal of body mass does not effect the classification of Puijila as a swimming arctoid for analyses involving S, C and Min. Removing of any one variable, or 
group of variables (S, C or Min) does not classify Puijila as terrestrial.

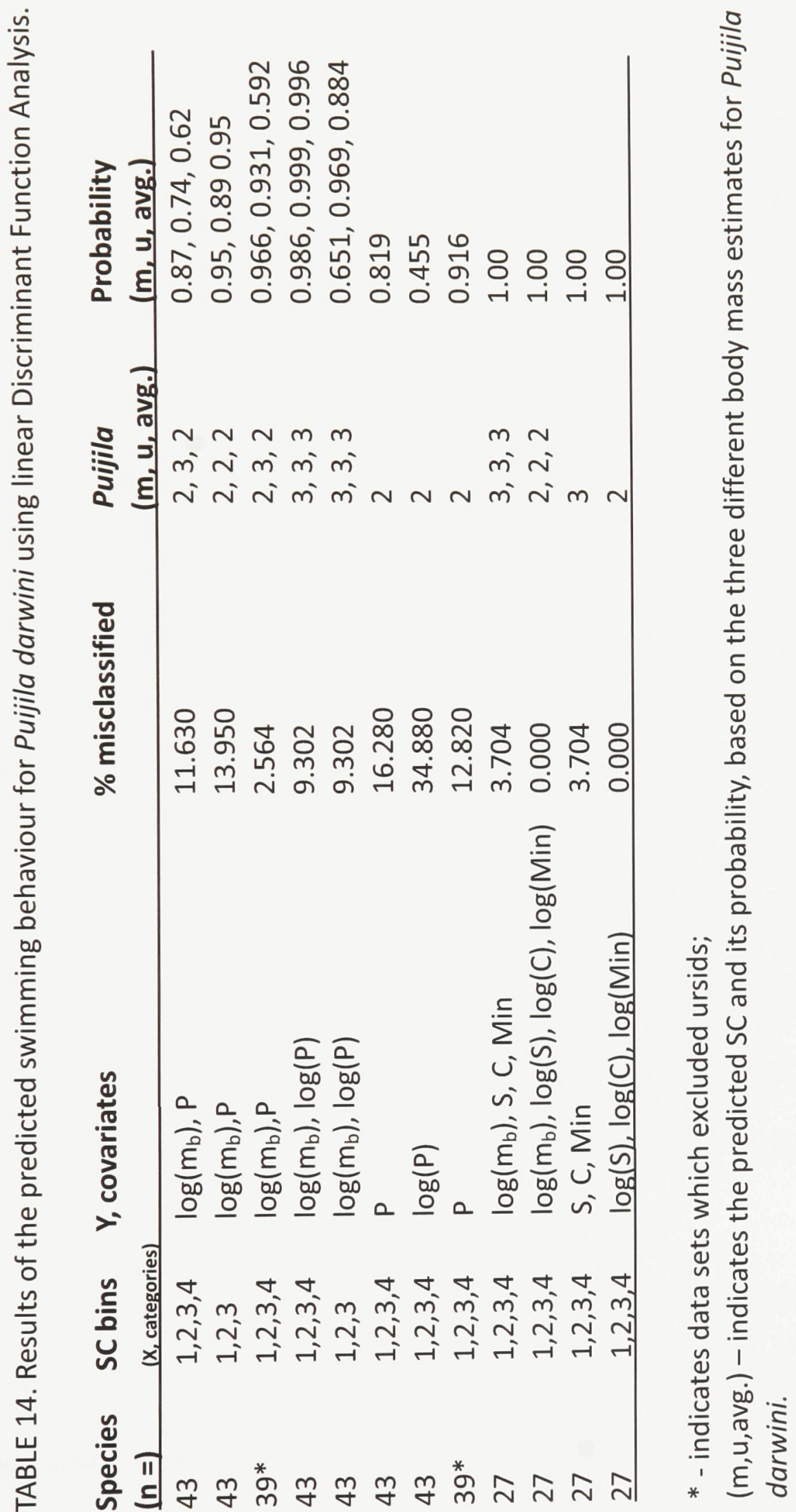


DISCUSSION

When discussing hypotheses of correlated evolution between limb bone density and swimming behaviour, it is important to recognize that changes in bone microstructure are driven by more than simply selective pressure for increased limb bone density to counter an animal's natural buoyancy. Long bones must be able to withstand the stress and strain associated with supporting their body on land during locomotor and other activities. Each animal requires a different optimal balance of cortical bone thickness and shaft diameter to achieve its equilibrium (Currey and Alexander, 1985). These functional requirements mean that bone microstructure should be heavily influenced by an animal's body mass. This should be especially true for terrestrial animals which must constantly support their entire weight on their limbs, without the aid of water, to help support their mass. Those animals which have become fully pelagic, such as modern cetaceans, are free of the structural constraints on their bone microstructure that arise from the use of limbs on land, though they would still be subject to the influence of the stress and strain on their limb bones which would arise from aquatic locomotion. Bone shape is also influenced by the need to provide attachment for the muscles which are involved in aquatic locomotion.

\section{Influence of Body Mass on Cortical Bone Thickness}

Pinnipeds are the most aquatic arctoids, yet they are not as aquatically specialized as some mammalian lineages such as cetaceans and sirenians. Otariids and odobenids continue to use some or all of their limbs on land, so it would be expected 
that the microstructure of the limb bones of these taxa retain evidence that the limb is used to support their weight. Therefore, body mass should still have some influence on the bone microstructure even in these aquatic arctoid taxa.

In a study that investigated the relationships between body mass and skeletal measurements of the humerus, femur and tibia of recent carnivores, Egi (2001) found that humeral and femur cortical cross-sectional areas were better predictors of body mass than the length or articular surface area of those bones. When the cortical bone thickness ratios $(\mathrm{P})$ of the humerus and femur of the 43 arctoids in this study are plotted as one group with body mass, and an ordinary least squares regression is performed, there is no correlation between the variables (humerus: $r=-0.009261, p$-value $=0.953$; femur: $r=0.07643, p$-value=0.626). However, when the species are divided into their swimming category bins (terrestrial, semi-aquatic and aquatic) there is a significant positive correlation between body mass and the humerus of terrestrial and semi-aquatic species (terrestrial: $r=0.52866, p$-value $=0.0166$; semi-aquatic: $r=0.90774$, $p$-value=0.012), but not with the femur. A higher value of $\mathrm{P}$ corresponds to a larger medullary cavity and less compact bone (Currey, 2003; Girondot and Laurin, 2003). The positive correlations within swimming behaviour groups are opposite of the observations of Egi (2001) that larger taxa had larger cortical bone area. The difference in results may be related to differences in the taxa sampled. In comparison to this study, Egi (2001) used only relatively small terrestrial carnivorous mammals in his body mass study (i.e. less than 25 kg). Another study that included larger and more taxonmically diverse terrestrial 
mammals in their analysis found poor correlation coefficients between body mass and cortical bone thickness (Currey and Alexander, 1985).

Currey and Alexander (1985) examined the mechanical properties of tubular long bones. They calculated ratios of $P$ that would be optimal for minimizing weight while also providing the greatest impact strength when loaded. The ratio $\mathrm{P}=0.55$ would be the theoretical optimum for terrestrial organisms' long bones to have ultimate strength and to best withstand impact loading, while minimizing weight, thus saving energy. Their examination of modern terrestrial mammals ranging in size from $2500 \mathrm{~kg}$ to $0.0057 \mathrm{~kg}$, revealed that this theoretical value was very close to the average values for the humeri and femora, but that more distal bones tended to be more compact than the optimum. They observed larger taxa tended to have lower values of $P$ than smaller taxa. In their study of 28 taxonomically diverse, terrestrial mammals, actual correlations between cortical bone thickness and body mass revealed that the only major long bone to show a significant negative correlation was the femur. They also stated that larger values of $P$ would be expected in taxa which had high selective pressure for weight reduction; an extreme example of which would be flying birds. Currey and Alexander (1985) did not investigate the relationship of body mass and cortical bone thickness in aquatic and semi-aquatic mammals; including only one sirenian as a representative in their analysis which are well known to have highly pachyostotic bones.

The terrestrial and semi-aquatic arctoids examined for this study display an average value of $\mathrm{P}$ that corresponds to the theoretical value for impact loading. They 
also conform to the previously observed trend (Currey and Alexander, 1985) that more distal long bones tend to be more compact than the optimum for impact loading. The relationship between $\mathrm{P}$ and body mass with arctoids and within each swimming behavioural grouping is positive for most bones, indicating that larger arctoids tend to have less compact bones than smaller arctoids. This seems counter to the predictions of Currey and Alexander (1985).

Other bone density studies found higher cortical bone thickness and compactness occur often in aquatic taxa; sometimes found in modern lineages (eg. sirenians) or ancestral fossil forms (eg. cetaceans) (Domning and Debuffrenil, 1991; Madar, 1998; Laurin et al., 2004; Thewissen et al., 2007; Houssaye, 2009; de Buffrenil et al., 2010). The mean values of the cortical bone thickness ratio (P) for aquatic arctoids in this study are larger than the terrestrial group and thus do not appear to follow these patterns. By excluding phocids from the mean, so that only aquatic arctoids that still use their limbs to support their weight on land are considered, the resulting value of $P$ conforms more to the predictions of Currey and Alexander (1985). The values for the humerus and femur of non-phocid aquatic taxa are more compact than their terrestrial relatives and distal bones are less or equally compact. The average $P$ for non-phocid aquatic taxa is slightly smaller than the average for the larger terrestrial taxa, though they also have higher average body mass. Phocid taxa have average less cortical bone thicknesses than terrestrial arctoids and they do not use their limbs to support their body weight on land. 
The shift to a relatively more compact humerus and femur in otariids and

Odobenus could be related to the shortening of those bones. However, when the log transformed length of these bones were plotted against their cortical bone thickness ratio in an ordinary least squares regression, there was no apparent relationship between the characters (humerus: $r=0.090224$, $p$-value $=0.56503$; femur: $r=-0.028272, p$ value $=0.85718$ ). Even when the large values of $P$ displayed by phocids are removed from the regression, there continues to be no significant relationship between cortical bone thickness and the length of the element (humerus: $r=0.19308, p$-value $=0.28969$; femur: $\mathrm{r}=-0.1641, \mathrm{p}$-value $=0.36974) . \quad$ Otariids and Odobenus retain a positive relationship between $\mathrm{P}$ and body mass. Therefore, it appears that within Arctoidea in general there is a decrease in cortical bone thickness with increasing body mass. This could be a result of selective pressure to optimize, and reduce where possible, an animal's body mass, and therefore the metabolic costs of locomotion (Currey and Alexander, 1985).

\section{Bone Microstructure and Swimming Behaviour}

Recent studies of bone microstructure in aquatic animals have often used linear measurements as an approximation of body size to compare with bone microstructure (Girondot and Laurin, 2003; Laurin et al., 2004; Cubo et al., 2005; Germain and Laurin, 2005; Laurin et al., 2006; Kriloff et al., 2008; Canoville and Laurin, 2010). However, an animal's size or length does not always accurately predict its actual body mass. Two animals of the same presacral length may have vastly different body masses. This is evident from attempts to predict body mass in fossil taxa by using linear regressions on 
skeletal measurements and body mass data of modern taxa (Van Valkenburgh, 1990). Regressions at the family level yield more accurate results than regressions at larger taxonomic groupings. This indicates there is a phylogenetic component to the relationship between skeletal measurements and body mass, and suggests that tetrapods from disparate lineages with similar body lengths may have very different body masses. This is supported by k-statistic results of this study, which found that both body mass and swimming behavioural data of the 43 arctoid species contained a strong phylogenetic signal. Therefore, examining the relationship between presacral length, or other linear body measurements, and bone microstructure may not be effective at representing the effect that an animal's mass has on bone microstructure, especially in taxonomically diverse data sets.

Previous studies using Bone Profiler have shown evidence of body size (using length measurements) correlating with certain aspects of bone microstructure and swimming behaviour in tetrapod groups. Laurin et al. (2004) found that body size and femur compactness both increased in aquatic lissamphibians, and Cubo et al. (2006) discovered correlated evolution between body size and swimming behaviour in sauropsids. Germain and Laurin (2005) found that the maximal diameter of the radius tended to be larger in aquatic amniotes. Canoville and Laurin (2010) discovered that body size measurements such as presacral length and bone diameter showed evidence for correlated evolution with swimming when compared using PIC analyses within amniotes. They did not specifically examine the relationship between body mass and 
bone microstructure variables in their analyses.

The results of this study show a relationship between body mass and bone microstructure. For the variables $\mathrm{S}$ and Min there is no evidence for correlated evolution with swimming behaviour, and only evidence of correlated evolution between S and Min of certain long bones, with body mass. The character $\mathrm{S}$ is related to the width of the transition zone between cortical bone and the trabecular bone of the medullary cavity (Girondot and Laurin, 2003). The variable S showed positive correlations with body mass indicating that as arctoids become larger the transition between medullary cavity and cortical bone becomes more gradual. Bone density near the center of the cross section (Min) shows a positive relationship with body size $\left(\log \left(m_{b}\right)\right)$ for the femur. The parameter Min is influenced by the prominence and quantity of trabeculae in the medulary cavity (Girondot and Laurin, 2003; Laurin et al., 2004). The positive relationship between body mass and Min suggests that as body mass increases in arctoids there is an increase of deposition of trabecular bone, increasing the prominence of the trabeculae in the femur.

The variables describing overall compactness $(C)$ and medullary size $(P)$ show evidence of correlated evolution with both body mass and swimming behaviour for some long bones. Only $\mathrm{C}_{\mathrm{fi}}$ correlated with swimming behaviour, but the variable is also correlated with body mass. The variable P correlated with swimming behaviour and also consistently correlated with body mass for most of the long bones. The exception is $\mathrm{P}_{\mathrm{fi}}$ which correlated with swimming behaviour and not body mass. The analysis included 
many pinniped species; many that do not support their full body weight with their hind limbs (Howell, 1929; Demere et al., 2003; Bebej, 2008). Not using their hind limbs for support on land may reduce the constraints that body mass places on the evolution of cortical bone thickness in these elements and could be a reason for a lack of a relationship between $P_{f i}$ and $\log \left(m_{b}\right)$. This suggests that in arctoids, the cortical bone thickness of the fibula may be less influenced by body mass than other elements and could be a better predictor of swimming behaviour. However, these results are to be taken with caution, because the fibula is the smallest bone in the sample and therefore more susceptible to measuring errors and CT scan distortion. Also, the small size of the fibula limits the impact that increasing its compactness would have on overall buoyancy control. Also, when phocids are removed from the analysis all relationships between long bone cortical bone thickness and swimming behaviour are lost, including those of $\mathrm{P}_{\mathrm{fi}}$ and $\mathrm{SC}$. This indicates that the correlation between $\mathrm{P}_{\mathrm{fi}}$ and $\mathrm{SC}$ is being driven by these large bodied aquatic taxa and that the relationship might not be an effective predictor for classifying smaller bodied transitional fossil arctoids that are semi-aquatic or terrestrial.

A combination of soft tissue specializations for swimming and diving and a decrease in the use of their limbs for structural support on land can create a scenario where cortical bone thickness decreases in aquatic taxa, a pattern seen in cetaceans (Gray et al., 2007). Phocids do not rely on any of their limbs to support their weight on land and in swimming use their hind feet for propulsion and their forelimbs for steering 
and stability (Howell, 1929; Bebej, 2008). Therefore, there should be fewer constraints from body mass on cortical bone thickness in this group. When phocids are removed from PIC analyses of $\mathrm{P}$, the positive relationships between medullary size of the long bones and swimming behaviour are no longer significant, suggesting that phocids are driving the trends in cortical bone thickness in arctoids.

The results of the PIC analyses in this study indicate that swimming behaviour and body mass were positively correlated. It is possible that the relationship seen between swimming behaviour and certain long bone compactness variables could simply be due to the larger average size of the aquatic and semi-aquatic arctoids. When the residuals of the characters that showed a relationship to both swimming behaviour and body mass (C, P) are plotted against the residuals of swimming behaviour and body mass, to remove the influence of body mass as well as phylogeny, the relationship between these characters and swimming behaviour is lost in all cases. This suggests that the evidence of correlated evolution between bone microstructure traits $(P, C)$ and swimming behaviour is driven by their relationship with body mass. Therefore, as an arctoid lineage becomes more aquatic it tends to increase its body mass and this may have an effect on its bone microstructure. Body mass and $\mathrm{P}$ are positively correlated and body mass and $\mathrm{C}$ are negatively correlated. This indicates that the trend in Arctoidea is towards a decrease in bone compactness as body mass increases. These results suggest that perhaps unlike other aquatic tetrapod groups, swimming arctoids do not tend to have more compact bones and that long bone microstructure may not be a good 
predictor of swimming behaviour in arctoids. Further studies of bone microstructure might use non-load bearing elements, such as ribs, to better understand whether changes in bone compactness are associated with aquaticism in arctoids.

\section{Bone Compactness in Puijila}

Is there evidence for increased bone density in fossil pinnipeds? Puijila has a larger body mass and thicker cortical bone than the average for all terrestrial arctoids in this study. Body mass estimates for Puijila are closer to the average size of semi-aquatic arctoids. The humerus and femur of Puijila have lower values of $P$ than semi-aquatic arctoids, but higher values than otariids and walrus. The more distal long bones have lower values of $\mathrm{P}$ than the average of any behavioural group. Therefore, its lower values of $\mathrm{P}$ which correspond to higher bone compactness may indicate compactness in this transitional fossil which is higher than expected. However, these results are taken solely from CT scan data and were not confirmed with natural breaks in the specimen. The resolution of the $\mathrm{CT}$ scans and the possibility of matrix infilling the medullary cavity could have artificially increased the compactness values for the long bones of Puijila.

Puijila was consistently predicted as a semi-aquatic or aquatic arctoid using DFA when bone microstructure variables and body mass data from the modern arctoids were used as covariates. However, when $\log \left(m_{b}\right)$ was removed from the analysis the overall predictive accuracy of the DFA usually decreased, though Puijila was still classified as a swimming arctoid. This is another indication that body mass is an important predictor of swimming behaviour in this mammal group. In the absence of body mass, removal of $P_{t}$ 
from DFA ( $n=43$ ) caused Puijila to be misclassified as terrestrial in most analyses indicating it may also be important to the classification of Puijila as a swimming arctoid. No one variable appeared to be driving the classification of Puijila in analyses involving C, S and Min ( $n=27)$. With or without the inclusion of body mass, Puijila was consistently classified as a swimming arctoid no matter which variable was removed.

\section{Implications for Other Aquatic Mammal Groups}

If body size plays such an important role in the microstructure of arctoid long bones, it is likely that changes in bone compactness in early pinniped evolution would have resulted only from correlated evolution between bone compactness and body mass. How does this affect the other groups which have been suggested to exhibit increased bone compactness for buoyancy control in their semi-aquatic fossil ancestors?

The land-to-sea evolution of sirenians is captured by the quadrupedal and semiaquatic fossil, Pezosiren portelli, and in cetaceans by transitional forms such as Indohyus, pakicetids and ambulocetids (Thewissen and Fish, 1997; Domning, 2001; Thewissen and Williams, 2002). Increased bone compactness in sirenians is found mostly in the ribs and is present in the quadrupedal form Pezosiren portelli (Domning, 2001). The specialization persists even in their modern fully aquatic forms, and has been shown by Domning and Debuffrenil (1991) to provide ballast and keep the animal parallel to the substrate while feeding. Therefore, there is good evidence that this specialization is related to their swimming behaviour and feeding and not to their large body mass. It has been suggested that early cetaceans show evidence of increased cortical 
bone thickness for buoyancy control during their evolution. Instead of thick cortical bone, modern cetaceans use trabecular struts to strengthen their bones and brace them against the physical stresses created during swimming (Madar, 1998; Gray et al., 2007)). Within ancestral cetaceans, which have been suggested to display increased bone density, there is also an increase in body size from the more terrestrial ancestors of cetaceans, such as Indohyus, to the more aquatic ancestral cetaceans such as bailosaurids. Based on a survey of modern artiodactyls that found their average cortical bone thickness ratio to be between 0.65 and 0.7 , Indohyus was interpreted to be semiaquatic as it had a smaller ratio of 0.42 (Thewissen et al., 2007). The earliest semiaquatic pakicetids and ambulocetids were still able to walk on land (Thewissen and Williams, 2002). Some pakicetid long bones have no medullary canal, being completely filled in with compact bone (Thewissen and Williams, 2002). There is evidence for systematic increases in bone density in ambulocetids as well (Gray et al., 2007; Madar, 2007). Therefore, although there is an increase in body size in ancestral cetaceans, there is evidence for increases in bone density that may not be explained by body mass increases alone.

\section{SUMMARY}

This study shows there is evidence in Arctoidea for correlated evolution between swimming behaviour and body mass and certain aspects of bone microstructure. Body mass is an important predictor of swimming behaviour within Arctoidea. Bone microstructure does not appear to be an effective predictor of swimming behaviour in 
arctoids when the influence of body mass is removed from the data. Arctoids tend to have reduced bone compactness as their body size increases, which is contrary to the observations of previous studies. Discriminant function analyses support the predictions made from the musculoskeletal specializations of Puijila that it was semi-aquatic. Puijila has a higher estimated body mass and more compact long bones than the average values for terrestrial arctoids. Its body mass estimates are most similar in size to the average of semi-aquatic arctoids, but its distal bones are more compact than semiaquatic arctoids. Although there is evidence to support that increase in bone compactness is an aquatic specialization in some mammal lineages, it does not appear to be the case for Arctoidea. More taxonomically specific investigations of other marine tetrapod lineages could determine whether increased bone compactness is truly correlated with swimming behaviour in other aquatic amniotes, independent of the influences of body size. 


\section{CONCLUSION}

The specializations of the forelimb of Puijila suggest that it was adapted to provide powerful movements and was likely used more frequently during swimming, than the forelimb of Lontra. Puijila appears to have a more specialized forelimb than modern lutrines, yet less specialized than its fossil relative Potamotherium. The long bones of Puijila appear to have higher compactness than those of terrestrial arctoids, possibly indicating their bone microstructure reflected a specialization for aquaticism.

Discriminant function analyses based on bone microstructure variables and body mass of modern arctoids predict Puijila was a semi-aquatic arctoid, which supports the fossil musculoskeletal evidence. In arctoids, there is a positive correlation between body mass and swimming behaviour and evidence for correlated evolution between bone microstructure and body mass. Results of phylogenetically independent contrasts analyses indicate that bone microstructure data is not as informative about an arctoid's swimming behaviour as it likely is for other aquatic mammal groups.

Examination of more fossil stem pinnipeds could provide further insight into the larger patterns of bone compactness in ancestral pinnipeds. This understanding of bone compactness in other ancestral pinnipeds would build on the evidence provided in this study from the comparative description of the forelimb of Puijila and the examination of bone compactness in arctoids, to shed further light on the early evolution of Pinnipedia. 


\section{REFERENCES}

Arnason, U., A. Gullberg, A. Janke, M. Kullberg, N. Lehman, E. A. Petrov, and R. Väinölä. 2006. Pinniped phylogeny and a new hypothesis for their origin and dispersal. Molecular Phylogenetics and Evolution 41:345-354.

Bebej, R. M. 2008. Swimming modeilnferred from skeletal proportions in the fossil pinnipeds Enaliarctos and Allodesmus (Mammalia, Carnivora). Journal of Mammalian Evolution 16:77-97.

Berry, K. "Lontra longicaudis" (On-line). http://animaldiversity.ummz.umich.edu/site/accounts/information/Lontra longic audis.html. Retrieved September 17, 2010.

Berta, A. 1991. New Enaliarctos* (Pinnipedimorpha) from the Oligocene and Miocene of Oregon and the role of "enaliarctids" in pinniped phylogeny. Smithsonian Contributions to Paleobiology 69:33.

Berta, A. 1994. New specimens if the Pinnipediform Pteronarctos from the Miocene of Oregon. Smithsonian Contributions to Paleobiology 78:29.

Berta, A., and A. R. Wyss. 1990. Oldest pinniped - Response. Science 248:499-500.

Berta, A., and C. E. Ray. 1990. Skeletal morphology and locomotor capabilities of the archaic pinniped Enaliarctos mealsi. Journal of Vertebrate Paleontology 10:141157.

Berta, A., and A. R. Wyss. 1994. Pinniped phylogeny. Proceedings of the San Diego Society of Natural History 29:33-56. 
Berta, A., C. E. Ray, and A. R. Wyss. 1989. Skeleton of the oldest known pinniped, Enaliarctos mealsi. Science 244:60-62.

Blomberg, S. P., T. Garland, and A. R. Ives. 2003. Testing for phylogenetic signal in comparative data: Behavioral traits are more labile. Evolution 57:717-745.

Canoville, A., and M. Laurin. 2010. Evolution of humeral microanatomy and lifestyle in amniotes, and some comments on palaeobiological inferences. Biological Journal of the Linnean Society 100:384-406.

Carroll, R. L. 1988. Vertebrate Paleontology and Evolution. W.H. Freeman, New York, NY. Clementz, M. T., A. Goswami, P. D. Gingerich, and P. L. Koch. 2006. Isotopic records from early whales and sea cows: Contrasting patterns of ecological transition. Journal of Vertebrate Paleontology 26:355-370.

Cubo, J., F. Ponton, M. Laurin, E. d. Margerie, and J. Castanet. 2005. Phylogenetic signal in bone microstructure of sauropsids. Systematic Biology 54:562-574.

Currey, J. 2003. The many adaptations of bone. Journal of Biomechanics 36:1487-1495.

Currey, J. D., and R. M. Alexander. 1985. The thickness of the walls of tubular bones. Journal of Zoology 206:453-468.

de Buffrenil, V., A. Canoville, R. D'Anastasio, and D. P. Domning. 2010. Evolution of sirenian pachyosteosclerosis, a model-case for the study of bone structure in aquatic tetrapods. Journal of Mammalian Evolution 17:101-120.

Demere, T. A., A. Berta, and P. J. Adam. 2003. Pinnipedimorph evolutionary biogeography. Bulletin of the American Museum of Natural History 279:32-76. 
Dewey, T., and E. Ellis. "Lontra canadensis" (On-line).

http://animaldiversity.ummz.umich.edu/site/accounts/information/Lontra cana densis.html Retrieved September 17, 2010.

Domning, D. P. 1982. Evolution of manatees - A speculative history. Journal of Paleontology 56:599-619.

Domning, D. P. 2001. The earliest known fully quadrupedal sirenian. Nature 413:625-627. Domning, D. P., and V. Debuffrenil. 1991. Hydrostasis in the Sirenia - Quantitative data and functional interpretations. Marine Mammal Science 7:331-368.

Egi, N. 2001. Body mass estimates in extinct mammals from limb bone dimensions: the case of North American hyaenodontids. Palaeontology 44:497-528.

English, A. W. 1976. Functional anatomy of hands of fur seals and sea lions. American Journal of Anatomy 147:1-17.

English, A. W. 1977. Structural correlates of forelimb function in fur seals and sea lions. Journal of Morphology 151:325-352.

Evans, H. E. 1993. Miller's Anatomy of the Dog, $3^{\text {rd }}$ Edition. W.B. Saunders, Philadelphia. Felsenstein, J. 1985. Phylogenies and the comparative method. American Naturalist 125:1-15.

Finarelli, J. A. 2008. A total evidence phylogeny of the Arctoidea (Carnivora: Mammalia): Relationships among basal taxa. Journal of Mammalian Evolution 15:231-259.

Fischer, E. M. 1942. The osteology and myology of the California river otter. Stanford University Press, Stanford University, California. 
Fish, F. E. 1996. Transitions from drag-based to lift-based propulsion in mammalian swimming. American Zoologist 36:628-641.

Fish, F. E., and B. R. Stein. 1991. Functional correlates of differences in bone density among terrestrial and aquatic genera in the family Mustelidae (Mammalia). Zoomorphology 110:339-345.

Flynn, J. J., J. A. Finarelli, S. Zehr, J. Hsu, and M. A. Nedbal. 2005. Molecular phylogeny of the Carnivora (Mammalia): Assessing the impact of increased sampling on resolving enigmatic relationships. Systematic Biology 54:317-337.

Frisch, T., and R. Thorsteinsson. 1978. Haughton-astrobleme - Mid-Cenozoic impact crater Devon Island, Canadian Arctic archipelago. Arctic 31:108-124.

Fulton, T. L., and C. Strobeck. 2006. Molecular phylogeny of the Arctoidea (Carnivora): Effect of missing data on supertree and supermatrix analyses of multiple gene data sets. Molecular Phylogenetics and Evolution 41:165-181.

Garland, T., and C. M. Janis. 1993. Does metatarsal/femur ratio predict maximal running speed in cursorial mammals? Journal of Zoology 229:133-151.

Garland, T., P. H. Harvey, and A. R. Ives. 1992. Procedures for the analysis of comparative data using phylogenetically independent contrasts. Systematic Biology 41:18-32.

Garland, T., A. W. Dickerman, C. M. Janis, and J. A. Jones. 1993. Phylogenetic analysis of covariance by computer simulation. Systematic Biology 42:265-292.

Germain, D., and M. Laurin. 2005. Microanatomy of the radius and lifestyle in amniotes (Vertebrata, Tetrapoda). Zoologica Scripta 34:335-350. 
Girondot, M., and M. Laurin. 2003. Bone profiler: A tool to quantify, model, and statistically compare bone-section compactness profiles. Journal of Vertebrate Paleontology 23:458-461.

Grafen, A. 1989. The phylogenetic regression. Philosophical Transactions of the Royal Society of London. Series B, Biological Sciences 326:119-157.

Gray, N.-M., K. Kainec, S. Madar, L. Tomko, and S. Wolfe. 2007. Sink or swim? Bone density as a mechanism for buoyancy control in early cetaceans. The Anatomical Record: Advances in Integrative Anatomy and Evolutionary Biology 290:638-653.

Hall, E. R. 1926. The muscular anatomy of three mustelid mammals, Mephitis, Spilogale, and Martes. University of California Publications in Zoology 30:7-38.

Hall, E. R. 1927. The muscular anatomy of the American badger (Taxidea taxus). University of California Publications in Zoology 30:205-219.

Hammer, O., D. A. T. Harper, and P. D. Ryan. 2001. PAST: Paleontological Statistics Software Package for education and data analysis. Palaeontologia Electronica 4. Hickey, L. J., K. R. Johnson, and M. R. Dawson. 1988. The stratigraphy, sedimentology, and fossils of the Haughton Formation - A post-impact crater-fill, Devon Island, NWT, Canada. Meteoritics 23:221-231.

Higdon, J. W., O. R. P. Bininda-Emonds, R. M. D. Beck, and S. H. Ferguson. 2007. Phylogeny and divergence of the pinnipeds (Carnivora: Mammalia) assessed using a multigene dataset. BMC Evolutionary Biology 7:216.

Houssaye, A. 2009. Pachyostosis in aquatic amniotes: a review. Integrative Zoology 
4:325-340.

Howard, L. D. 1973. Muscular anatomy of the forelimb of the sea otter (Enhydra lutris). Proceedings of the California Academy of Sciences, 4th Series 39:411-500.

Howell, A. B. 1929. Contribution to the comparative anatomy of the eared and earless seals. Proceedings of the United States National Museum 73:1-142.

Howell, A. B. 1930. Aquatic mammals : their adaptations to life in the water. C. C. Thomas, Springfield, IL.

Jessberger, E. K. 1988. Ar-40-Ar-39 dating of the Haughton impact structure. Meteoritics 23:233-234

Koepfli, K.-P., K. Deere, G. Slater, C. Begg, K. Begg, L. Grassman, M. Lucherini, G. Veron, and R. Wayne. 2008. Multigene phylogeny of the Mustelidae: Resolving relationships, tempo and biogeographic history of a mammalian adaptive radiation. BMC Biology 6:10.

Kriloff, A., D. Germain, A. Canoville, P. Vincent, M. Sache, and M. Laurin. 2008. Evolution of bone microanatomy of the tetrapod tibia and its use in palaeobiological inference. Journal of Evolutionary Biology 21:807-826.

Laurin, M., M. Girondot, and M. M. Loth. 2004. The evolution of long bone microstructure and lifestyle in lissamphibians. Paleobiology 30:589-613.

Laurin, M., D. Germain, J. S. Steyer, and M. Girondot. 2006. Microanatomical data and the conquest of land by vertebrates. Comptes Rendus Palevol 5:603-618.

Leach, D. 1977a. Descriptive and comparative postcranial osteology of the Marten 
(Martes americana turton) and Fisher (Martes pennanti erxleben) - Appendicular skeleton. Canadian Journal of Zoology-Revue Canadienne De Zoologie 55:199214.

Leach, D. 1977b. Forelimb musculature of the Marten (Martes americana turton) and Fisher (Martes pennanti erxleben). Canadian Journal of Zoology-Revue Canadienne De Zoologie 55:31-41.

Lento, G. M., R. E. Hickson, G. K. Chambers, and D. Penny. 1995. Use of spectral-analysis to test hypotheses on the origin of pinnipeds. Molecular Biology and Evolution $12: 28-52$

Madar, S. 1998. Structural adaptations of early archaeocete long bones; p.p. 353-378 in J. G. M. Thewissen (ed.), The emergence of whales : evolutionary patterns in the origin of Cetacea. Plenum Press, New York, NY.

Madar, S. I. 2007. The postcranial skeleton of early eocene pakicetid cetaceans. Journal of Paleontology 81:176-200.

Maddison, W. P., and D. R. Maddison. 2006. Mesquite: A modular system for evolutionary analysis. Version 1.1.

McLaren, I. A. 1960. Are the Pinnipedia biphyletic. Systematic Zoology 9:18-28.

Midford, P. E., T. Garland Jr., and W. P. Maddison. 2005. PDAP:PTREE Package of Mesquite. Version 1.15.

Nowak, R. M. 1991. Walker's Mammals of the World, $5^{\text {th }}$ Edition Johns Hopkins University Press, Baltimore, Md. 
Nowak, R. M. 2003. Walker's Marine Mammals of the World. Johns Hopkins University Press, Baltimore, Md.

Omar, G., K. R. Johnson, L. J. Hickey, P. B. Robertson, M. R. Dawson, and C. W. Barnosky. 1987. Fission-Track dating of Haughton astrobleme and included biota, Devon Island, Canada. Science 237:1603-1605.

Orlov, J. A. 1933. Semantor macrurus (Ord. Pinnipedia, Fam. Semantoridae Fam. Nova) aus dem Neogen-Ablagerungen Westsiberiens. Trudy Paleont. Inst. Akad. Nauk SSSR 2:165-262.

Osinski, G. R., and P. Lee. 2005. Intra-crater sedimentary deposits at the Haughton impact structure, Devon Island, Canadian High Arctic. Meteoritics \& Planetary Science 40:1887-1899.

Osinski, G. R., P. Lee, J. G. Spray, J. Parnell, D. S. S. Lim, T. E. Bunch, C. S. Cockell, and B. Glass. 2005. Geological overview and cratering model for the Haughton impact structure, Devon Island, Canadian High Arctic. Meteoritics \& Planetary Science 40:1759-1776.

Pagel, M. D. 1992. A method for the analysis of comparative data. Journal of Theoretical Biology 156:431-442.

Purvis, A. 1995. A composite estimate of primate phylogeny. Philosophical Transactions: Biological Sciences 348:405-421.

Reidenerg, J. S. 2007. Anatomical adaptations of aquatic mammals. Anatomical RecordAdvances in Integrative Anatomy and Evolutionary Biology 290:507-513. 
Rybczynski, N., M. R. Dawson, and R. H. Tedford. 2009. A semi-aquatic Arctic mammalian carnivore from the Miocene epoch and origin of Pinnipedia. Nature 458:10211024.

Sato, J. J., M. Wolsan, H. Suzuki, T. Hosoda, Y. Yamaguchi, K. Hiyama, M. Kobayashi, and S. Minami. 2006. Evidence from nuclear DNA sequences sheds light on the phylogenetic relationships of Pinnipedia: Single origin with affinity to Musteloidea. Zoological Science 23:125-146.

Savage, M. "Lontra felina" (On-line). http://animaldiversity.ummz.umich.edu/site/accounts/information/Lontra felina .html. Retrieved September 17, 2010.

Savage, R. J. G. 1957. The anatomy of Potamotherium an Oligocene lutrine. Proceedings of the Zoological Society of London 129:151-244.

Sherlock, S. C., S. P. Kelley, J. Parnell, P. Green, P. Lee, G. R. Osinsk, and C. S. Cockell. 2005. Re-evaluating the age of the Haughton impact event. Meteoritics \& Planetary Science 40:1777-1787.

Silva, M., and J. A. Downing. 1995. CRC handbook of mammalian body masses. CRC Press Inc., Boca Raton, FL.

Stein, B. R. 1989. Bone-density and adaptation in semiaquatic mammals. Journal of Mammalogy 70:467-476.

Tarasoff, F. J., A. P. Whitt, Bisaillo.A, and J. Pierard. 1972. Locomotory patterns and external morphology of river otter, sea otter, and harp seal (Mammalia). 
Canadian Journal of Zoology 50:915-928.

Tedford, R. H. 1976. Relationship of pinnipeds to other carnivores (Mammalia).

Systematic Zoology 25:363-374.

Thewissen, J. G. M., and F. E. Fish. 1997. Locomotor evolution in the earliest cetaceans:

functional model, modern analogues, and paleontological evidence. Paleobiology 23:482-490.

Thewissen, J. G. M., and E. M. Williams. 2002. The early radiations of Cetacea

(Mammalia): Evolutionary pattern and developmental correlations. Annual

Review of Ecology and Systematics 33:73-90.

Thewissen, J. G. M., L. N. Cooper, M. T. Clementz, S. Bajpai, and B. N. Tiwari. 2007.

Whales originated from aquatic artiodactyls in the Eocene epoch of India. Nature 450:1190-1194.

Uhen, M. D. 2007. Evolution of marine mammals: Back to the sea after 300 million years. The Anatomical Record: Advances in Integrative Anatomy and Evolutionary Biology 290:514-522.

Van Valkenburgh, B. 1990. Skeletal and dental predictors of body mass in carnivores; pp. 181-206 in J. Damuth and B. J. MacFadden (eds.), Body Size in Mammalian Paleobiology: Estimations and Biological Implications. Cambridge University Press, New York, NY.

Wall, W. P. 1983. The correlation between high limb-bone density and aquatic habits in recent mammals. Journal of Paleontology 57:197-207. 
Wang, X., M. C. McKenna, and D. Dashzeveg. 2005. Amphicticeps and Amphicynodon

(Arctoidea, Carnivora) from Hsanda Gol Formation, central Mongolia and phylogeny of basal arctoids with comments on zoogeography. American Museum Novitates:1-60.

Whitlock, C., and M. R. Dawson. 1990. Pollen and vertebrates of the Early Neogene Haughton Formation, Devon Island, Arctic Canada. Arctic 43:324-330.

Wolsan, M. 1993. Phylogeny and classification of early European Mustelidae (Mammalia, Carnivora). Acta Theriologica 38:345-384.

Wyss, A. R., and J. J. Flynn. 1993. A phylogenetic analysis and definition of the Carnivora; pp. 32-52 in F. S. Szalay, M. J. Novacek, and M. C. McKenna (eds.), Mammal Phylogeny: Placentals. Springer-Verlag, New York, NY. 
APPENDIX 1

SUMMARY OF IMPORTANT RECONSTRUCTED MUSCULATURE, THEIR VISIBLE POINTS OF

ORIGIN AND INSERTION AND THEIR PROPOSED FUNCTION,

IN THE FORELIMB OF PUIJILA DARWINI 


\begin{tabular}{|c|c|c|c|c|c|}
\hline 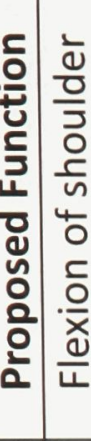 & 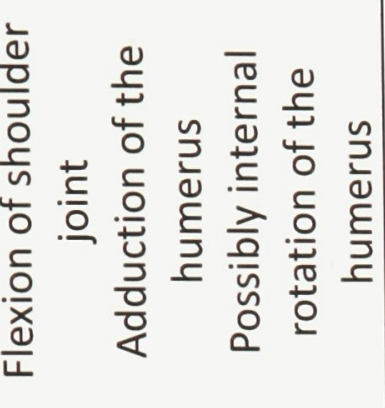 & 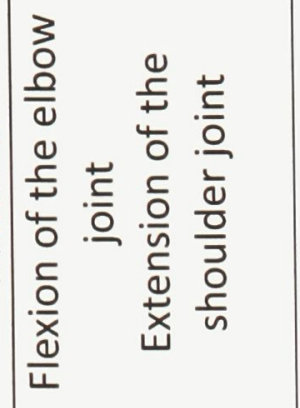 & \multicolumn{3}{|c|}{ 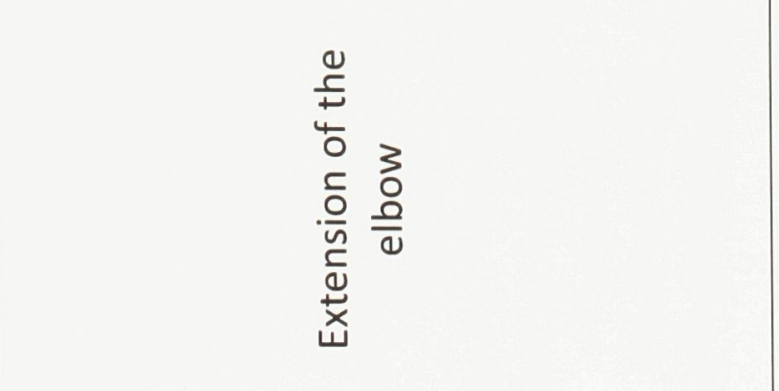 } \\
\hline 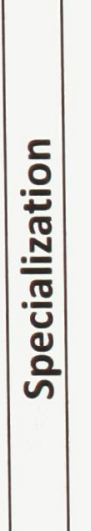 & 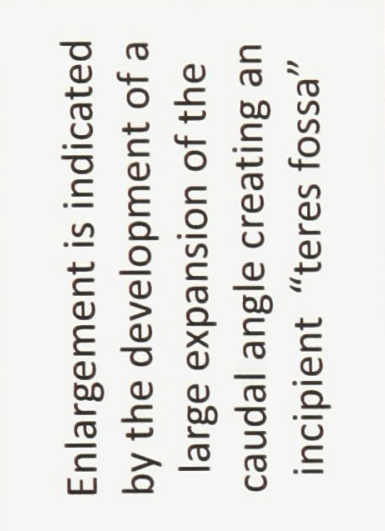 & 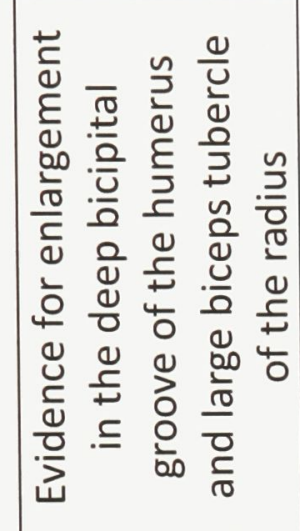 & & 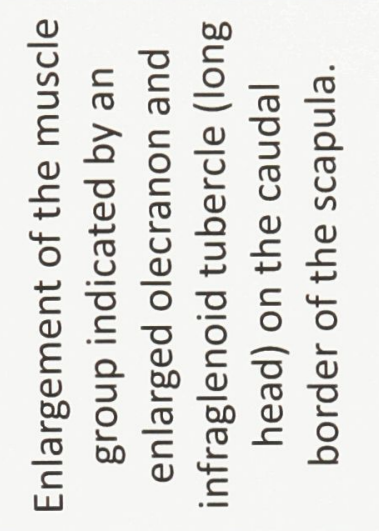 & \\
\hline & 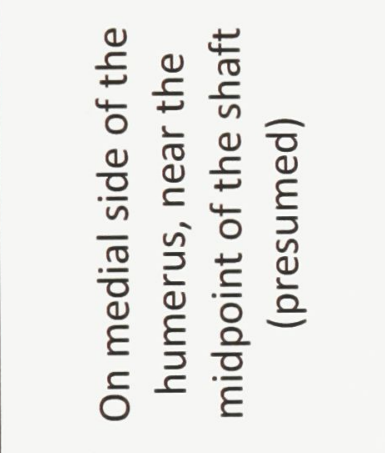 & 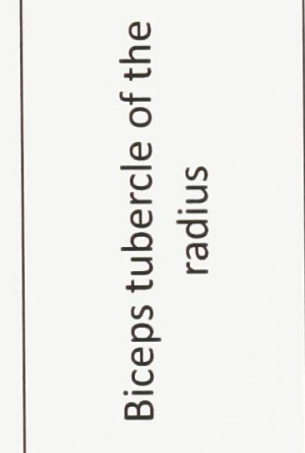 & & 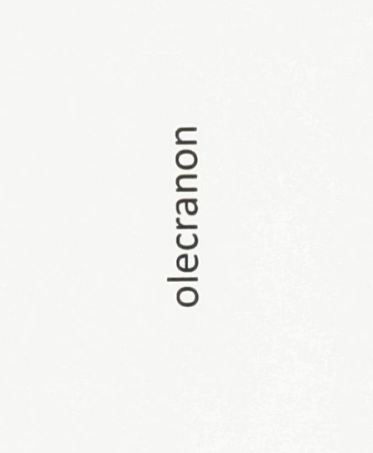 & \\
\hline 獣 & 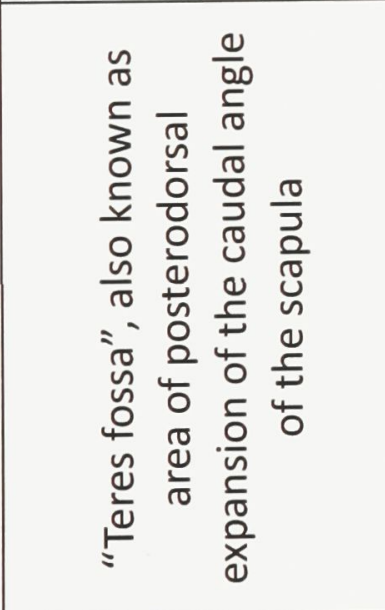 & 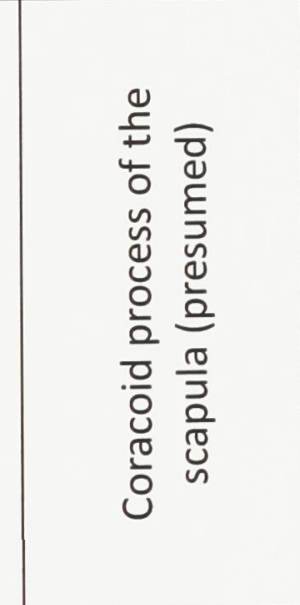 & 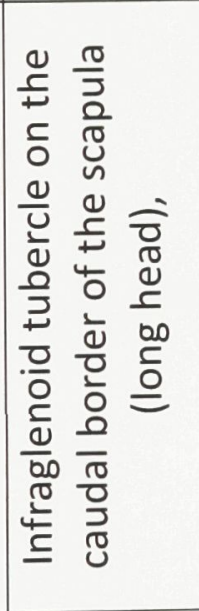 & 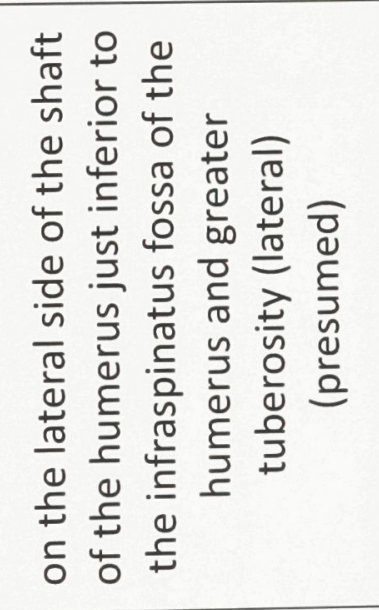 & 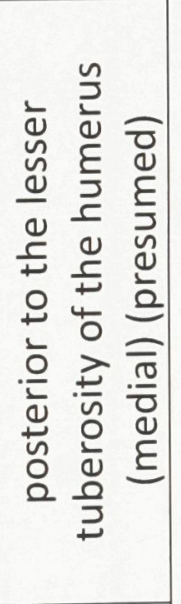 \\
\hline 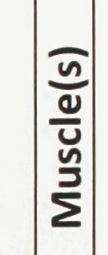 & 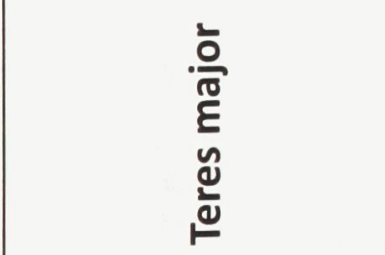 & $\frac{\text { ŏ }}{\stackrel{0}{\circ}}$ & & 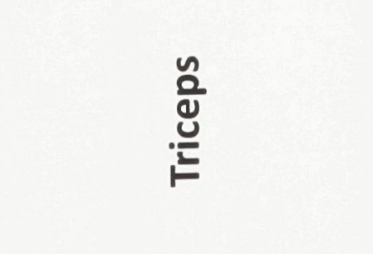 & \\
\hline
\end{tabular}




\begin{tabular}{|c|c|c|c|c|c|}
\hline 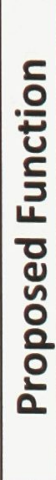 & $\begin{array}{l}3 \\
0 \\
0 \\
0 \\
0 \\
\frac{0}{ \pm} \\
\frac{0}{0} \\
\frac{0}{0}\end{array}$ & 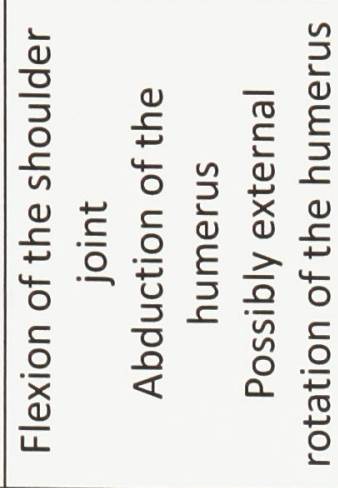 & 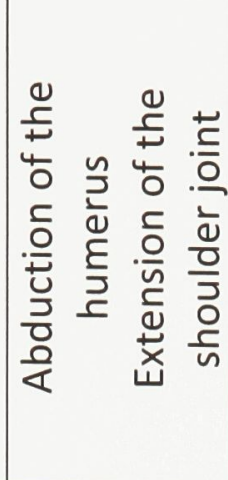 & 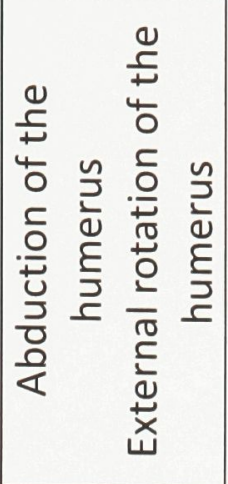 & 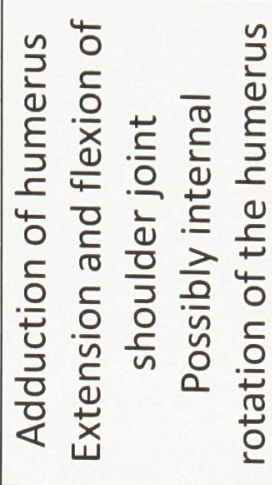 \\
\hline 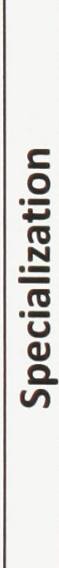 & 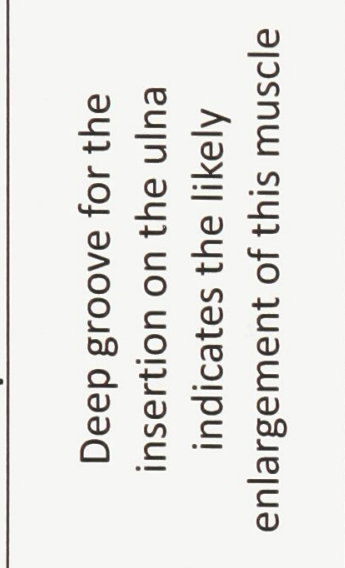 & 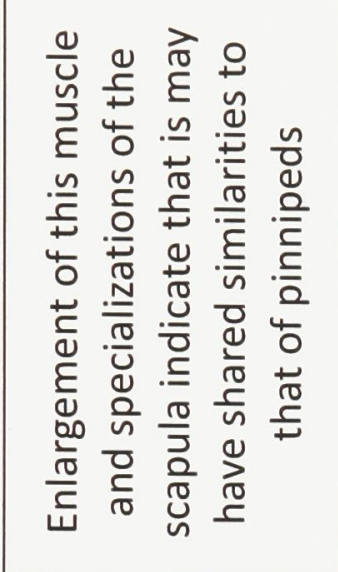 & 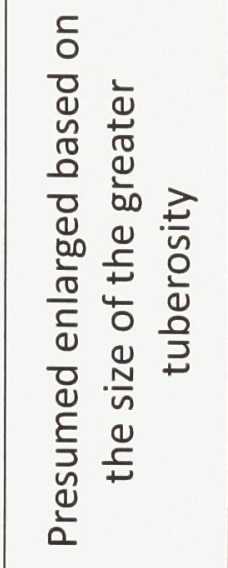 & 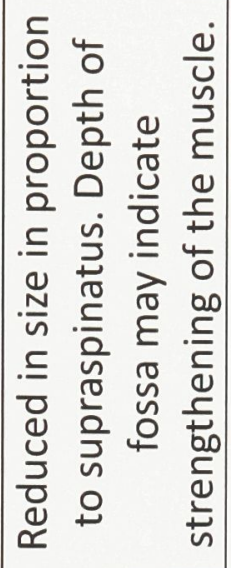 & 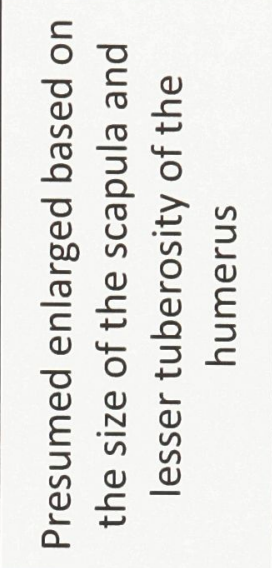 \\
\hline 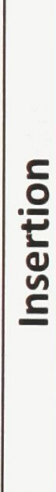 & 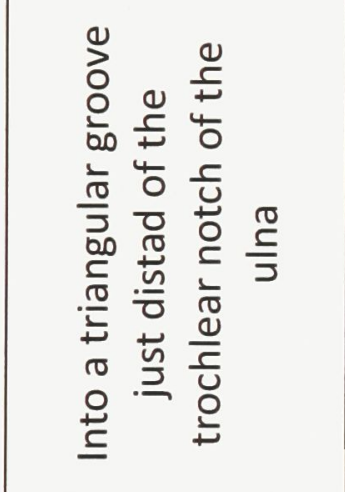 & 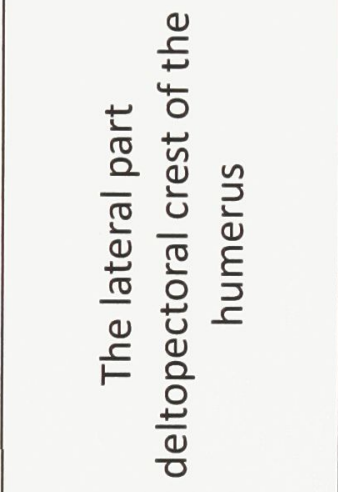 & 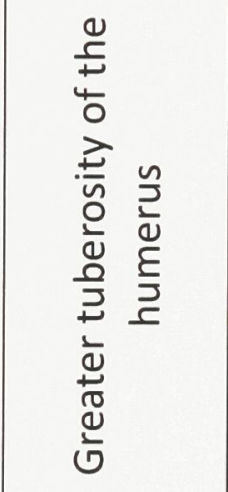 & 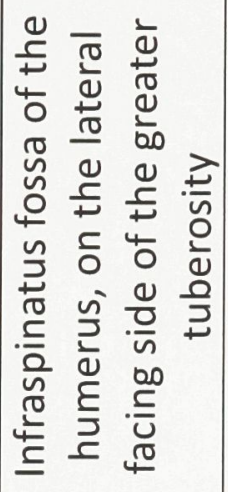 & 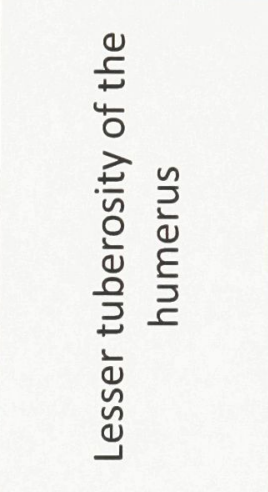 \\
\hline ס & 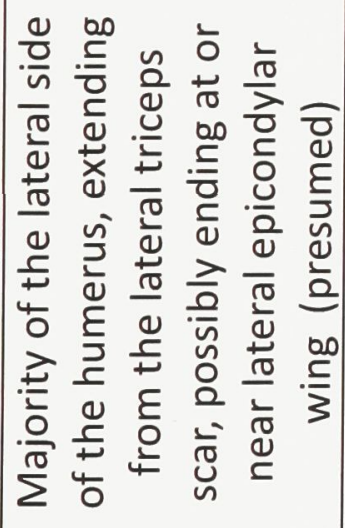 & 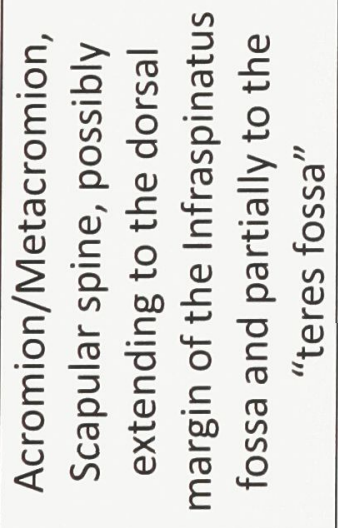 & 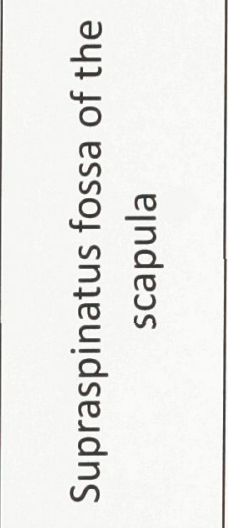 & 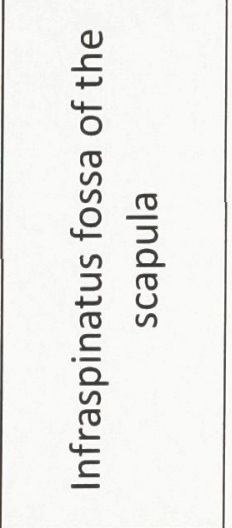 & 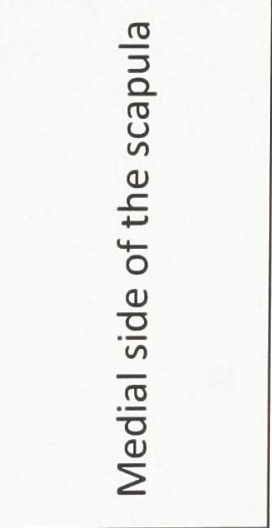 \\
\hline $\begin{array}{l}\frac{\bar{\sigma}}{0} \\
\frac{\mathrm{U}}{\mathrm{N}} \\
\frac{\mathrm{n}}{\Sigma}\end{array}$ & 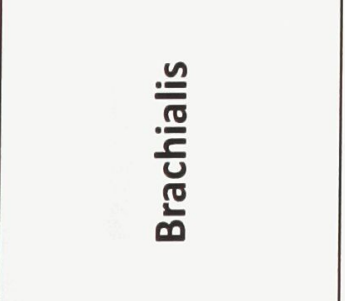 & $\frac{.00}{0}$ & $\begin{array}{l}\frac{n}{7} \\
\frac{\pi}{\pi} \\
\frac{.0}{2} \\
\frac{2}{0} \\
\frac{\pi}{2} \\
\frac{0}{3}\end{array}$ & 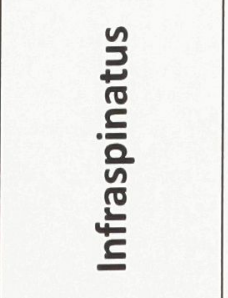 & 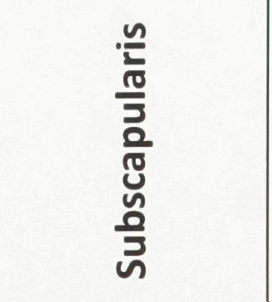 \\
\hline
\end{tabular}




\begin{tabular}{|c|c|c|c|}
\hline 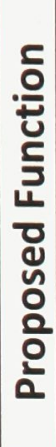 & 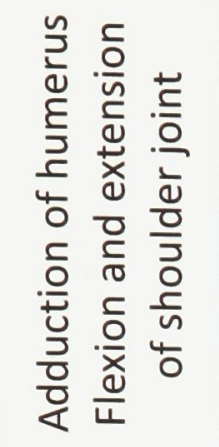 & 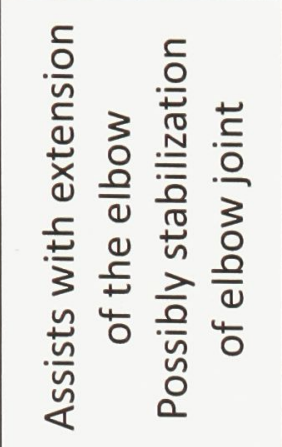 & 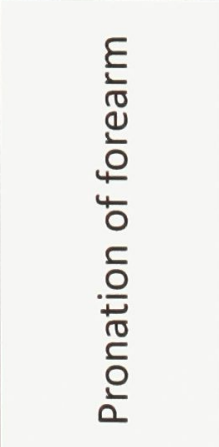 \\
\hline & 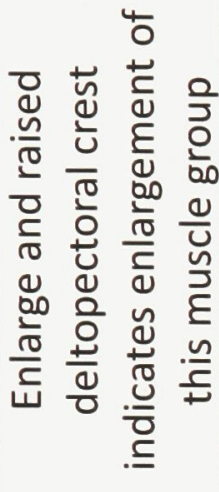 & 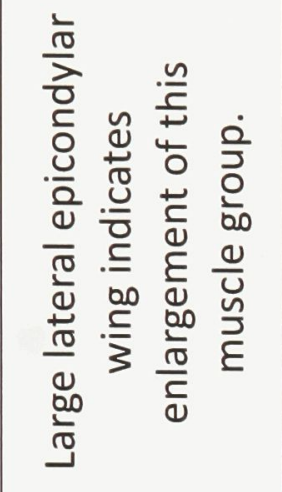 & \\
\hline $\begin{array}{l}\frac{5}{0} \\
\frac{t}{0} \\
\underline{y} \\
\underline{\underline{n}}\end{array}$ & 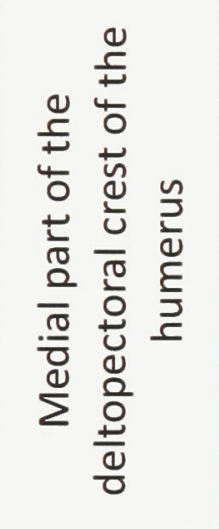 & 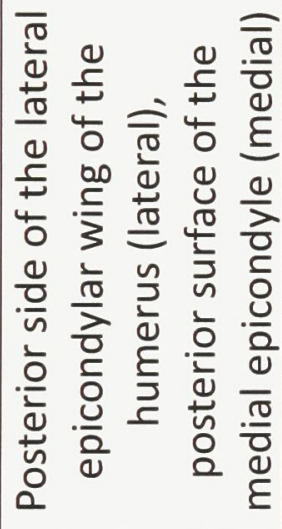 & 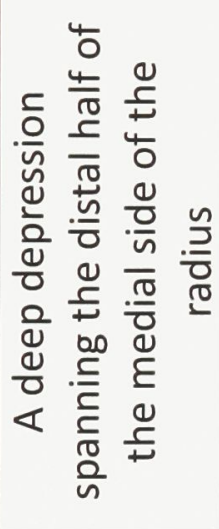 \\
\hline 次 & 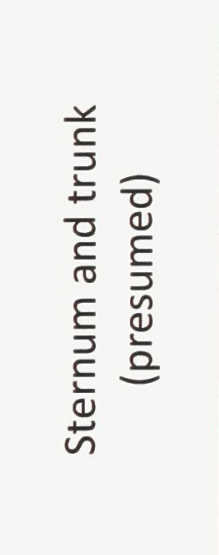 & 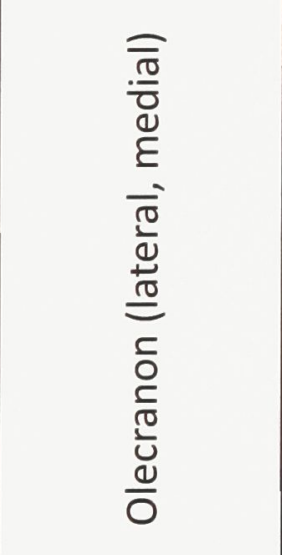 & 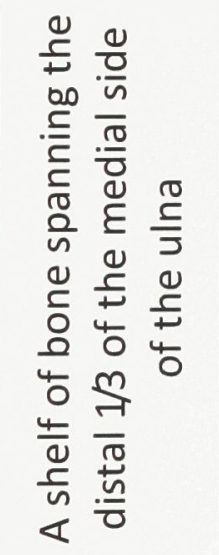 \\
\hline $\begin{array}{l}\frac{\tilde{n}}{0} \\
\frac{0}{u} \\
\bar{y} \\
\Sigma\end{array}$ & 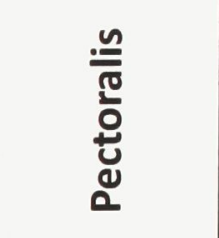 & 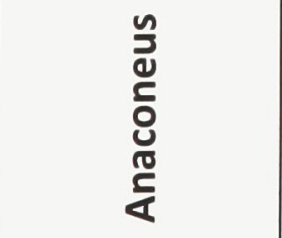 & 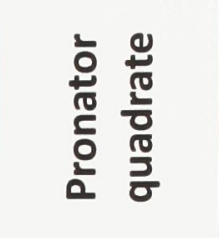 \\
\hline
\end{tabular}




\section{APPENDIX 2}

LIST OF POTAMOTHERIUM MATERIAL AT THE CANADIAN MUSEUM OF NATURE,

OTTAWA, CANADA

\begin{tabular}{|c|c|c|}
\hline Element & Specimen Number & Notes \\
\hline Humerus & CMNFV-54090 & left, complete \\
\hline Ulna & CMNFV- 54091 & Right, complete, weathered \\
\hline Ulna & CMNFV - 54092 & $\begin{array}{c}\text { Right, partial, lacks distal } 1 / 4 \\
\text { of shaft }\end{array}$ \\
\hline Radius & CMNFV - 54093 & Left, complete \\
\hline Radius & CMNFV - 54094 & Right, complete \\
\hline Femur & CMNFV - 54095 & Left, complete \\
\hline Tibia & CMNFV - 54096 & Right, complete \\
\hline Partial Pelvis & CMNFV - 54097 & $\begin{array}{l}\text { Left illium and } 1 / 2 \\
\text { acetabulum }\end{array}$ \\
\hline Partial Pelvis & CMNFV - 54098 & $\begin{array}{l}\text { Left acetabulum and partial } \\
\text { ischium }\end{array}$ \\
\hline Calcaneum & CMNFV - 54099 & Right, complete \\
\hline Proximal Phalanx & CMNFV - 54100 & Unknown, compete \\
\hline Proximal Phalanx & CMNFV - 54101 & Unknown, compete \\
\hline Proximal Phalanx & CMNFV - 54102 & Unknown, compete \\
\hline Proximal Phalanx & CMNFV - 54103 & Unknown, compete \\
\hline Intermediate Phalanx & CMNFV -54104 & Unknown, compete \\
\hline
\end{tabular}




\section{APPENDIX 3}

LIST OF SPECIES, WITH SPECIMEN NUMBERS, CT SCANNED AND X-RAY IMAGED AT THE SMITHSONIAN NATIONAL MUSEUM OF NATURAL HISTORY 


\begin{tabular}{|c|c|c|c|}
\hline USNM \# & Species name & Common Name & Gender \\
\hline 259027 & Ailuropoda melanoleuca & Giant Panda & male \\
\hline 305771 & Ailurus fulgens & Red panda & male \\
\hline 155324 & Aonyx cinereus & Oriental small-clawed otter & male \\
\hline A23331 & Arctocephalus australis & South American Fur Seal & male \\
\hline 396921 & Arctocephalus forsteri & New Zealand Fur & male \\
\hline 258588 & Callorhinus ursinus & Northern Fur Seal & male \\
\hline 550317 & Cystophora cristata & Hooded Seal & male \\
\hline A21336 & Enhydra lutris & Sea otter & male \\
\hline 500251 & Erignathus barbatus & Bearded Seal & male \\
\hline A7141 & Eumetopias jubatus & Northern Sea Lion & male \\
\hline 272316 & Gulo gulo & Wolverine & male \\
\hline 446405 & Halichoerus grypus & Grey Seal & male \\
\hline 550358 & Hydrurga leptonyx & Leopard Seal & male \\
\hline 504875 & Leptonychotes weddellii & Weddell Seal & Unknown \\
\hline 256976 & Lontra canadensis & River otter & male \\
\hline 512791 & Lontra felina & Marine otter & female \\
\hline 255133 & Lontra longicaudis & Neotropical otter & male \\
\hline 505316 & Martes americana & American marten & male \\
\hline 173316 & Martes flavigula & Yellow-throated marten & male \\
\hline 319224 & Martes foina & Beech marten & male \\
\hline 188221 & Martes pennanti & Fisher & male \\
\hline 296107 & Mellivora capensis & Honey Badger & male \\
\hline 564278 & Mephitis mephitis & Striped skunk & male \\
\hline 219058 & Mirounga angustirostris & Northern Elephant Seal & male \\
\hline 219059 & Monachus monachus & Mediterranean Monk Seal & Unknown \\
\hline 546171 & Mustela ermina & Ermine & male \\
\hline A35088 & Mustela frenata & Long-tailed weasel & male \\
\hline 233978 & Mustela nivalis & Least weasel & male \\
\hline 257966 & Mustela putorius & European polecat & male \\
\hline 239584 & Mustela sibirica & Siberian weasel & male \\
\hline 134019 & Mustela vision & American mink & male \\
\hline 504729 & Neophoca cinerea & Australian Sea Lion & male \\
\hline A07139 & Odobenus rosmarus & Walrus & male \\
\hline 484912 & Otaria flavescens & South American Sealion & male \\
\hline 504298 & Phoca vitulina & Harbor Seal & male \\
\hline 396274 & Procyon lotor & Raccoon & male \\
\hline 304663 & Pteronura brasiliensis & Giant Otter & male \\
\hline 564281 & Spilogale putorius & Western spotted skunk & male \\
\hline 264140 & Taxidea taxus & American badger & male \\
\hline 303193 & Ursus americanus & Black Bear & male \\
\hline 265076 & Ursus arctos & Brown Bear & male \\
\hline 260231 & Ursus martimus & Polar Bear & male \\
\hline 200847 & Zalophus californianus & California Sea Lion & male \\
\hline
\end{tabular}


APPENDIX 4

RAW DATA FROM ALL LONG BONES COLLECTED FROM CT SCANS, USING BONE PROFILER V.4.11.11 (FOR WINDOWS), AND FROM X-RAY IMAGES 
里 순 $=$ ¿ 定

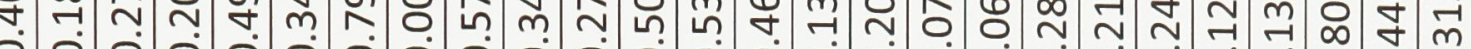
$\begin{array}{lllllllllllllllllllllllllllllllll}0 & 0 & 0 & 0 & 0 & 0 & 0 & 0 & 0 & 0 & 0 & 0 & 0 & 0 & 0 & 0 & 0 & 0 & 0 & 0 & 0 & 0 & 0 & 0 & 0 & 0\end{array}$

ஸิ ฯ ป

๔ 光 $m$ m

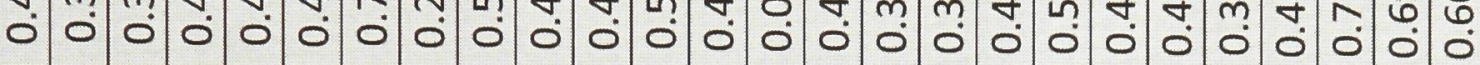

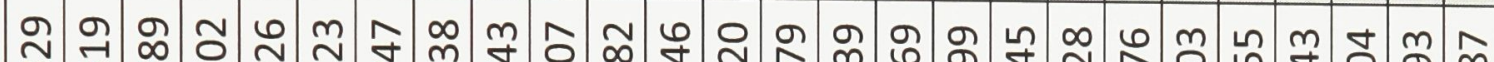

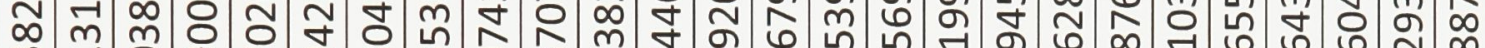
^

守

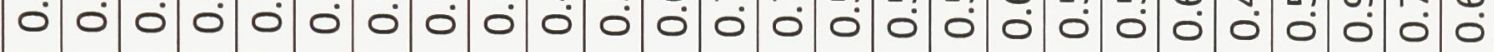

m 유 궁유 ๙

口

นn $m$ m

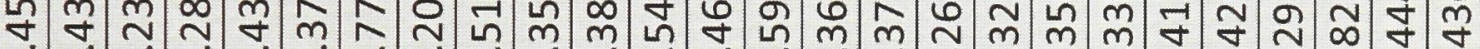
$\begin{array}{llllllllllllllllllllllllllll}0 & 0 & 0 & 0 & 0 & 0 & 0 & 0 & 0 & 0 & 0 & 0 & 0 & 0 & 0 & 0 & 0 & 0 & 0 & 0 & 0 & 0 & 0 & 0 & 0 & 0\end{array}$

인

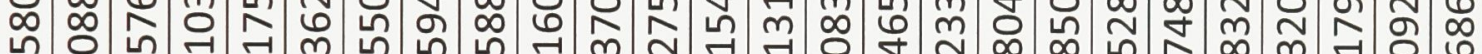

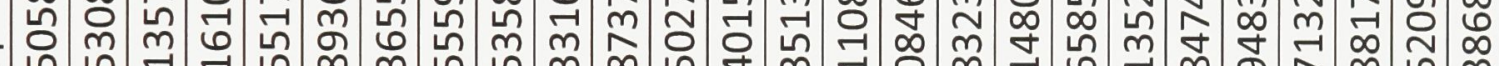

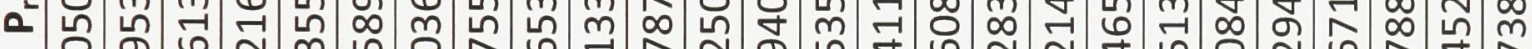
율

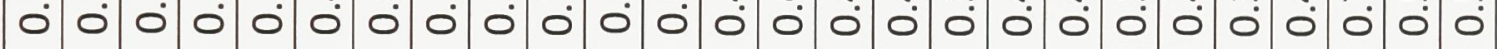

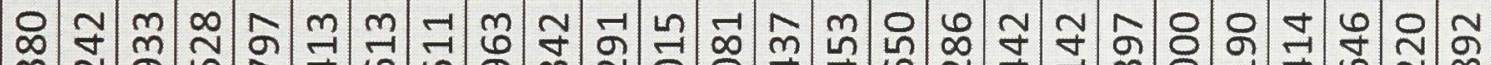
^

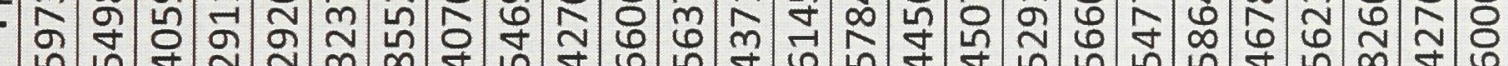
นก น

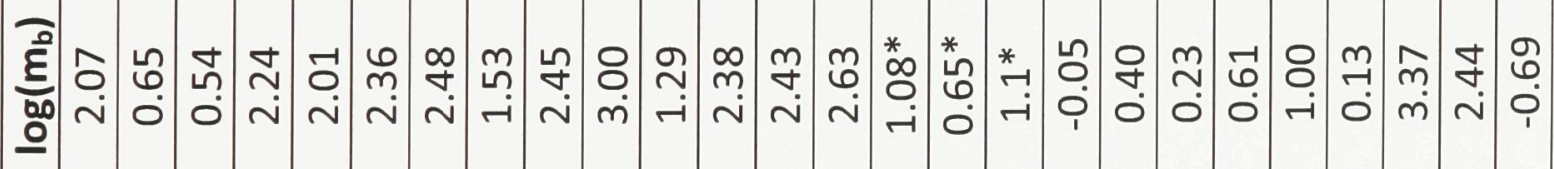

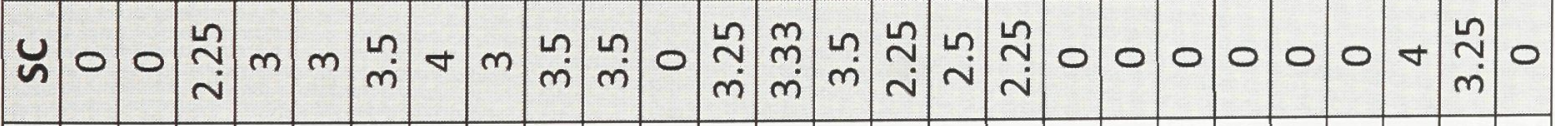

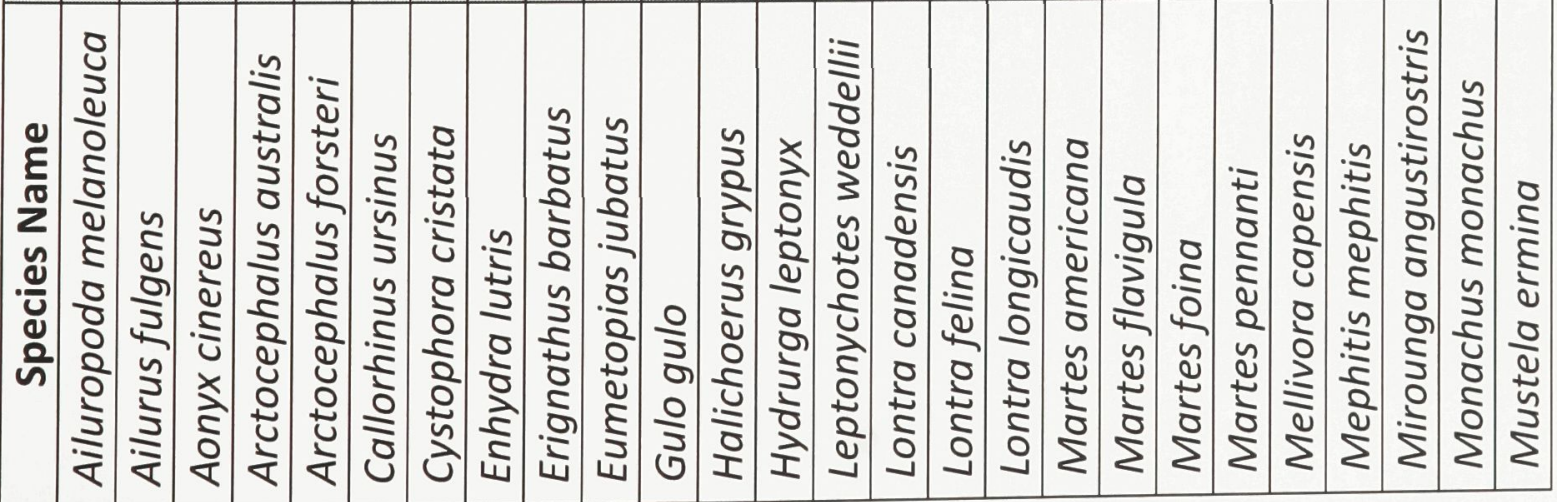


m =

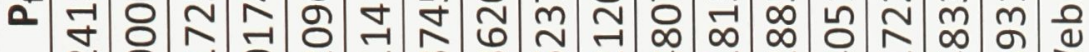
సิ

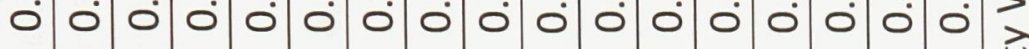

ผูก ชิ

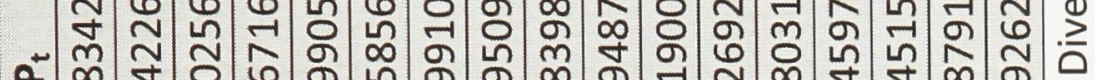
๑ 守

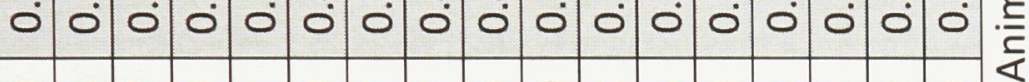

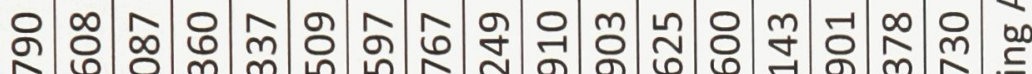
m. ๑

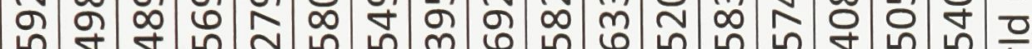
ஸุ.

m

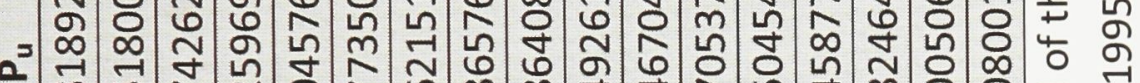

霍

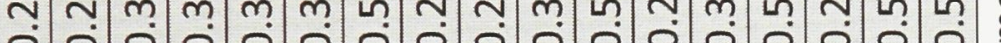

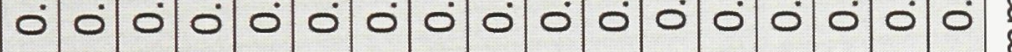

న 오ำ 虽

ఎ

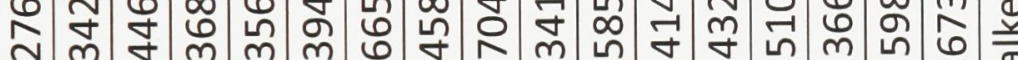

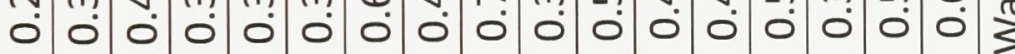

ำ స్-

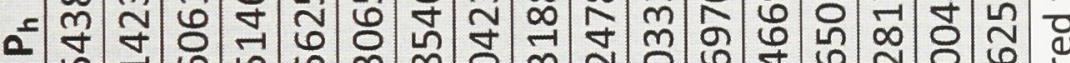

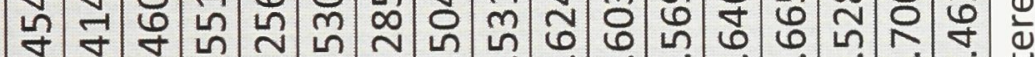

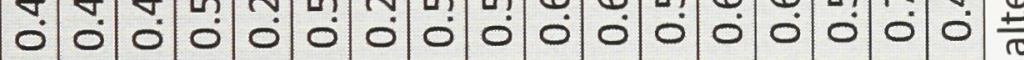

हี

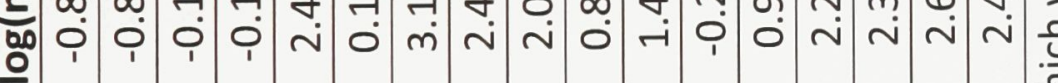
으

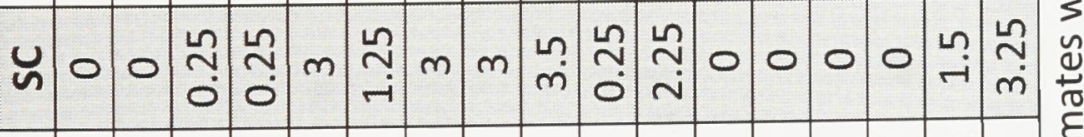

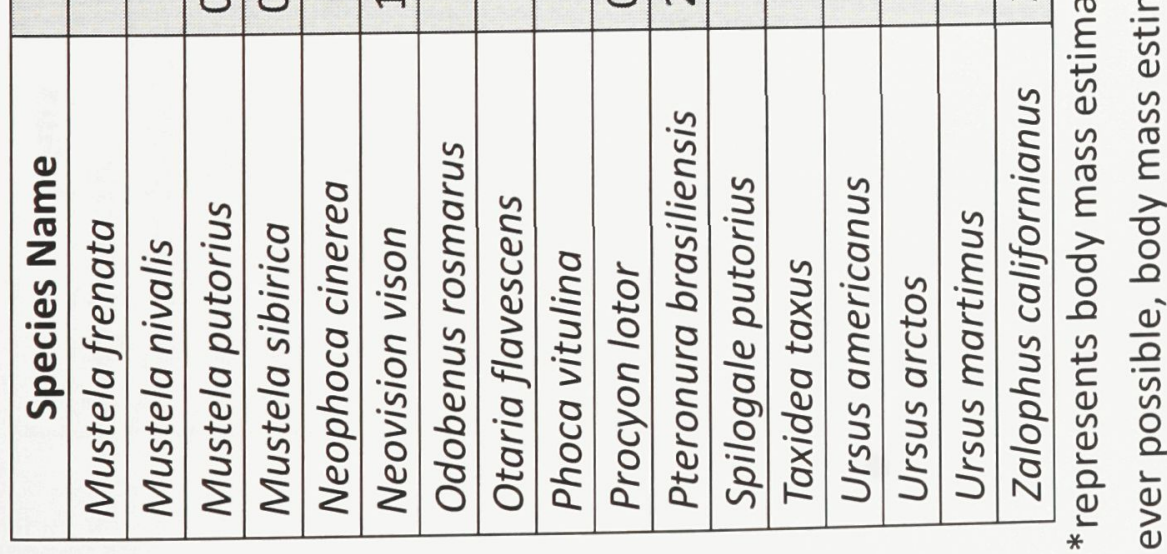

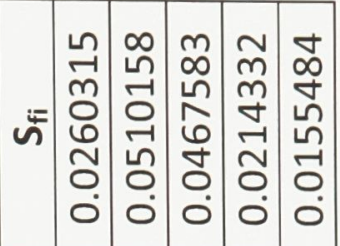

g $m m$ $\infty m \infty$ ஸे กิ ○் น ᄂ 잉 ทัก ก न ம 구 $\infty$ 에 m $\forall$ $m$ \& $m$ m $\begin{array}{lllll}0 & 0 & 0 & 0 & 0 \\ 0 & 0 & 0 & 0 & 0\end{array}$ $+\infty$ 시 $\infty$ $\infty$ ๒

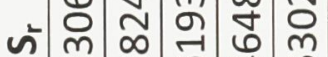
กิ ம $\dot{0} 0 \dot{0} \dot{0}$

む $\infty$ v รี ㄷํㅇ in 少 - 10.0010 .0

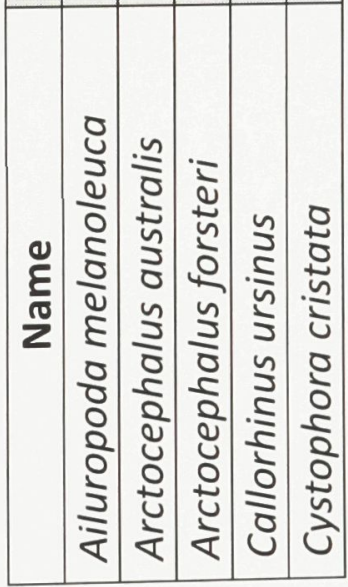




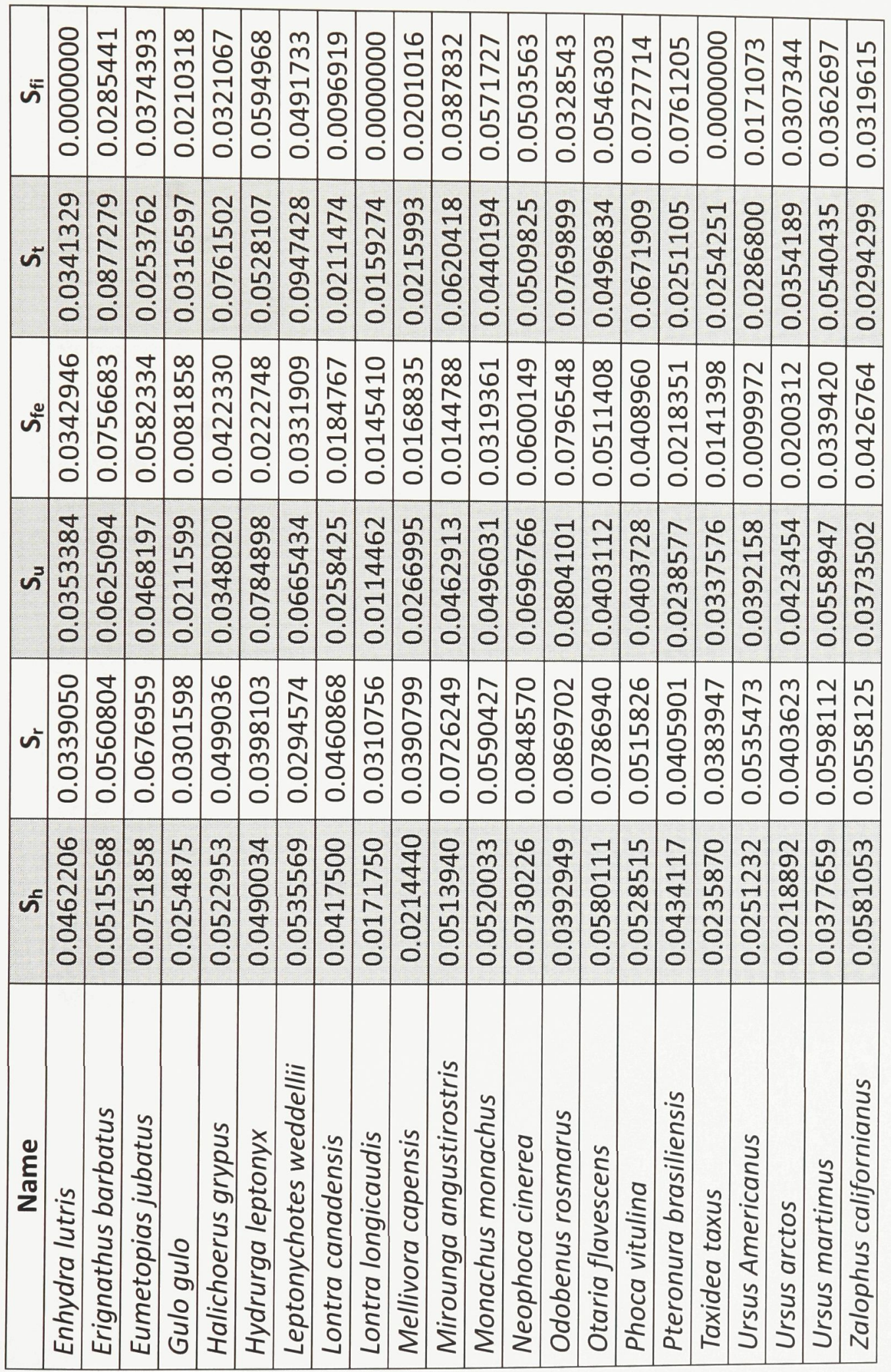




\begin{tabular}{|l|c|c|c|c|c|c|}
\hline \multicolumn{1}{|c|}{ Name } & $\mathbf{C}_{\mathrm{h}}$ & $\mathbf{C}_{\mathrm{r}}$ & $\mathrm{C}_{\mathrm{u}}$ & $\mathrm{C}_{\mathrm{fe}}$ & $\mathrm{C}_{\mathrm{t}}$ & $\mathbf{C}_{\mathrm{fi}}$ \\
\hline Ailuropoda melanoleuca & 0.638 & 0.737 & 0.789 & 0.749 & 0.791 & 0.834 \\
\hline Gulo gulo & 0.562 & 0.766 & 0.851 & 0.696 & 0.781 & 0.926 \\
\hline Mellivora capensis & 0.779 & 0.886 & 0.812 & 0.772 & 0.856 & 0.984 \\
\hline Taxidea taxus & 0.571 & 0.804 & 0.872 & 0.656 & 0.685 & 1.000 \\
\hline Ursus americanus & 0.547 & 0.727 & 0.690 & 0.661 & 0.662 & 0.832 \\
\hline Ursus arctos & 0.716 & 0.860 & 0.913 & 0.827 & 0.876 & 0.967 \\
\hline Ursus martimus & 0.501 & 0.622 & 0.736 & 0.736 & 0.686 & 0.760 \\
\hline Lontra canadensis & 0.655 & 0.794 & 0.862 & 0.653 & 0.820 & 0.966 \\
\hline Lontra longicaudis & 0.794 & 0.887 & 0.929 & 0.680 & 0.906 & 1.000 \\
\hline Pteronura brasiliensis & 0.626 & 0.651 & 0.695 & 0.591 & 0.670 & 0.749 \\
\hline Arctocephalus australis & 0.899 & 0.713 & 0.944 & 0.805 & 0.829 & 0.947 \\
\hline Arctocephalus forsteri & 0.904 & 0.931 & 0.823 & 0.749 & 0.743 & 0.755 \\
\hline Enhydra lutris & 0.825 & 0.966 & 0.955 & 0.649 & 0.939 & 1.000 \\
\hline Neophoca cinerea & 0.914 & 0.854 & 0.903 & 0.909 & 0.911 & 0.948 \\
\hline Odobenus rosmarus & 0.937 & 0.627 & 0.712 & 0.697 & 0.914 & 0.895 \\
\hline Otaria flavescens & 0.763 & 0.784 & 0.944 & 0.827 & 0.776 & 0.892 \\
\hline Halichoerus grypus & 0.704 & 0.599 & 0.709 & 0.565 & 0.654 & 0.776 \\
\hline Monachus monachus & 0.812 & 0.663 & 0.792 & 0.455 & 0.512 & 0.812 \\
\hline Zalophus californianus & 0.801 & 0.533 & 0.740 & 0.696 & 0.740 & 0.843 \\
\hline Hydrurga leptonyx & 0.799 & 0.750 & 0.768 & 0.424 & 0.779 & 0.698 \\
\hline Callorhinus ursinus & 0.888 & 0.789 & 0.854 & 0.929 & 0.751 & 0.882 \\
\hline Erignathus barbatus & 0.697 & 0.676 & 0.722 & 0.603 & 0.720 & 0.753 \\
\hline Eumetopias jubatus & 0.795 & 0.475 & 0.880 & 0.821 & 0.789 & 0.873 \\
\hline Leptonychotes weddellii & 0.655 & 0.534 & 0.630 & 0.460 & 0.749 & 0.771 \\
\hline Phoca vitulina & 0.743 & 0.495 & 0.944 & 0.514 & 0.833 & 0.708 \\
\hline Cystophora cristata & 0.322 & 0.354 & 0.401 & 0.187 & 0.469 & 0.376 \\
\hline Mirounga angustirostris & 0.325 & 0.381 & 0.316 & 0.116 & 0.372 & 0.349 \\
\hline
\end{tabular}




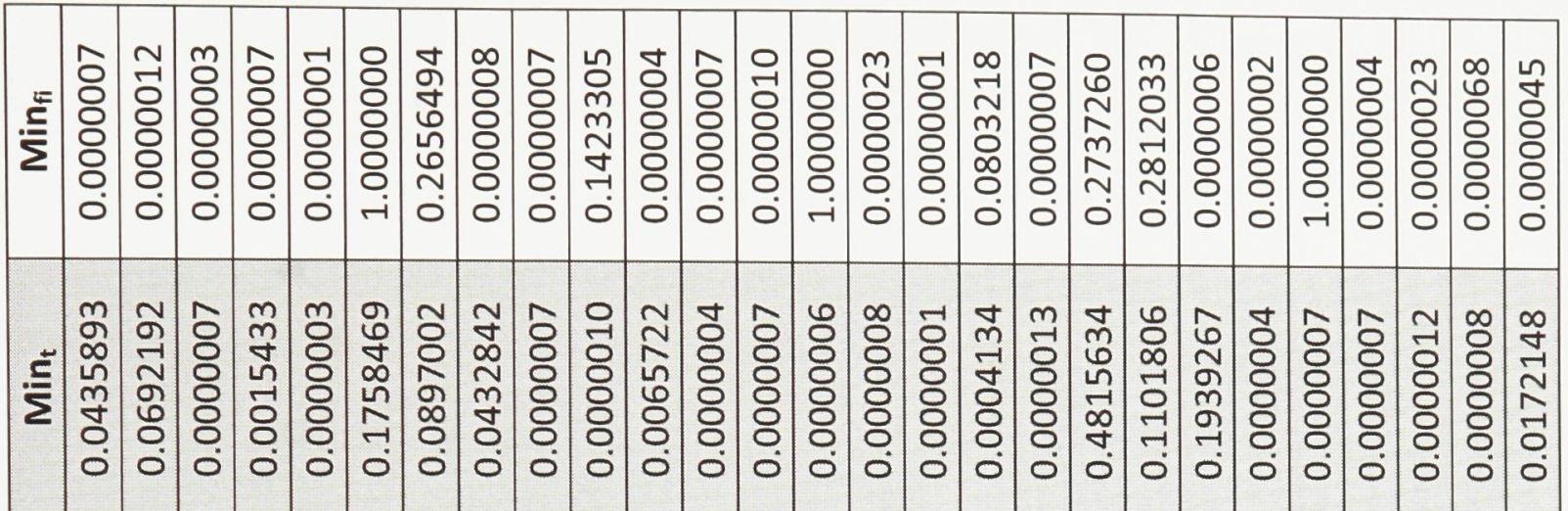

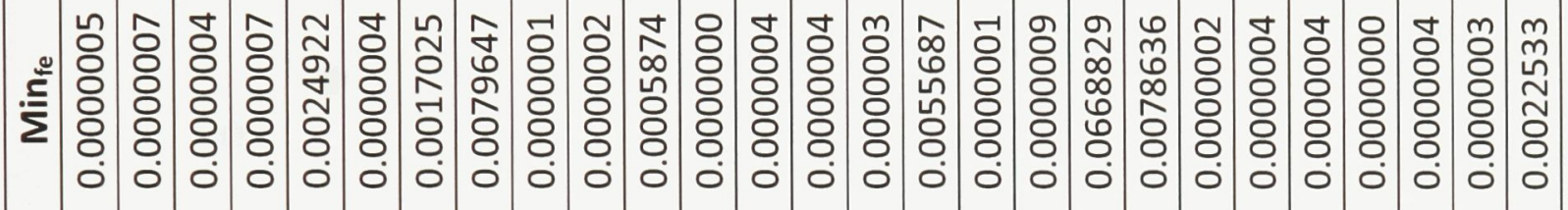

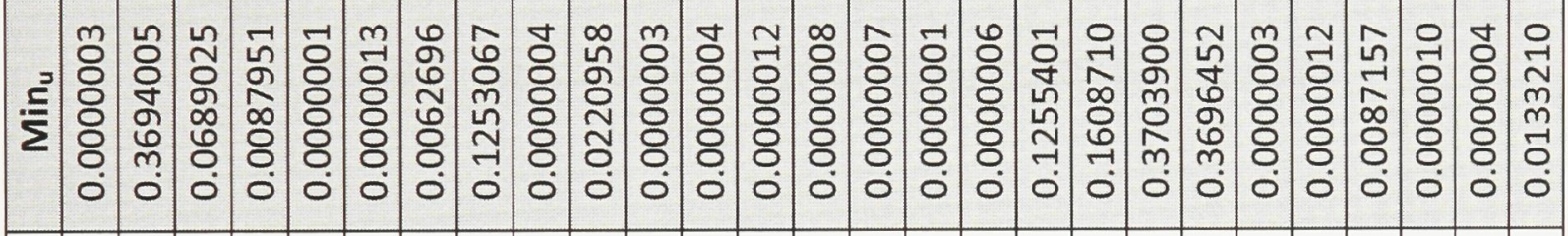

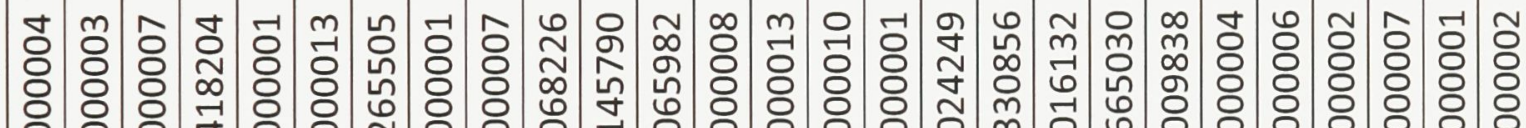

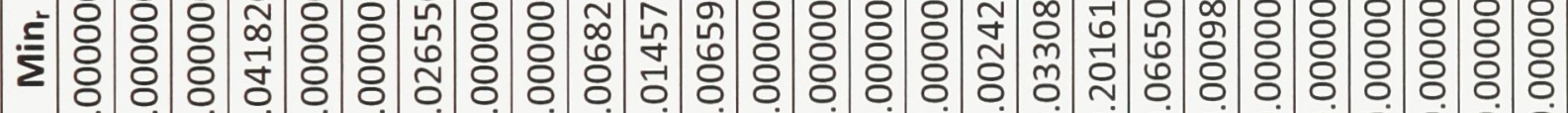

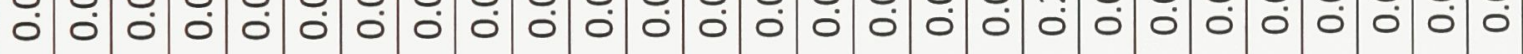

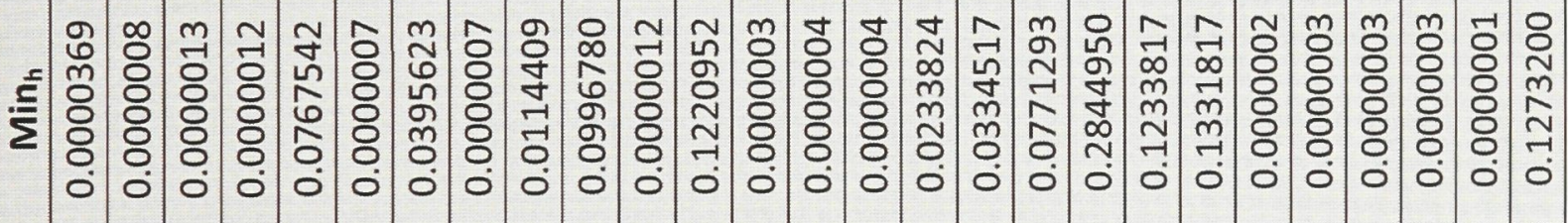

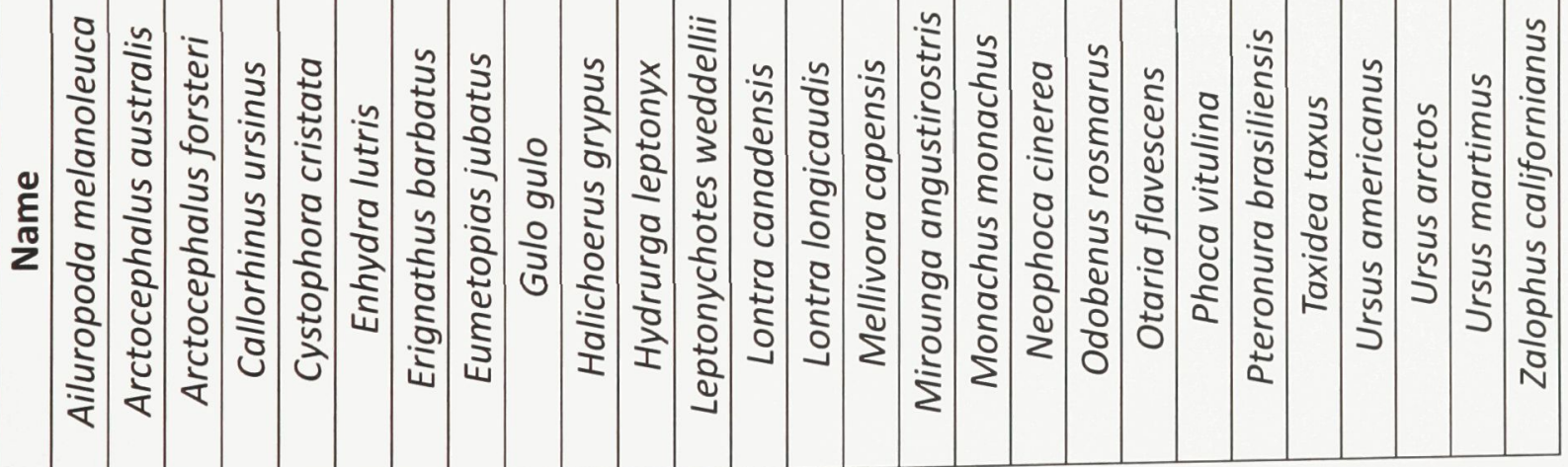


APPENDIX 5

RUBRIC USED FOR CALCULATING SWIMMING CATEGORY 


\begin{tabular}{|c|c|c|c|c|}
\hline$\nabla$ & 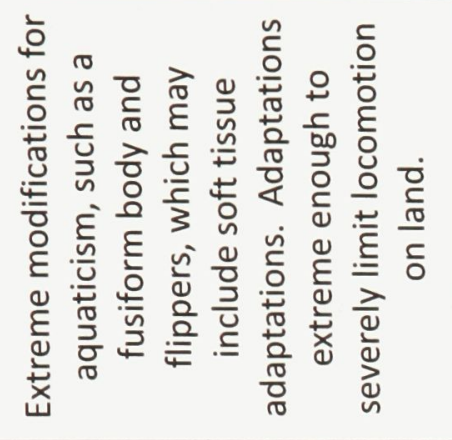 & 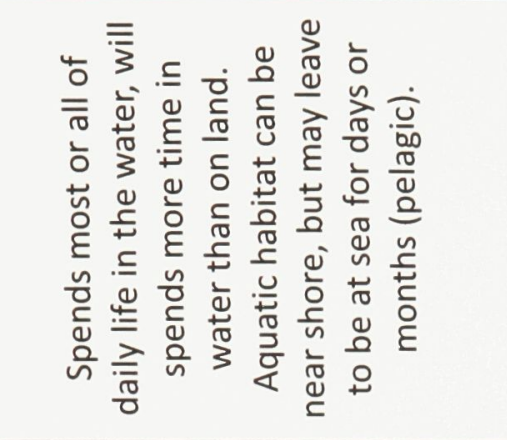 & 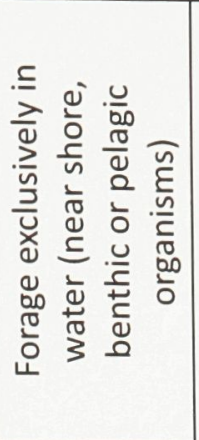 & 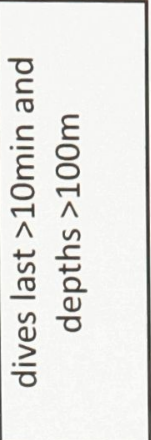 \\
\hline$m$ & 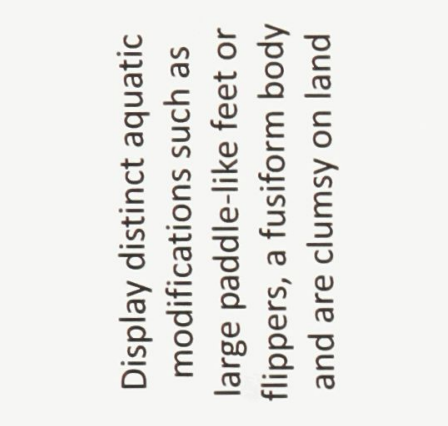 & 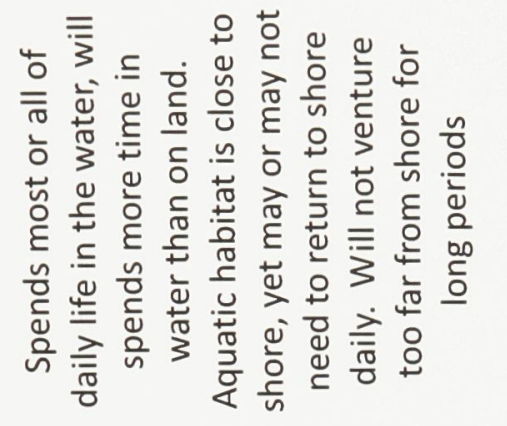 & 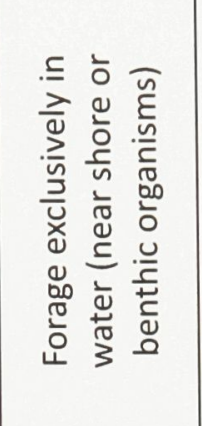 & 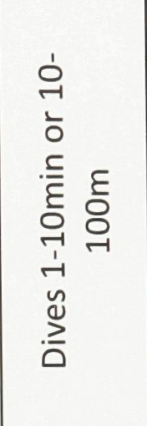 \\
\hline$\sim$ & 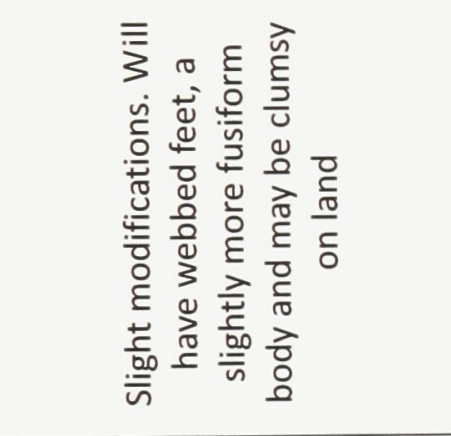 & 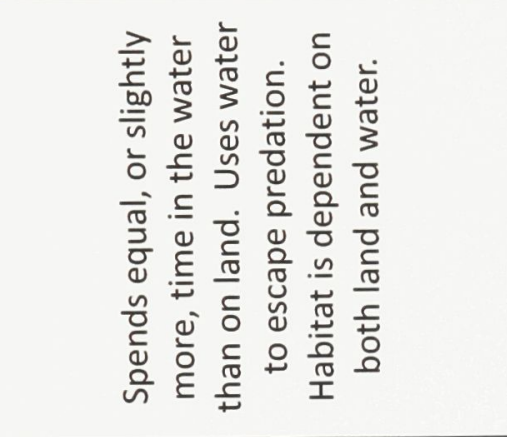 & 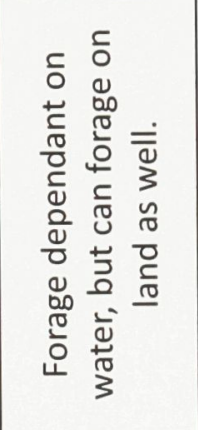 & 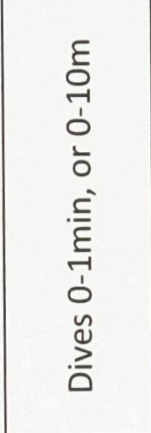 \\
\hline-1 & 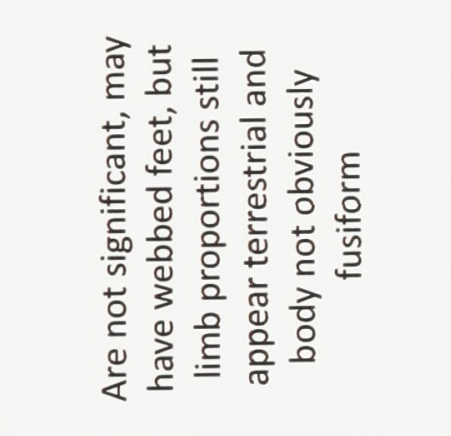 & 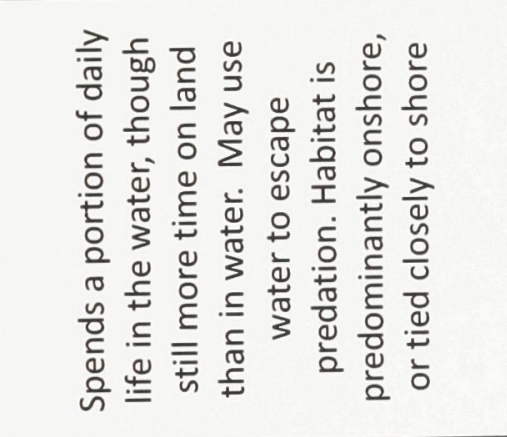 & 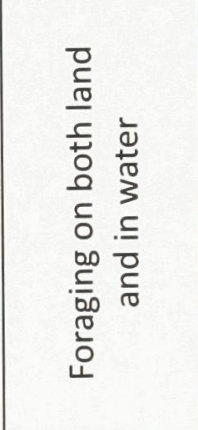 & 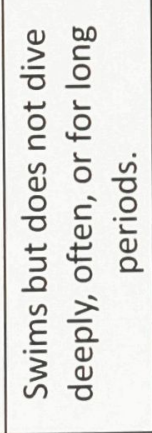 \\
\hline 0 & 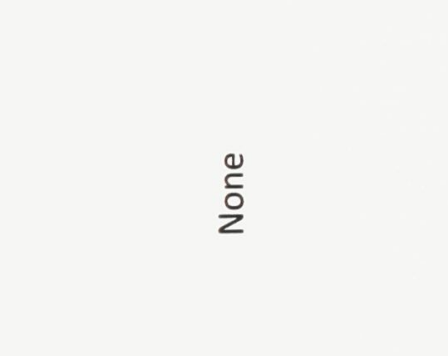 & $\begin{array}{l}0 \\
\text { Oे } \\
z\end{array}$ & 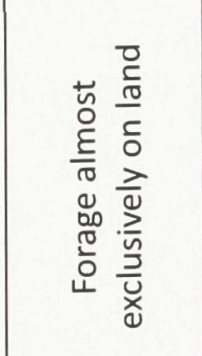 & 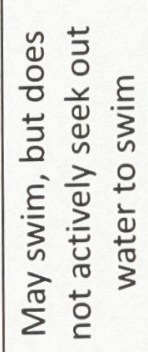 \\
\hline & 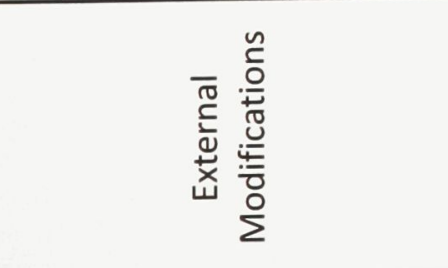 & $\begin{array}{l}\frac{\pi}{\pi} \\
\frac{0}{0} \\
\frac{\pi}{10}\end{array}$ & $\begin{array}{l}\searrow \\
\stackrel{y}{0} \\
0 \\
0 \\
0 \\
0 \\
0\end{array}$ & 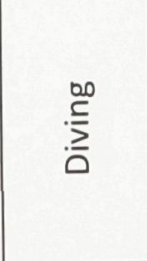 \\
\hline
\end{tabular}


APPENDIX 6

VARIABLE NAMES AND DEFINITIONS 


\begin{tabular}{|c|c|c|c|c|c|c|c|c|c|}
\hline & 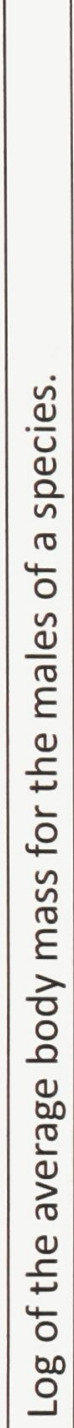 & 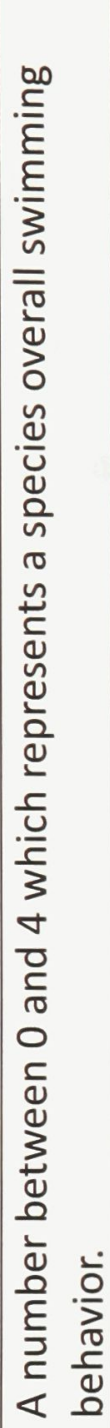 & 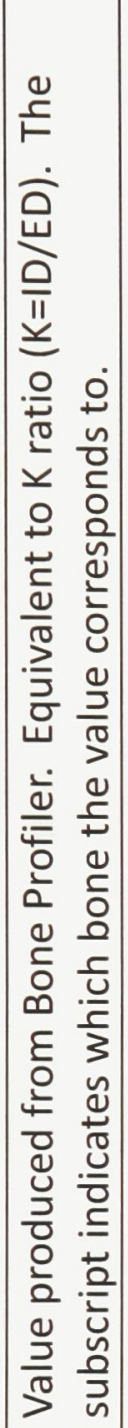 & 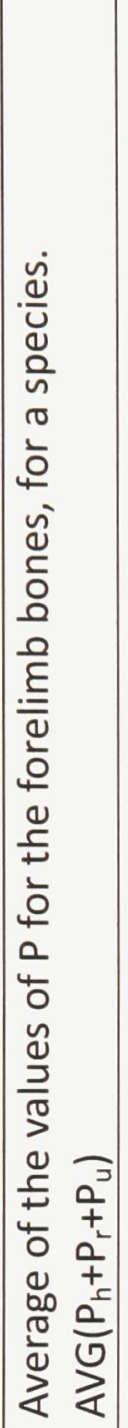 & 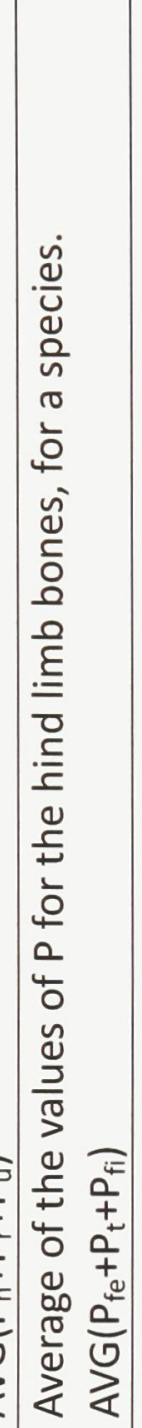 & 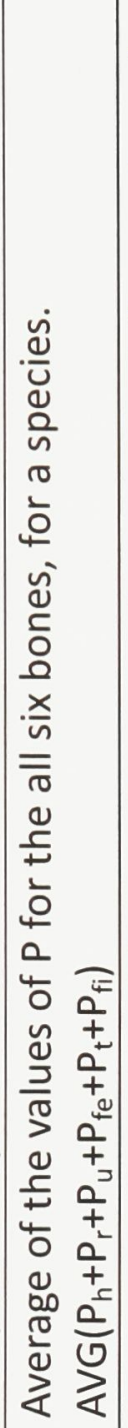 & 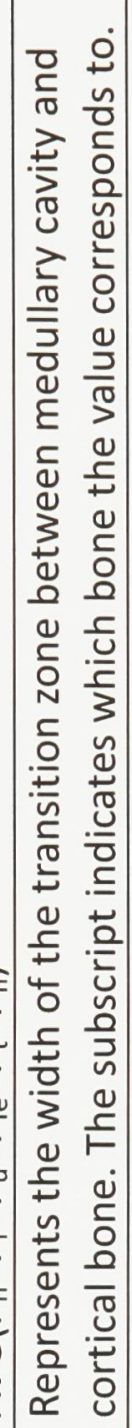 & 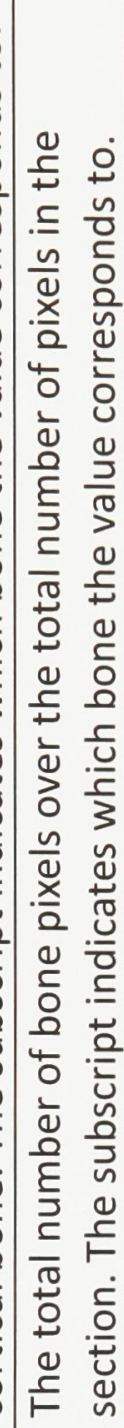 & 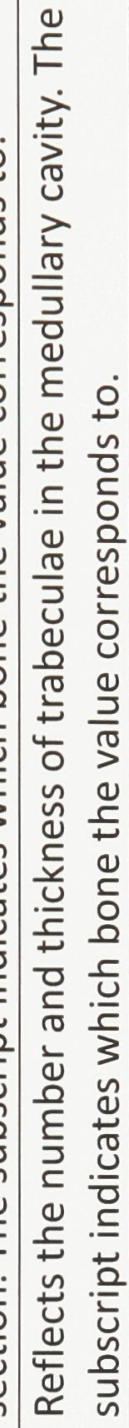 \\
\hline 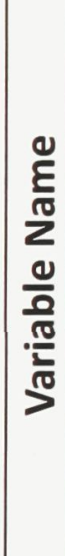 & 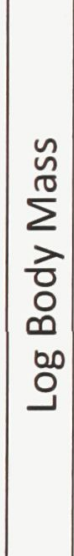 & 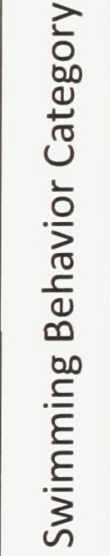 & \multicolumn{4}{|c|}{ 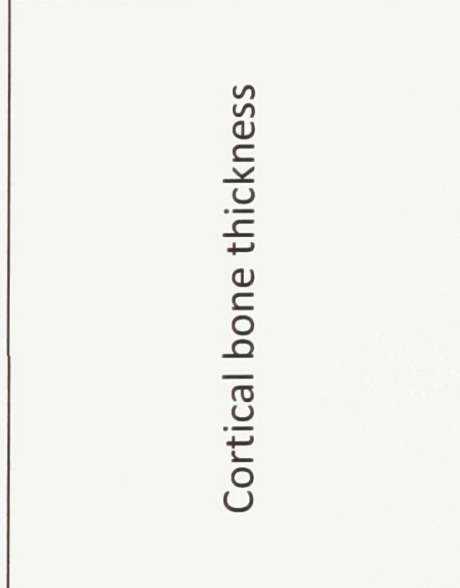 } & 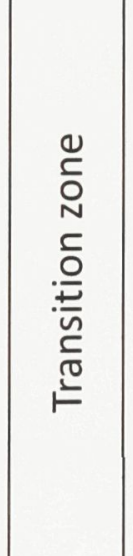 & 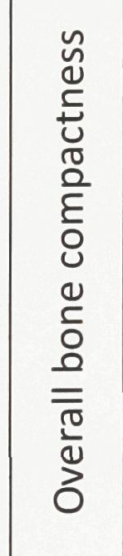 & 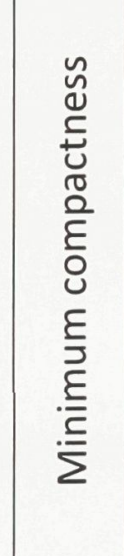 \\
\hline है & 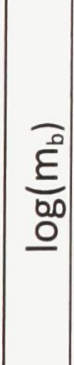 & $n$ & تص & $a^{\frac{0}{2}}$ & 豪 & $a^{\frac{l_{0}^{10}}{10}}$ & 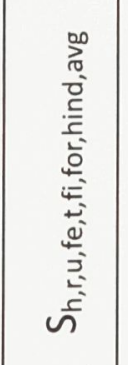 & 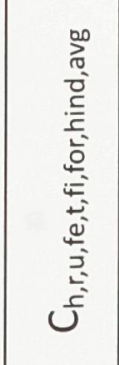 & 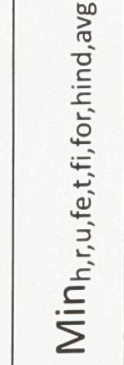 \\
\hline
\end{tabular}




\section{APPENDIX 7}

\section{INSTRUCTIONS ON HOW TO CALCULATE K-STATISTIC IN R USING NEXUS FILES CREATED} FROM MESQUITE

1. Create a nexus file of your tree in Mesquite (the order of the taxa in the nexus file must follow the order of the taxa in the text file of characters you created. It is easiest to alphabetize the taxa in the taxa block in mesquite and your excel file)

a. Select a branch length algorithm from the "Tree" menu

b. "Tree" menu ->"Store Tree", then "File" menu-> "Export"... and choose "Export Nexus file" (the first option) and hit OK, then choose your "Tree Block" and hit OK and then check off the box "Include Taxa Block" and hit OK. Give your nexus file a name and "Save".

2. Create a .txt file by choosing "Save as..." in excel and choosing "Text (tab delimited)" from the "Save as type:" options. Make a separate .txt file for all your continuous characters. (REMEMBER: The order of the taxa in the Table must match the order of the taxa in the nexus file exactly. This is easiest by alphabetizing them in both Mesquite and Excel. DO NOT INCLUDE TAXA NAMES in you .txt files.)

3. Place both the nexus tree file and the character text files in "My Documents"

4. Install the latest version of $\mathrm{R}$.

5. Open R and Install the following packages: ape, picante, and vegan. 
a. "Packages" menu -> "Install Packages..."-> select your region from the list and hit OK $->$ select one of the packages you would like to install and hit OK. Repeat if needed for other packages.

6. Load the following packages: ape, picante, vegan (Hint: loading picante first will automatically load the other needed packages)

a. "Packages"menu -> "Load Package..."-> select one of the packages you would like to load and hit OK. Repeat if need for other packages.

7. To open and view the nexus file in R type read.nexus("nameofyourfile") into the command line and hit enter.

8. To assign the tree to the variable "phy" type Phy<-read.nexus("nameofyourfile") into the command line and hit enter.

9. Then to open and view a txt character file in R type read.table("nameofyourfile.txt") into the command line and hit enter.

10. Then assign the character values to " $x$ " by typing $x<-$ read.table("nameofyourfile.txt") into the command line and hitting enter.

11. To calculate K-statistic enter $\mathbf{K c a l c}(\mathbf{x}, \mathbf{p h y})$ into the command line and hit enter.

12. Repeat steps 9- 11 for all your characters.

a. If you wish to calculate the K-Statistic for your characters using a different branch length algorithm, repeat step 7-8 to open the new nexus file and assign it to "phy" and then repeat steps 9-12 to calculate K-statistic for your characters. (Hint: once you have opened a nexus or .txt file in R, by 
using the commands from steps 7 and 9, they remain available and can be used in the calculation by simply reassigning their values to either "phy" or " $\mathrm{x}$ " by using steps 8 or 10 ) 
APPENDIX 8

DISCRIMIANT FUNCTION ANALYSIS RESULTS CALCULATED IN JMP 
Legend:

$\square=$ Terrestrial $(\mathrm{SC}=1) \quad=$ Semi-aquatic $(\mathrm{SC}=2) \quad \mathrm{O}=$ Aquatic $(\mathrm{SC}=3)$
$\mathbf{X}=$ Semi-Pelagic $(\mathrm{SC}=4) *=$ Puijila darwini

43 Taxa Analyses

\begin{tabular}{|c|c|}
\hline Row & Species name: \\
\hline 1 & Ailuropoda melanoleuca \\
\hline 2 & Ailurus fulgens \\
\hline 3 & Aonyx cinereus \\
\hline 4 & Arctocephalus australis \\
\hline 5 & Arctocephalus forsteri \\
\hline 6 & Callorhinus ursinus \\
\hline 7 & Cystophora cristata \\
\hline 8 & Enhydra lutris \\
\hline 9 & Erignathus barbatus \\
\hline 10 & Eumetopias jubatus \\
\hline 11 & Gulo gulo \\
\hline 12 & Halichoerus grypus \\
\hline 13 & Hydrurga leptonyx \\
\hline 14 & Leptonychotes weddellii \\
\hline 15 & Lontra canadensis \\
\hline 16 & Lontra felina \\
\hline 17 & Lontra longicaudis \\
\hline 18 & Martes americana \\
\hline 19 & Martes flavigula \\
\hline 20 & Martes foina \\
\hline 21 & Martes pennanti \\
\hline 22 & Mellivora capensis \\
\hline 23 & Mephitis mephitis \\
\hline 24 & Mirounga angustirostris \\
\hline 25 & Monachus monachus \\
\hline 26 & Mustela ermina \\
\hline 27 & Mustela frenata \\
\hline 28 & Mustela nivalis \\
\hline 29 & Mustela putorius \\
\hline 30 & Mustela sibirica \\
\hline 31 & Neophoca cinerea \\
\hline 32 & Neovision vison \\
\hline 33 & Odobenus rosmarus \\
\hline 34 & Otaria flavescens \\
\hline 35 & Phoca vitulina \\
\hline 36 & Procyon lotor \\
\hline 37 & Pteronura brasiliensis \\
\hline 38 & Spilogale putorius \\
\hline 39 & Taxidea taxus \\
\hline 40 & Ursus americanus \\
\hline 41 & Ursus arctos \\
\hline 42 & Ursus martimus \\
\hline 43 & Zalophus californianus \\
\hline 44 & Puijila darwini (must.) \\
\hline 45 & Puijila darwini (ursid) \\
\hline 46 & Puijila darwini (avg.) \\
\hline
\end{tabular}

\section{Taxa Analyses}

\begin{tabular}{|c|c|}
\hline Row & Species name: \\
\hline 1 & Ailurus fulgens \\
\hline 2 & Aonyx cinereus \\
\hline 3 & Arctocephalus australis \\
\hline 4 & Arctocephalus forsteri \\
\hline 5 & Callorhinus ursinus \\
\hline 6 & Cystophora cristata \\
\hline 7 & Enhydra lutris \\
\hline 8 & Erignathus barbatus \\
\hline 9 & Eumetopias jubatus \\
\hline 10 & Gulo gulo \\
\hline 11 & Halichoerus grypus \\
\hline 12 & Hydrurga leptonyx \\
\hline 13 & Leptonychotes weddellii \\
\hline 14 & Lontra canadensis \\
\hline 15 & Lontra felina \\
\hline 16 & Lontra longicaudis \\
\hline 17 & Martes americana \\
\hline 18 & Martes flavigula \\
\hline 19 & Martes foina \\
\hline 20 & Martes pennanti \\
\hline 21 & Mellivora capensis \\
\hline 22 & Mephitis mephitis \\
\hline 23 & Mirounga angustirostris \\
\hline 24 & Monachus monachus \\
\hline 25 & Mustela ermina \\
\hline 26 & Mustela frenata \\
\hline 27 & Mustela nivalis \\
\hline 28 & Mustela putorius \\
\hline 29 & Mustela sibirica \\
\hline 30 & Neophoca cinerea \\
\hline 31 & Neovision vison \\
\hline 32 & Odobenus rosmarus \\
\hline 33 & Otaria flavescens \\
\hline 34 & Phoca vitulina \\
\hline 35 & Procyon lotor \\
\hline 36 & Pteronura brasiliensis \\
\hline 37 & Spilogale putorius \\
\hline 38 & Taxidea taxus \\
\hline 39 & Zalophus californianus \\
\hline 40 & Puijila darwini (must.) \\
\hline 41 & Puijila darwini (ursid) \\
\hline 42 & Puijila darwini (avg.) \\
\hline
\end{tabular}

27 Taxa Analyses

\begin{tabular}{|c|c|}
\hline Row & Species name: \\
\hline 1 & Ailuropoda melanoleuca \\
\hline 2 & Arctocephalus australis \\
\hline 3 & Arctocephalus forsteri \\
\hline 4 & Callorhinus ursinus \\
\hline 5 & Cystophora cristata \\
\hline 6 & Enhydra lutris \\
\hline 7 & Erignathus barbatus \\
\hline 8 & Eumetopias jubatus \\
\hline 9 & Gulo gulo \\
\hline 10 & Halichoerus grypus \\
\hline 11 & Hydrurga leptonyx \\
\hline 12 & Leptonychotes weddellii \\
\hline 13 & Lontra canadensis \\
\hline 14 & Lontra longicaudis \\
\hline 15 & Mellivora capensis \\
\hline 16 & Mirounga angustirostris \\
\hline 17 & Monachus monachus \\
\hline 18 & Neophoca cinerea \\
\hline 19 & Odobenus rosmarus \\
\hline 20 & Otaria flavescens \\
\hline 21 & Phoca vitulina \\
\hline 22 & Pteronura brasiliensis \\
\hline 23 & Taxidea taxus \\
\hline 24 & Ursus americanus \\
\hline 25 & Ursus arctos \\
\hline 26 & Ursus martimus \\
\hline 27 & Zalophus californianus \\
\hline 28 & Puijila darwini (must.) \\
\hline 29 & Puijila darwini (ursid) \\
\hline 30 & Puijila darwini (avg.) \\
\hline
\end{tabular}


ANALYSIS \#1:

\# of Taxa: 43

Y, covariates: $\log \left(m_{b}\right), P_{h}, P_{r}, P_{u}, P_{f e}, P_{t}, P_{f i}$

$X$, categories: SC (1-4)

\section{Canonical Plot}

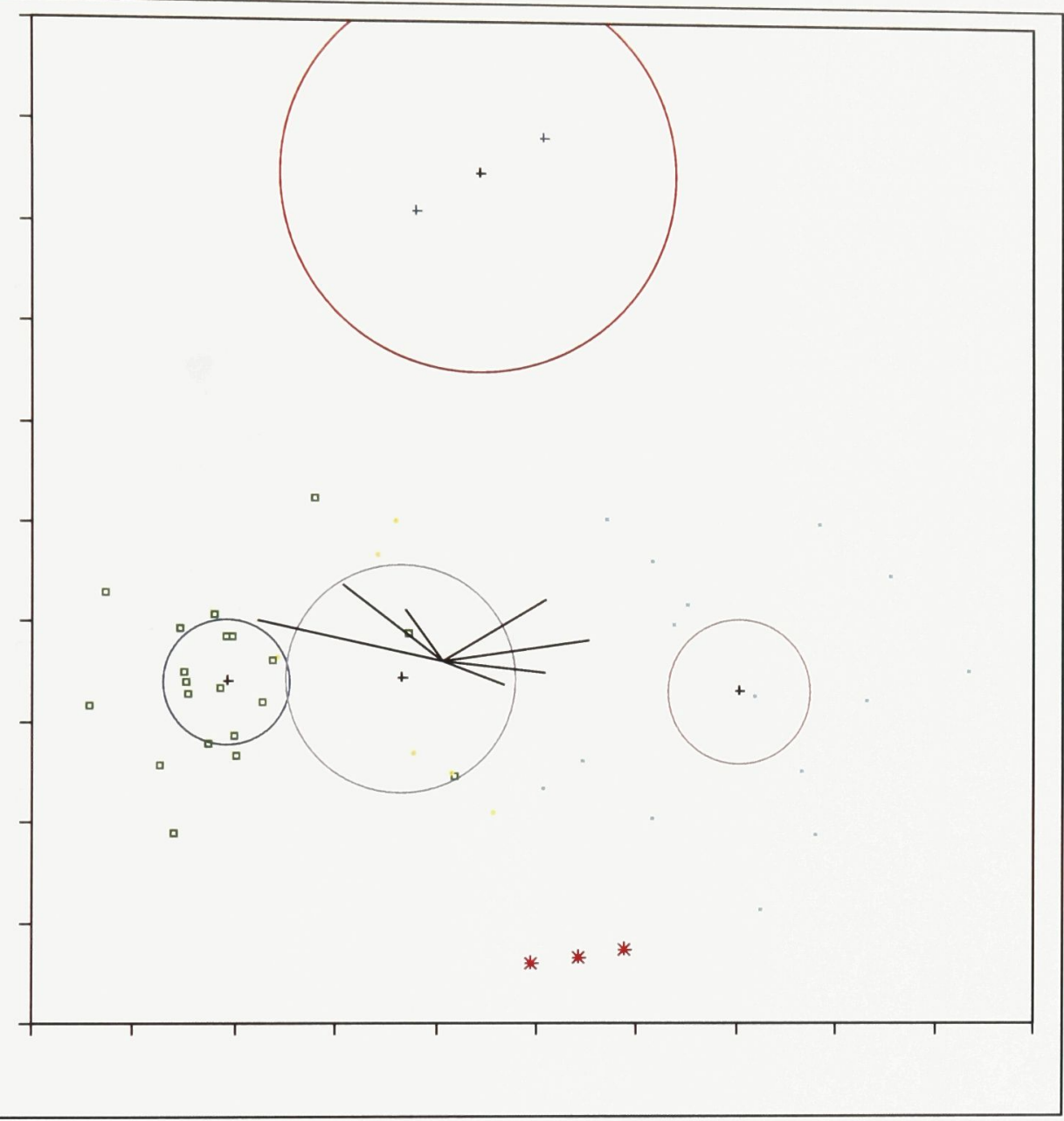

\section{Discriminant Scores}

Number Misclassified

Percent Misclassified -2LogLikelihood

$\begin{array}{rr}\text { Training } & \text { Excluded } \\ 5 & 0 \\ 11.63 & 0 \\ 25.55 & \end{array}$

\begin{tabular}{|c|c|c|c|c|c|c|}
\hline Row SC & SqDist(Actual) & Prob(Actual) & -Log(Prob) & Plot -Log(Prob) & Predicted SC & Prob(Pred) \\
\hline 11 & 6.06390 & 0.1308 & 2.034 & $\square$ & * 2 & 0.8665 \\
\hline 21 & 2.04096 & 0.9037 & 0.101 & $\square$ & 1 & 0.9037 \\
\hline 32 & 7.66963 & 0.9075 & 0.097 & $\square$ & 2 & 0.9075 \\
\hline 43 & 5.35353 & 0.9999 & 0.000 & $\square$ & 3 & 0.9999 \\
\hline 53 & 14.41796 & 0.9982 & 0.002 & $\square$ & 3 & 0.9982 \\
\hline 63 & 9.58951 & 0.9646 & 0.036 & $\square$ & 3 & 0.9646 \\
\hline 74 & 1.27550 & 1.0000 & 0.000 & $\square$ & 4 & 1.0000 \\
\hline 83 & 17.83902 & 0.2207 & 1.511 & $\square$ & * 2 & 0.7699 \\
\hline
\end{tabular}


Row SC SqDist(Actual) Prob(Actual) - Log(Prob) Plot -Log(Prob)

\begin{tabular}{|c|c|c|c|c|c|c|c|}
\hline 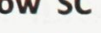 & SUISt(ACtUaI) & Prod(Actual) & -Log(Prob) & Plot -Log(Prob) & Predicted SC & Prob(Pred) & Others \\
\hline 93 & 3.96150 & 0.9244 & 0.079 & $\square$ & 3 & 0.9244 & \\
\hline 103 & 8.08164 & 0.9997 & 0.000 & $\square$ & 3 & 0.9997 & \\
\hline 111 & 2.20820 & 0.7516 & 0.286 & $\square$ & 1 & 0.7516 & 20.25 \\
\hline 123 & 4.86380 & 0.7690 & 0.263 & $\square$ & 3 & 0.7690 & 20.22 \\
\hline 133 & 8.31309 & 1.0000 & 0.000 & $\square$ & 3 & 1.0000 & \\
\hline 143 & 26.31980 & 0.9442 & 0.057 & $\square$ & 3 & 0.9442 & \\
\hline 152 & 3.86911 & 0.3487 & 1.054 & $\square$ & * 1 & 0.6513 & \\
\hline 162 & 2.79068 & 0.8173 & 0.202 & $\square$ & 2 & 0.8173 & 10.18 \\
\hline 172 & 4.06772 & 0.9109 & 0.093 & $\square$ & 2 & 0.9109 & \\
\hline 181 & 3.48875 & 0.8725 & 0.136 & 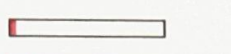 & 1 & 0.8725 & 20.13 \\
\hline 191 & 1.23123 & 0.7025 & 0.353 & $\square$ & 1 & 0.7025 & 20.30 \\
\hline 201 & 0.71400 & 0.8990 & 0.106 & $\square$ & 1 & 0.8990 & 20.10 \\
\hline 211 & 0.81269 & 0.7983 & 0.225 & $\square$ & 1 & 0.7983 & 20.20 \\
\hline 221 & 4.41381 & 0.7390 & 0.303 & $\square$ & 1 & 0.7390 & 20.26 \\
\hline 231 & 1.90305 & 0.8748 & 0.134 & 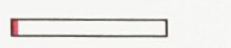 & 1 & 0.8748 & 20.13 \\
\hline 244 & 1.27550 & 1.0000 & 0.000 & $\square$ & 4 & 1.0000 & \\
\hline 253 & 12.62158 & 0.9998 & 0.000 & $\square$ & 3 & 0.9998 & \\
\hline 261 & 8.62602 & 0.9864 & 0.014 & $\square$ & 1 & 0.9864 & \\
\hline 271 & 7.13548 & 0.8337 & 0.182 & $\square$ & 1 & 0.8337 & 20.17 \\
\hline 281 & 4.82476 & 0.9499 & 0.051 & $\square$ & 1 & 0.9499 & \\
\hline 291 & 3.35583 & 0.8607 & 0.150 & $\square$ & 1 & 0.8607 & 20.14 \\
\hline 301 & 3.75449 & 0.9830 & 0.017 & $\square$ & 1 & 0.9830 & \\
\hline 313 & 7.54055 & 0.9988 & 0.001 & $\square$ & 3 & 0.9988 & \\
\hline 321 & 1.28064 & 0.9191 & 0.084 & $\square$ & 1 & 0.9191 & \\
\hline 333 & 13.57138 & 1.0000 & 0.000 & $\square$ & 3 & 1.0000 & \\
\hline 343 & 8.52702 & 0.5588 & 0.582 & $\square$ & 3 & 0.5588 & 20.44 \\
\hline 353 & 16.62844 & 0.9999 & 0.000 & $\square$ & 3 & 0.9999 & \\
\hline 361 & 2.63551 & 0.8880 & 0.119 & $\square$ & 1 & 0.8880 & 20.11 \\
\hline 372 & 3.98852 & 0.7614 & 0.273 & ॠ & 2 & 0.7614 & 10.23 \\
\hline 381 & 3.32611 & 0.9291 & 0.074 & $\square$ & 1 & 0.9291 & \\
\hline 391 & 2.61949 & 0.8317 & 0.184 & $\square$ & 1 & 0.8317 & 20.17 \\
\hline 401 & 7.22762 & 0.4685 & 0.758 & $\square$ & * 2 & 0.5261 & \\
\hline 411 & 12.01635 & 0.0508 & 2.980 & $\square$ & * 2 & 0.9373 & \\
\hline 422 & 6.72007 & 0.8091 & 0.212 & $\square$ & 2 & 0.8091 & 110.19 \\
\hline 433 & 4.03558 & 0.9804 & 0.020 & $\square$ & 3 & 0.9804 & \\
\hline $44 ?$ & \multicolumn{3}{|c|}{ Puijila darwini (mustelid) } & $\square$ & 2 & 0.8724 & 40.12 \\
\hline $45 ?$ & \multirow{2}{*}{\multicolumn{3}{|c|}{$\begin{array}{l}\text { Puijila darwini (ursid) } \\
\text { Puijila darwini (avg.) }\end{array}$}} & $\square$ & -3 & 0.7381 & 120.26 \\
\hline $46 ?$ & & & & $\square$ & -2 & 0.6151 & 130.38 \\
\hline
\end{tabular}


ANALYSIS \#2:

\# of Taxa: 43

Y, covariates: $\log \left(m_{b}\right), \log \left(P_{h}\right), \log \left(P_{r}\right), \log \left(P_{u}\right), \log \left(P_{f e}\right), \log \left(P_{t}\right), \log \left(P_{f i}\right)$

$X$, categories: SC (1-4)

\section{Canonical Plot}

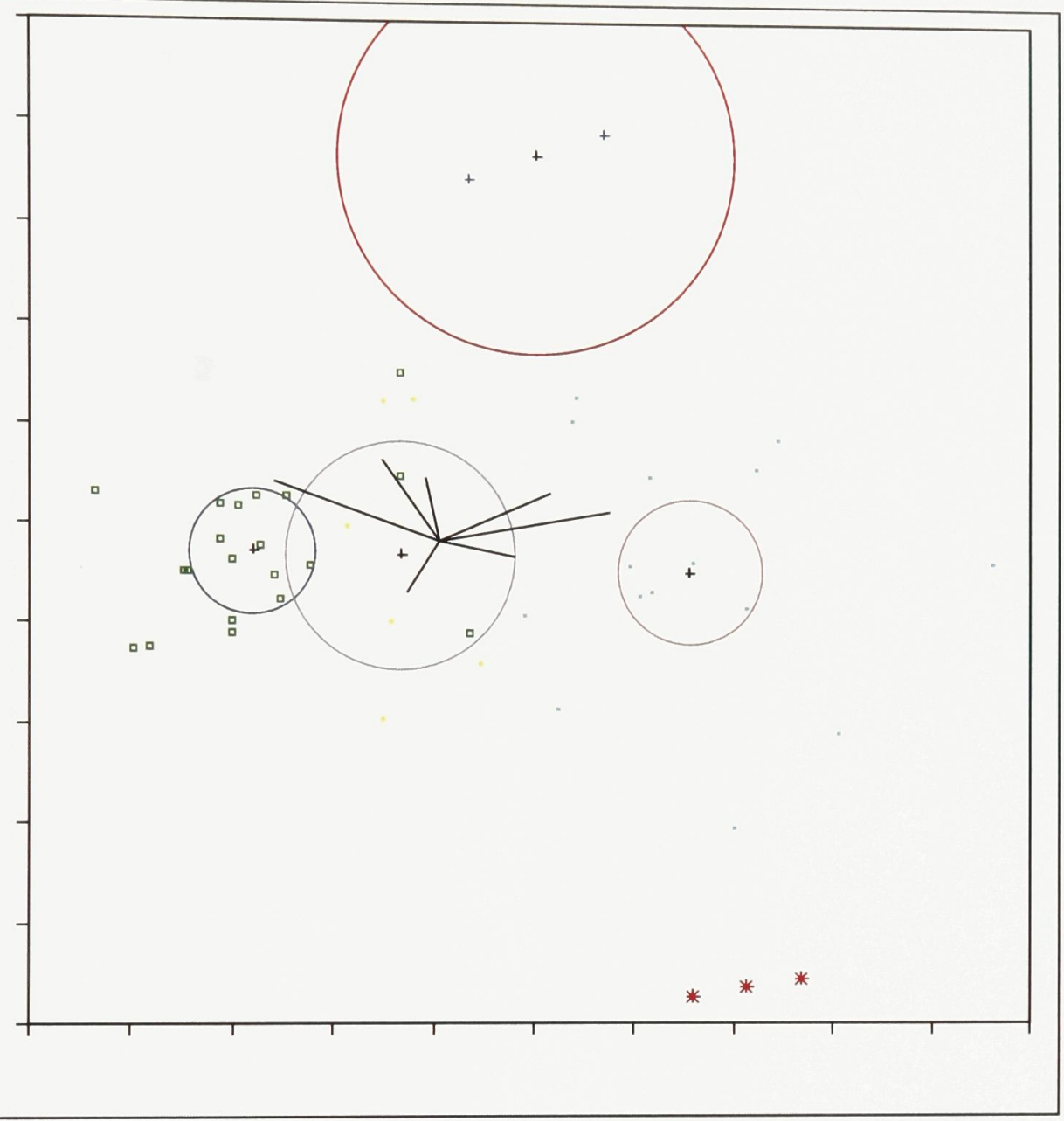

\section{Discriminant Scores}

Number Misclassified

$\begin{array}{rr}\text { Training } & \text { Excluded } \\ 4 & 0 \\ 9.302 & 0 \\ 28.95 & \end{array}$

Percent Misclassified

-2LogLikelihood

\begin{tabular}{|c|c|c|c|c|c|c|}
\hline Row SC & SqDist(Actual) & Prob(Actual) & -Log(Prob) & Plot -Log(Prob) & Predicted SC & Prob(Pred) Others \\
\hline 11 & 4.51328 & 0.2653 & 1.327 & $\square$ & * 2 & 0.7227 \\
\hline 21 & 1.70505 & 0.8644 & 0.146 & $\square$ & 1 & 0.864420 .14 \\
\hline 32 & 5.88556 & 0.8372 & 0.178 & 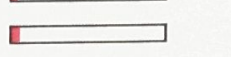 & 2 & 0.837210 .16 \\
\hline 43 & 7.23689 & 0.9999 & 0.000 & $\square$ & 3 & 0.9999 \\
\hline 53 & 14.32955 & 0.9366 & 0.065 & $\square$ & 3 & 0.9366 \\
\hline 63 & 13.67650 & 0.7988 & 0.225 & $\square$ & 3 & $0.7988 \quad 20.19$ \\
\hline 74 & 0.65223 & 0.9991 & 0.001 & $\square$ & 4 & 0.9991 \\
\hline 83 & 24.46813 & 0.9330 & 0.069 & $\square$ & 3 & 0.9330 \\
\hline
\end{tabular}




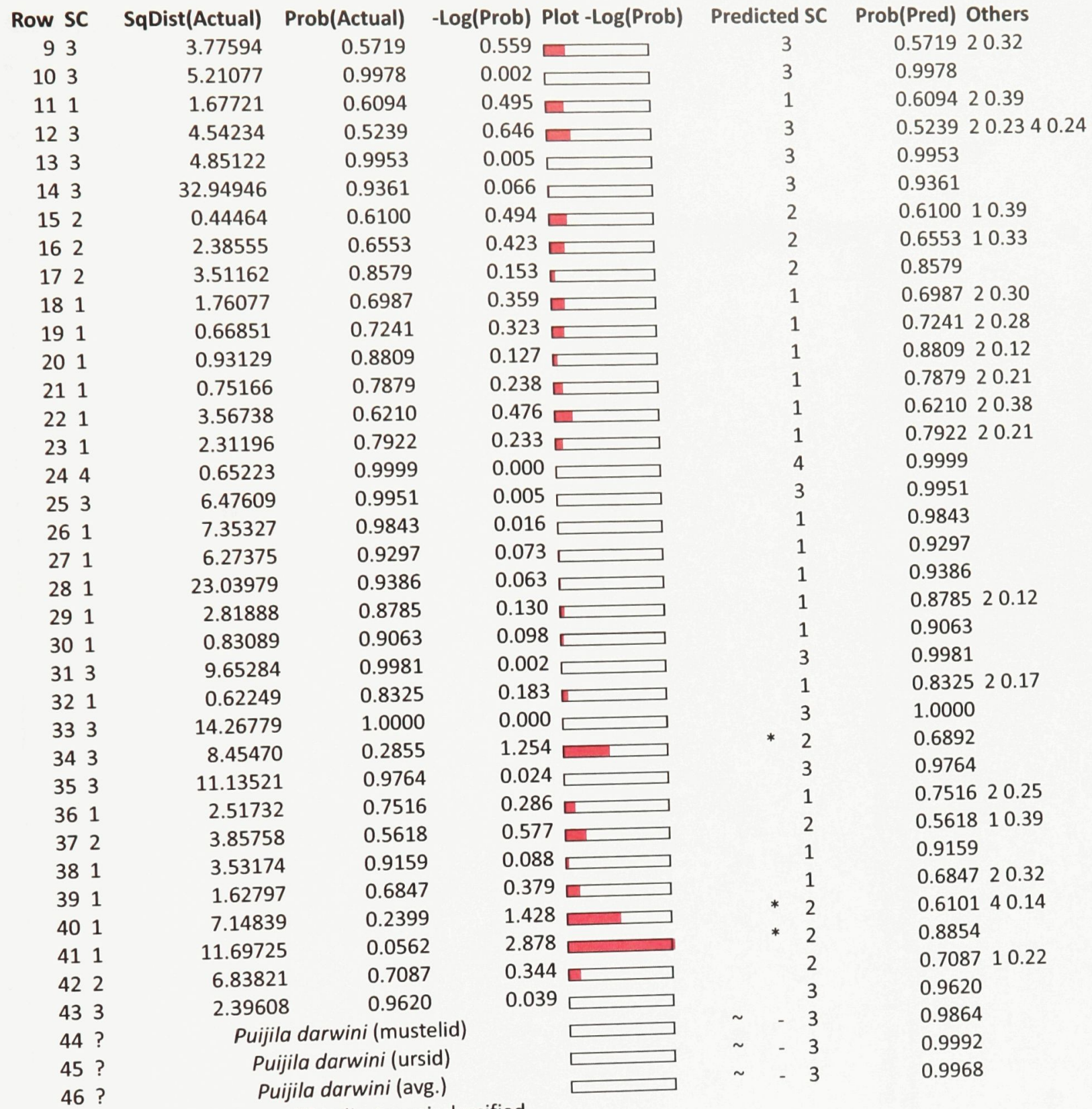

\footnotetext{
" " indicates excluded row; ${ }^{\prime * 1}$ indicates misclassified
} 
ANALYSIS \#3:

\# of Taxa: 43

$Y$, covariates: $P_{h}, P_{r}, P_{u}, P_{f e}, P_{t}, P_{f i}$

$X$, categories: SC (1-4)

\section{Canonical Plot}

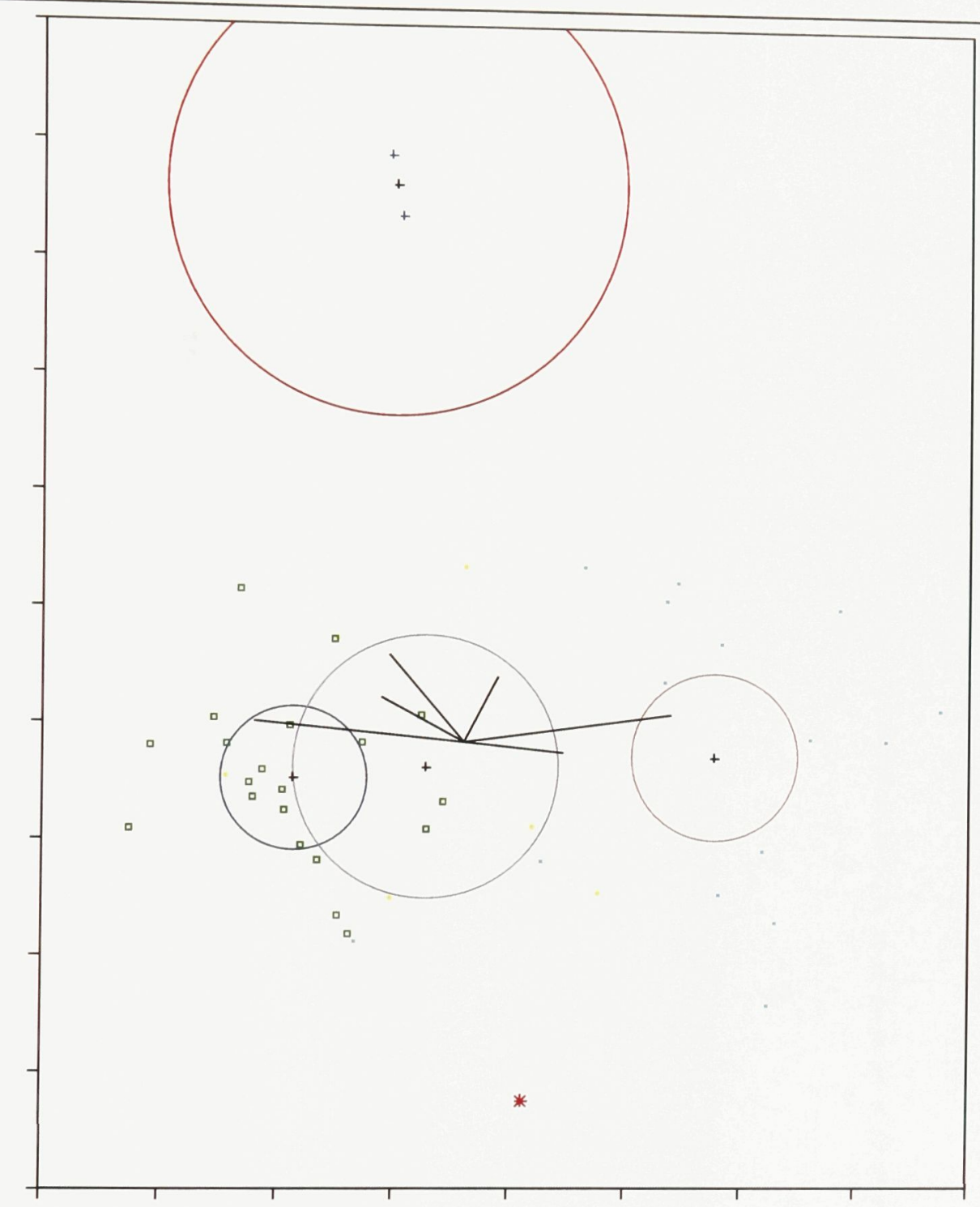

\section{Discriminant Scores}

Number Misclassified

$\begin{array}{rr}\text { Training } & \text { Excluded } \\ 7 & 0 \\ 16.28 & 0\end{array}$

Percent Misclassified

-2LogLikelihood

44.04

$\begin{array}{crrrccc}\text { Row SC } & \text { SqDist(Actual) } & \text { Prob(Actual) } & \text {-Log(Prob) } & \text { Plot - Log(Prob) } & \text { Predicted SC } & \text { Prob(Pred) Others } \\ 11 & 4.07734 & 0.2820 & 1.266 & * & 2 & 0.6958\end{array}$ 


\begin{tabular}{|c|c|c|c|c|c|c|c|}
\hline Row SC & SqDist(Actual) & Prob(Actual) & -Log(Prob) & Plot -Log(Prob) & Predicted SC & Prob(Pred) & Others \\
\hline 21 & 1.92573 & 0.7205 & 0.328 & $\square$ & 1 & 0.7205 & 20.28 \\
\hline 32 & 7.64776 & 0.4429 & 0.814 & $\square$ & * 3 & 0.5252 & \\
\hline 43 & 4.89177 & 0.9920 & 0.008 & $\square$ & 3 & 0.9920 & \\
\hline 53 & 14.03268 & 0.9943 & 0.006 & $\square$ & 3 & 0.9943 & \\
\hline 63 & 8.16438 & 0.9676 & 0.033 & $\square$ & 3 & 0.9676 & \\
\hline 74 & 0.40596 & 1.0000 & 0.000 & $\square$ & 4 & 1.0000 & \\
\hline 83 & 17.60540 & 0.0036 & 5.632 & $\square$ & * 1 & 0.5046 & 20.49 \\
\hline 93 & 3.09287 & 0.8823 & 0.125 & $\square$ & 3 & 0.8823 & 20.11 \\
\hline 103 & 7.79030 & 0.9879 & 0.012 & $\square$ & 3 & 0.9879 & \\
\hline 111 & 1.82052 & 0.7445 & 0.295 & ए & 1 & 0.7445 & 20.26 \\
\hline 123 & 4.13890 & 0.6191 & 0.479 & $\square$ & 3 & 0.6191 & 20.34 \\
\hline 133 & 7.35996 & 0.9970 & 0.003 & $\square$ & 3 & 0.9970 & \\
\hline 143 & 25.54015 & 0.9046 & 0.100 & $\square$ & 3 & 0.9046 & \\
\hline 152 & 3.86894 & 0.1891 & 1.666 & $\square$ & * 1 & 0.8108 & \\
\hline 162 & 2.27007 & 0.6174 & 0.482 & $\square$ & 2 & 0.6174 & 10.1230 .26 \\
\hline 172 & 2.85724 & 0.5515 & 0.595 & $\square$ & 2 & 0.5515 & 10.44 \\
\hline 181 & 3.42510 & 0.8026 & 0.220 & $\square$ & 1 & 0.8026 & 20.20 \\
\hline 191 & 1.23101 & 0.5048 & 0.684 & $\square$ & 1 & 0.5048 & 20.49 \\
\hline 201 & 0.52354 & 0.6830 & 0.381 & $\square$ & 1 & 0.6830 & 20.32 \\
\hline 211 & 0.81250 & 0.6242 & 0.471 & $\square$ & 1 & 0.6242 & 20.38 \\
\hline 221 & 4.04499 & 0.7273 & 0.318 & $\square$ & 1 & 0.7273 & 20.27 \\
\hline 231 & 1.80985 & 0.6671 & 0.405 & $\square$ & 1 & 0.6671 & 20.33 \\
\hline 244 & 0.40596 & 1.0000 & 0.000 & $\square$ & 4 & 1.0000 & \\
\hline 253 & 10.71169 & 0.9571 & 0.044 & $\square$ & 3 & 0.9571 & \\
\hline 261 & 3.99467 & 0.6501 & 0.431 & $\square$ & 1 & 0.6501 & 20.35 \\
\hline 271 & 5.71354 & 0.2994 & 1.206 & $\square$ & * 2 & 0.6592 & \\
\hline 281 & 3.51931 & 0.6449 & 0.439 & $\square$ & 1 & 0.6449 & 20.35 \\
\hline 291 & 2.31010 & 0.3986 & 0.920 & $\square$ & * 2 & 0.5706 & \\
\hline 301 & 3.51358 & 0.9289 & 0.074 & $\square$ & 1 & 0.9289 & \\
\hline 313 & 7.54051 & 0.9834 & 0.017 & $\square$ & 3 & 0.9834 & \\
\hline 321 & 1.24209 & 0.7900 & 0.236 & $\square$ & 1 & 0.7900 & 20.21 \\
\hline 333 & 11.91345 & 0.9998 & 0.000 & $\square$ & 3 & 0.9998 & \\
\hline 343 & 8.11135 & 0.2675 & 1.319 & $\square$ & * 2 & 0.6379 & \\
\hline 353 & 16.53366 & 0.9986 & 0.001 & $\square$ & 3 & 0.9986 & \\
\hline 361 & 2.34612 & 0.8725 & 0.136 & $\square$ & 1 & 0.8725 & 20.13 \\
\hline 372 & 3.66381 & 0.6700 & 0.401 & $\square$ & 2 & 0.6700 & 10.23 \\
\hline 381 & 2.09476 & 0.5685 & 0.565 & $\square$ & 1 & 0.5685 & 20.43 \\
\hline 391 & 2.39106 & 0.7977 & 0.226 & 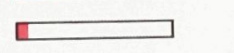 & 1 & 0.7977 & 720.20 \\
\hline 401 & 4.76698 & 0.7437 & 0.296 & $\square$ & 1 & 0.7437 & 720.25 \\
\hline 411 & 3.54671 & 0.5056 & 0.682 & $\square$ & 1 & 0.5056 & 620.49 \\
\hline 422 & 6.59606 & 0.5343 & 0.627 & $\square$ & 2 & 0.5343 & 310.46 \\
\hline 433 & 3.74763 & 0.9230 & 0.080 & $\square$ & 3 & 0.9230 & \\
\hline $44 ?$ & & uijila darwini & & $\square$ & -2 & 0.8194 & \\
\hline
\end{tabular}


ANALYSIS \#4:

\# of Taxa: 43

Y, covariates: $\log \left(P_{h}\right), \log \left(P_{r}\right), \log \left(P_{u}\right), \log \left(P_{f e}\right), \log \left(P_{t}\right), \log \left(P_{f i}\right)$

$X$, categories: SC (1-4)

\section{Canonical Plot}

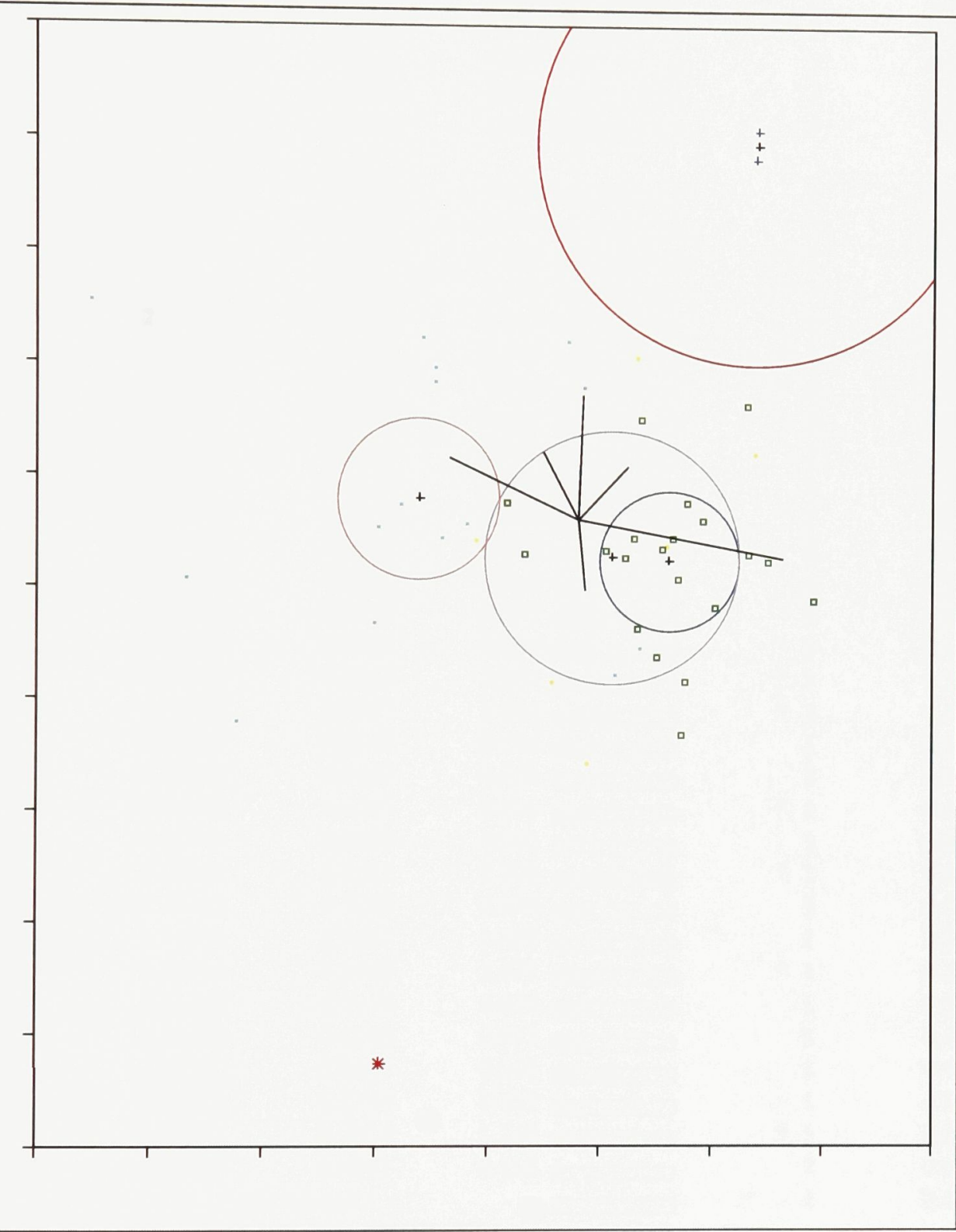

\section{Discriminant Scores}

Number Misclassified

Percent Misclassified

-2LogLikelihood

$\begin{array}{rr}\text { Training } & \text { Excluded } \\ 15 & 0 \\ 34.88 & 0 \\ 60.05 & \end{array}$

$\begin{array}{rrrrrr}\text { Row SC } & \text { SqDist(Actual) } & \text { Prob(Actual) } & \text {-Log(Prob) Plot -Log(Prob) } & \text { Pred. SC } & \text { Prob(Pred) Others } \\ 11 & 1.66072 & 0.5717 & 0.559 & 1 & 0.571720 .39\end{array}$ 


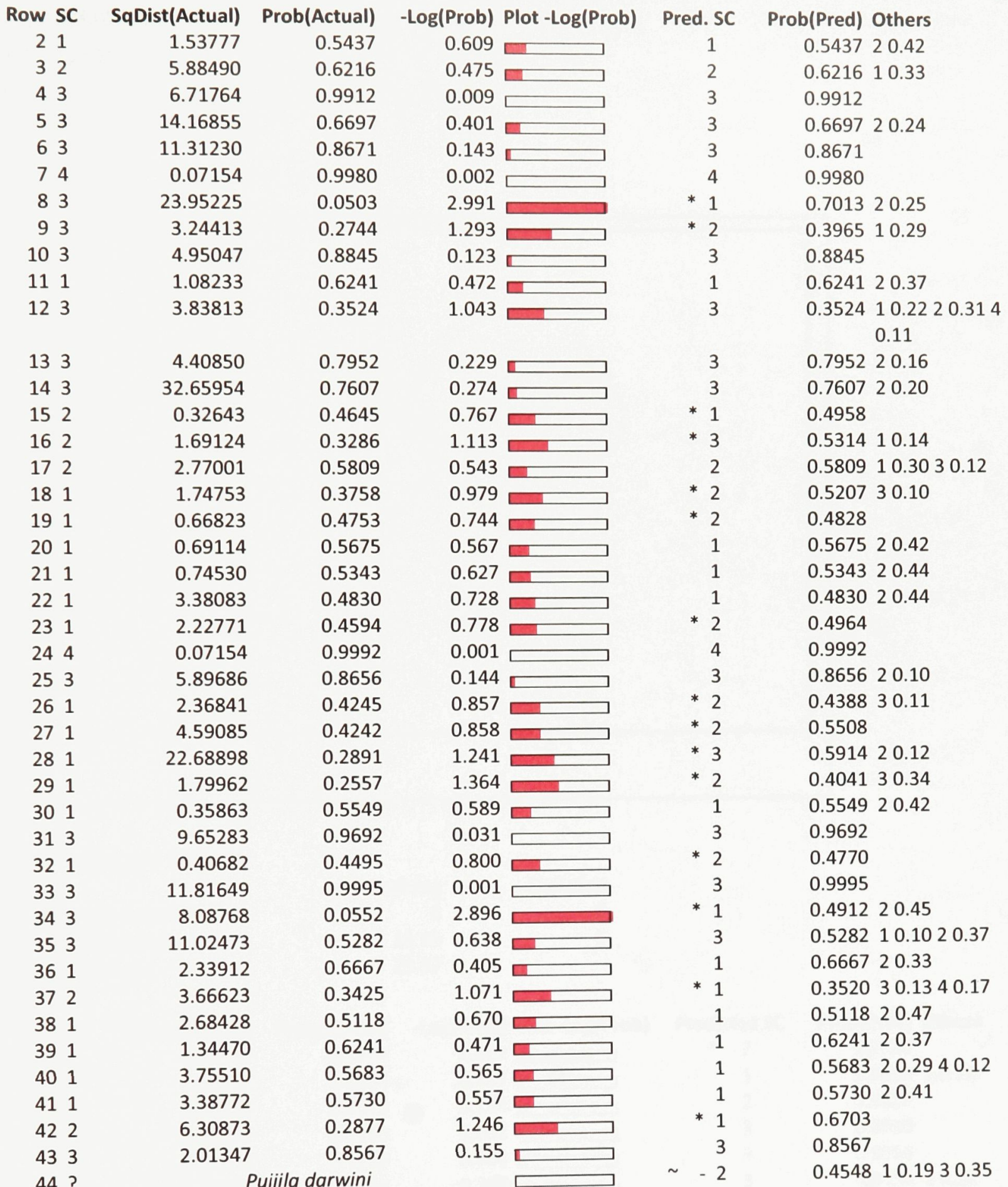

" " indicates excluded row; ${ }^{\prime * 1}$ indicates misclassified 
ANALYSIS \#5:

\# of Taxa: 43

Y, covariates: $\log \left(m_{b}\right), P_{h}, P_{r}, P_{u}, P_{f e}, P_{t}, P_{f i}$

$X$, categories: SC (1-3)

\section{Canonical Plot}

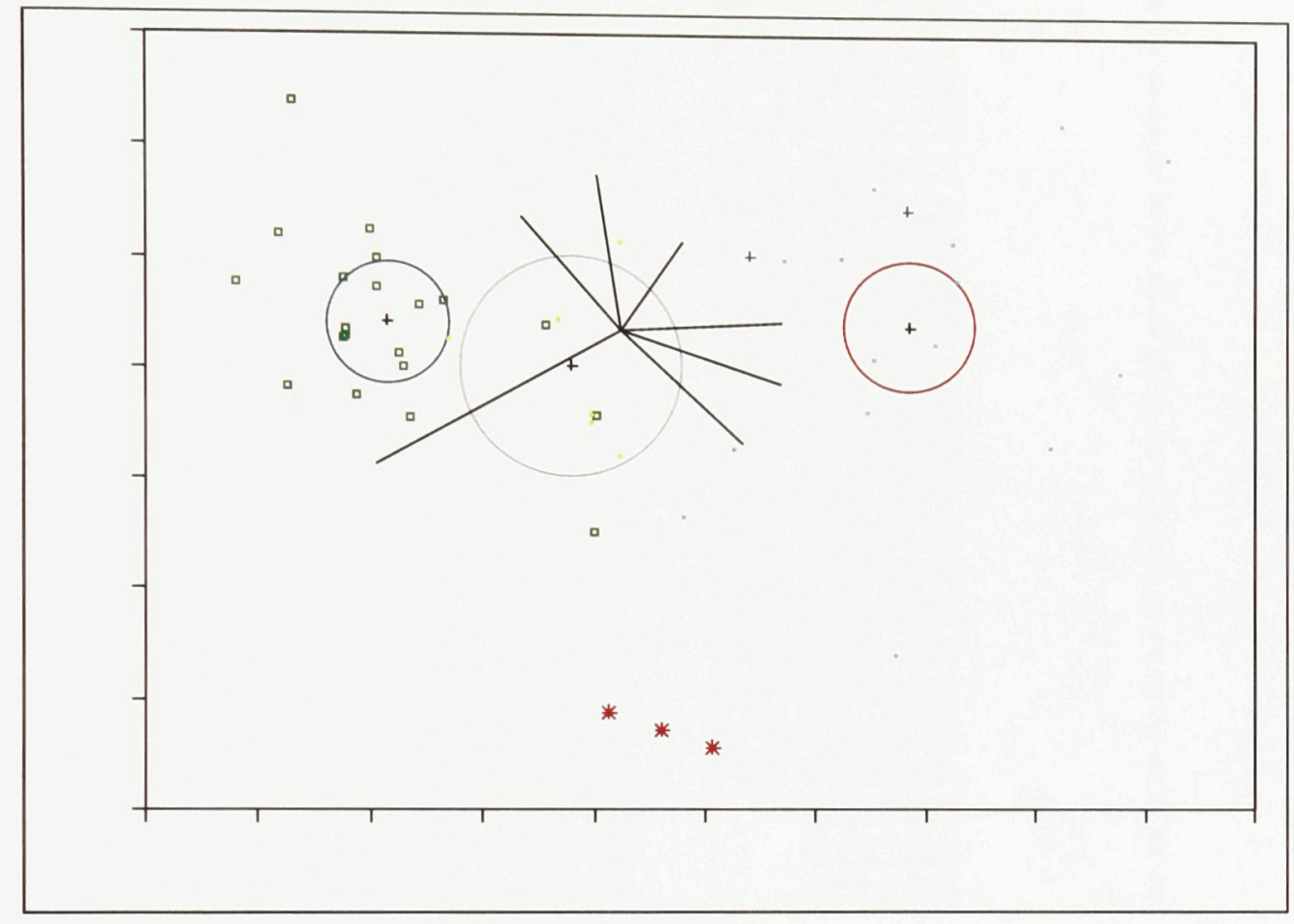

\section{Discriminant Scores}

Number Misclassified

Percent Misclassified

-2LogLikelihood

$\begin{array}{rr}\text { Training } & \text { Excluded } \\ 6 & 0 \\ 13.95 & 0 \\ 29.37 & \end{array}$

\begin{tabular}{|c|c|c|c|c|c|c|c|}
\hline Row SC & SqDist(Actual) & Prob(Actual) & -Log(Prob) & Plot -Log(Prob) & Predicted SC & Prob(Pred) & Others \\
\hline 11 & 6.14156 & 0.1234 & 2.092 & $\square$ & * 2 & 0.8644 & \\
\hline 21 & 2.04560 & 0.8806 & 0.127 & $\square$ & 1 & 0.8806 & 20.12 \\
\hline 32 & 6.27673 & 0.9010 & 0.104 & $\square$ & 2 & 0.9010 & \\
\hline 43 & 4.93721 & 0.9980 & 0.002 & $\square$ & 3 & 0.9980 & \\
\hline 53 & 15.03648 & 0.9956 & 0.004 & $\square$ & 3 & 0.9956 & \\
\hline 63 & 10.08716 & 0.8154 & 0.204 & $\square$ & 3 & 0.8154 & 20.18 \\
\hline 73 & 11.76624 & 0.6203 & 0.478 & $\square$ & 3 & 0.6203 & 20.37 \\
\hline 83 & 18.47921 & 0.0993 & 2.309 & $\square$ & * 2 & 0.8770 & \\
\hline 93 & 1.89713 & 0.9748 & 0.026 & $\square$ & 3 & 0.9748 & \\
\hline 103 & 8.40963 & 0.9981 & 0.002 & $\square$ & 3 & 0.9981 & \\
\hline 111 & 2.16923 & 0.6868 & 0.376 & $\square$ & 1 & 0.6868 & 20.31 \\
\hline 123 & 1.22909 & 0.9561 & 0.045 & $\square$ & 3 & 0.9561 & \\
\hline 133 & 8.43665 & 1.0000 & 0.000 & $\square$ & 3 & 1.0000 & \\
\hline 143 & 25.97880 & 0.9643 & 0.036 & $\square$ & 3 & 0.9643 & \\
\hline 152 & 3.63047 & 0.3841 & 0.957 & $\square$ & * 1 & 0.6158 & \\
\hline 162 & 2.54329 & 0.7400 & 0.301 & ए & 2 & 0.7400 & 10.25 \\
\hline 172 & 3.46957 & 0.8624 & 0.148 & $\square$ & 2 & 0.8624 & +10.13 \\
\hline
\end{tabular}




$\begin{array}{rlrrr}\text { Row SC } & \text { SqDist(Actual) } & \text { Prob(Actual) } & \text {-Log(Prob) Plot -Log(Prob) } \\ 18 & 1 & 3.57793 & 0.8596 & 0.151 \\ 19 & 1 & 1.26280 & 0.6710 & 0.399 \\ 20 & 1 & 0.72964 & 0.8851 & 0.122 \\ 21 & 1 & 0.72764 & 0.7409 & 0.300 \\ 22 & 1 & 4.46245 & 0.7399 & 0.301 \\ 23 & 1 & 1.82571 & 0.8840 & 0.123 \\ 24 & 3 & 12.09531 & 0.9935 & 0.006 \\ 25 & 3 & 11.74292 & 0.9999 & 0.000 \\ 26 & 1 & 7.73973 & 0.9736 & 0.027 \\ 27 & 1 & 7.15530 & 0.8480 & 0.165 \\ 28 & 1 & 4.19342 & 0.9663 & 0.034 \\ 29 & 1 & 3.15124 & 0.8821 & 0.125 \\ 30 & 1 & 3.75058 & 0.9783 & 0.022 \\ 31 & 3 & 6.45835 & 0.9649 & 0.036 \\ 32 & 1 & 1.28966 & 0.9031 & 0.102 \\ 33 & 3 & 14.11949 & 1.0000 & 0.000 \\ 34 & 3 & 8.88312 & 0.3616 & 1.017 \\ 35 & 3 & 17.33931 & 0.9998 & 0.000 \\ 36 & 1 & 2.39739 & 0.8363 & 0.179 \\ 37 & 2 & 2.83414 & 0.8130 & 0.207 \\ 38 & 1 & 3.29080 & 0.9353 & 0.067 \\ 39 & 1 & 2.40986 & 0.7617 & 0.272 \\ 40 & 1 & 6.42383 & 0.2945 & 1.223 \\ 41 & 1 & 10.26556 & 0.0885 & 2.425 \\ 42 & 2 & 5.96807 & 0.8582 & 0.153 \\ 43 & 3 & 3.37171 & 0.9855 & 0.015 \\ 44 & ? & \text { Puijila darwini (mustelid) } & \\ 45 & ? & \text { Puijila darwini (ursid) } & \\ 46 & ? & \text { Puijila darwini (avg.) } & \\ \text { " " indicates excluded row; '*' indicates misclassified } \\ \end{array}$

Predicted SC Prob(Pred) Others 0.859620 .14

0.671020 .33

0.885120 .11

0.740920 .26

0.739920 .26

0.884020 .12

0.9935

0.9999

0.9736

0.848020 .15

0.9663

0.882120 .12

0.9783

0.9649

0.9031

1.0000

0.6282

0.9998

0.836320 .16

0.813010 .15

0.9353

$0.7617 \quad 20.24$

0.7022

0.9032

0.858210 .13

0.9855

0.9539

0.887830 .11

0.9541 
ANALYSIS \#6:

\# of Taxa: 43

$Y$, covariates: $\log \left(m_{b}\right), \log \left(P_{h}\right), \log \left(P_{r}\right), \log \left(P_{u}\right), \log \left(P_{f e}\right), \log \left(P_{t}\right), \log \left(P_{f i}\right)$

$X$, categories: SC (1-3)

\section{Canonical Plot}

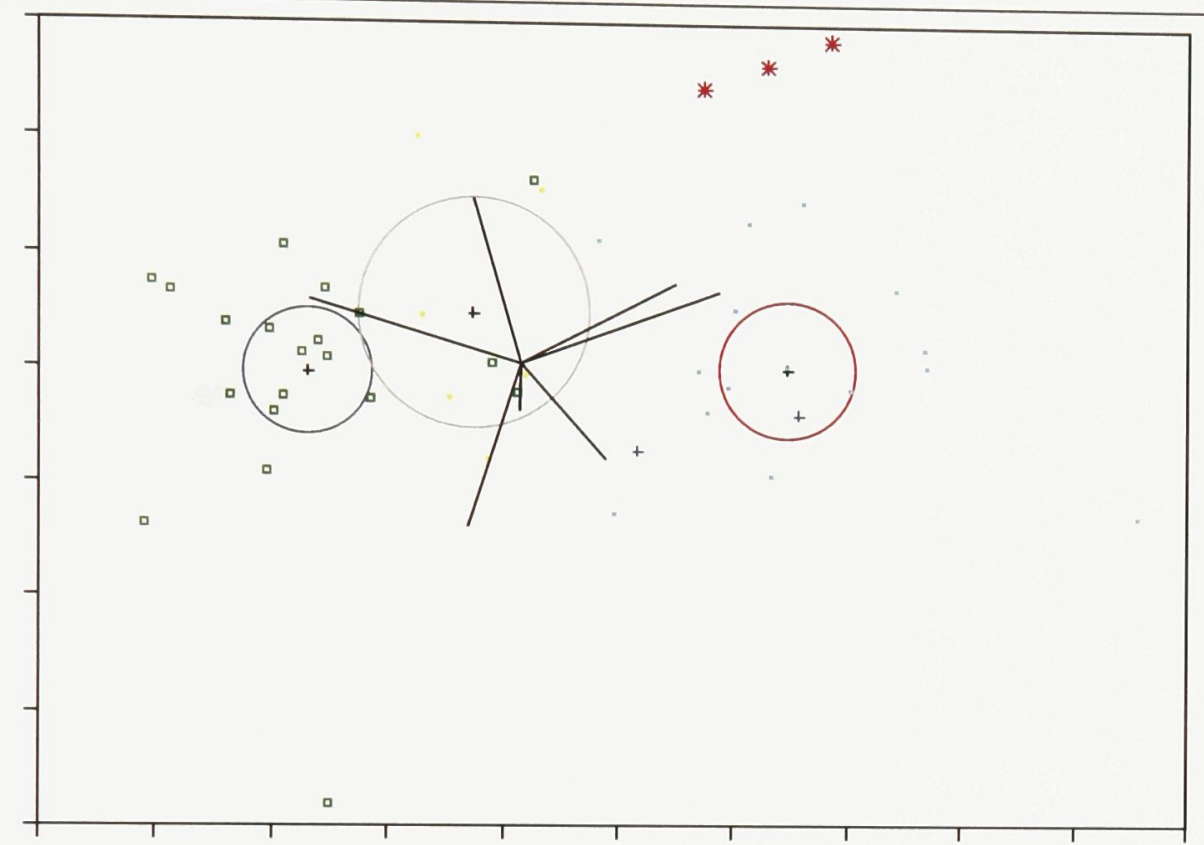

\section{Discriminant Scores}

Number Misclassified

Percent Misclassified

-2LogLikelihood

Training

Excluded

9.302

29.66

\begin{tabular}{rlrrr} 
Row & SC & SqDist(Actual) & Prob(Actual) & \multicolumn{1}{l}{ Log(Prob) Plot -Log(Prob } \\
1 & 1 & 4.60577 & 0.2325 & 1.459 \\
2 & 1 & 1.72144 & 0.8541 & 0.158 \\
3 & 2 & 5.00030 & 0.7773 & 0.252 \\
4 & 3 & 6.71510 & 0.9993 & 0.001 \\
5 & 3 & 14.87403 & 0.9100 & 0.094 \\
6 & 3 & 14.30682 & 0.5612 & 0.578 \\
7 & 3 & 9.05830 & 0.6383 & 0.449 \\
8 & 3 & 25.06525 & 0.9254 & 0.078 \\
9 & 3 & 1.40191 & 0.8452 & 0.168 \\
10 & 3 & 5.65636 & 0.9957 & 0.004 \\
11 & 1 & 1.63569 & 0.5687 & 0.564 \\
12 & 3 & 1.65268 & 0.8932 & 0.113 \\
13 & 3 & 4.43748 & 0.9977 & 0.002 \\
14 & 3 & 33.97009 & 0.9095 & 0.095 \\
15 & 2 & 0.35642 & 0.6227 & 0.474 \\
16 & 2 & 2.27117 & 0.6082 & 0.497 \\
17 & 2 & 2.80152 & 0.8773 & 0.131 \\
\end{tabular}

\begin{tabular}{|c|c|c|}
\hline Predicted SC & Prob(Pred) & Others \\
\hline * 2 & 0.7381 & \\
\hline 1 & 0.8541 & 20.15 \\
\hline 2 & 0.7773 & 10.22 \\
\hline 3 & 0.9993 & \\
\hline 3 & 0.9100 & \\
\hline 3 & 0.5612 & 20.39 \\
\hline 3 & 0.6383 & 20.34 \\
\hline 3 & 0.9254 & \\
\hline 3 & 0.8452 & 20.15 \\
\hline 3 & 0.9957 & \\
\hline 1 & 0.5687 & 20.43 \\
\hline 3 & 0.8932 & 20.10 \\
\hline 3 & 0.9977 & \\
\hline 3 & 0.9095 & \\
\hline 2 & 0.6227 & 10.37 \\
\hline 2 & 0.6082 & 10.38 \\
\hline 2 & 0.8773 & \\
\hline
\end{tabular}




$\begin{array}{rlrrr}\text { Row } & \text { SC } & \text { SqDist(Actual) } & \text { Prob(Actual) } & \text {-Log(Prob) Plot -Log(Prob) } \\ 18 & 1 & 1.76443 & 0.7044 & 0.350 \\ 19 & 1 & 0.68453 & 0.7123 & 0.339 \\ 20 & 1 & 0.95273 & 0.8769 & 0.131 \\ 21 & 1 & 0.65874 & 0.7596 & 0.275 \\ 22 & 1 & 3.61039 & 0.6266 & 0.467 \\ 23 & 1 & 2.21450 & 0.8101 & 0.211 \\ 24 & 3 & 8.89198 & 0.9866 & 0.014 \\ 25 & 3 & 5.83682 & 0.9991 & 0.001 \\ 26 & 1 & 6.97112 & 0.9800 & 0.020 \\ 27 & 1 & 6.32452 & 0.9372 & 0.065 \\ 28 & 1 & 23.47405 & 0.9465 & 0.055 \\ 29 & 1 & 2.66619 & 0.8944 & 0.112 \\ 30 & 1 & 0.85126 & 0.9043 & 0.101 \\ 31 & 3 & 8.33810 & 0.9790 & 0.021 \\ 32 & 1 & 0.63845 & 0.8283 & 0.188 \\ 33 & 3 & 14.87324 & 1.0000 & 0.000 \\ 34 & 3 & 8.71183 & 0.2297 & 1.471 \\ 35 & 3 & 11.51364 & 0.9706 & 0.030 \\ 36 & 1 & 2.41860 & 0.7138 & 0.337 \\ 37 & 2 & 2.89147 & 0.6398 & 0.447 \\ 38 & 1 & 3.49066 & 0.9252 & 0.078 \\ 39 & 1 & 1.53169 & 0.6425 & 0.442 \\ 40 & 1 & 6.65208 & 0.1955 & 1.632 \\ 41 & 1 & 10.93685 & 0.0718 & 2.634 \\ 42 & 2 & 6.04572 & 0.7610 & 0.273 \\ 43 & 3 & 1.52607 & 0.9804 & 0.020 \\ 44 & ? & \text { Puijila darwini (mustelid) } & \\ 45 & ? & \text { Puijila darwini (ursid) } & \\ 46 & ? & \text { Puijila darwini (avg.) } & \\ \text { " " indicates excluded row; '*' indicates misclassified } \\ \end{array}$

Predicted SC Prob(Pred) Others

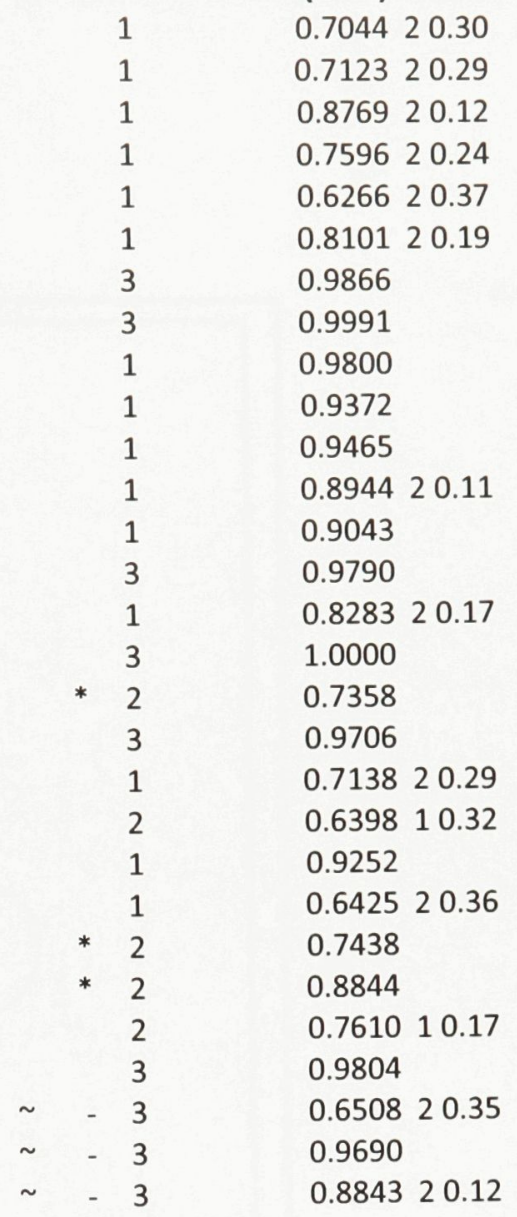




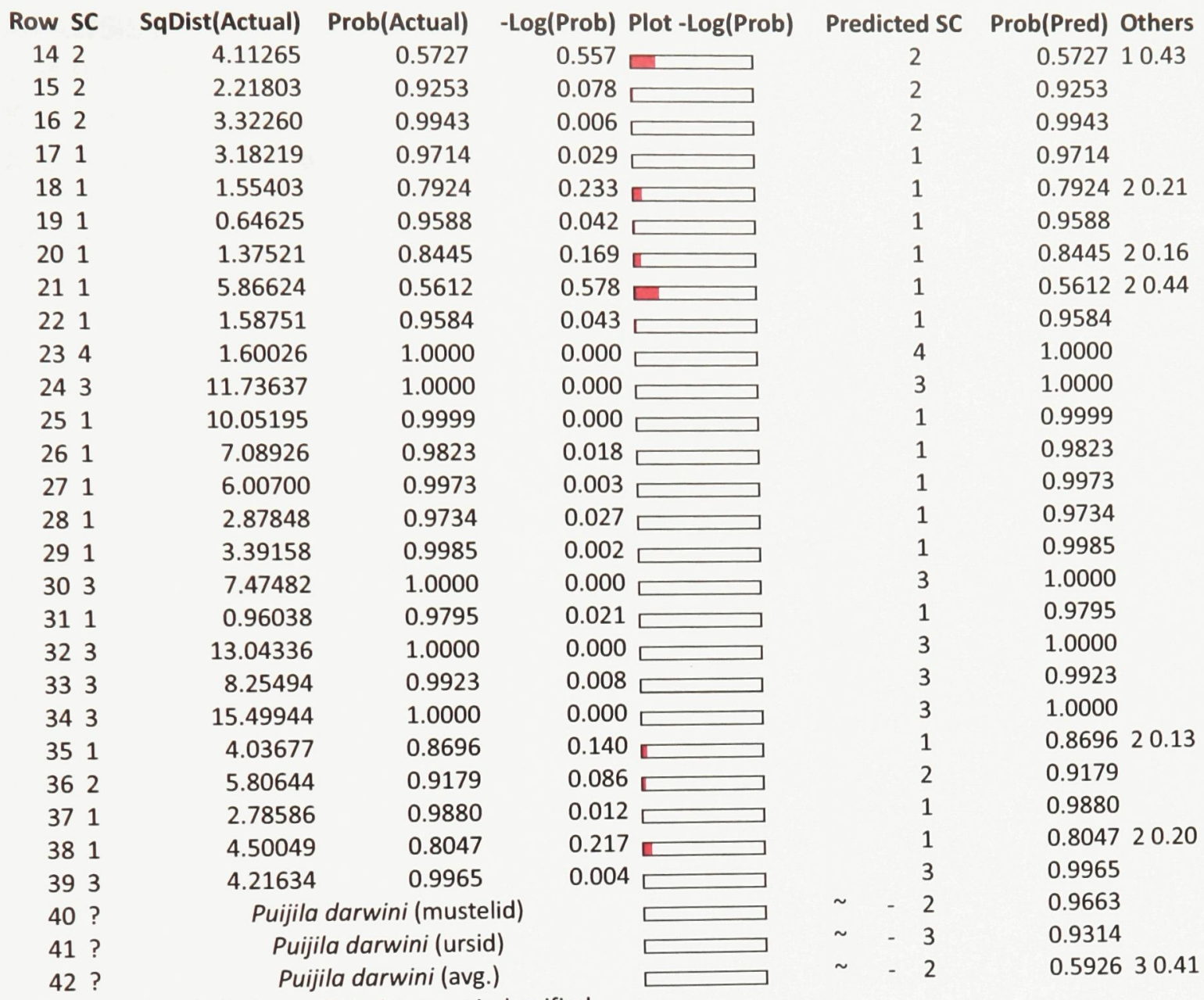

" " indicates excluded row; '*' indicates misclassified 
ANALYSIS \#8:

\# of Taxa: 39 (no bears)

$Y$, covariates: $P_{h}, P_{r}, P_{u}, P_{f e}, P_{t}, P_{f i}$

$X$, categories: SC (1-4)

\section{Canonical Plot}

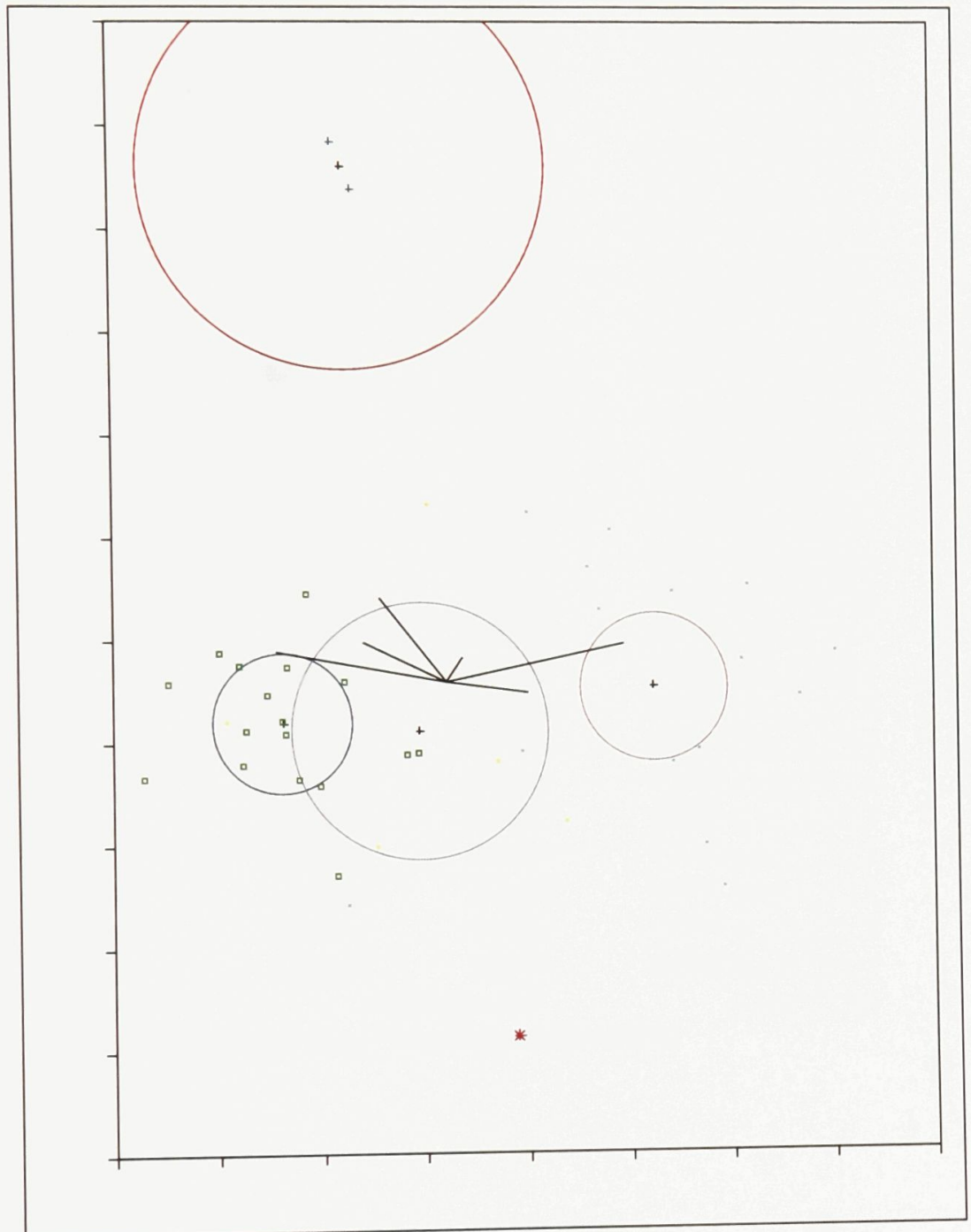

\section{Discriminant Scores}

Number Misclassified Percent Misclassified -2LogLikelihood

$\begin{array}{rr}\text { Training } & \text { Excluded } \\ 5 & 0 \\ 12.82 & 0 \\ 37.37 & \end{array}$

\begin{tabular}{|c|c|c|c|c|c|c|}
\hline Row SC & SqDist(Actual) & Prob(Actual) & -Log(Prob) & Plot -Log(Prob) & Predicted SC & Prob(Pred) Others \\
\hline 11 & 2.18639 & 0.7609 & 0.273 & 世 & 1 & 0.760920 .24 \\
\hline 22 & 6.46777 & 0.5434 & 0.610 & $\square$ & 2 & 0.543430 .44 \\
\hline 33 & 5.07871 & 0.9761 & 0.024 & $\square$ & 3 & 0.9761 \\
\hline 43 & 12.86131 & 0.9890 & 0.011 & $\square$ & 3 & 0.9890 \\
\hline 53 & 8.09767 & 0.9750 & 0.025 & $\square$ & 3 & 0.9750 \\
\hline 64 & 0.41112 & 1.0000 & 0.000 & $\square$ & 4 & 1.0000 \\
\hline
\end{tabular}




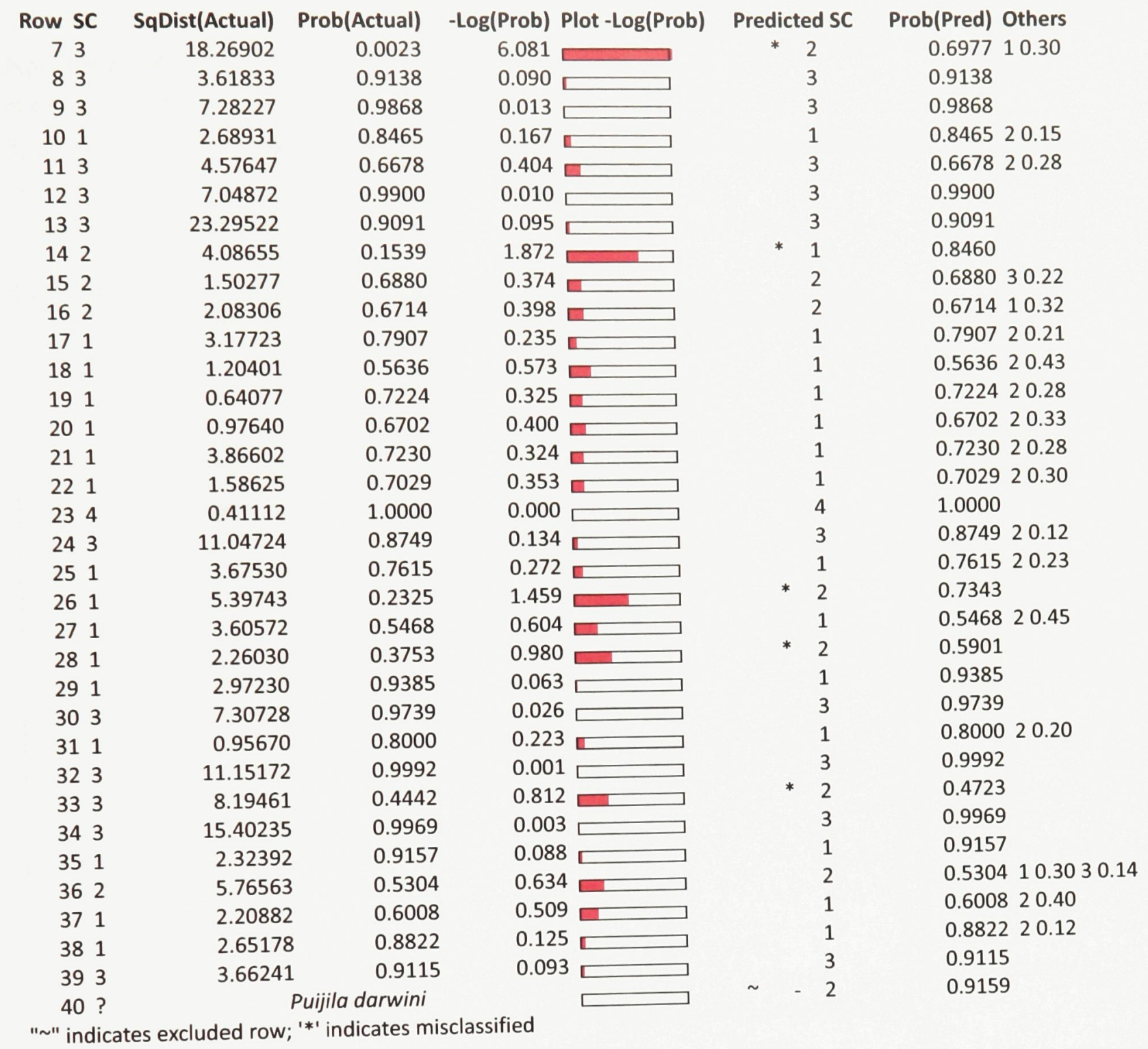


ANALYSIS \#9:

\# of Taxa: 27

Y, covariates: $\log \left(m_{b}\right), S_{h}, S_{r}, S_{u}, S_{f e}, S_{t}, S_{f i}, C_{h}, C_{r}, C_{u}, C_{f e}, C_{t}, C_{f i}, \operatorname{Min}_{h}, \operatorname{Min}_{r}, M_{i n}, M_{i n} n_{f e}$ $\operatorname{Min}_{\mathrm{t}}, \operatorname{Min}_{\mathrm{fi}}$

$X$, categories: SC (1-4)

\section{Canonical Plot}

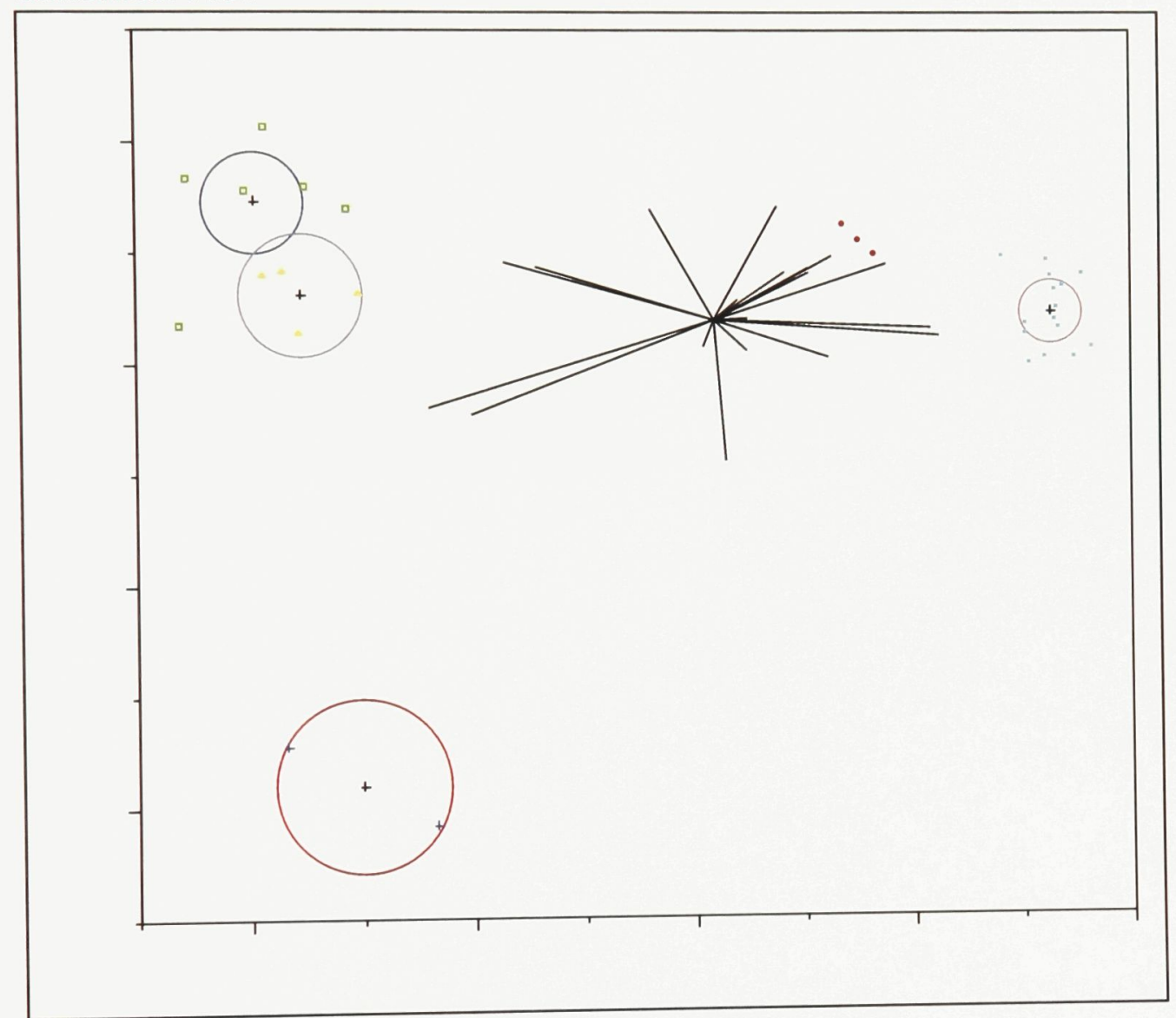

\section{Discriminant Scores}

Number Misclassified Percent Misclassified -2LogLikelihood

$\begin{array}{rrrr}\text { Row } & \text { SC } & \text { SqDist(Actual) } & \text { Prob(Actual) } \\ 1 & 1 & 10.41746 & 0.9986 \\ 2 & 3 & 18.60200 & 1.0000 \\ 3 & 3 & 19.94524 & 1.0000 \\ 4 & 3 & 18.74777 & 1.0000 \\ 5 & 4 & 9.11832 & 1.0000 \\ 6 & 3 & 21.17332 & 1.0000 \\ 7 & 3 & 20.92414 & 1.0000 \\ 8 & 3 & 18.92942 & 1.0000 \\ 9 & 1 & 10.21564 & 0.9992\end{array}$

$\begin{array}{rr}\text { Training } & \text { Excluded } \\ 1 & 0 \\ 3.704 & 0 \\ 1.802 & \end{array}$

-Log(Prob) Plot-Log(Prob) Predicted SC Prob(Pred) Others

$\begin{array}{lll}0.001 \square & 1 & 0.9986 \\ 0.000 \square & 3 & 1.0000 \\ 0.000 \square & 1.0000 \\ 0.000 \square & 3 & 1.0000 \\ 0.000 \square & 3 & 1.0000 \\ 0.000 \square & 4 & 1.0000 \\ 0.000 \square & 3 & 1.0000 \\ 0.000 \square & 3 & 1.0000 \\ 0.001 \square & 3 & 0.9992\end{array}$


Row SC SqDist(Actual) Prob(Actual) -Log(Prob) Plot-Log(Prob) Predicted SC Prob(Pred) Others

\begin{tabular}{|c|c|c|c|c|c|c|c|}
\hline 103 & 15.31169 & 1.0000 & 0.000 & 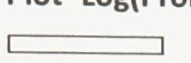 & & 3 & 1.0000 \\
\hline 113 & 18.63000 & 1.0000 & 0.000 & $\square$ & & 3 & 1.0000 \\
\hline 123 & 15.85525 & 1.0000 & 0.000 & $\square$ & & 3 & 1.0000 \\
\hline 132 & 15.92627 & 0.9984 & 0.002 & $\square$ & & 2 & 0.9984 \\
\hline 142 & 15.69304 & 1.0000 & 0.000 & $\square$ & & 2 & 1.0000 \\
\hline 151 & 10.00526 & 0.9983 & 0.002 & $\square$ & & 1 & 0.9983 \\
\hline 164 & 9.11832 & 1.0000 & 0.000 & $\square$ & & 4 & 1.0000 \\
\hline 173 & 19.11103 & 1.0000 & 0.000 & $\square$ & & 3 & 1.0000 \\
\hline 183 & 17.03041 & 1.0000 & 0.000 & $\square$ & & 3 & 1.0000 \\
\hline 193 & 21.33697 & 1.0000 & 0.000 & $\square$ & & 3 & 1.0000 \\
\hline 203 & 17.35498 & 1.0000 & 0.000 & $\square$ & & 3 & 1.0000 \\
\hline 213 & 19.65953 & 1.0000 & 0.000 & $\square$ & & 3 & 1.0000 \\
\hline 222 & 15.54646 & 1.0000 & 0.000 & $\square$ & & 2 & 1.0000 \\
\hline 231 & 18.08188 & 0.9989 & 0.001 & $\square$ & & 1 & 0.9989 \\
\hline 241 & 15.93592 & 0.9991 & 0.001 & $\square$ & & 1 & 0.9991 \\
\hline 251 & 12.68523 & 0.9999 & 0.000 & $\square$ & & 1 & 0.9999 \\
\hline 262 & 15.04092 & 0.4092 & 0.894 & $\square$ & & * 1 & 0.5908 \\
\hline 273 & 16.60354 & 1.0000 & 0.000 & $\square$ & & 3 & 1.0000 \\
\hline $28 ?$ & \multicolumn{3}{|c|}{ Puijila darwini (mustelid) } & $\square$ & $\sim$ & 3 & 1.0000 \\
\hline 29 ? & \multirow{2}{*}{\multicolumn{3}{|c|}{ Puijila darwini (ursid) }} & $\square$ & $\sim$ & 3 & 1.0000 \\
\hline $30 ?$ & & & & $\square$ & $\sim$ & -3 & 1.0000 \\
\hline
\end{tabular}

" $\sim$ " indicates excluded row; '*' indicates misclassified 
ANALYSIS \#10:

\# of Taxa: 27

Y, covariates: $\log \left(m_{b}\right), \log \left(S_{h}\right), \log \left(S_{r}\right), \log \left(S_{u}\right), \log \left(S_{f e}\right), \log \left(S_{t}\right), \log \left(S_{f_{i}}\right), \log \left(C_{h}\right), \log \left(C_{r}\right)$, $\log \left(C_{u}\right), \log \left(C_{f e}\right), \log \left(C_{t}\right), \log \left(C_{f i}\right), \log \left(M_{i n}\right), \log \left(M_{i n}\right), \log \left(M_{i n}\right), \log \left(M_{i n} f_{f e}, \log \left(M_{i n}\right)\right.$, $\log \left(\operatorname{Min}_{\mathrm{fi}}\right)$

$X$, categories: SC (1-4)

\section{Canonical Plot}

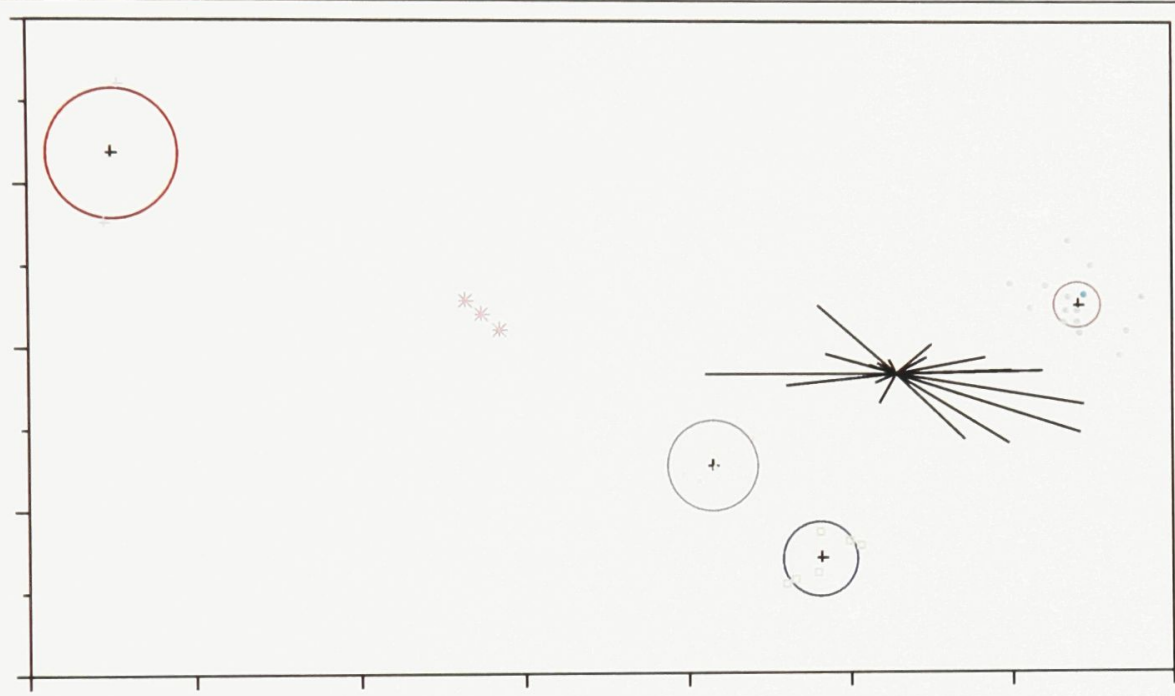

\section{Discriminant Scores}

Number Misclassified Percent Misclassified

$\begin{array}{rr}\text { Training } & \text { Excluded } \\ 0 & 0 \\ 0 & 0 \\ 3 e-8 & \end{array}$

\begin{tabular}{|c|c|c|c|c|c|c|}
\hline Row SC & SqDist(Actual) & Prob(Actual) & -Log(Prob) & Plot -Log(Prob) & Predicted SC & Prob(Pred) \\
\hline 11 & 14.58813 & 1.0000 & 0.000 & $\square$ & 1 & 1.0000 \\
\hline 23 & 16.20720 & 1.0000 & 0.000 & $\square$ & 3 & 1.0000 \\
\hline 33 & 20.37092 & 1.0000 & 0.000 & $\square$ & 3 & 1.0000 \\
\hline 43 & 21.05425 & 1.0000 & 0.000 & $\square$ & 3 & 1.0000 \\
\hline 54 & 10.21319 & 1.0000 & 0.000 & $\square$ & 4 & 1.0000 \\
\hline 63 & 20.07836 & 1.0000 & 0.000 & $\square$ & 3 & 1.0000 \\
\hline 73 & 13.93836 & 1.0000 & 0.000 & $\square$ & 3 & 1.0000 \\
\hline 83 & 18.05779 & 1.0000 & 0.000 & $\square$ & 3 & 1.0000 \\
\hline 91 & 10.63920 & 1.0000 & 0.000 & $\square$ & 1 & 1.0000 \\
\hline 103 & 18.29525 & 1.0000 & 0.000 & $\square$ & 3 & 1.0000 \\
\hline 113 & 20.66119 & 1.0000 & 0.000 & $\square$ & 3 & 1.0000 \\
\hline 123 & 19.80932 & 1.0000 & 0.000 & $\square$ & 3 & 1.0000 \\
\hline 132 & 10.90047 & 1.0000 & 0.000 & $\square$ & 2 & 1.0000 \\
\hline 142 & 14.72119 & 1.0000 & 0.000 & $\square$ & 2 & 1.0000 \\
\hline 151 & 12.64222 & 1.0000 & 0.000 & $\square$ & 1 & 1.0000 \\
\hline 164 & 10.21319 & 1.0000 & 0.000 & $\square$ & 4 & 1.0000 \\
\hline 173 & 20.37186 & 1.0000 & 0.000 & $\square$ & 3 & 1.0000 \\
\hline
\end{tabular}


Row SC SqDist(Actual) Prob(Actual) -Log(Prob) Plot-Log(Prob) Predicted SC Prob(Pred) Others

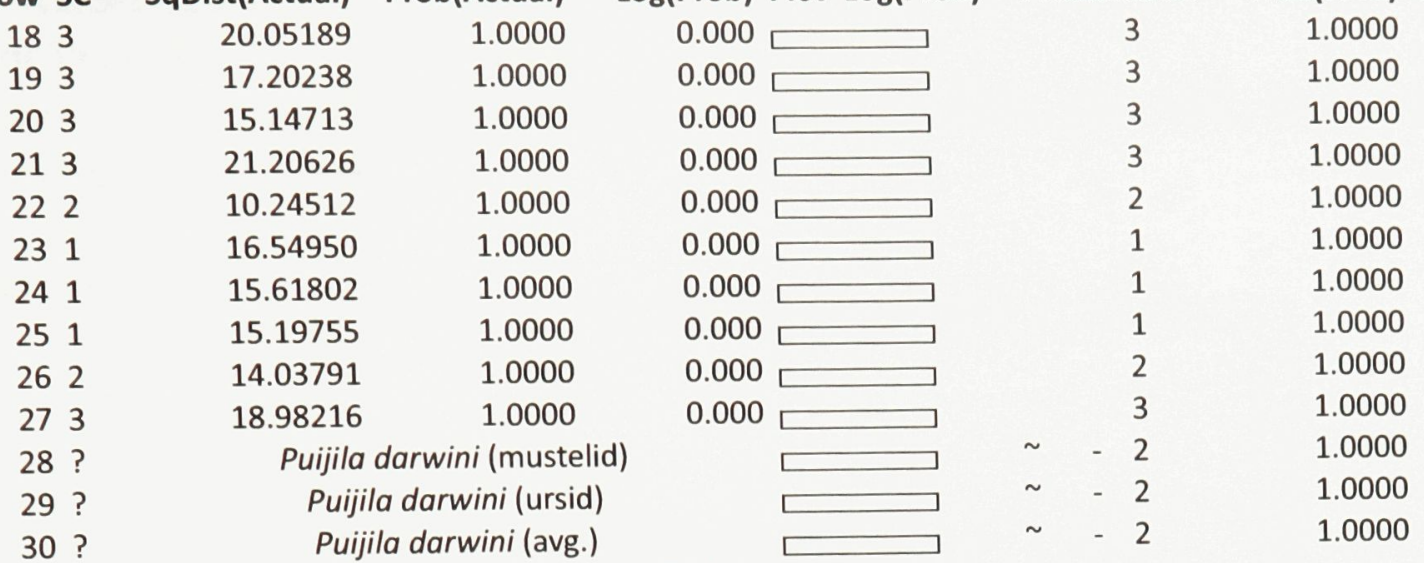

" indicates excluded row; '*' indicates misclassified 
ANALYSIS \#11:

\# of Taxa: 27

Y, covariates: $S_{h}, S_{r}, S_{u}, S_{f e}, S_{t}, S_{f i}, C_{h}, C_{r}, C_{u}, C_{f e}, C_{t}, C_{f i}, M_{h}, M_{i n}, M_{i n}, M_{i n} \operatorname{Min}_{t}, \operatorname{Min}_{f i}$ $X$, categories: SC (1-4)

\section{Canonical Plot}

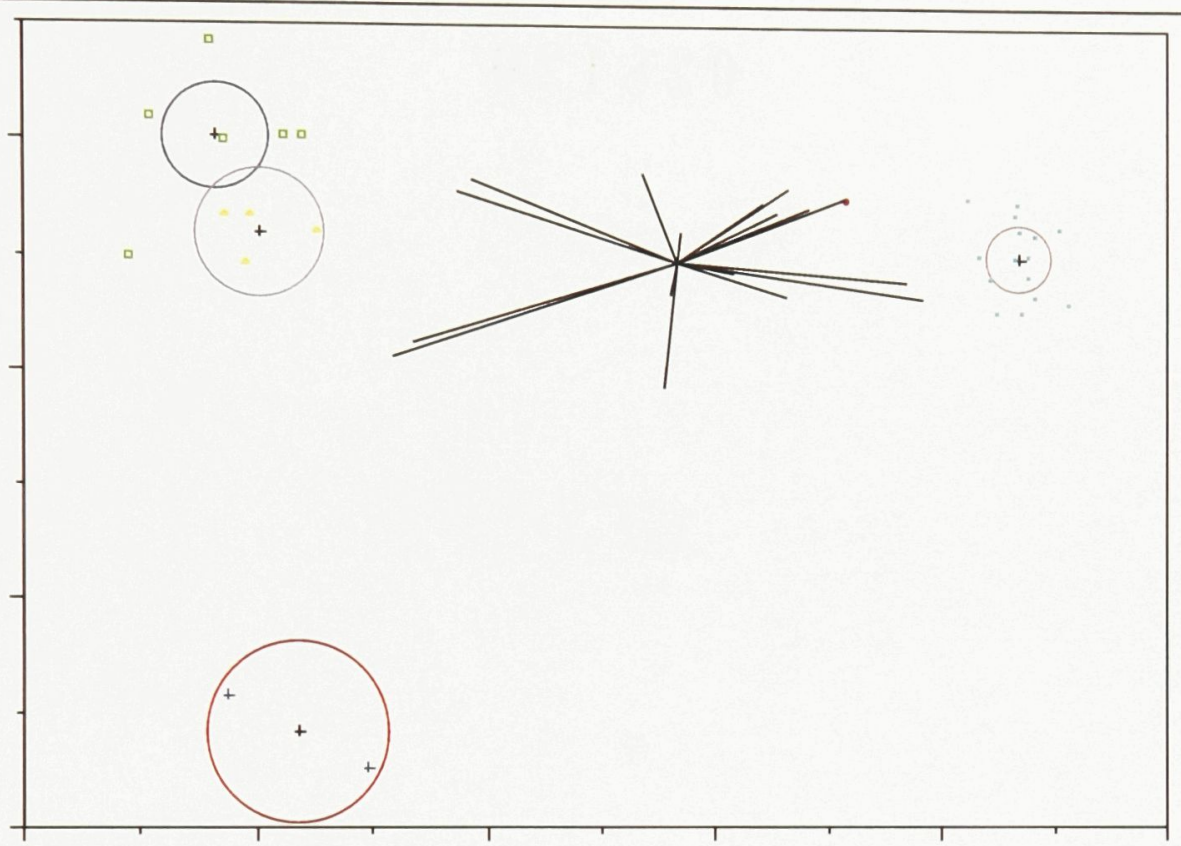

\section{Discriminant Scores}

Number Misclassified

Percent Misclassified

-2LogLikelihood

$\begin{array}{rr}\text { Training } & \text { Excluded } \\ 1 & 0 \\ 3.704 & 0 \\ 1.469 & \end{array}$

$\begin{array}{rlrrr}\text { Row } & \text { SC } & \text { SqDist(Actual) } & \text { Prob(Actual) } & \text {-Log(Prob) } \text { Plot -Log(Pro } \\ 1 & 1 & 8.79288 & 0.9991 & 0.001 \\ 2 & 3 & 18.56893 & 1.0000 & 0.000 \\ 3 & 3 & 19.86298 & 1.0000 & 0.000 \\ 4 & 3 & 18.43512 & 1.0000 & 0.000 \\ 5 & 4 & 8.24702 & 1.0000 & 0.000 \\ 6 & 3 & 21.16022 & 1.0000 & 0.000 \\ 7 & 3 & 20.14669 & 1.0000 & 0.000 \\ 8 & 3 & 18.92212 & 1.0000 & 0.000 \\ 9 & 1 & 9.69021 & 0.9988 & 0.001 \\ 10 & 3 & 14.45452 & 1.0000 & 0.000 \\ 11 & 3 & 18.55849 & 1.0000 & 0.000 \\ 12 & 3 & 15.68870 & 1.0000 & 0.000 \\ 13 & 2 & 15.82250 & 0.9980 & 0.002 \\ 14 & 2 & 14.37008 & 1.0000 & 0.000 \\ 15 & 1 & 6.83623 & 0.9957 & 0.004 \\ 16 & 4 & 8.24702 & 1.0000 & 0.000 \\ 17 & 3 & 18.82078 & 1.0000 & 0.000\end{array}$

$\begin{array}{cr}\text { Predicted SC } & \text { Prob(Pred) Others } \\ 1 & 0.9991 \\ 3 & 1.0000 \\ 3 & 1.0000 \\ 3 & 1.0000 \\ 4 & 1.0000 \\ 3 & 1.0000 \\ 3 & 1.0000 \\ 3 & 1.0000 \\ 1 & 0.9988 \\ 3 & 1.0000 \\ 3 & 1.0000 \\ 3 & 1.0000 \\ 2 & 0.9980 \\ 2 & 1.0000 \\ 1 & 0.9957 \\ 4 & 1.0000 \\ 3 & 1.0000\end{array}$

